\title{
Surface Chemistry and Development of Group 11 and 13 Thin Film Vapour Deposition Precursors
}

\author{
by \\ Peter Jackson Pallister
}

A thesis submitted to the Faculty of Graduate and Postdoctoral Affairs in partial fulfillment of the requirements for the degree of

Doctor of Philosophy

in

Chemistry

Carleton University

Ottawa, Ontario

(C) 2015

Peter Jackson Pallister 
This thesis is dedicated to my grandmother, Elizabeth Pallister. 


\section{Abstract}

Techniques for depositing thin films of metals or ceramics, such as atomic layer deposition (ALD) and chemical vapour deposition (CVD), are well established and used in a wide variety of industries and applications, such as for dielectric layers, passivation coatings, surface functionalization, conductive layers, catalysis, anti-reflection coatings, optical property modification, etc. These techniques make use of a series of vapourous precursor/solid substrate interactions, typically at elevated temperatures and low pressures, to ultimately deposit a thin, conformal, uniform film of desired material. The nature of this vapour/solid surface chemistry is paramount to determining the what material is deposited as well as its properties. Determining the specific chemistry occurring at the vapour/solid interface is not a trivial task and typically requires expensive and potentially complicated characterization techniques. Generally, ALD and CVD processes of novel materials typically suffer from purity and uniformity issues that prevents them from being widely adopted by industry. By experimentally determining the surface chemistry of these processes it is possible to logically assess and modify existing processes to address these issues. This work examined the surface chemistry of several group 11 and group 13 vapour deposition precursors using a variety of characterization techniques, primarily solid-state nuclear magnetic resonance spectroscopy (SS-NMR). In group 11, several novel Cu ALD precursors were studied, including a copper(I)-tert-butyl-iminopyrrolidinate and several copper(I)-hexamethyldisilazide- $N$-heterocyclic carbene complexes, as well as a novel $\mathrm{Au}$ ALD precursor; a $\mathrm{Me}_{3} \mathrm{AuPMe}_{3}$ complex. By using ex situ characterization techniques such as SS-NMR $\left({ }^{13} \mathrm{C}\right.$ and $\left.{ }^{29} \mathrm{Si}\right)$, high-resolution NMR (HR-NMR) $\left({ }^{1} \mathrm{H}\right.$ and ${ }^{13} \mathrm{C}$ ), energy dispersive X-ray spectroscopy (EDX), and elemental analysis the initial chemisorption of these precursors on high surface area silica (HSAS) was determined. In group 13, a gallium complex (acetamidinatediethylgallium(III)) was exposed to high surface area silica (HSAS) and the initial chemisorption mechanism was quantitatively determined by using primarily ${ }^{29} \mathrm{Si}$ SS-NMR as well as the techniques used to study group 11 complexes. Overall, this work demonstrates the novelty of using techniques like SS-NMR to examine the chemisorption mechanism of ALD precursors on high surface area substrates quantitatively. The nature of precursor chemisorption can be used to develop new precursors and new deposition processes with more efficient deposition (no impurities, higher growth rates, better uniformity) with the results gathered in this work. 


\section{Preface}

This preface provides full bibliographical details for each article included in this thesis, as well as whether the article is reproduced in whole or in part. Use of copyrighted material is likewise acknowledged here. When citing material from this thesis, please the cite the article relevant to the chapter, if the chapter is based on a publication.

Pursuant to the Integrated Thesis policy of Carleton University, the supervisor (Seán Barry) and the "student" (Peter J. Pallister) confirm that the student was fully involved in setting up and conducting the research, obtaining data and analyzing results, as well as preparing and writing the material presented in the co-authored article(s) integrated in the thesis. Additionally, the supervisor confirms the information provided by the student in this preface.

\section{Chapter 2}

Pallister, P.J., Buttera, S.C., and Barry, S.T., Quantitative Surface Coverage Calculations via Solid-State NMR for Thin Film Depositions: A Case Study for Silica and a Gallium Amidinate, J. Phys. Chem. C, 2014, 118, 1618-1627.

This article is wholly reproduced and edited for formatting and clarity of presentation. Peter J. Pallister performed the experimentation for this publication and was aided by (undergraduate at the time) Sydney C. Buttera. The publication was written by Peter J. Pallister.

\section{Chapter 3}

Pallister, P.J., Buttera, S.C., and Barry, S.T., Self-seeding Gallium Oxide Nanowire Growth by Pulsed Chemical Vapor Deposition, Phys. Status Solidi A, 2015, 212, 1514-1518.

This article is wholly reproduced and edited for formatting and clarity of presentation. Peter J. Pallister performed all synthesis, deposition, and characterization work. Sydney C. Buttera determined the lower limit of depositions by performing initial low temperature experiments. The publication was written by Peter J. Pallister. 


\section{Chapter 4}

Pallister, P.J., Pallister, J.R., Dao, H.A., Yap, G.P.A., and Barry, S.T., Synthesis and Thermal Characterization of Novel, Heteroleptic Aluminum Hydrides, Dalton Trans., submitted for review but was not ultimately published.

This submission is wholly reproduced and edited for formatting and clarity of presentation. Peter J. Pallister was responsible for synthesis and characterization of compound 8 as well as the reproducibility of synthesis and characterization for the other compounds. Julie R. Pallister was responsible for the synthesis and characterization of the other 5 compounds. Crystallography was performed by H. Dao and Glenn P. A. Yap. This manuscript was written by Peter J. Pallister.

\section{Chapter 5}

Coyle, J.P., Kurek, A., Pallister, P.J., Sirianni, E.R., Yap, G.P.A., and Barry, S.T., Preventing Thermolysis: Precursor Design for Volatile Copper Compounds, Chem. Comm., 2012, 48, 10440-10442. Coyle, J.P., Pallister, P.J., Kurek, A., Sirianni, E.R., Yap, G.P.A., and Barry, S.T., Copper Iminopyrrolidinates: A Study of Thermal and Surface Chemistry, Inorg. Chem., 2013, 52, 910-917.

These articles are partially reproduced and edited for formatting and clarity of presentation and to prevent repetition. Peter J. Pallister performed all the surface chemistry experiments and characterization. Jason P. Coyle performed the synthesis and characterization of the compounds as well as the thermogravimetric analysis experiments. Agnes Kurek performed the solution thermolysis studies. Crystallography was performed by Eric R. Sirianni and Glenn P. A. Yap. This publication was written collaboratively between all co-authors.

\section{Chapter 6}

Griffiths, M.B.E., Pallister, P.J., Mandia, D.J., and Barry, S.T., Atomic Layer Deposition of Gold Metal, Chem. Mater., 2016, asap (DOI: 10.1021/acs.chemmater.5b04562).

This article is wholly reproduced and edited for formatting and clarity of presentation. Peter J. Pallister performed the nucleation studies and transmission electron microscopy characterization as well as several of the depositions that contributed to the saturation curve. Matthew B. E. Griffiths performed the synthesis and characterization, process development, and film characterizations. David J. Mandia performed the x-ray photoelectron spectroscopy experiments. This publication was written collaboratively between all co-authors. 


\section{Acknowledgements}

It is impossible to think that I could have completed the work presented here by myself. There are numerous people who helped make it possible and they deserve my deepest thanks.

Of course, not a single experiment could have been accomplished without the resources and guidance of my Ph.D. supervisor, Dr. Seán T. Barry. I have gained so much being a part of his lab and I am eternally grateful for everything. Being given the independence to pursue my own goals and curiosities, yet always offering sound guidance and direction has made my studies fun, interesting, and always exciting.

While Seán was an excellent supervisor, the other members of the Barry lab, past and present, really made the day-to-day operations in the lab a fun, productive, and thoroughly enjoyable working environment. While I would love to thank each member individually for everything they have done, that would take another thesis entirely. Peter Gordon, Jason Coyle, Agnes Kurek, David Mandia, Monica Gill, Sara Koponen, Matthew Griffiths, Goran Bačić, Adam Wells, Andrew Lushington, and all other honours students, I cannot thank you enough for the impact you've made on my life and research career. I would like to especially mention my gratitude to Sydney Buttera. Having an apprentice for the last half of my Ph.D. career was fun, very rewarding and produced a lifelong friend. I wholeheartedly insist that everyone I've mentioned be successful and happy in everything they choose to do.

This work would not have been possible without the aid of the fantastic staff members at Carleton University and University of Ottawa. Dr. Glenn Facey (facility 
manager) and Dr. Eric Ye (technician) run the NMR facility at University of Ottawa and are the most helpful, knowledgeable, and hardworking people I have ever met. If all academic facilities were run like Glenn's, research would never be halted by the need for characterization ever again. I'd also like to thank Peter Mosher, Susa Chandabrose, and Tanya Rudd for keeping the Stores running and your vigilance in maintaining Steacie building's infrastructure. Being a TA was a large part of my Ph.D. studies and Elena Munteanu and Daniel Sun made that a fantastic experience. Labs were always well-organized which made teaching very enjoyable.

I would not even be here today if it were not for my family. My grandmother, Elizabeth Pallister, and my parents: Alexander Pallister, Karen Pallister, Wanda McWilliams, and James Rawlings have provided never-ending love and support my entire life. Their insistence that I follow my heart got me to where I am today.

Most importantly, I must thank Julie Pallister. My life partner, co-author, wife, fellow scientist and best friend. I would not have accomplished any of this work without you there to support me. Our son, Graham (16 months at time of writing), has given my life meaning and I am eternally grateful to him and Julie for the motivation when it was needed. I look forward to our discussions of this thesis when you (and our future children, whoever you may be) are old enough. 


\section{Contents}

1 Introduction 1

1.1 Vapour Phase Thin Film Deposition . . . . . . . . . . . . . 1

1.1.1 Chemical Vapour Deposition . . . . . . . . . . . . . . 2

1.1.2 Atomic Layer Deposition . . . . . . . . . . . . . . . . . 5

1.2 Surface Chemistry . . . . . . . . . . . . . . . . . 8

1.2.1 Copper(I) Iminopyrrolidinate / Guanidinate on $\mathrm{Ni}(110)$. . . . 9

1.2.2 Titanium(III) Cyclopentadienyl Guanidinate on Silica . . . . . 12

1.3 Solid-State Nuclear Magnetic Resonance Spectroscopy . . . . . . . . . 15

1.4 Methodology for Examining Surface Chemistry using Solid-State Nuclear Magnetic Resonance Spectroscopy . . . . . . . . . . . . . . . . . 27

I Group $13 \quad 29$

2 Quantitative Surface Coverage Calculations via Solid-State NMR for Thin Film Depositions: A Case Study for Silica and a Gallium $\begin{array}{ll}\text { Amidinate } & 30\end{array}$

2.1 Abstract . . . . . . . . . . . . . . . . . 31

2.2 Introduction . . . . . . . . . . . . . . . . . . . . 32

2.3 Experimental . . . . . . . . . . . . . . . . . . . . . . 34

2.4 Results and Discussion . . . . . . . . . . . . . . . . 38

2.5 Conclusions ........................... 54 
2.6 Supporting Information . . . . . . . . . . . . . . . . . . 55

3 Self-Seeding Gallium Oxide Nanowire Growth by Pulsed Chemical Vapour Deposition $\quad 62$

3.1 Abstract . . . . . . . . . . . . . . . . . . . 63

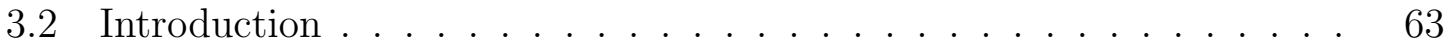

3.3 Experimental . . . . . . . . . . . . . . . . . . . . 65

3.4 Results and Discussion . . . . . . . . . . . . . 66

3.5 Additional Results . . . . . . . . . . . . . . . . . . . . 74

3.6 Conclusions . . . . . . . . . . . . . . . . . . . . . . . . . . . . . . . . . . 79

4 Synthesis and Thermal Characterization of Novel, Heteroleptic Aluminum Hydrides

4.1 Abstract . . . . . . . . . . . . . . . . . 83

4.2 Introduction . . . . . . . . . . . . . . . . . . 84

4.3 Experimental . . . . . . . . . . . . . . . . . . 85

4.4 Results and Discussion . . . . . . . . . . . . . . . . . 92

4.5 Conclusions . . . . . . . . . . . . . . . . . . . . . . . . 104

4.6 Supporting Information . . . . . . . . . . . . . . . . 107

$\begin{array}{ll}\text { II Group } 11 & 111\end{array}$

5 Copper Iminopyrrolidinates: A Study of Thermal and Surface Chemistry 112

5.1 Abstract . . . . . . . . . . . . . . . . . . . 113

5.2 Introduction . . . . . . . . . . . . . . . . . . . . . . . 113

5.3 Experimental . . . . . . . . . . . . . . . 116

5.4 Results and Discussion . . . . . . . . . . . . . . . . 121

5.5 Additional Results . . . . . . . . . . . . . . . . . . . . . 139 
5.6 Conclusions . . . . . . . . . . . . . . . . . . . . 146

6 Atomic Layer Deposition of Gold Metal 148

6.1 Abstract . . . . . . . . . . . . . . . . . . 149

6.2 Introduction . . . . . . . . . . . . . . . . . . 149

6.3 Experimental . . . . . . . . . . . . . . . . . 150

6.4 Results and Discussion . . . . . . . . . . . . . . . 156

6.5 Additional Results . . . . . . . . . . . . . . . . . . . . 161

6.6 Conclusions . . . . . . . . . . . . . . . . . . . 168

6.7 Supplementary Material . . . . . . . . . . . . . . . . 169

$\begin{array}{lll}7 \text { Conclusions } & 171\end{array}$

$\begin{array}{ll}\text { References } & 178\end{array}$ 


\section{List of Figures}

1.1 General schematic of a thermal CVD process . . . . . . . . . . 3

1.2 Schematic diagram of the typical growth rate behaviour for thermal CVD processes as a function of temperature . . . . . . . . . . . . 4

1.3 Comparison of typical growth rates for CVD and ALD processes . . . 6

1.4 Cyclical ALD growth process for $\mathrm{Al}_{2} \mathrm{O}_{3}$ using TMA and $\mathrm{H}_{2} \mathrm{O} \ldots \ldots$

1.5 Schematics of the main features of the surface chemistry of copper(I) sec-butyl-iminopyrrolidinate and copper(I) N,N-diisopropyl- $N, N$-dimethyl guanidinate ALD precursors on $\mathrm{Ni}(110)$ single crystals . . . . . . . . 11

1.6 The surface active sites of silica and the concentration of surface hydroxyl groups . . . . . . . . . . . . . . . . . . . . 13

1.7 Nuclear Zeeman splitting for the ${ }^{1} \mathrm{H},{ }^{13} \mathrm{C}$, and ${ }^{25} \mathrm{Mg}$ nuclear ground states .................................. 17

$1.8{ }^{13} \mathrm{C}$ SS-NMR spectra of a labeled glycine powder sample showing the effect of MAS . . . . . . . . . . . . . . . . . . . 21

1.9 Schematic showing the geometry of two spin dipole-dipole coupling . 23

1.10 Schematic diagram of the CP experiment . . . . . . . . . . . . . 24

1.11 Apparatus used to study surface chemistry of vapour-phase thin film deposition precursors on HSAS with SS-NMR . . . . . . . . . . 28

2.1 Table of Contents graphic used for publication described in Chapter 231

2.2 Thermogravimetric analysis data for compound $\mathbf{2}$. . . . . . . . . . 39 
2.3 Clausius-Clapeyron evaporation kinetics of compound 2 . . . . . . . 41

$2.4{ }^{29} \mathrm{Si} \mathrm{CP} / \mathrm{MAS}$ SS-NMR spectrum of the silica substrate annealed at

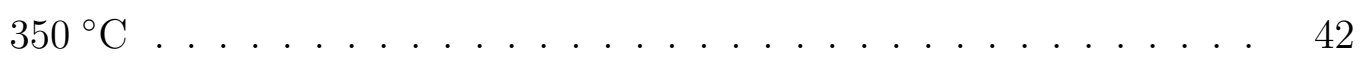

$2.5{ }^{29} \mathrm{Si} \mathrm{CP} / \mathrm{MAS}$ SS-NMR spectrum of the silica substrate exposed to 244

2.6 Proposed reaction mechanism for compound $\mathbf{2}$ on high surface area silica at $100{ }^{\circ} \mathrm{C}$ and $200{ }^{\circ} \mathrm{C}$ deposition temperature . . . . . . . . . . 49

$2.7{ }^{13} \mathrm{C}\left\{{ }^{1} \mathrm{H}\right\}$ SS-NMR and HR-NMR of 2 exposed to silica . . . . . . . 51

$2.8{ }^{1} \mathrm{H}$ HR-NMR of $\mathbf{2}$ exposed to silica etched with $\mathrm{D}_{2} \mathrm{O} \ldots \ldots . . . . \quad 53$

3.1 Table of Contents graphic used for publication described in Chapter 363

3.2 Proposed reaction mechanism for monoacetamidinatodiethylgallium(III) on high surface area silica at $100{ }^{\circ} \mathrm{C}$ and $200{ }^{\circ} \mathrm{C}$ deposition temperature 64

3.3 SEM micrographs of p-CVD process using only 2 without the addition of $\mathrm{H}_{2} \mathrm{O}$ or $\mathrm{O}_{2}$ in the pulse program at $500{ }^{\circ} \mathrm{C} \ldots \ldots . . . . . .667$

3.4 EDX spectrum of p-CVD process using only 2 without the addition of $\mathrm{H}_{2} \mathrm{O}$ or $\mathrm{O}_{2}$ in the pulse program at $500{ }^{\circ} \mathrm{C} \ldots \ldots$. . . . . . . 68

3.5 SEM micrographs of 2 p-CVD with $\mathrm{H}_{2} \mathrm{O} \ldots \ldots$. . . . . . . . . 70

3.6 TEM micrographs of p-CVD of 2 with $\mathrm{H}_{2} \mathrm{O}$ at $500{ }^{\circ} \mathrm{C}$. . . . . . . . 72

3.7 SEM micrographs of 2 p-CVD with $\mathrm{H}_{2} \mathrm{O}$ and $\mathrm{O}_{2}$ at $500{ }^{\circ} \mathrm{C} \ldots \ldots$

3.8 SEM micrographs of further p-CVD experiments with 2 but without the use of a co-reactant . . . . . . . . . . . . . . . . 75

3.9 SEM micrographs of p-CVD with 2 without a co-reactant followed by

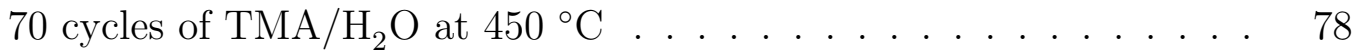

3.10 SEM micrographs of p-CVD with 2 and $\mathrm{O}_{2}$ co-reactant . . . . . 80

4.1 Table of Contents graphic used for publication described in Chapter $4 \quad 83$

4.2 Synthesis route for producing bisamidinato monohydrido aluminum (III) compounds . . . . . . . . . . . . . . . . . . . . . . 92 
4.3 Molecular crystal structure diagram for 4, 6, and 7 . . . . . . . 95

4.4 Solution-phase decomposition of compounds $\mathbf{3}-\mathbf{8} \ldots \ldots$. . . . . . . 98

4.5 Thermogravimetric analysis (ramp of $5^{\circ} \mathrm{C} / \mathrm{min}$ ) of $3-\mathbf{8} \ldots \ldots 9$

4.6 Reaction by-product monitoring from the solution-phase decomposi-

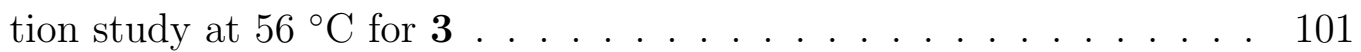

4.7 Proposed solution-phase decomposition mechanism for bisamidinato monohydride aluminum (III) compounds by sequential deinsertion / reinsertion of a carbodiimide moiety . . . . . . . . . . . . . . . 102

4.8 Stepped-isotherm TGA for $8 \ldots \ldots$. . . . . . . . . . 103

$4.9{ }^{1} \mathrm{H}$ HR-NMR spectra for the thermolysis of $\mathbf{3} \ldots \ldots$. . . . . . . . 107

$4.10{ }^{1} \mathrm{H}$ HR-NMR spectra for the thermolysis of 4 . . . . . . . . . . . . 108

$4.11{ }^{1} \mathrm{H}$ HR-NMR spectra for the thermolysis of $\mathbf{5} \ldots \ldots$. . . . . . . 108

$4.12{ }^{1} \mathrm{H}$ HR-NMR spectra for the thermolysis of 6 . . . . . . . . . . 109

$4.13{ }^{1} \mathrm{H}$ HR-NMR spectra for the thermolysis of $7 \ldots \ldots$. . . . . . . . 109

$4.14{ }^{1} \mathrm{H}$ HR-NMR spectra for the thermolysis of $8 \ldots \ldots$. . . . . . . 110

5.1 Table of Contents graphic used for publication described in Chapter 5113

5.2 Two thermal decomposition pathways for a copper(I) guanidinate species 114

5.3 Series of amidinate-type ligands with differing numbers of $\beta$-hydrogens, shown as their corresponding copper(I) compounds . . . . . . . . . 116

5.4 The synthetic procedure for producing the ligand used to make 11 . . 122

5.5 X-ray structures of (a) 9 and (b) $10 \ldots \ldots$. . . . . . . . 123

5.6 X-ray structure of $11 \ldots \ldots \ldots$. . . . . . . . . . . . . . . 124

5.7 Thermal stress test of compounds $\mathbf{9}$ and $\mathbf{1 1}$ shown by ramped TGA . 127

5.8 Thermal stress test trends for compounds $\mathbf{9}-\mathbf{1 2} \ldots \ldots$. . . . . . . . 128

5.9 Evaporation kinetics of $\mathbf{9}-\mathbf{1 2}$ by TGA . . . . . . . . . . . . . . 129

5.10 Thermal decomposition of $\mathbf{9 - 1 2}$ at $165{ }^{\circ} \mathrm{C}$ over 21 days in solution . . 130




$5.12{ }^{13} \mathrm{C}\left\{{ }^{1} \mathrm{H}\right\}$ HR-NMR of $\mathbf{1 1}$ and ${ }^{13} \mathrm{C}\left\{{ }^{1} \mathrm{H}\right\}$ CP/MAS SS-NMR of high surface area silica samples $\mathbf{B}$ and $\mathbf{C} \ldots \ldots \ldots \ldots$

$5.13{ }^{1} \mathrm{H}$ HR-NMR of pure $\mathbf{1 1}$ in $\mathrm{D}_{2} \mathrm{O}$ and $\mathrm{D}_{2} \mathrm{O}$ after it was washed over sample $\mathbf{B}$ and $\mathbf{C} \ldots \ldots \ldots \ldots \ldots$

5.14 Possible thermolysis of the surface species formed by $\mathbf{1 1}$ on HSAS . . 138

$5.15{ }^{29} \mathrm{Si}\left\{{ }^{1} \mathrm{H}\right\} \mathrm{CP} / \mathrm{MAS}$ SS-NMR of HMDS, 13, and $\mathbf{1 4}$ exposed to HSAS 140

$5.16{ }^{13} \mathrm{C}\left\{{ }^{1} \mathrm{H}\right\} \mathrm{CP} / \mathrm{MAS}$ SS-NMR of HMDS exposed to HSAS at $250{ }^{\circ} \mathrm{C}$. 142

$5.17{ }^{13} \mathrm{C}\left\{{ }^{1} \mathrm{H}\right\}$ HR-NMR of $\mathbf{1 3}$ and CP/MAS SS-NMR of $\mathbf{1 3}$ exposed to HSAS at $250{ }^{\circ} \mathrm{C}$ and $150{ }^{\circ} \mathrm{C} \ldots \ldots \ldots \ldots \ldots$

$5.18{ }^{13} \mathrm{C}\left\{{ }^{1} \mathrm{H}\right\}$ HR-NMR of $\mathbf{1 4}$ and CP/MAS SS-NMR of $\mathbf{1 4}$ exposed to HSAS at $250{ }^{\circ} \mathrm{C}$ and $150{ }^{\circ} \mathrm{C} \ldots \ldots \ldots \ldots \ldots$

5.19 Proposed surface adsorption mechanism for $\mathbf{1 3}$ and $\mathbf{1 4}$ on HSAS . . . 146

6.1 Table of Contents graphic used for publication described in Chapter 6149

6.2 XPS spectra of the phosphorous 2p and gold $4 \mathrm{f}$ regions for Au ALD films157

6.3 Saturation curve of $\mathbf{1 5}$ showing ALD behaviour . . . . . . . . . . 159

6.4 TEM of gold metal nanoparticles deposited on a TEM grid after 5 ALD cycles using 15 with oxygen plasma and water co-reactants . . . . . 160

$6.5{ }^{29} \mathrm{Si} \mathrm{CP} / \mathrm{MAS}$ SS-NMR spectrum of HSAS exposed to 15 at $100{ }^{\circ} \mathrm{C}$. 163

6.6 ${ }^{31} \mathrm{P}$ HR-NMR and SS-NMR of $\mathbf{1 5}$ and HSAS exposed to $\mathbf{1 5}$ at $100{ }^{\circ} \mathrm{C} \quad 164$

$6.7{ }^{13} \mathrm{C}$ HR-NMR and SS-NMR of 15, $\mathrm{MeAu}\left(\mathrm{PMe}_{3}\right)$ and HSAS exposed to 15 at $100{ }^{\circ} \mathrm{C} \ldots \ldots \ldots \ldots \ldots \ldots \ldots \ldots$

6.8 Proposed surface adsorption species for $\mathbf{1 5}$ on HSAS at $100{ }^{\circ} \mathrm{C} \ldots . \quad 167$

6.9 TGA traces for $15 \ldots \ldots \ldots$

6.10 The evaporation rate for $\mathbf{1 5}$ determined from TGA $\ldots \ldots$. . . . 169

6.11 SEM micrographs of gold metal films deposited by $15 \ldots$. . . . . 170

6.12 XPS survey spectrum of a gold film deposited on $\mathrm{Si}(100)$ with native

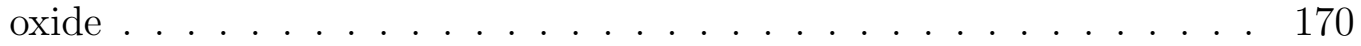




\section{List of Tables}

2.1 Surface Coverage of Compound 2 on Silica . . . . . . . . . . . . . . . 42

3.1 p-CVD deposition parameters used for $\mathrm{Ga} / \mathrm{Ga}_{2} \mathrm{O}_{3}$ depositions . . . 69

3.2 Gallium metal particle sizes obtained when undergoing self-seeding p-

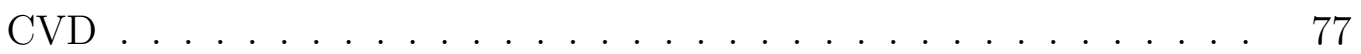

4.1 Selected bond lengths $(\AA)$ and angles $\left(^{\circ}\right)$ for compounds $\mathbf{3}, \mathbf{4}, \mathbf{6}$ and $\mathbf{7} 96$

4.2 Solution-phase kinetic thermal decomposition of $\mathbf{3}-\mathbf{8} \ldots \ldots$. . . . . . 98

4.3 Thermal characteristics of compounds $3-8 \ldots \ldots$. . . . . . . . . 100

5.1 Selected Bond Lengths and Angles for 9-11 . . . . . . . . . . . . 125

5.2 Kinetic Data for the Thermal Decomposition of $\mathbf{9 - 1 1}$ at $165{ }^{\circ} \mathrm{C}$. . . 132

5.3 Elemental Analysis of Samples A-C . . . . . . . . . . . . 136

6.1 Compositional analysis (at.\%) by XPS of the film formed without water and the film formed with water . . . . . . . . . . . 158

6.2 Surface Coverage of Compound 15 on Silica . . . . . . . . . . . . . . 162 


\section{List of Compounds}
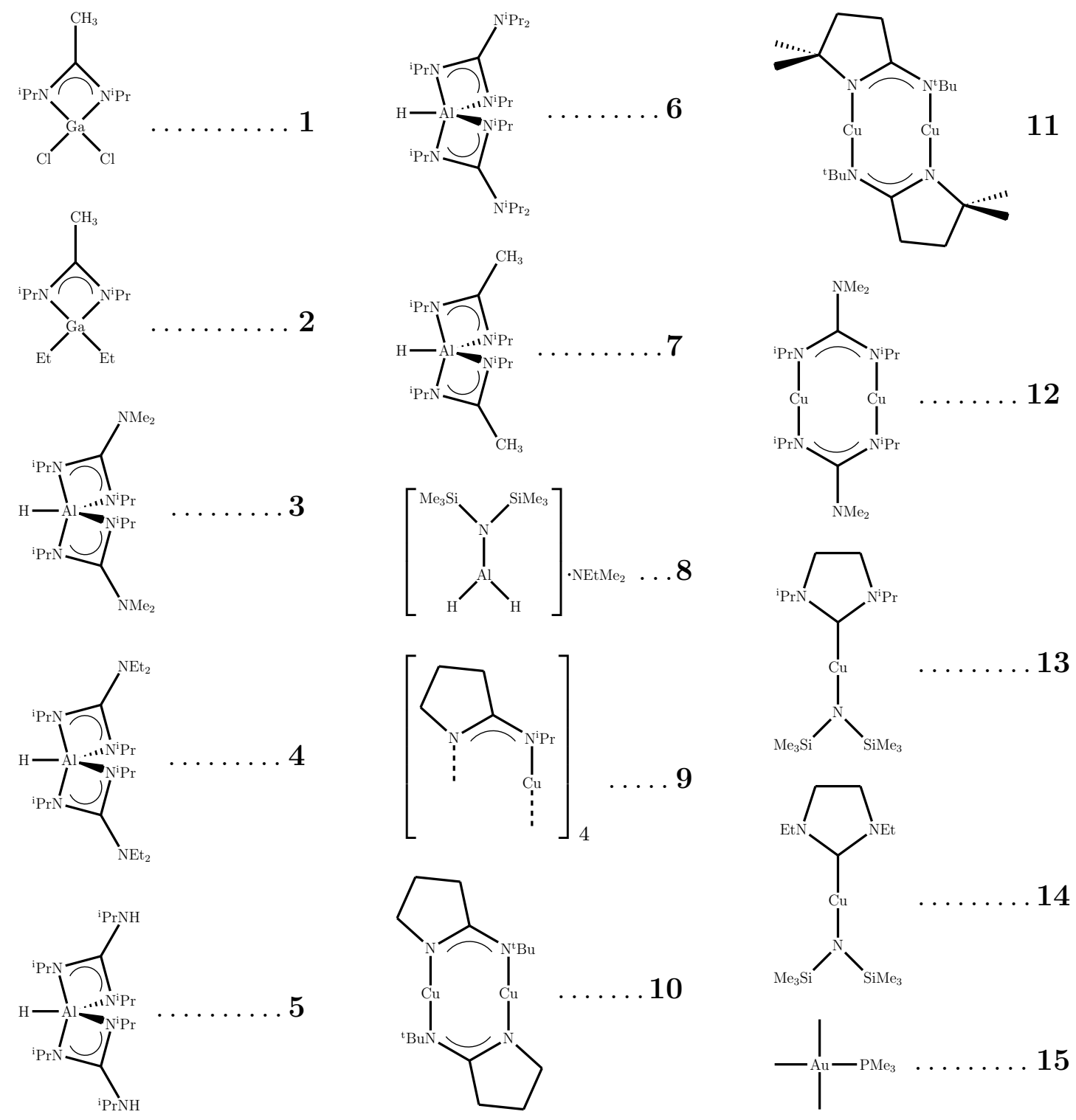


\title{
Acronyms
}

\author{
ALD atomic layer deposition \\ CDI carbodiimide \\ CP cross-polarization \\ CVD chemical vapour deposition \\ DFT density functional theory \\ EDX energy dispersive X-ray spectroscopy
}

FIB focused ion beam

FTIR Fourier transform infrared spectroscopy

GPC growth per cycle

HR-NMR high resolution nuclear magnetic resonance spectroscopy

HSAS high surface area silica

IR infrared

LEED low-energy electron diffraction

LEIS low-energy ion scattering

MAS magic angle spinning

MBE molecular beam epitaxy

MO-CVD metal-organic chemical vapour deposition

MS mass spectrometry

p-CVD pulsed chemical vapour deposition 
PE-ALD plasma-enhanced atomic layer deposition

QCM quartz crystal microbalance

scXRD single-crystal X-ray diffraction

SE spectroscopic ellipsometry

SEM scanning electron microscopy

SERS surface-enhanced Raman spectroscopy

SS-NMR solid-state nuclear magnetic resonance spectroscopy

TEM transmission electron microscopy

TGA thermogravimetric analysis

TMA trimethylaluminum

TPD temperature programmed desorption

UHV ultra-high vacuum

UV-vis UV-visible spectroscopy

XPS X-ray photoelectron spectroscopy

XRD X-ray diffraction 


\section{Chapter 1}

\section{Introduction}

\subsection{Vapour Phase Thin Film Deposition}

The study of materials chemistry is necessary for technological advancements in our society. Nearly all of the tools and materials we use today come from the ability to control the structure and properties of new materials. Within the last 50 years, we have gained the ability to manipulate atoms and molecules on the nano-scale and to control the synthesis of a host of new materials. Organic nanomaterials, such as the fullerenes or $\mathrm{C}_{60}$ (their discovery was awarded the Nobel Prize in Chemistry in 1996) and single sheets of $s p_{2}$ hybridized carbon called graphene, as well as inorganic nanomaterials such as metal nanoparticles and quantum dots, have made a considerable impact on global technological advancements.

Not only is the discovery of novel materials important, but the ability to control the growth and/or synthesis of these materials is essential for the viability of these materials as a new technology. There are two approaches to controlling nanomaterial synthesis: top down methods typically start with a bulk material and use techniques

such as lithography, etching or focused ion beam (FIB) milling to generate features of the desired size and morphology. ${ }^{1}$ While this method allows for nano-sized features 
with spatial control, the feature size is limited by the resolution of whatever method is used to etch the material and typically masks or resists are required for feature selectivity. ${ }^{1}$ The alternative approach is the bottom up method where the material is grown atom-by-atom or molecule-by-molecule until the desired morphology/properties are reached. Solution-based synthesis of nanoparticles, self-assembly, and thin film deposition techniques all fall within the bottom up approach to nanoscale synthesis of materials. The study of vapour phase thin film deposition is the focus of this work.

Novel, nanoscale thin film materials currently have applications in a very wide variety of disciplines. Microelectronics, optics, energy production and storage, protective coatings, biosensors and biocompatibile coatings are just a few of the areas where controlled growth of thin film materials have some application.

The fabrication of thin films can be done in a variety of ways. There are physical methods of thin film deposition, such as sputtering, laser ablation or molecular beam epitaxy (MBE). ${ }^{2}$ These methods generate a beam or stream of atoms or molecules of the desired thin film material in a vacuum. This beam is then directed at a surface and the desired material is deposited. While these techniques are capable of depositing high quality films relatively quickly, they have some limitations. Given that the deposited material is condensed from the vapour-phase these methods are "line of sight" deposition techniques that are incapable of coating complex nanostructured or porous surfaces. As well, given the high energy needed to produce a beam of, typically, atoms, the range of materials that can be deposited with these methods are limited.

\subsubsection{Chemical Vapour Deposition}

Chemical vapour deposition (CVD) has the potential to overcome some of the limitations of physical deposition methods. CVD relies on producing one or more vapourphase precursors, typically in a vacuum, that then undergo some form of chemical 


\section{(1) Main Gas Flow Region}



Figure 1.1: General schematic of a thermal CVD process. Adapted from Jensen and Kern. ${ }^{3}$

reaction at a surface to ultimately deposit a thin film of desired material. By controlling the nature of the precursor(s), the ultimate film deposition is controlled by surface chemistry. This avoids the need to use elements and compounds that typically require relatively large amounts of energy to get them into the gas phase like in physical deposition methods. It also allows for more control during the growth process since the material deposits only where it is possible to undergo surface chemistry, not just wherever it strikes the substrate. A general schematic of a CVD process can be found in Figure 1.1. Thin film growth via CVD is not as straight-forward as in physical methods. First, the precursor must be transported into the main reaction chamber (1), typically aided by an inert gas solvent. Although not always necessary, there are many cases where the vapour-phase precursor undergoes reactions before interacting with the surface to form film precursors and by-products (2). The precursor must then be mass-transported to the surface through a combination of diffusion and advection (3). Once it has reached the substrate adsorption of the precursor takes places (4). This typically begins as a physisorbed state which after appropriate diffusion (5) either desorbs from the surface (6) or chemisorption occurs creating a nucleation site for film growth (7). Chemisorption typically produces unwanted 


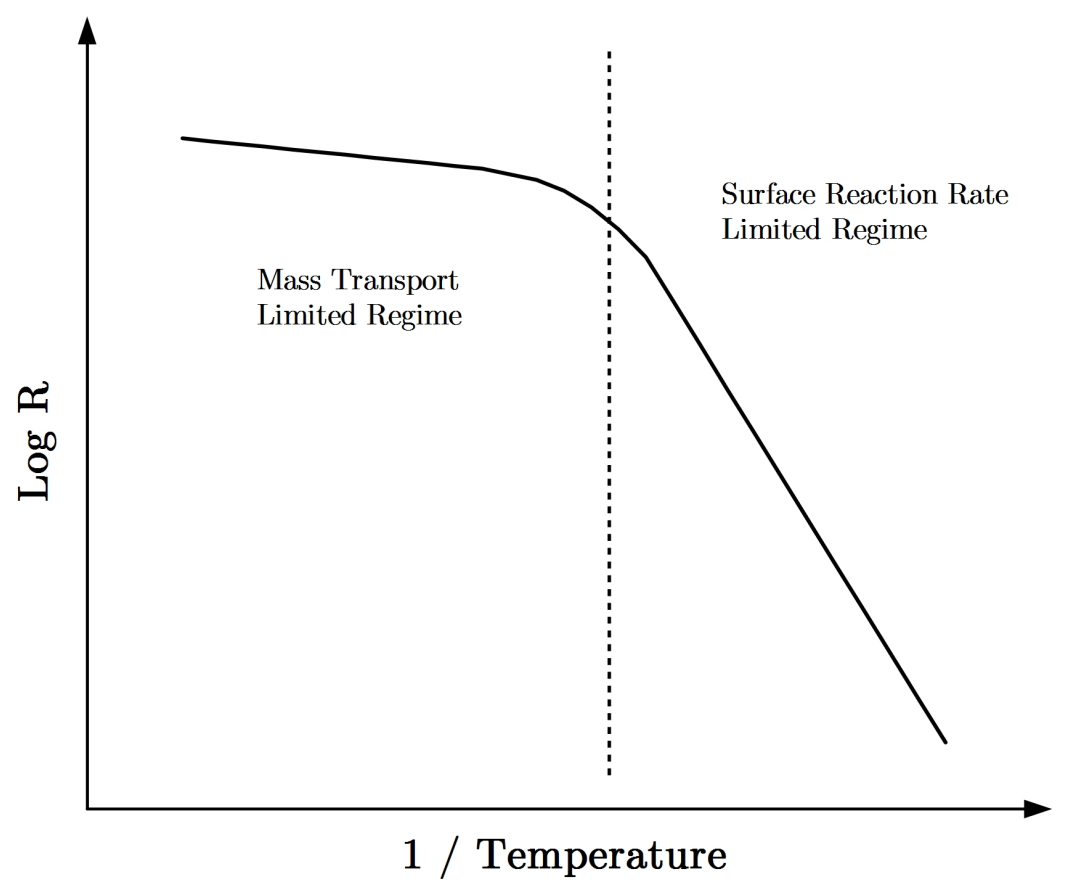

Figure 1.2: Schematic diagram of the typical growth rate behaviour for thermal CVD processes as a function of temperature. Two-limiting regimes are shown. At high temperature mass-transport limits growth while at low temperature the surface reaction kinetics limits the overall growth rate. Adapted from Crowell. ${ }^{4}$

byproducts that are, ideally, volatile and can be mass-transported away from the growing film and removed from the reaction chamber (8).

For a CVD process to be scalable and have use in an industrial application, the rate of film growth is a very important property to understand for usable thin films. While the overall growth rate is dependent on all the processes occurring in Figure 1.1, when considered as a function of reactor temperature, the growth rate can generally be simplified to two regimes that combine many of the processes occurring in Figure 1.1. ${ }^{4}$ These two regimes are shown in Figure 1.2. At high temperature, the reactions occurring at the surface ((4)-(6) in Figure 1.1) happen very quickly compared to the ability of precursor to make it to the surface through mass-transport. This means that convection of the precursor to the surface and removal of reaction by-products ((1), (3), (7), and (8) in Figure 1.1) controls the growth rate of the CVD process. Typically mass-transport phenomena and the solution to the mass flux continuity equations in a vapour deposition apparatus are dominated by advection of the carrier gas instead of the temperature-dependent precursor diffusion. ${ }^{5}$ This is why the growth rate does not 
change significantly with temperature in this regime. However, at low temperature the growth rate is limited by the surface reaction chemistry $((4)-(6))$ instead of masstransport phenomena. Since chemical reaction kinetics, and more specifically the rate constant, is highly temperature dependent, the growth rate can vary significantly in this regime. A number of studies have been done to model these phenomena in detail for CVD and atomic layer deposition (ALD) (see below) processes. ${ }^{5-11}$

From all the necessary steps for CVD film growth shown in Figure 1.1, it is important to consider a number of factors when developing an ideal CVD process. Precursor design, the nature of the substrate, and reactor design must all be carefully chosen to work together and ultimately deposit a thin film of desired material in a reasonable amount of time. Precursors, typically metal-containing, must be designed to be volatile, thermally stable in the gas-phase yet also reactive with the substrate, and produces volatile non-reactive by-products. The need for proper precursor design in CVD processes is paramount for high purity, conformal thin films and typical requirements for CVD precursors have been reviewed recently. ${ }^{12}$ Since the precursor must ultimately react with the surface, the chemical nature of the surface governs what material is ultimately deposited. This is the focus of this work and is discussed more thoroughly in a subsequent section (Section 1.2). The ability to get the precursor to the substrate in an efficient way is also important for film growth and so reactor design and engineering will affect growth, particularly uniformity. There are a number of different reactor configurations known ${ }^{4}$ and the choice of reactor design will affect the mass-transport properties of the precursor which ultimately affects the growth of the desired film.

\subsubsection{Atomic Layer Deposition}

Atomic layer deposition (ALD) is a subset of CVD that introduces self-terminating surface reactions between precursor and substrate and ultimately improves the control 




Figure 1.3: Comparison of typical growth rates for CVD and ALD processes. and conformality of film growth. Originally rooted in experiments done in the early 1960s and 1970s, ${ }^{13,14}$ it was called atomic layer epitaxy (ALE) as it was primarily used to grow monocrystalline ceramic materials. Since these initial experiments, it has come to include polycrystalline and amorphous materials and now describes a cyclical deposition process that hinges on self-terminating surface reactions and atomic precision in film growth. ${ }^{15,16}$

Figure 1.3 shows the fundamental difference between ALD and CVD. CVD does not necessarily exhibit a saturating growth rate behaviour as precursor exposure is increased. In ALD, however, once the surface is saturated with chemisorbed precursor, there is no further growth. Figure 1.4 shows an idealized schematic of the general principle behind ALD thin film growth using trimethylaluminum (TMA) and $\mathrm{H}_{2} \mathrm{O}$ to deposit $\mathrm{Al}_{2} \mathrm{O}_{3}$, one of the most well studied processes, ${ }^{17-20}$ as an example. First, a surface with a given amount of reactive surface sites is exposed to the first precursor (Figure 1.4-top left), in this case TMA exposed to a surface that is terminated in hydroxyl groups. In step 1 the TMA chemisorbs to the surface by reacting with the hydroxyl groups to produce methane and a surface terminated in methyl groups. This 


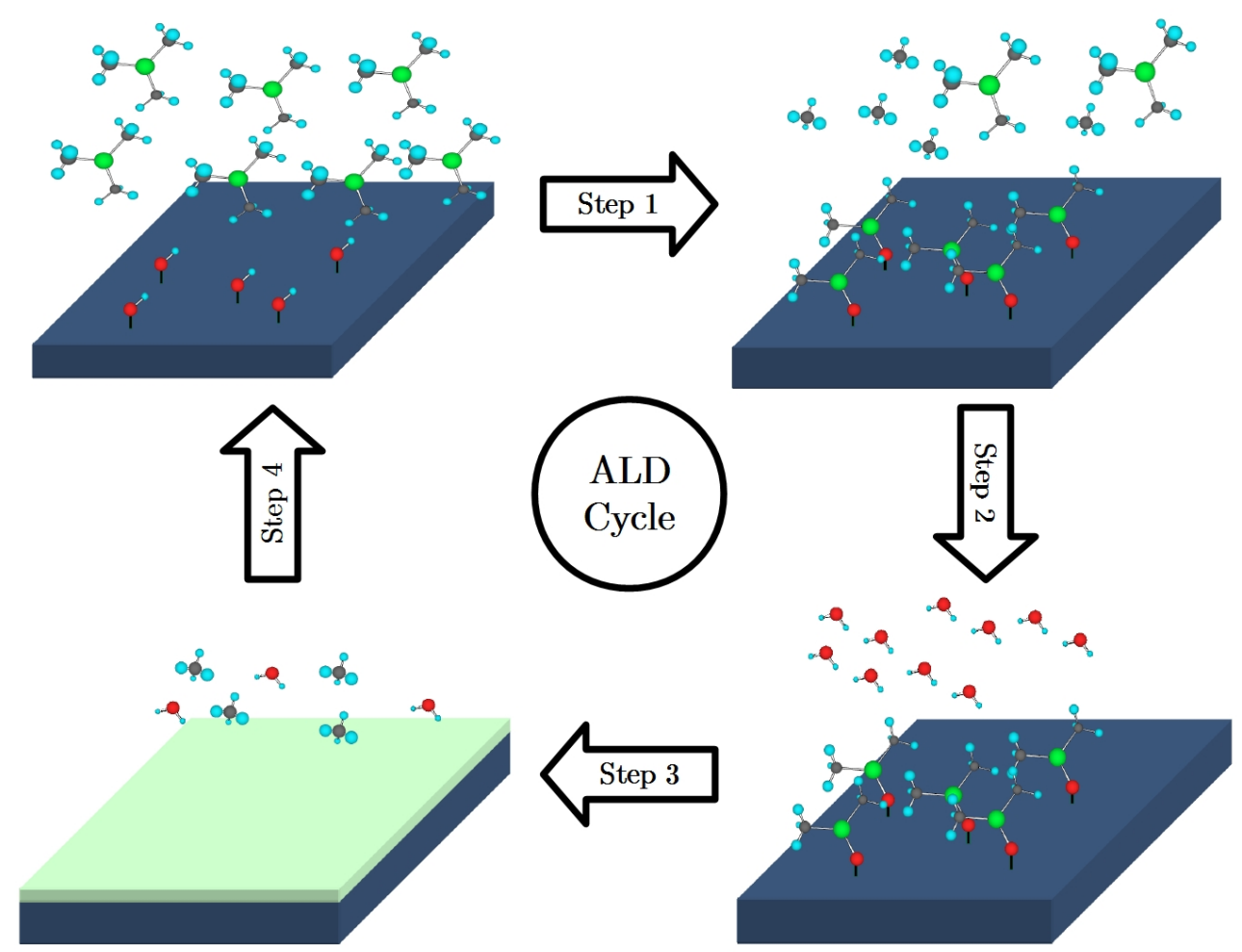

Figure 1.4: Cyclical ALD growth process for $\mathrm{Al}_{2} \mathrm{O}_{3}$ using TMA and $\mathrm{H}_{2} \mathrm{O}$.

surface is then unreactive to increased exposure to TMA which is the key to an ALD process. In step 2 the excess TMA and byproducts are flushed from the reaction chamber and the second precursor, in this case $\mathrm{H}_{2} \mathrm{O}$, is dosed into the chamber. The $\mathrm{H}_{2} \mathrm{O}$ reacts with the surface methyl groups (step 3) to produce methane and regenerate the surface hydroxyl groups. The water is unreactive to the surface hydroxyl groups thus again forming a self-terminating monolayer. The excess water and byproducts can be again purged from the system (step 4). This produces one layer of $\mathrm{Al}_{2} \mathrm{O}_{3}$ and completes 1 ALD cycle. This can be repeated to produce films with Ångström-level thickness control. As well, the self-terminating monolayer allows for excellent control over conformality when growing films on complex nanostructured substrates. With ALD it is possible to coat pores with aspect ratios (pore length:pore diametre) greater than 40 uniformly. ${ }^{7}$

The co-reactants used in ALD processes are typically simple, highly volatile liquids or gases. Commonly $\mathrm{H}_{2} \mathrm{O}, \mathrm{O}_{2}$, or $\mathrm{O}_{3}$ are used to deposit oxide films; $\mathrm{NH}_{3}$ for nitrides; $\mathrm{H}_{2} \mathrm{~S}$ /other water analogues for sulfides and other chalcogenide materials; $\mathrm{H}_{2}$ 
for metal deposition. ${ }^{20}$ In this context these processes are considered to be thermal ALD processes. This meaning that the energy necessary for the surface reactions to occur is obtained through heat transfer from the surrounding reactor. Recently, the use of a plasma as a second co-reactant has gained considerable popularity for developing new ALD processes. Plasma-enhanced atomic layer deposition (PE-ALD), in general, requires lower temperatures than traditional thermal ALD processes, which is useful for depositing on thermally sensitive substrates, as well as providing access to a wider variety of materials, such as metals. ${ }^{21,22}$ Thermal ALD and PE-ALD have provided access to the deposition of over 175 materials and that list continues to grow. ${ }^{20}$

\subsection{Surface Chemistry}

Given the nature of thin film vapour deposition techniques like CVD and ALD, it is clear that these processes rely heavily on very specific surface chemistry. Surface science is a well-established field that uses a wide variety of techniques to probe the physical and chemical interactions at solid-vapour interfaces. However, the study of solid-vapour interactions in CVD and ALD processes is yet only known for only a handful of processes. ${ }^{23}$ For the development of industrially relevant ALD processes, it is not sufficient to simply invent a novel process where the precursor exhibits ALDbehaviour, the specific surface chemistry is also very important. Not only does the study of surface chemistry for ALD processes answer fundamental questions about solid-vapour interactions, but it allows for the improvement of existing processes and directs the invention of new processes. There are many ALD processes that, although they excel at depositing a conformal, thin film, are plagued with impurities and have uniformity issues with respect to nucleation and island growth. ${ }^{24-26}$ This is due to potential ligand decomposition, generally misunderstood reaction stoichiometry, the 
nature of nucleation sites and initial deposition, unknown redox chemistry at the metal centre, and the possibility of CVD interference during deposition. ${ }^{23}$

To study the surface chemistry of ALD processes there are a variety of techniques that are commonly used. First, it should be noted that while there are a wide variety of techniques available for studying solid-vapour interactions, quite a few of them are not amenable for studying ALD processes. This is due to the fact that most surface science techniques are operated at ultra-high vacuum (UHV) conditions $\left(<10^{-9}\right.$ Torr $)$, require very well-defined surfaces (freshly cleaved single crystals) and use relatively expensive equipment that require trained operators. However, there are still a number of techniques that have been used successfully to determine some aspect of the surface chemistry occurring in an ALD process. Both in situ characterization methods, such as mass spectrometry (MS) (or temperature programmed desorption (TPD)), quartz crystal microbalance (QCM), spectroscopic ellipsometry (SE), low-energy electron diffraction (LEED), low-energy ion scattering (LEIS) and infrared (IR) spectroscopy, and ex situ methods, such as X-ray photoelectron spectroscopy (XPS) and solid-state nuclear magnetic resonance spectroscopy (SS-NMR) have been used and there have been several reviews published on the topic in recent years. ${ }^{23,26,27}$

\subsubsection{Copper(I) Iminopyrrolidinate / Guanidinate on Ni(110)}

To highlight the information and impact one can obtain by performing an in depth surface chemistry study on an ALD process or precursor, an example by Zaera's group 28 will be discussed. This study used a combination of XPS and TPD to determine the thermal chemistry of copper(I) sec-butyl-iminopyrrolidinate and $\operatorname{copper}(\mathrm{I}) \mathrm{N}, \mathrm{N}$ diisopropyl- $N, N$-dimethyl guanidinate (compound 12 from Chapter 5) on a $\mathrm{Ni}(110)$ surface to study the viability of these compounds as ALD precursors for the deposition of copper metal. All the data from this work was obtained in UHV conditions in a chamber capable of dosing known quantities of vapour-phase precursor to a $\mathrm{Ni}(110)$ 
sample and performing XPS and TPD studies on the adsorbate.

In a typical TPD study, the substrate is first dosed with a small amount of precursor, measured in terms of exposure (in units of Langmuirs, L [10 ${ }^{-6}$ Torr $\left.\cdot \mathrm{s}\right]$ ) at low temperatures, typically $<100 \mathrm{~K}$. Then, the substrate is heated and the desorption products are monitored using MS. In this study the TPD results were quite complicated showing a large number of surface decomposition products for both the iminopyrrolidinate and guanidinate compound from $100 \mathrm{~K}$ to $900 \mathrm{~K}$. In the case of the iminopyrrolidinate compound, molecular desorption was observed at around 230 $\mathrm{K}$ and between $300 \mathrm{~K}$ to $700 \mathrm{~K}$ evolution of hydrogen was observed. The evolution of hydrogen would indicate extensive ligand decomposition between these temperatures. Indeed, between these temperatures there was also evidence of hydrogen cyanide, acetonitrile, and 2-sec-butyleneamino-1-pyrroline. This shows that at elevated temperatures, after initial chemisorption, there is $\beta$-hydrogen elimination occurring in the ligand framework. The TPD results were similar for the copper(I) guanidinate compound as well. Again between about $300 \mathrm{~K}$ to $600 \mathrm{~K}$ the desorption of molecular hydrogen was observed indicating ligand decomposition. Propene, acetonitrile, $N, N$-dimethyl- $N$-isopropyl- $N$-isopropylidene-guanidine are all $\beta$-hydrogen elimination products of the ligand framework and were observed in the TPD data. It is suspected that the $\beta$-hydrogen elimination of the ligand framework in both cases produces a transient unstable copper species on the surface that ultimately reduces to copper metal on the surface.

To determine what species remained on the surface during the TPD study, XPS was performed on the substrates at a variety of temperatures after initial adsorption. By monitoring the $\mathrm{Cu} 2 \mathrm{p}, \mathrm{C}$ 1s, and $\mathrm{N}$ 1s regions they determined that both the iminopyrrolidinate and guanidinate compounds behave somewhat similarly. Both show a shift from $\mathrm{Cu}(\mathrm{I})$ to $\mathrm{Cu}(0)$ between about $350 \mathrm{~K}$ and $400 \mathrm{~K}$ indicating that these ligand systems are capable of reducing the copper centre on $\mathrm{Ni}(110)$ at elevated 


\section{$\mathrm{Cu}(\mathrm{I})$-Iminopyrrolidinate}

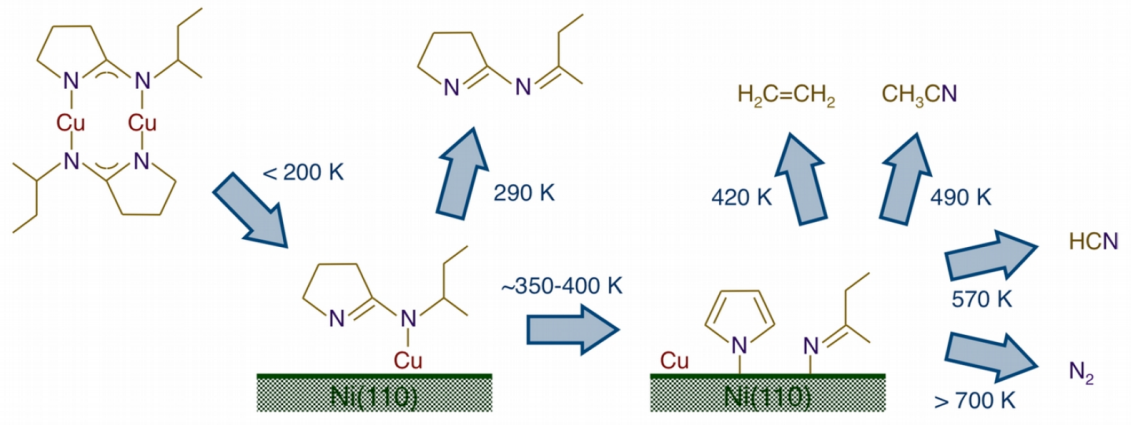

\section{$\mathrm{Cu}(\mathrm{I})$-Guanidinate}

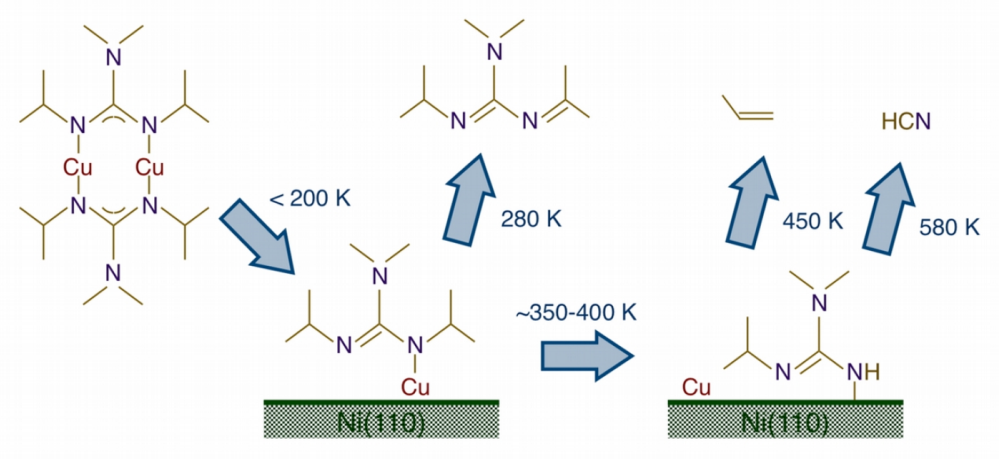

Figure 1.5: Schematics of the main features of the surface chemistry of copper(I) secbutyl-iminopyrrolidinate (top) and copper(I) $N, N$-diisopropyl- $N, N$-dimethyl guanidinate (bottom) ALD precursors on $\mathrm{Ni}(110)$ single crystals. Adapted from Kim et $a l .{ }^{28}$

temperatures. From the $\mathrm{C} 1 \mathrm{~s}$ and $\mathrm{N}$ 1s signals it was determined that even at elevated temperatures there was a significant quantity of both carbon and nitrogen still left on the surface. The nature of these species was slightly different in both cases but both were fragments of the initial ligand system.

The overall surface adsorption and subsequent surface chemistry for these two compounds is shown in Figure 1.5. Both compounds undergo dissociative adsorption followed by complex decomposition at elevated temperatures. The decomposition of both show $\beta$-hydrogen elimination as the major mechanism for ligand decomposition at higher temperatures. Another important feature is that above $350 \mathrm{~K}$ both compounds showed the presence of metallic copper on the surface. This indicates that above these temperatures these precursors will start exhibiting CVD-like behaviour. This is interesting as most thermal ALD processes are done above $100{ }^{\circ} \mathrm{C}$ and so 
this indicates that CVD-like behaviour can happen at much lower temperatures than what is typically expected. As well, at these temperatures there is still evidence of carbon and nitrogen-containing species on the surface. This shows that without the appropriate choice of co-reactant in an ALD process, these species will contribute to potential impurities in the resultant film. Overall, this study is an excellent example of how knowing the specific surface chemistry of a given precursor can provide insight into the potential self-terminating behaviour of an ALD precursor as well as indicate the potential source for impurities in an ALD process.

\subsubsection{Titanium(III) Cyclopentadienyl Guanidinate on Silica}

Another study by Wasslen et al. ${ }^{29}$ highlights the importance of examining the surface chemistry of ALD precursors. This work also provided much of the motivation for this thesis. In this study, a titanium(III) mono- $N, N$-diisopropyl- $N$-isopropyl-guanidinate biscyclopentadienyl ( $\mathrm{TiCp}_{2}$ guan) compound was exposed to HSAS at a variety of temperatures and characterized ex situ using SS-NMR and elemental analysis as well as by density functional theory (DFT) computational methods.

In this study the substrates were amorphous silica. This is beneficial because these substrates are more commonly used in ALD processes rather than the single crystal metals as described in the previous example. This means that the surface chemistry determined on these substrate is more indicative of what is actually happening during initial nucleation in an ALD process. The disadvantage is that these substrates are not as well-defined as a single crystal and so there are a large variety of nucleation sites with differing geometries and energies. For this reason it is difficult to determine individual nucleation mechanisms and typically in these cases a bulk chemisorption mechanism averaged over all surface reactive sites is determined. Even though the surface of silica is not as well-defined as a single crystal, it has been studied extensively ${ }^{30}$ and it is generally known that the chemisorption of ALD precursors on silica 




Figure 1.6: The surface active sites of silica and the concentration of surface hydroxyl groups. a) shows the different surface active sites that exist on silica. b) shows how the concentration of hydroxyl groups decreases while the surface siloxane (or dehydrated silicon) species increases with increasing temperature. Adapted from Bergna ${ }^{30}$ and Kiselev and Lygin ${ }^{33}$

typically occurs at surface hydroxyl sites. ${ }^{19,31,32}$ However, the concentration and type of surface hydroxyl groups that are accessible is highly dependent on the reaction conditions. For instance, at elevated temperature hydroxyl groups on the surface of silica will react with each other, effectively dehydrating the surface and reducing the overall number of surface reactive sites. The known types of surface reactive sites and how they change with temperature is shown in Figure 1.6. Above $200{ }^{\circ} \mathrm{C}$, physisorbed water is removed from the surface and only a relatively high concentration of surface hydroxyl species are present. At these temperatures there is a high enough concentration (between $2.5-5 \mathrm{OH} / \mathrm{nm}^{2}$ ) of hydroxyl groups that there are a larger number of geminal silandiols and vicinal $\mathrm{OH}$ species on the surface. However, above $400{ }^{\circ} \mathrm{C}$ significant dehydration of the surface occurs and there are fewer silandiol and vicinal species and more single silanol species and dehydrated surface siloxanes. This means that when studying the chemisorption chemistry on silica it is important to consider the type and density of hydroxyl groups on the surface.

In Wasslen et al. ${ }^{29}$ the chemisorption of the titanium precursor was examined at two different silica pre-treatment temperatures, $350{ }^{\circ} \mathrm{C}$ and $900{ }^{\circ} \mathrm{C}$. Looking at Figure 1.6 this means the $350{ }^{\circ} \mathrm{C}$ pre-treatment would have about $3 \mathrm{OH} / \mathrm{nm}^{2}$ and 
would consist of silandiols as well as silanols while at $900{ }^{\circ} \mathrm{C}$ pre-treatment there would be, on average, $<1 \mathrm{OH} / \mathrm{nm}^{2}$ and would be only single silanol species and dehydrated silica left on the surface. After pre-treatment the silica was heated to between $180{ }^{\circ} \mathrm{C}$ and $330{ }^{\circ} \mathrm{C}$ and exposed to vapour-phase $\mathrm{TiCp}_{2}$ guan for several hours. The optimal temperature for chemisorption was found to be $240{ }^{\circ} \mathrm{C}$ based on the saturation of the precursor on HSAS indicated by a colour change (orange) after exposure. Using ${ }^{13} \mathrm{C}$ SS-NMR they determined that for the $350{ }^{\circ} \mathrm{C}$ pre-treatment exposure there were two broad signals present at $24 \mathrm{ppm}$ and $115 \mathrm{ppm}$. This indicates that both guanidinate and cyclopentadienyl species are present on the surface for this sample. For the $900{ }^{\circ} \mathrm{C}$ pre-treatment exposure there was only one signal observed in the ${ }^{13} \mathrm{C}$ SS-NMR at 115 ppm. This shows that only cyclopentadienyl species are present on the surface of the HSAS when pre-treated to $900{ }^{\circ} \mathrm{C}$. This data is corroborated by elemental analysis of $\mathrm{Ti}$ content on the surface via neutron activation and $\mathrm{C}$ content on the surface via carbon analyzer. From this data it was found that the following chemisorption occurs for $\mathrm{TiCp}_{2}$ guan on HSAS:

For $350{ }^{\circ} \mathrm{C}$ HSAS pre-treatment (chemisorption at $240{ }^{\circ} \mathrm{C}$ )

$2 \|-\mathrm{SiO}_{2}(\mathrm{OH})+2 \mathrm{TiCp}_{2}$ guan $\longrightarrow\|-\mathrm{SiO}-\mathrm{Tiguan}+\|-\mathrm{SiO}-\mathrm{TiCp}+2 \mathrm{CpH}$

For $900{ }^{\circ} \mathrm{C}$ HSAS pre-treatment (chemisorption at $240{ }^{\circ} \mathrm{C}$ )

$2 \|-\mathrm{SiO}_{2}(\mathrm{OH})+2 \mathrm{TiCp}_{2}$ guan $\longrightarrow\|-\mathrm{SiO}-\mathrm{TiCp}+\|-\mathrm{SiO}-\mathrm{TiCp}_{2}+\mathrm{CpH}+$ guanH

From this mechanism it was determined that a titanium guanidinate and a titanium cyclopentadienyl species exists on the surface when HSAS was pre-treated to $350{ }^{\circ} \mathrm{C}$, while at $900{ }^{\circ} \mathrm{C}$ pre-treatment temperature only titanium cyclopentadienyl species were observed. This difference in pre-treatment temperature reactivity is attributed to the hydroxyl density available on chemisorption. At lower hydroxyl densities (higher pre-treatment temperature) the chemisorbed surface species is allowed to form the more favourable, yet sterically bulky titanium cyclopentadienyl species. At higher hydroxyl densities, however, the proximity of already adsorbed titanium 
species only allows access to a titanium guanidinate species to be left on the surface.

This study is important for the surface chemistry of ALD precursors for several reasons. It shows that chemisorption mechanisms can be determined for not welldefined substrates and relatively complex vapour-phase adsorption precursors. It also shows the importance of understanding the nature of the surface reactive sites of the substrate being used. It also demonstrates the usefulness and efficacy of ex situ characterization techniques, such as elemental analysis and SS-NMR, for studying surface chemistry. This gives the advantage of performing characterization without the need for complicated equipment as well as being able to study the surface under conditions that are more applicable to industrial applications.

While elucidating the initial chemisorption mechanism on silica or other substrates is necessary to understand the initial stages of growth and nucleation, it is important to consider the inevitability of changing substrates. In typical CVD or ALD processes, after initial nucleation events occur, a continuous or semi-continuous film forms on the initial substrate. This will ultimately change the surface chemistry as the "substrate" is now the growing film, rather than the initial substrate. This means that to fully understand the nature of the vapour-solid interactions occurring at the surface in CVD and ALD processes, it is, in general, beneficial to study a wide variety of substrates.

\subsection{Solid-State Nuclear Magnetic Resonance Spec- troscopy}

Nuclear magnetic resonance spectroscopy, in general, is a powerful technique capable of probing a variety of local interactions. The method is based on an intrinsic nuclear property called spin. For fermions, such as protons and neutrons, the total intrinsic spin of each particle is $1 / 2$. When protons and neutrons are brought together in a nucleus, the combination of these particles creates non-degenerate total nuclear spins 
for the entire nucleus. The ground state nuclear spin, $I$, is typically what is reported for a given isotope of a given nucleus. For example, ${ }^{1} \mathrm{H}(I=1 / 2),{ }^{13} \mathrm{C}(I=1 / 2),{ }^{29} \mathrm{Si}$ $(I=1 / 2),{ }^{14} \mathrm{~N}(I=1),{ }^{25} \mathrm{Mg}(I=5 / 2)$, etc. The ground state nuclear spin of a nucleus then gives rise to $(2 I+1)$-degenerate spin states ranging from $-I$ to $+I$. When these spins are placed in a magnetic field, $B_{0}$, these spin states become non-degenerate. This effect is called nuclear Zeeman splitting and can be seen in Figure 1.7.

The relative splittings between the spin states of different nuclei at the same magnetic field are different. The separation is proportional to the intrinsic magnetic moment and spin of a given nucleus, and related by the proportionality constant, $\gamma$, or the magnetogyric ratio. The energy of a spin state is given as:

$$
E=-\gamma m_{l} \hbar B_{0}
$$

and the difference in energy between spin states is:

$$
\Delta E=\gamma \hbar B_{0}
$$

The nucleons that make up a nucleus have an intrinsic magnetic moment thus giving atomic nuclei an intrinsic magnetic moment. Nuclei that have a non-zero nuclear spin will then have a non-zero magnetic moment. The interaction of a nuclear spin of a nucleus with an external magnetic field gives rise to spin precession. The precession frequency is called the Larmor frequency and is given by:

$$
\omega_{0}=-\gamma B_{0}
$$

where $\omega_{0}$ is the angular Larmor frequency, $\gamma$ is the magnetogyric ratio, and $B_{0}$ is the strength of the external magnetic field. While this precession happens continuously, tiny distortions, from a variety of sources, in the external field felt by a nucleus cause 


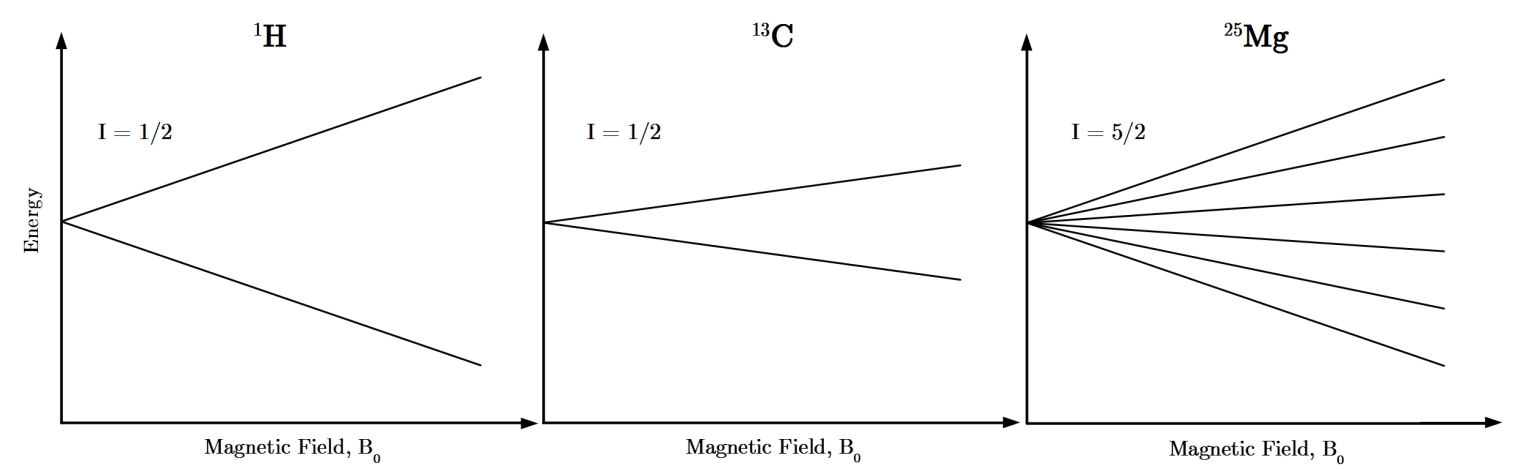

Figure 1.7: Nuclear Zeeman splitting for the ${ }^{1} \mathrm{H},{ }^{13} \mathrm{C}$, and ${ }^{25} \mathrm{Mg}$ nuclear ground states. Adapted from Levitt. ${ }^{34}$

fluctuations in the orientation of the nucleus' magnetic moment. These fluctuations break the isotropy of the nuclear spin polarization and a macroscopic nuclear magnetic moment will begin to develop. The Zeeman interaction dictates that there is a higher probability to find the nuclear spin at the lower magnetic energy state. The difference in populations of the energy levels at thermal equilibrium results in bulk magnetization within a sample and is the origin of an NMR signal.

If all nuclei of the same type precessed at exactly their Larmor frequency, then NMR spectroscopy would be practically useless. It is minor perturbations in the Zeeman interaction from external and internal sources that provide interesting and detailed insights into the chemical environments of a given nucleus. While most chemists are familiar with the chemical shift (or chemical shielding) interaction in NMR spectroscopy there are quite a few other interactions that are equally as important, especially when studying systems in the solid-state. These include dipole-dipole coupling, J-coupling, quadrupolar coupling (for spins $I>1 / 2$ ), spin-rotation interactions, and the Knight interaction present in electrically conductive samples. ${ }^{34,35}$ Although all these interactions contribute to the overall signal observed in an NMR spectrum, for the purposes of the work described in this thesis, only a brief description of the chemical shielding interaction and the dipole-dipole interaction will be included.

The nature of an NMR signal can best be described by examining the quantum state of the system of interest. The quantum state of an entire system can be de- 
scribed by a wavefunction that contains information about the motion, positions, and spin states of all electrons and nuclei. This wavefunction obeys the time-dependent Schrödinger equation:

$$
\frac{d}{d t}\left|\Psi_{\text {full }}(t)\right\rangle=-i \hat{H}_{\text {full }}\left|\Psi_{\text {full }}(t)\right\rangle
$$

where $\hat{H}_{\text {full }}$ contains all interactions within a system. Although complete, this equation is almost impossible to solve for any realistic system. Typically for NMR, the interactions within a system are simplified to include only the terms which may affect the nuclear spin states. This means that the time-dependent Schrödinger equation can be simplified to: ${ }^{34}$

$$
\frac{d}{d t}\left|\Psi_{\text {spin }}(t)\right\rangle \cong-i \hat{H}_{\text {spin }}\left|\Psi_{\text {spin }}(t)\right\rangle
$$

where $\left|\Psi_{\text {spin }}(t)\right\rangle$ is the spin state of the nuclei and $\hat{H}_{\text {spin }}$ is the nuclear spin Hamiltonian, which is the sum of terms that only involve interactions in the nuclear spin states. This simplification works largely because it can be assumed that contributions from fast-moving electrons can be averaged due to the differences in time-scale for nuclear motions compared to electron motions.

One of the most important interactions in NMR is nuclear shielding, or the chemical shift interaction. Nuclear shielding is the effect surrounding electrons have on the magnetic field experienced by a given nuclear spin. Electronic currents occurring in the surrounding electron cloud will generate an induced magnetic field that effectively screens or shields the nuclei of the system from the external, static magnetic field. This was first discovered by Ramsey ${ }^{36}$ and Pople $^{37}$ and the actual magnetic field experienced by a given nucleus can be given as:

$$
B_{n u c l}=(1-\sigma) B_{0}
$$


or written as the Hamiltonian of the interaction:

$$
\hat{H}^{C S}=-\gamma B_{0} \cdot \sigma \cdot \hat{I}
$$

where $B_{\text {nucl }}$ is the magnetic field experienced by the nucleus, $\hat{I}$ is the nuclear spin operator, and $\sigma$ is the chemical shielding interaction. $\sigma$ is not simply a scalar value representing an increase or decrease in the magnetic field experienced at the nucleus but is a $2^{\text {nd }}$ rank tensor that is dependent on the orientation of a given nuclear environment. If a fixed axis system is placed such that the external magnetic field is along the z-direction, then (1.6) becomes:

$$
\left[\begin{array}{l}
B_{\text {nucl, } x} \\
B_{\text {nucl, }, y} \\
B_{\text {nucl }, z}
\end{array}\right]=\left(1-\left[\begin{array}{ccc}
\sigma_{x x} & \sigma_{x y} & \sigma_{x z} \\
\sigma_{y x} & \sigma_{y y} & \sigma_{y z} \\
\sigma_{z x} & \sigma_{z y} & \sigma_{z z}
\end{array}\right]\right) \cdot\left[\begin{array}{c}
0 \\
0 \\
B_{0}
\end{array}\right]
$$

where 1 is the identity matrix.

The terms in the shielding tensor describe the resulting induced magnetic field at a given nucleus and its orientational dependence with respect to the external magnetic field. Luckily, this tensor can be decomposed into a symmetric and antisymmetric part. The symmetric part is the basis for the isotropic chemical shift and is typically what is measured in a high resolution nuclear magnetic resonance spectroscopy (HR-NMR) experiment. The antisymmetric, or anisotropic part can be quite complicated and when there is no motional averaging of the shielding interaction, as in a liquid sample, it can lead to very broad signals in an NMR spectrum. These chemical shielding anisotropy signals are commonly observed in SS-NMR. However, the anisotropic part of the shielding tensor has a dependence on the $2^{\text {nd }}$ order Legendre polynomial (with respect to the cosine function), or $\left(3 \cos ^{2} \theta-1\right)$ where $\theta$ is the angle between the principal component of an axially symmetric shielding tensor and the 
external magnetic field. This function has a zero point at an angle of $54.74^{\circ}$ and this is the basis for the magic angle spinning (MAS) technique used in SS-NMR. If a solid sample is spun very quickly at the "magic" angle $\left(54.74^{\circ}\right)$ then many of the complicated interactions are averaged to the isotropic value typical in an HR-NMR experiment. An example of the MAS technique is shown in Figure 1.8. In this example, ${ }^{13} \mathrm{C}$-labeled glycine, a solid powder, is examined with ${ }^{13} \mathrm{C}$ SS-NMR. If the sample is left stationary (bottom spectrum) both ${ }^{13} \mathrm{C}$ signals shows very broad, complicated patterns. However, if the sample is spun at an angle of $54.74^{\circ}$ from the direction of the external magnetic field the powder pattern is broken up into a series of spinning sidebands that are separated by the spinning frequency. If the spinning frequency is high enough, only the isotropic peak remains (top spectrum).

It is important to note that typical shielding values are generally quite small, on the order of $10^{-6}$ with respect to the Zeeman interaction, and so are generally reported in parts per million, or ppm, away from the Zeeman interaction Larmor frequency. Since it is quite difficult to measure exact or absolute shielding values, especially due to the variation between environments, ${ }^{39}$ this interaction is reported as an observable difference, called the chemical shift, $\delta$, with respect to a reference compound. Ideally the reference is chosen such that it has shielding values as close to zero, representing a bare, isolated nucleus, as possible. The chemical shift scale and shielding scale are related as follows:

$$
\delta_{i j}=\frac{\sigma_{i s o, r e f}-\sigma_{i j}}{1-\sigma_{i s o, r e f}}
$$

where $\sigma_{i s o, r e f}$ is the isotropic shielding reference, $\sigma_{i j}$ is the shielding component of interest, and $\delta_{i j}$ is the chemical shift component relative to the reference. Typically the chemical shift is reported with respect to a common accepted reference. For example, tetramethylsilane (TMS), is used as a $\delta_{i s o}=0 \mathrm{ppm}$ chemical shift reference 


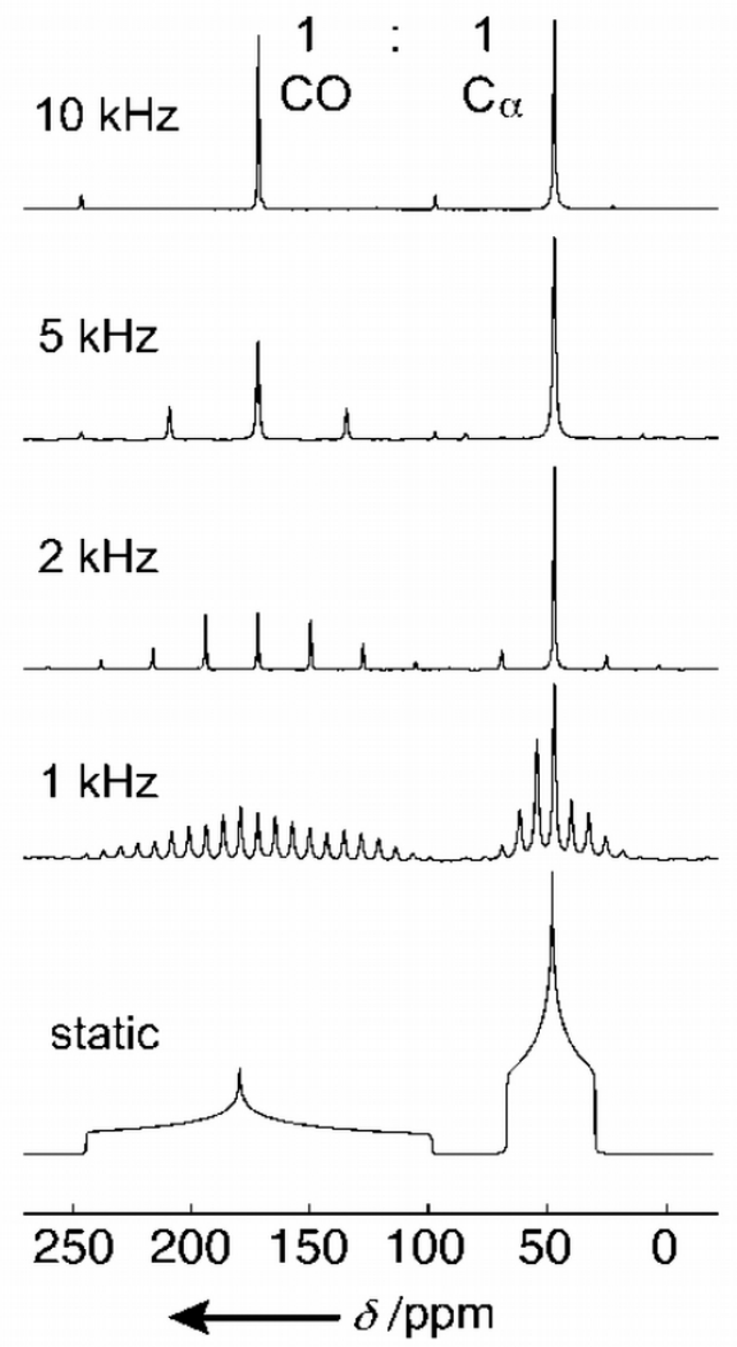

Figure 1.8: ${ }^{13} \mathrm{C}$ SS-NMR spectra (at $B_{0}=11.7 \mathrm{~T}$ ) of a labeled glycine powder sample showing the effect of MAS. MAS spinning speed is shown in each spectrum. As spinning speed is increased the anisotropy is averaged to only the isotropic peak (top spectrum). Adapted from Laws. ${ }^{38}$ 
for ${ }^{1} \mathrm{H},{ }^{29} \mathrm{Si}$ and ${ }^{13} \mathrm{C} \mathrm{NMR}$.

It is not only important to consider the interaction between a nucleus and its own electron cloud, but also how that nucleus and electrons might interact with other nuclei in a sample and possibly cause further perturbations in the observed chemical shift. Many chemists are familiar with the J-coupling, or indirect spin-spin coupling, interaction which describes the influence that bonding electrons, and subsequently other nuclei connected through a chemical bond, have on the observed chemical shift. While J-coupling is an indispensable tool in HR-NMR, it is a relatively weak interaction in SS-NMR. The direct dipole-dipole interaction, however, is a relatively strong interaction that has a strong orientational dependence and so is very important to consider when performing any SS-NMR experiment. The dipole-dipole interaction is a through-space interaction that is relatively easy to understand qualitatively. Since each nuclear spin is itself magnetic, it generates a magnetic field that extends out into space around the nucleus. A second spin that is in close proximity to the first one will be effected by the magnetic field generated by the first nucleus. The effect is, of course, mutual and so the first nucleus is affected by the magnetic field generated by the second nucleus. The quantitative treatment of the dipole-dipole coupling in nuclei has been known since before the $1950 \mathrm{~s}^{40}$ and so has developed into a relatively well understood phenomenon. First, a formalism for how two interacting nuclei are oriented in space is developed. This is shown in Figure 1.9. It shows two nuclei ( $I$ and $S$ ) separated by a distance, $r$, and the vector connecting the two nuclei is described by the two angles, $\theta$ and $\phi$. Traditionally, $I$ represents an abundant, high sensitivity nucleus, such as ${ }^{1} \mathrm{H}$, and $S$ represents the nucleus of interest and typically has much lower sensitivity in an NMR experiment, such as ${ }^{13} \mathrm{C}$.

The strength of the dipole-dipole interaction between these two nuclei is deter- 




Figure 1.9: Schematic showing how the polar angles $\theta$ and $\phi$ and internuclear distance, $r$ are defined for two spins $I$ and $S$ experiencing dipole-dipole coupling. The external magnetic field, $B_{0}$ is oriented along the laboratory frame $z$ axis.

mined by the corresponding dipole-dipole interaction Hamiltonian:

$$
\hat{H}_{I S}^{D D}=-\frac{\mu_{0}}{4 \pi} \frac{\gamma_{I} \gamma_{S} \hbar}{r_{I S}^{3}}\left(3 \cos ^{2} \theta_{I S}-1\right) \hat{I}_{z} \hat{S}_{z}
$$

where $\hat{I}$ and $\hat{S}$ are the nuclear spin operators, and $\mu_{0}$ is the magnetic constant. The first term in (1.10) $\left(-\frac{\mu_{0}}{4 \pi} \frac{\gamma_{I} \gamma_{S} \hbar}{r_{I S}^{3}}\right)$ is called the dipolar-coupling constant and is reported in $\mathrm{Hz}$ similar to J-coupling. Note that again there is a dependence on $\left(3 \cos ^{2} \theta-1\right)$ in the case for dipole-dipole interactions. This means that MAS can be used to reduce the effects of this interaction to reduce the broadening from the dipole-dipole interaction in SS-NMR spectra.

This, then, leads to a discussion of one of the most useful experiments in SS-NMR, cross-polarization (CP), typically coupled with MAS. CP is used primarily to assist in observing low sensitivity, or dilute, spins ( $S$ in Figure 1.9 ), such as ${ }^{13} \mathrm{C}$. Observing dilute nuclei is difficult for several reasons: The natural abundance and magneto- 

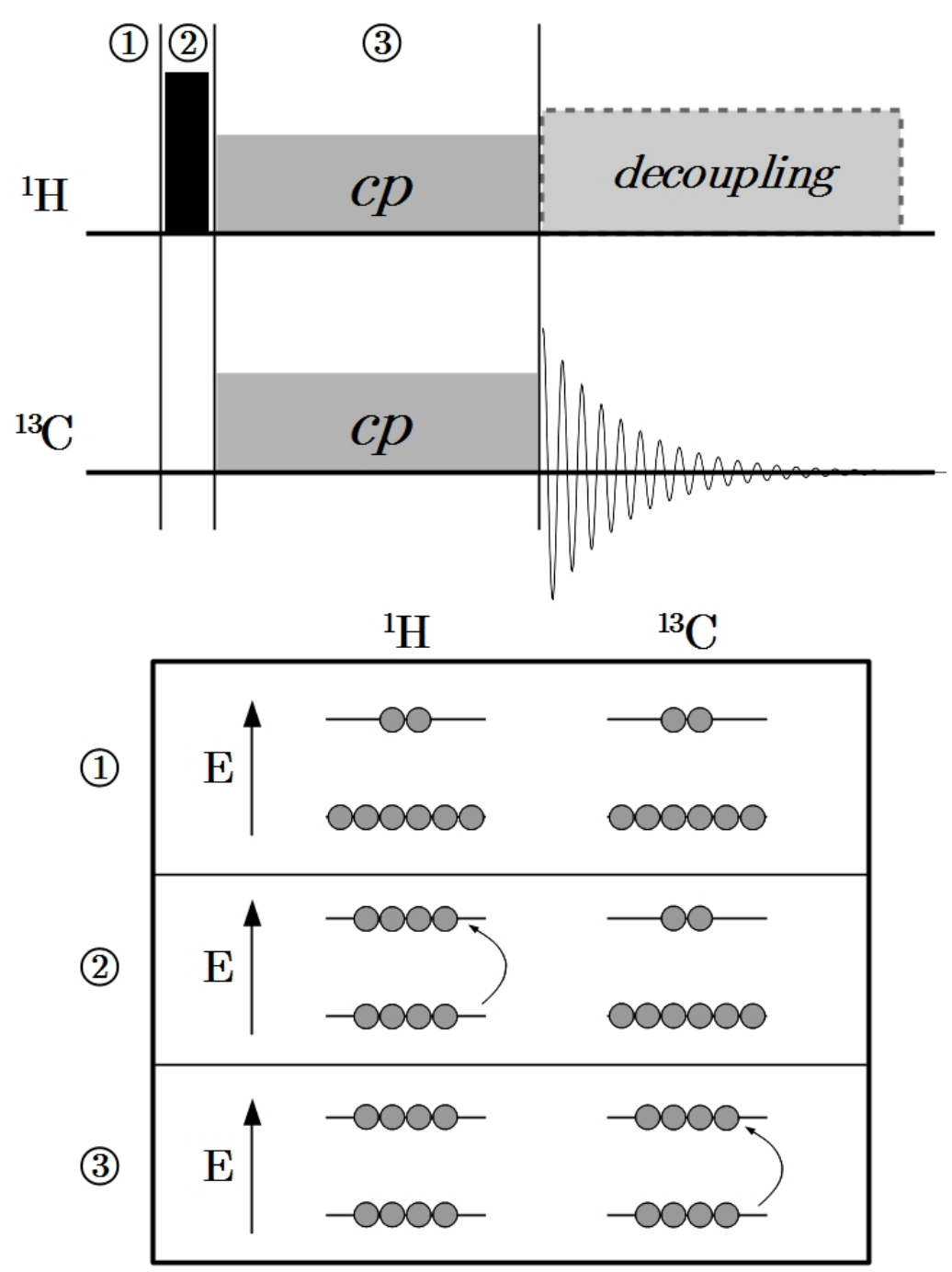

Figure 1.10: Schematic diagram of the CP experiment. The top shows the pulse sequence for a typical CP experiment: after thermal equilibrium is reached (1) there is a hard $90^{\circ}$ radio frequency pulse on the ${ }^{1} \mathrm{H}$ (abundant spin) channel (2). This is followed by a Hartman-Hahn matched contact pulse on both ${ }^{1} \mathrm{H}$ and ${ }^{13} \mathrm{C}$ (dilute spin) channels. This is followed by acquisition on the ${ }^{13} \mathrm{C}$ channel typically accompanied by decoupling on the ${ }^{1} \mathrm{H}$ channel. The bottom shows the relative population distributions at each step. 
gyric ratio are typically quite low which means that without thousands of scans, the signal-to-noise ratio is already low to begin with. The second problem is that because there are large distances between active nuclei (low natural abundance) there is very little homonuclear dipole-dipole interactions. This has the effect of making the relaxation times for these nuclei quite long (sometimes as large as minutes). ${ }^{35}$ This, then, increases the amount of time between scans, and when several thousand scans are required to produce good signal-to-noise, experiments can take too long to acquire. These problems can be alleviated by the $\mathrm{CP}$ experiment. Although the quantitative theory behind how a signal is produced with $\mathrm{CP}$ is quite complicated, qualitatively it is relatively simple. The experiment has a few main steps and these are shown in Figure 1.10. First, both abundant and dilute spins are in thermal equilibrium in the external magnetic field (1). Then, the abundant spins in a sample (typically ${ }^{1} \mathrm{H}$ ) are excited by a radio frequency pulse at their Larmor resonance frequency (2). Both abundant and dilute spins are then continuously excited in what is known as a Hartman-Hahn match or contact pulse which effectively transfers magnetization from the abundant spins to the dilute spins (3). As shown in Figure 1.10 (3), this causes an equalization of the population distribution among both sets of spins. This means that magnetization of the dilute spins can be measured without specifically exciting those spins. Finally, the signal is acquired on the dilute spin channel while typically also decoupling the abundant spins (to remove the line broadening J-coupling interaction).

What is important to consider about the $\mathrm{CP}$ experiment is that it acts through the dipole-dipole interaction. That is, only nuclei that are close to each other in space can have a population redistribution during the contact pulse. So, nuclei with a stronger dipole-dipole interaction will exhibit a stronger $\mathrm{CP}$ signal. This has incredible implications for examining nuclei on surfaces. Say, for example, there is an organic compound adsorbed onto the surface of HSAS. If a ${ }^{29} \mathrm{Si} \mathrm{CP}$ experiment is performed such that polarization is transferred from ${ }^{1} \mathrm{H}$ nuclei to ${ }^{29} \mathrm{Si}$ nuclei, then 
only ${ }^{29} \mathrm{Si}$ nuclei that are in close proximity to ${ }^{1} \mathrm{H}$ nuclei will give a measurable signal. This means that the spectrum will not be overshadowed by an enormous ${ }^{29} \mathrm{Si}$ signal from the bulk silica and only surface silicon nuclei will be observed. The same is true for other dilute nuclei, such as ${ }^{13} \mathrm{C}$, as well, and this is exploited in subsequent thesis chapters. It was also previously mentioned that relaxation is an issue for acquiring high quality spectra of low abundant nuclei. The $\mathrm{CP}$ experiment aids in this regard as, by nature of the polarization transfer, relaxation of the nuclei back to thermal equilibrium is governed by the relaxation time of the abundant nuclei $\left({ }^{1} \mathrm{H}\right)$ which is typically quite short (milliseconds to seconds). This means more transients can be acquired in a shorter amount of time increasing the signal-to-noise.

One last point to consider about $\mathrm{CP}$ is the effect of MAS on the data acquired when doing a CP SS-NMR experiment. On the one hand MAS is extremely useful for reducing line-broadening from unwanted interactions like chemical shielding anisotropy. However, as shown previously, MAS also reduces the dipole-dipole interaction between different spins. But, since the $\mathrm{CP}$ experiment relies on the existence of a dipole-dipole interaction, MAS can actually reduce the signal measured by destroying any dipole-dipole coupling. So, it is important to strike a balance where there is fast enough spinning to reduce broadening from chemical shielding anisotropy but not so fast that there is no polarization transfer. This typically means spinning speeds between $3-12 \mathrm{kHz}$. 


\subsection{Methodology for Examining Surface Chemistry using Solid-State Nuclear Magnetic Resonance Spectroscopy}

One last detail that deserves a brief introduction is the methodology and apparatus that was used to perform the majority of the surface studies highlighted in this thesis. One of the main goals of this work was to examine the chemisorption behaviour of vapour-phase thin film deposition precursors on typical substrates. One of the techniques used to study the chemisorption behaviour was SS-NMR. However, to obtain a sample with a significant quantity of adsorbed material where temperature and exposure to air could be controlled onto a substrate that could be studied ex situ was a real design challenge.

First, it was important to determine the necessary requirements for such a methodology. The substrate needed to be a solid that was not necessarily crystalline and capable of high precursor loading. HSAS was chosen as the primary substrate as the surface area is quite large $\left(\approx 300 \mathrm{~m} /{ }^{2} \mathrm{~g}\right)$ and the surface chemistry of silica was already relatively well-known (mentioned previously). As well, since HSAS is a powder, it can easily be handled and used in modern SS-NMR instruments. As described previously, the hydroxyl density on HSAS is dependent on pre-treatment temperature and to get a well-controlled surface reactive site density temperatures upwards of $900{ }^{\circ} \mathrm{C}$ could be required. Being able to study a variety of precursor adsorption temperatures was a key requirement for apparatus design. This meant that the materials used had to be able to withstand relatively high temperatures. Stainless steel or quartz are obvious choices for material. Given the other requirements, stainless steel was used for the majority of the apparatus. Another important consideration is that every part of the apparatus had to be kept air-free. Most CVD and ALD precursors are highly reactive 




Figure 1.11: Apparatus used to study surface chemistry of vapour-phase thin film deposition precursors on HSAS with SS-NMR. Schematic representation of the apparatus (right) and an actual photograph (left) is shown.

to both oxygen and water and so it was important to ensure that these were kept out of the apparatus. Since the nature of the surface chemistry was entirely unknown for all precursors studied, it was a safe assumption to make that the substrate should be kept air-free at all times as well. This meant using air-free fittings that were capable of withstanding relatively high temperatures. For these reasons Swagelok's VCR ${ }^{\circledR}$ and Varian Inc.'s ConFlat fitings were used. Lastly, the apparatus needed to be modular. Since it was important that both precursor and substrate were not exposed to air before analysis, the apparatus was designed so it could be separated into small isolatable pieces and brought into a drybox for handling. Once in a drybox the substrate could be packed into air-tight SS-NMR tubes to be characterized. This last point proved to be one of the more restricting design criteria. However, given all these requirements, the reactor used in a large number of the studies presented in this thesis is shown in Figure 1.11. Bellows-sealed valves were installed at appropriate locations to allow for the modular design. As well, an inlet for high purity helium was included to perform leak-checks as well as ensure the interior of the system could be dosed with inert gas prior to disassembly. A thermocouple pressure gauge was used to monitor system pressure and precursor delivery during experiments. 


\section{Part I}

Group 13 


\section{Chapter 2}

\section{Quantitative Surface Coverage Calculations}

via Solid-State NMR for Thin Film Depositions: A Case Study for Silica and a Gallium Amidinate

Modified from the original manuscript published as:

Pallister, P.J., Buttera, S.C., and Barry, S.T., Quantitative Surface Coverage Calculations via Solid-State NMR for Thin Film Depositions: A Case Study for Silica and a Gallium Amidinate, J. Phys. Chem. C, 2014, 118, 1618-1627.

Department of Chemistry, Carleton University, 1125 Colonel By Drive, Ottawa, Ontario, K1S 5B6, Canada 


\subsection{Abstract}

For the interrogation of precursor nucleation for vapour deposition processes like atomic layer deposition (ALD) and chemical vapour deposition (CVD), a modified method for quantitative analysis of surface

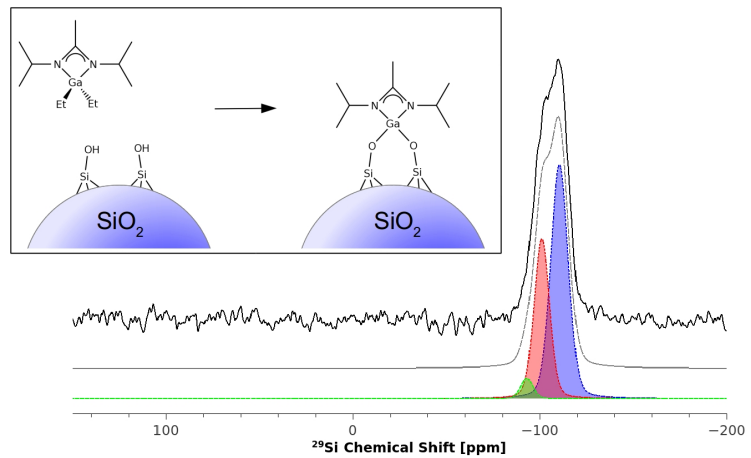

coverage was undertaken via NMR. Figure 2.1: Table of Contents graphic used for The initial chemisorption of a new publication described in Chapter 2 gallium(III) alkyl amidinate compound was investigated on high-surface area silica. $N, N^{\prime}$-Diisopropylacetamidinatediethylgallium(III) (2) was found to have excellent volatility with no decomposition during a ramped thermogravimetric analysis experiment. Stepped-isotherm experiments showed a 1 Torr vapour pressure at $64{ }^{\circ} \mathrm{C}$. Compound 2 was exposed to a pretreated high-surface area silica substrate at $100{ }^{\circ} \mathrm{C}$, $200{ }^{\circ} \mathrm{C}$, and $300{ }^{\circ} \mathrm{C}$ and was found to exhibit stable, persistent chemisorbed surface species at all three temperatures. Substrates were analyzed by ${ }^{29} \mathrm{Si}$ and ${ }^{13} \mathrm{C}$ solid-state nuclear magnetic resonance spectroscopy (SS-NMR) and ${ }^{1} \mathrm{H}$ high resolution nuclear magnetic resonance spectroscopy (HR-NMR). At $100{ }^{\circ} \mathrm{C}$ and $200{ }^{\circ} \mathrm{C}$ the reactivity of compound 2 to geminal and lone hydroxyl surface sites varied slightly eliminating either one or both ethyl groups to produce an alkylated (or nonalkylated) gallium acetamidinate on the silica surface and producing fractional coverages of 0.087-0.088. At $300{ }^{\circ} \mathrm{C}$ there was a larger degree of reactivity producing a minor amount of the same surface species as at $100{ }^{\circ} \mathrm{C}$ and $200{ }^{\circ} \mathrm{C}$ but also producing additional chemisorbed products likely arising from the decomposition of the ligand framework but ultimately giving a fractional coverage of 0.232 on hydroxyl-terminated silica. 


\subsection{Introduction}

Gallium is an important element for a variety of thin film applications. $\mathrm{Ga}_{2} \mathrm{O}_{3}$ is a wide band gap material ${ }^{41}$ that has a wide range of thin film applications from gas sensing ${ }^{42}$ to optoelectronic devices. ${ }^{43}$ The group V gallium thin film materials, $\mathrm{GaN},{ }^{44} \mathrm{GaP},{ }^{45}$ and $\mathrm{GaAs},{ }^{46}$ are also of great interest to the semiconductor industry for their optoelectronic and band gap properties.

Gallium thin films are typically deposited using vapour deposition techniques like metal-organic chemical vapour deposition (MO-CVD) $)^{47-49}$ or ALD. ${ }^{50-53}$ Precursors used to deposit gallium-based thin films come in a variety of classifications, commonly alkyl,${ }^{54}$ halide,${ }^{55}$ or $\beta$-diketonate,${ }^{50}$ and more recently alkoxy ${ }^{49,56,57}$ based compounds. The success of these compounds for vapour deposition of gallium thin films is well-documented; however, there are a few drawbacks to these precursors. Halide containing precursors have the potential to produce unwanted byproducts such as $\mathrm{HCl}$ or $\mathrm{Cl}_{2} \cdot{ }^{58}$ For the precursors containing oxygen, there have been no studies showing deposition of a material other than $\mathrm{Ga}_{2} \mathrm{O}_{3} \cdot{ }^{20}$ Given the electropositive nature of gallium, it is likely that these types of precursors are limited to oxide films for simple two precursor ALD processes. Thus, there is an ongoing need for novel gallium precursors for vapour-phase thin film deposition, particularly for III-V semiconductor thin films.

Given the importance of gallium-based thin films and the variety of precursors used for vapour phase deposition, there is also significant interest in the surface chemistry of gallium precursors. Determining the nature of the initial adsorption complex (for CVD) and the first half-cycle surface species (for ALD) during deposition is a need that must be addressed: how this first chemisorbed layer forms can have significant impact on the film-substrate interface. For instance, the growth per precursor dose may be enhanced or inhibited by the substrate on the basis of the initial precursor- 
substrate interaction. ${ }^{19}$ Investigation into the initial chemisorption species of these precursors on a typical substrate will enhance our understanding of the overall growth mechanism. Current techniques for examining the surface mechanism of CVD and ALD precursors include TPD and in situ XPS; investigations of this type were recently reviewed by Zaera. ${ }^{23}$ Another common technique for examining surface mechanisms for vapour deposition precursors in in situ Fourier transform infrared spectroscopy (FTIR), and a review of this type of characterization was recently published by Chabal et al. ${ }^{59}$ Other experimental techniques for studying reaction mechanisms in ALD include $\mathrm{QCM}^{27}$ and optical methods like spectroscopic ellipsometry. ${ }^{60}$ There has also been a significant amount of research in the simulation of ALD precursor surface mechanisms using DFT. A recent review by Elliott ${ }^{61}$ outlines work done on ALD precursor surface mechanisms. There are only a few studies on the first principles simulations of gallium-based precursor chemisorption mechanisms, and up to this point, reports are limited to the study of simple gallium halides, ${ }^{62}$ alkoxy, alkyl, and amide species. ${ }^{63}$

This paper describes the synthesis of a novel gallium(III) compound and its thermolysis characteristics with regards to its employment as an ALD or CVD precursor. Additionally, the initial chemisorption mechanism for this compound was examined on HSAS. In this study the silica was saturated with gaseous gallium precursor while under dynamic vacuum and studied ex situ using MAS/CP SS-NMR. Silicon29 MAS/CP SS-NMR has been shown to be a useful tool in examining the nature of a silica surface when exposed to a gaseous precursor. ${ }^{31}$ In particular, it is useful for determining the relative saturation of the surface and the identity of the initial reactive surface site. ${ }^{64,65}$ There are, in fact, several benefits to using CP as a technique to probe the bonding environments on the surface of a substrate. The most obvious advantage is the ability to obtain more transients in less time than with direct polarization. This is due to the fact the overall relaxation in a ${ }^{1} \mathrm{H} \longrightarrow \mathrm{X} C \mathrm{P}$ 
experiment, where $\mathrm{X}$ is the spin-active nucleus of interest, is governed primarily by the spin-lattice $\left(T_{1 H}\right)$ relaxation of the protons in the sample and not the $\mathrm{X}$ nuclei. Since spin-lattice relaxation times of ${ }^{1} \mathrm{H}$ are, in general, shorter than those of ${ }^{29} \mathrm{Si}$ and ${ }^{13} \mathrm{C}$, there is a significant benefit to running a $\mathrm{CP}$ experiment in terms of overall experiment time. The other major benefit to the $\mathrm{CP}$ experiment is the ability to probe only the surface species of the substrate. Since the majority of the protons in a silica sample are on the surface of the substrate, the polarization transfer from ${ }^{1} \mathrm{H}$ to the $\mathrm{X}$ nuclei will primarily happen at the surface, making $\mathrm{CP} / \mathrm{MAS}$ an excellent technique for probing any chemisorbed species on the surface of a silica substrate. The surface of silica itself has been well-studied using ${ }^{29} \mathrm{Si}$ CP/MAS SS-NMR. ${ }^{31,64-68}$ Carbon-13 $\mathrm{CP} / \mathrm{MAS}$ SS-NMR is also useful in examining the potential structure and/or bonding of any ligand system that remains as a chemisorbed species on the surface. This technique has been used to determine the initial chemisorption mechanism of a heteroleptic Ti(IV) guanidinate on alumina and silica. ${ }^{29}$ The current study shows the thermal characteristics of $N, N^{\prime}$-diisopropylacetamidinatodiethylgallium(III) (2) and its initial adsorption mechanism onto HSAS at several temperatures.

\section{$2.3 \quad$ Experimental}

\section{General Considerations}

All handling and manipulations of starting materials were performed in a nitrogen drybox. Diisopropyl carbodiimide and 1.6 M MeLi in ether were purchased from Sigma-Aldrich and used as received. $\mathrm{GaCl}_{3}$ and $2.0 \mathrm{M} \mathrm{EtMgCl}$ in ether were purchased from Strem Chemicals Inc. and used as received. Anhydrous pentane was purchased from Sigma-Aldrich and used as received. All other solvents used were ACS grade and purified from an MBraun Solvent Purifier System. $\mathrm{MeC}\left(\mathrm{N}^{i} \mathrm{Pr}\right)_{2} \mathrm{Li}$ was synthesized following literature procedures. ${ }^{69}$ Thermogravimetric analysis was performed on a TA 
Instruments Q50 in a dedicated $\mathrm{N}_{2}$-filled drybox.

\section{$\left(\mathrm{MeC}\left(\mathrm{N}^{i} \mathrm{Pr}\right)_{2}\right) \mathrm{GaCl}_{2}(1)$}

In a $50 \mathrm{ml}$ Schlenk flask, methyllithium (1.6 M in diethyl ether, $5.5 \mathrm{ml}, 8.8 \mathrm{mmol})$ was added to diethyl ether $(10 \mathrm{ml})$. Cold $\left(-30^{\circ} \mathrm{C}\right)$ 1,3-diisopropylcarbodiimide $(1.12 \mathrm{~g}$, $8.9 \mathrm{mmol}$ ) was added dropwise to the solution with stirring. The flask was allowed to stir at room temperature for $20 \mathrm{~h} . \mathrm{GaCl}_{3}(1.63 \mathrm{~g}, 9.2 \mathrm{mmol})$ was suspended in $2 \mathrm{ml}$ of hexanes in a $50 \mathrm{ml}$ Schlenk flask. Diethyl ether $(20 \mathrm{ml})$ was added to the flask slowly with stirring to afford a mildly yellow solution. A nitrogen assisted addition of the $\mathrm{GaCl}_{3}$ solution to the lithium 1,3-diisopropylacetamidinate solution dropwise was done at $-78^{\circ} \mathrm{C}$ producing a white precipitate. The cloudy yellow solution was left to stir at room temperature for $30 \mathrm{~h}$. The white precipitate was filtered, and the volatiles from the slightly yellow filtrate were removed under vacuum to produce a faded yellow solid. The solid was recrystallized from diethyl ether at $-30{ }^{\circ} \mathrm{C}$ to give compound 1 as faded yellow crystals (7.1 mmol, $80.8 \%$ ). ${ }^{1} \mathrm{H}$ NMR $(300 \mathrm{MHz}$, $\left.\mathrm{C}_{6} \mathrm{D}_{6}\right): \delta 2.965$ (sept, 2H, CH(Me) $\left.\left.)_{2}\right), 0.996\left(\mathrm{~s}, 3 \mathrm{H},\left({ }^{i} \mathrm{PrN}\right)_{2} \mathrm{CCH}_{3}\right)\right), 0.886(\mathrm{~d}, 12 \mathrm{H}$, $\left.\mathrm{CH}\left(\mathrm{CH}_{3}\right)_{2}\right)$. HRMS (EI) $m / z$ calc'd for $\left(\mathrm{GaN}_{2} \mathrm{C}_{8} \mathrm{H}_{17} \mathrm{Cl}_{2}\right)^{+} 282.0000$, found 282.0004 .

\section{$\left(\mathrm{MeC}\left(\mathrm{N}^{i} \mathrm{Pr}\right)_{2}\right) \mathrm{GaEt}_{2}(2)$}

In a $50 \mathrm{ml}$ round-bottom flask, compound $\mathbf{1}$ (0.96 g, $3.4 \mathrm{mmol})$ was dissolved in diethyl ether $(30 \mathrm{ml})$. EtMgCl $(2.06 \mathrm{M}$ in diethyl ether, $3.5 \mathrm{ml}, 7.2 \mathrm{mmol})$ was added to the solution dropwise with stirring at $-30{ }^{\circ} \mathrm{C}$. A white precipitate formed on addition of EtMgCl. The cloudy colourless solution was allowed to stir at room temperature for $20 \mathrm{~h}$. White precipitate was filtered, and volatiles were removed from the slightly yellow filtrate under vacuum to produce a yellow viscous liquid (0.83 g, $90.9 \%$ ). The liquid was stored at $-30{ }^{\circ} \mathrm{C}$ and remained a liquid at this temperature. Compound 2 was distilled at $35^{\circ} \mathrm{C}$ and 79 mTorr to yield a colourless liquid $(0.80 \mathrm{~g}$, 
$96.0 \%$ ). ${ }^{1} \mathrm{H}$ NMR (400 MHz, $\left.\mathrm{C}_{6} \mathrm{D}_{6}\right): \delta 3.276$ (sept, 2H, $\left.\left.\mathrm{C} H(\mathrm{Me})_{2}\right)\right), 1.424(\mathrm{t}, 6 \mathrm{H}$, $\left.\left.\left.\mathrm{CH}_{2} \mathrm{CH}_{3}\right), 1.351\left(\mathrm{~s}, 3 \mathrm{H},\left({ }^{i} \mathrm{PrN}\right)_{2} \mathrm{CCH}_{3}\right)\right), 0.967\left(\mathrm{~d}, 12 \mathrm{H}, \mathrm{CH}\left(\mathrm{CH}_{3}\right)_{2}\right)\right), 0.746(\mathrm{q}, 4 \mathrm{H}$,


$25.4\left(\mathrm{NCH}\left(\mathrm{CH}_{3}\right)_{2}\right), 10.7\left(\mathrm{CH}_{2} \mathrm{CH}_{3}\right), 10.2\left(\mathrm{NC}\left(\mathrm{C} \mathrm{H}_{3}\right) \mathrm{N}\right), 4.7\left(\mathrm{C} \mathrm{H}_{2} \mathrm{CH}_{3}\right)$. HRMS (EI) $m / z$ calc'd for $\left(\mathrm{GaN}_{2} \mathrm{C}_{12} \mathrm{H}_{26}-\mathrm{C}_{2} \mathrm{H}_{4}\right)^{+} 239.1039$, found 239.1030 .

\section{Surface Exposure Experiments}

The exposure experiments were performed in a home-built reactor. A stainless steel tube reactor was fitted with a stainless steel ring support covered in 200 stainless steel mesh with a plug of glass wool to hold the substrate powder. The system had one inlet for a heated stainless steel bubbler and one inlet for He (purity of $99.999 \%$ ). Pressure was monitored using a VCR-531 thermocouple (Vacuum Research Corp.). All fittings used in this system were either CF or VCR to ensure an air-free highvacuum seal. The system was leak checked using a gas thermal conductivity/leak detector (Gow-Mac Instrument Co.) and an overpressure of He. For exposure experiments, typically about $1 \mathrm{~g}$ of high surface area $\mathrm{SiO}_{2}$ powder (EP10X; PQ Corp.; $300 \mathrm{~m}^{2} /$ g S.A.; $1.8 \mathrm{~cm}^{3} /$ g P.V.; $24 \mathrm{~nm}$ P.S.; $100 \mu \mathrm{m}$ P.D.) was used as the substrate. The substrate was pretreated in the reactor at $350{ }^{\circ} \mathrm{C}$ overnight under vacuum before exposure to the precursor. The base pressure after pretreatment was typically around $20 \mathrm{mTorr}$. The reactor and lines were heated to temperature and allowed to equilibrate for $1-2 \mathrm{~h}$ before introduction of the precursor. The precursor (typically $0.4-0.8 \mathrm{~g}$ was then vapourized and transported to the substrate with the system under $10^{-3}$ Torr vacuum. The substrate was exposed to volatilized precursor for $20 \mathrm{~h}$ before the system was cooled to room temperature for handling. After exposure was complete, the system (precursor bubbler and reaction chamber) was filled with an overpressure of He (99.999 \%), closed, disassembled, and brought into a nitrogen drybox for handling. 


\section{Characterization of Surface Species}

Solid-state NMR experiments were performed at 4.7 T on a Bruker Avance III console. All spectra were obtained using a Bruker $7 \mathrm{~mm}{ }^{1} \mathrm{H} / \mathrm{X} / \mathrm{Y}$ probe. ${ }^{13} \mathrm{C}\left(\nu_{0}=50.3 \mathrm{MHz}\right)$ cross-polarization magic angle spinning (CP/MAS) experiments were collected at a spinning rate of $4.5 \mathrm{kHz}$ using a $3.35 \mu \mathrm{s} 90^{\circ}$ proton pulse with a contact time of $2 \mathrm{~ms}$ where the contact pulse was ramped on the ${ }^{1} \mathrm{H}$ channel. A relaxation delay of $2 \mathrm{~s}$ was sufficient to prevent saturation, and typically, total acquisition times were $23 \mathrm{~h}$. Glycine was used as an external secondary reference for the ${ }^{13} \mathrm{C}$ chemical shift scale. Spectra were treated with $40 \mathrm{~Hz}$ line broadening during processing. ${ }^{29} \mathrm{Si}$ $\left(\nu_{0}=39.8 \mathrm{MHz}\right) \mathrm{CP} / \mathrm{MAS}$ experiments were collected at a spinning rate of $4.5 \mathrm{kHz}$ using a $3.7 \mu \mathrm{s} 90^{\circ}$ proton pulse with a contact time of $10 \mathrm{~ms}$ where the ${ }^{1} \mathrm{H}$ channel contact pulse was ramped. The relaxation delay was $2 \mathrm{~s}$ and typically required $1-2 \mathrm{~h}$ acquisition times. TMSS was used as an external reference for the ${ }^{29} \mathrm{Si}$ chemical shift scale. Spectra were treated with $30 \mathrm{~Hz}$ line broadening during processing. Peak deconvolution was accomplished using the dmfit software package (v. 20110512)36 and the Solids Lineshape Analysis tool included in the Bruker Topspin software package (version 3.2). The sites were fit using a mixed Gaussian/Lorentz fit with a $0.8 \mathrm{G} / \mathrm{L}$ ratio. Both ${ }^{13} \mathrm{C}$ and ${ }^{29} \mathrm{Si}$ spectra were obtained with high power proton decoupling during acquisition.

Samples were prepared for HR-NMR by adding a small amount, typically 40-50 $\mathrm{mg}$, of modified silica powder to $2 \mathrm{ml}$ of $\mathrm{D}_{2} \mathrm{O}$ (Sigma-Aldrich), agitating, and sitting for 15 min. The $\mathrm{D}_{2} \mathrm{O}$ solution was then decanted and studied via HR-NMR. $d_{4}$-TSP was used as an internal reference.

Energy dispersive X-ray spectroscopy (EDX) was performed on the modified silica samples as qualitative proof for the presence of gallium. Samples were mounted on an aluminum support covered with carbon tape and loaded into a Tescan Vega II SEM 
equipped with an Oxford Inca 200 EDX for analysis.

\subsection{Results and Discussion}

$N, N^{\prime}$-Diisopropylacetamidinatedichlorogallium(III) (1) was made by a salt metathesis reaction of $\mathrm{GaCl}_{3}$ with 1 equiv. of lithium $N, N^{\prime}$-diisopropylacetamidinate to produce this intermediate. Compound $\mathbf{1}$ is isolated as a yellow crystalline material in very good yields $(80.8 \%)$. In a subsequent salt metathesis reaction, 2 equiv. of ethyl Grignard can be added to compound $\mathbf{1}$ to produce $N, N^{\prime}$-diisopropylacetamidinatediethyl gallium(III) (2) in very good yields (>80\%). Compound $\mathbf{2}$ can be isolated by distillation at $35^{\circ} \mathrm{C}$ and reduced pressure to produce a colorless liquid. The initial thermal behaviour of $\mathbf{2}$ showed promising volatility and little to no thermolysis.

Figure 2.2 shows the thermogravimetric analysis (TGA) for $\mathbf{2}$. For both ramp rates only one feature is observed in the weight loss curve, which suggests that the compound is easily volatilized. In all TGA experiments the residual mass was less than $0.3 \%$ which indicates excellent volatility. The shape of the weight loss curve (sharp asymptotic drop in weight \%) shows that this compound likely does not undergo significant decomposition below about $175^{\circ} \mathrm{C}$. The lack of decomposition is also verified in the derivative weight loss curves (Figure 2.2(inset)) which show an asymmetric peak indicative of volatilization. If decomposition were occurring then the peak in the derivative curve would be more symmetrical.

To further study the volatility of this compound, a stepped-isotherm TGA experiment was performed (raw data not shown). In this experiment the sample mass is monitored over time while the temperature is raised in $10{ }^{\circ} \mathrm{C}$ increments (starting at $30{ }^{\circ} \mathrm{C}$ ) and then held isothermally for $5 \mathrm{~min}$. It is expected the mass loss over time would be linear if only volatilization was occurring, and that the surface area of the

sample would not change significantly during the course of the experiment. ${ }^{70}$ Indeed, 


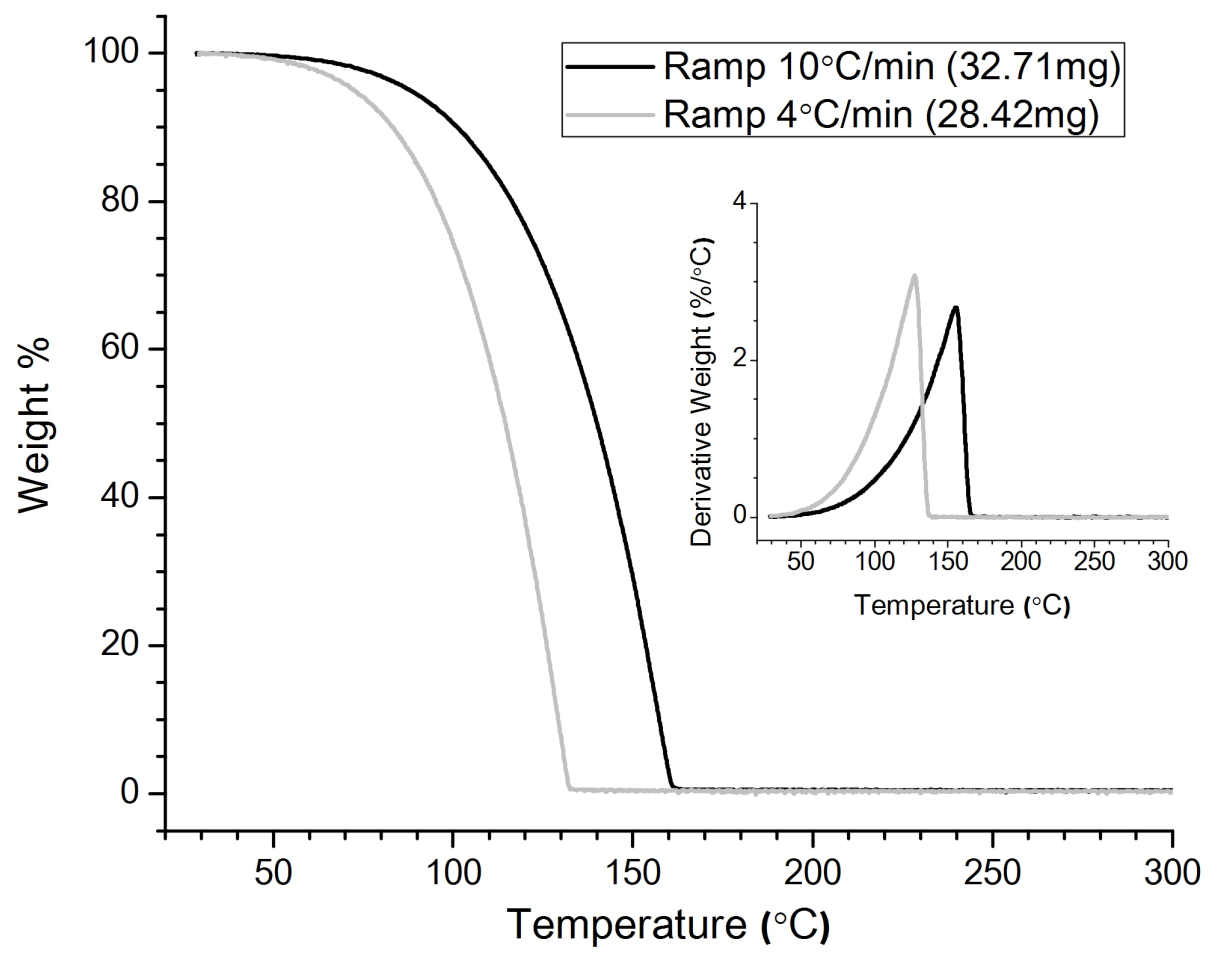

Figure 2.2: Thermogravimetric analysis data for compound 2 at two different temperature ramp rates. The $10{ }^{\circ} \mathrm{C} / \mathrm{min}$ ramp rate shows a $1 \%$ mass loss at $62.5^{\circ} \mathrm{C}$. The $4{ }^{\circ} \mathrm{C} / \mathrm{min}$ shows a similar mass loss at $51.6^{\circ} \mathrm{C}$. The inset shows the corresponding derivative weight curves.

looking at Figure 2.3, the evaporation rate of $\mathbf{2}$ is found to be relatively linear with respect to temperature with a correlation coefficient of 0.99 . The points at higher temperature seem to deviate from linearity slightly. This is likely due to either a change in the enthalpy of vapourization or to the relatively small mass left at higher temperatures resulting in a change in the surface area of the evaporating liquid. However, using the linear evaporation data and the Langmuir model for mass loss in a TGA experiment, ${ }^{71}$ the 1 Torr vapour pressure was determined to occur at $64{ }^{\circ} \mathrm{C}$. This gives more evidence to the excellent volatility of $\mathbf{2}$. To further study the thermal stability of this compound, a HR-NMR thermolysis study of $\mathbf{2}$ was undertaken as well. A small amount of $\mathbf{2}$ was dissolved in $d_{6}$-benzene and flame-sealed under vacuum in a thick-walled glass HR-NMR tube. The tube was placed in an isothermal oven and allowed to equilibrate. To monitor potential decomposition, the tube was removed from the oven and allowed to cool to room temperature, and then a ${ }^{1} \mathrm{H} \mathrm{HR}-$ NMR spectrum was collected. It was found that $\mathbf{2}$ is stable for days in $d_{6}$-benzene 
up to $200{ }^{\circ} \mathrm{C}$. There are signs of slow decomposition above $200{ }^{\circ} \mathrm{C}$, but the nature of the decomposition products requires further investigation. However, this excellent thermal stability allowed the further study of the chemisorption of $\mathbf{2}$ on HSAS.

Given the excellent thermal stability and volatility of $\mathbf{2}$ an experiment was carried out to examine the chemisorption of the compound on a high-surface area substrate. Similar to previous work, ${ }^{29,72,73}$ a combination of SS-NMR and HR-NMR was used to determine the initial monolayer and surface chemistry of $\mathbf{2}$ on HSAS. Approximately $1 \mathrm{~g}$ of HSAS was loaded into a reactor and annealed under vacuum at $350{ }^{\circ} \mathrm{C}$ for about $16 \mathrm{~h}$ prior to exposure to the volatile compound. This ensured a consistent hydroxyl density at the surface between each exposure experiment. Under these conditions, silica is expected to have a hydroxyl density of $2-3.5 \mathrm{OH} / \mathrm{nm} .{ }^{30}$ To compare with known ${ }^{29} \mathrm{Si} \mathrm{CP} / \mathrm{MAS}$ data, the ${ }^{29} \mathrm{Si}$ signal was examined for the pretreated substrate used for chemisorption of $\mathbf{2}$. The spectrum for silica pretreated at $350{ }^{\circ} \mathrm{C}$ is shown in Figure 2.4. It can be seen that there is one large ${ }^{29} \mathrm{Si}$ signal. This is characteristic of silica, and the signal can be deconvoluted into three separate known surface silicon species. The peak at $-101 \mathrm{ppm}$ represents silanol surface species $\left((\|-\mathrm{Si}-\mathrm{O})_{3}-\mathrm{Si}^{*}-\mathrm{OH}\right)$, and at $350{ }^{\circ} \mathrm{C}$ pretreatment, this signal represents the largest component of the surface. The peak at $-110 \mathrm{ppm}$ is the second largest component, and it represents fully dehydroxylated silica $\left((\|-\mathrm{Si}-\mathrm{O})_{4}-\mathrm{Si}^{*}\right)$. Finally, there is a small contribution at -93 ppm which is due to silandiol species at the surface $\left((\|-\mathrm{Si}-\mathrm{O})_{2}-\mathrm{Si}^{*}-(\mathrm{OH})_{2}\right)$. One factor to consider when attempting quantitative analysis using deconvolution data from a $\mathrm{CP} / \mathrm{MAS}$ experiment is the cross-polarization efficiency of a given species. For silica it is known that the resonance at around -110 ppm due to fully dehydroxylated silicon on the surface has unfavourable relaxation properties with respect to the $\mathrm{CP}$ experiment. The time required to build up magnetization on ${ }^{29} \mathrm{Si}$ from ${ }^{1} \mathrm{H}$, $T_{H S i}$, is relatively long for the silicon site at $-110 \mathrm{ppm}$ so this peak is generally not suitable for quantitative analysis. ${ }^{66}$ However, the cross-polarization efficiencies of the 




Figure 2.3: Clausius-Clapeyron evaporation kinetics of compound $\mathbf{2}$ with respect to temperature, determined through a stepped-isotherm TGA experiment described in the references herein. ${ }^{71,72}$ The line of best fit is shown with evaporation rate = $\left[1.680 \cdot 10^{12}\left( \pm 1.184 \cdot 10^{12}\right)\right] e^{\frac{-7145( \pm 241)}{T}}$ and $R^{2}=0.994$. Note that evaporation rate is in a natural logarithm-based scale.

hydroxyl-terminated silicon surface species, specifically $T_{H S i}$, are very similar ${ }^{66}$ which makes them suitable for quantitative analysis. By using the change in the integration intensity of these signals before and after chemisorption of a gas phase precursor, it is possible to draw some conclusions about the overall coverage of this species on silica (formalism shown later). ${ }^{64}$ Table 2.1 shows the normalized ${ }^{29} \mathrm{Si}$ SS-NMR integration of the lone hydroxylated and geminal hydroxylated silicon on the surface of silica pretreated to $350{ }^{\circ} \mathrm{C}$. The integration was normalized to the total ${ }^{29} \mathrm{Si}$ signal shown in Figure 2.4. As one would expect, there is a much larger contribution to the ${ }^{29} \mathrm{Si}$ signal from lone hydroxyl surface sites compared to geminal hydroxyl surface sites, and the data shown here agrees with previous reports on silica pretreated to $350{ }^{\circ} \mathrm{C}$. ${ }^{6-67}$

To examine the chemisorption properties of $\mathbf{2}$ on silica, an exposure experiment was performed using $\operatorname{HSAS}$ at $100{ }^{\circ} \mathrm{C}, 200{ }^{\circ} \mathrm{C}$, and $300{ }^{\circ} \mathrm{C}$. It should be noted that the silica was pretreated to $350{ }^{\circ} \mathrm{C}$ before exposure to gaseous precursor. Given the 


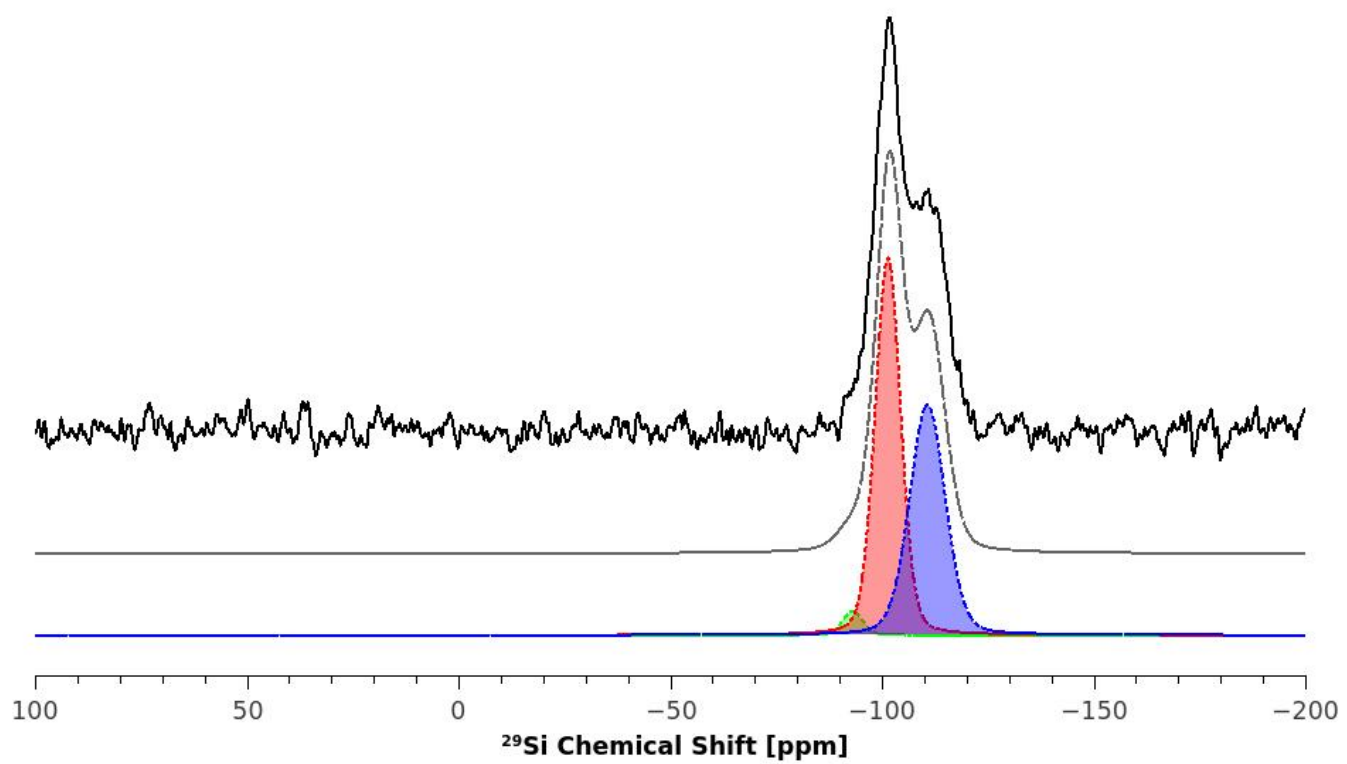

Figure 2.4: ${ }^{29} \mathrm{Si} \mathrm{CP} / \mathrm{MAS}$ SS-NMR spectrum of the silica substrate annealed at $350{ }^{\circ} \mathrm{C}$ (top). Deconvolution spectrum (middle) has contributions from three separate silica surface species (bottom). The peaks at $-94,-101$, and $-110 \mathrm{ppm}$ represent geminalhydroxyl, lonehydroxyl, and dehydroxylated silicon signals, respectively.

Table 2.1: Normalized Integration and Surface Coverage of Compound 2 from ${ }^{29} \mathrm{Si}$ CP/MAS SS-NMR Signal of Pure and Modified Silica ${ }^{a}$

\begin{tabular}{lccccc} 
& \multicolumn{2}{c}{ normalized integration of ${ }^{29} \mathrm{Si}$} & \multicolumn{3}{c}{ surface coverage $^{c}$} \\
& $\begin{array}{c}\mathrm{SS}-\mathrm{NMR}{ }^{b} \\
\|-\mathrm{Si}-\mathrm{OH}\end{array}$ & $\|-\mathrm{Si}-(\mathrm{OH})_{2}$ & $\theta$ & $\theta_{g}$ & $\theta_{l}$ \\
sample & $\| .518 \pm 0.015$ & $0.029 \pm 0.002$ & & & \\
$\begin{array}{l}\text { pretreated silica } \\
\text { silica exposed to }\end{array}$ & $0.487 \pm 0.009$ & $0.021 \pm 0.003$ & $0.088 \pm 0.031$ & $0.286 \pm 0.113$ & $0.079 \pm 0.032$ \\
$\mathbf{2}$ at $100{ }^{\circ} \mathrm{C}$ & & & & & \\
silica exposed to & $0.492 \pm 0.011$ & $0.019 \pm 0.004$ & $0.087 \pm 0.036$ & $0.364 \pm 0.164$ & $0.074 \pm 0.037$ \\
$\mathbf{2}$ at $200{ }^{\circ} \mathrm{C}$ & & & & & \\
silica exposed to & $0.411 \pm 0.021$ & $0.019 \pm 0.003$ & $0.232 \pm 0.045$ & $0.347 \pm 0.115$ & $0.226 \pm 0.046$ \\
$\mathbf{2}$ at $300{ }^{\circ} \mathrm{C}$ & & &
\end{tabular}

\footnotetext{
${ }^{a} \theta$ represents the overall coverage of hydroxyl groups on the surface of the silica. $\theta_{g}$ and $\theta_{l}$ correspond to coverage on geminal and lone-hydroxyl surface sites, respectively; ${ }^{b}$ Assuming that all the surface ${ }^{29} \mathrm{Si}$ sites are accounted for in the observed spectrum; ${ }^{c}$ On the basis of coverage change from initial concentration of surface hydroxyl sites.
} 
excellent volatility of $\mathbf{2}$, a bubbler temperature of $50{ }^{\circ} \mathrm{C}$ was sufficient for delivering precursor to the substrate. Typically, an exposure of more than $12 \mathrm{~h}$ was necessary to saturate the high surface area substrate. Parsons et al. ${ }^{74}$ have shown that $>5 \mathrm{~h}$ of constant precursor vapour pressure exposure is necessary for substrates with similar surface area. Given the system used here and the time necessary to build up sufficient vapour pressure, exposure times were chosen as such. Even though long exposure times and, generally, long NMR acquisition times are necessary, the data gathered shows that the monolayers formed during exposure are thermodynamically quite stable. This has been previously shown to be true in a similar experiment on a vapourous $\mathrm{Cu}(\mathrm{I})$ precursor. ${ }^{72}$ It is notable that $\mathbf{2}$ will form a stable surface species over this $12 \mathrm{~h}$ experiment. This indicates that the surface species itself is thermodynamically stable at these deposition temperatures, and that there is no thermal decomposition of the surface species. This suggests that $\mathbf{2}$ would make an excellent ALD precursor at these temperatures, and that there would be no CVD component to film growth. Figure 2.5 shows the ${ }^{29} \mathrm{Si} \mathrm{CP} / \mathrm{MAS}$ SS-NMR spectrum (experimental and deconvoluted) of silica exposed to $\mathbf{2}$ at all three temperatures studied. The most prominent feature in all three spectra is the decrease in the lone hydroxyl silicon surface species and a marked increase in dehydroxylated silicon surface species. This provides evidence of a chemical reaction between the volatile precursor and the hydroxyl groups present at the surface of the silica. As well, one of the most important features in Figure 2.5 is the lack of any other silicon environments at the surface. The only silicon surface environments present are those that are also present in the initial pretreated silica, demonstrating that, on the surface, silicon is only coordinating to oxygen atoms and no other bonding environments are formed during the chemisorption process. This is rather interesting as it implies that if gallium is present on the surface of the substrate it bonds through oxygen to the silicon surface and there is no formation of silicon bonds to the metal or the ligand system. 

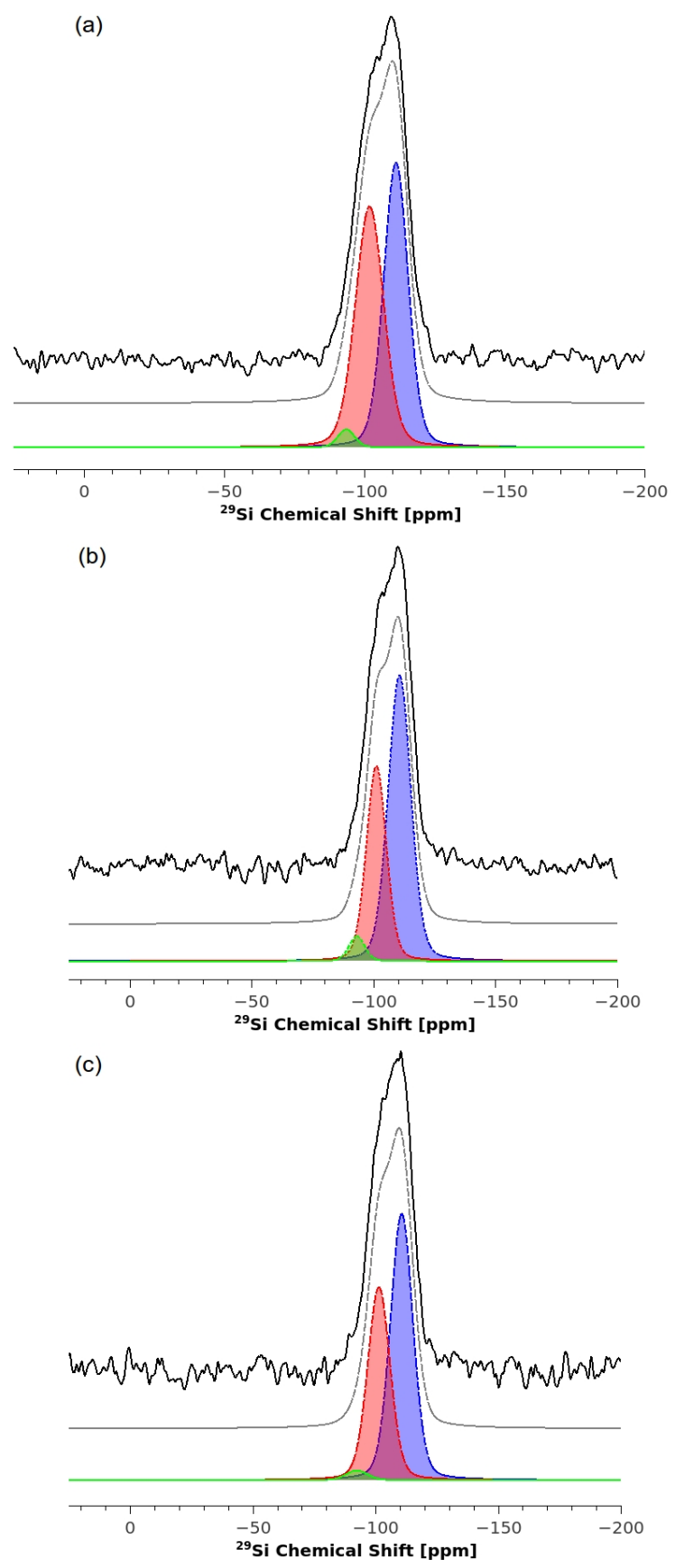

Figure 2.5: ${ }^{29} \mathrm{Si} \mathrm{CP} / \mathrm{MAS}$ SS-NMR spectrum of the silica substrate exposed to $\mathbf{2}$ at $100{ }^{\circ} \mathrm{C}(\mathrm{a}), 200{ }^{\circ} \mathrm{C}(\mathrm{b})$, and $300{ }^{\circ} \mathrm{C}(\mathrm{c})$. Deconvolution spectra (middle line of each spectrum) show only contributions from three separate silica surface species (bottom lines in each spectrum). The peaks at $-94,-101$, and -110 ppm represent geminalhydroxyl, lonehydroxyl, and dehydroxylated silicon signals, respectively. 
To examine the coverage of $\mathbf{2}$ on silica at the temperatures studied, a methodology previously used by Sindorf and Maciel to examine the surface coverage of trimethylsilane (TRMS) on silica via reaction with hexamethyldisilazane (HMDS) was employed. ${ }^{64,65}$ In these studies, simple arguments are used to develop a mathematical relationship between integrated ${ }^{29} \mathrm{Si}$ SS-NMR intensity and coverage on the surface of the silica. Only the final results of the derivation are shown here, and details regarding the full derivation can be found in the Supporting Information (Section 2.6).

This methodology starts by defining the concentration of lone silanol and geminal disilanol on the surface of the silica: ${ }^{64}$

$$
\begin{aligned}
& G^{r}+G^{u}=G^{i} \\
& L^{r}+L^{u}=L^{i}
\end{aligned}
$$

$L$ and $G$ refer to the concentration of lone and geminal hydroxyl groups on the surface, respectively, and the superscripts $i, r$, and $u$ refer to initial, reacted, and unreacted species on the surface, respectively. With the assumption that any compound that is allowed to react with the silica will react at the hydroxyl surface sites, then an expression for the concentration of chemisorbed precursor, $C$, can be given as

$$
C=G^{r}+L^{r}
$$

Since the cross-polarization efficiencies of lone and geminal hydroxyl sites are similar, ${ }^{66}$ a direct comparison between the ${ }^{29} \mathrm{Si}$ SS-NMR signal integrations and the atom concentrations can be made and formulated into an expression for the fraction of silicon sites that are of a particular type. Using the fraction of geminal hydroxyl 
sites, $f_{g}$, as a basis for further expressions ${ }^{64}$

$$
f_{g}^{i}=\frac{I_{g}^{i}}{I_{g}^{i}+I_{l}^{i}}=\frac{K G^{i}}{K G^{i}+K L^{i}}=\frac{G^{i}}{G^{i}+L^{i}}
$$

Equation 2.4 describes the fraction of geminal hydroxyl sites on silica before any exposure to precursor where $I$ refers to the integration intensity of the ${ }^{29} \mathrm{Si}$ SS-NMR signal and $K$ is a proportionality constant to relate surface concentration to measured signal intensity. Once the silica has been exposed to a volatile compound and reaction has occurred, the surface populations will be

$$
\begin{aligned}
& f_{g}^{r}=\frac{I_{g}^{r}}{I_{g}^{r}+I_{l}^{r}}=\frac{K G^{u}}{K G^{u}+K\left(L^{u}+G^{r}\right)}=\frac{G^{u}}{G^{i}+L^{u}} \\
& f=\frac{I_{c}^{r}}{I_{g}^{r}+I_{l}^{r}}=\frac{K C}{K G^{u}+K\left(L^{u}+G^{r}\right)}=\frac{C}{G^{i}+L^{u}}
\end{aligned}
$$

In equations 2.5 and 2.6 it is assumed that both unreacted lone hydroxyl species and singly reacted geminal hydroxyl species will contribute to the signal at -101 ppm. Equation 2.6 describes the ratio of the chemisorbed species from exposure, C, to the residual silanol silicons. Since there was no signal present in the ${ }^{29} \mathrm{Si}$ SS-NMR, shown in Figure 2.5, for a chemisorbed precursor species $\left(I_{c}^{r}\right)$ this element needs to be stated in terms of the measurable signals. This is where the present analysis deviates from Sindorf and Maciel. With the expressions relating signal intensity to surface concentration for lone and geminal hydroxyl sites and equation 2.3, then $I_{c}^{r}$ can be expressed as

$$
I_{c}^{r}=I_{l}^{i}+2 I_{g}^{i}-2 I_{g}^{r}-I_{l}^{r}
$$

This can be used in equation 2.6 to determine the ratio of chemisorbed precursor species to residual silanol species using only the ${ }^{29} \mathrm{Si}$ signals for lone and geminal 
hydroxyl sites. Expressing these fractional populations in terms of overall surface coverage would be an extremely useful way to gain meaningful insight into the nature of the precursorsilica chemisorption process. This is done by making a few definitions for the surface coverage, $\theta:{ }^{64}$

$$
\theta=\frac{G^{r}+L^{r}}{G^{i}+L^{i}}
$$

Also, the relative coverages on the two different silanol sites can be given by

$$
\begin{gathered}
\theta_{g}=\frac{G^{r}}{G^{i}} \\
\theta_{l}=\frac{L^{r}}{L^{i}}
\end{gathered}
$$

The way that equations $2.8-2.10$ are defined gives the ratio of reacted silanol species concentration to the initial silanol species concentration. Since they do not take into account all possible surface active sites, $\theta$ in this case more closely resembles an extent of reaction parameter. However, from the combination of equations 2.1-2.7, the following definitions for coverage can be obtained:

$$
\begin{aligned}
\theta & =\frac{f\left(1+f_{g}^{i}\right)}{1+f+f_{g}^{r}} \\
\theta_{g} & =\frac{1+f-\left(\frac{f_{g}^{r}}{f_{g}^{i}}\right)}{1+f+f_{g}^{r}} \\
\theta_{l} & =\left(\frac{1}{1-f_{g}^{i}}\right)\left(\frac{f+f_{g}^{r}-f_{g}^{i}}{1+f+f_{g}^{r}}\right)
\end{aligned}
$$

Using equations 2.11-2.13, the surface coverage of chemisorbed 2 on silica was determined, and this data is shown in Table 2.1. The uncertainty on the data presented was propagated using standard methods, and more details can be found in Section 2.6 . 
The data for the chemisorption of $\mathbf{2}$ at $100{ }^{\circ} \mathrm{C}$ shows an overall surface coverage of about 0.088 , and the coverage at $200{ }^{\circ} \mathrm{C}$ shows a similar overall coverage of 0.087 . The $300{ }^{\circ} \mathrm{C}$ exposure experiment shows a significantly higher coverage of 0.232 . The nature of this high coverage value will be discussed in more detail when discussing the ${ }^{13} \mathrm{C}$ SS-NMR and ${ }^{1} \mathrm{H}$ HR-NMR, but it demonstrates that there was a higher reactivity of the precursor at the silica surface at $300{ }^{\circ} \mathrm{C}$. All three values are lower than what was previously reported for the chemisorption of HMDS on silica. ${ }^{64}$ This makes sense given the greater steric requirements for $\mathbf{2}$ to chemisorb to a hydroxyl-terminated surface compared to the less sterically demanding HDMS molecule.

The other interesting feature of the data in Table 2.1 is the difference in coverage on lone hydroxyl sites versus geminal hydroxyl sites. For the $100{ }^{\circ} \mathrm{C}$ and $200{ }^{\circ} \mathrm{C}$ exposures, the coverage at geminal hydroxyl sites is about 3 times that of the coverage at lone hydroxyl sites. The coverage at geminal hydroxyl sites after the $300{ }^{\circ} \mathrm{C}$ exposure is also greater than the coverage at lone hydroxyl sites. This is interesting as it shows that $\mathbf{2}$ has a greater reactivity toward geminal hydroxyl than lone hydroxyl sites. The coverage at the geminal hydroxyl sites at $200{ }^{\circ} \mathrm{C}$ is slightly higher than at $100{ }^{\circ} \mathrm{C}$ which indicates higher reactivity at these sites at $200{ }^{\circ} \mathrm{C}$. The coverage of lone hydroxyl groups, however, at $100{ }^{\circ} \mathrm{C}$ and $200{ }^{\circ} \mathrm{C}$ is quite similar. This shows that at these temperatures the reactivity of lone hydroxyl groups is somewhat similar. As will be discussed later, the lower temperature reactivity occurs via the loss of one of the ethyl groups of $\mathbf{2}$ (b in Figure 2.6) whereas the reactivity at $200{ }^{\circ} \mathrm{C}$ favors the loss of both ethyl groups to form the final chemisorbed product (a and c in Figure 2.6 ). However, at $200{ }^{\circ} \mathrm{C} 2$ preferentially loses both ethyl groups via reaction with geminal hydroxyl sites (a in Figure 2.6 ) rather than through a two-step reaction with lone hydroxyl sites (b then c in Figure 2.6 ) based on the coverage values. The coverage values from the $300{ }^{\circ} \mathrm{C}$ exposure show similar coverage at the geminal hydroxyl sites as the $200{ }^{\circ} \mathrm{C}$ exposure but significantly higher coverage at the lone hydroxyl sites. 
a)

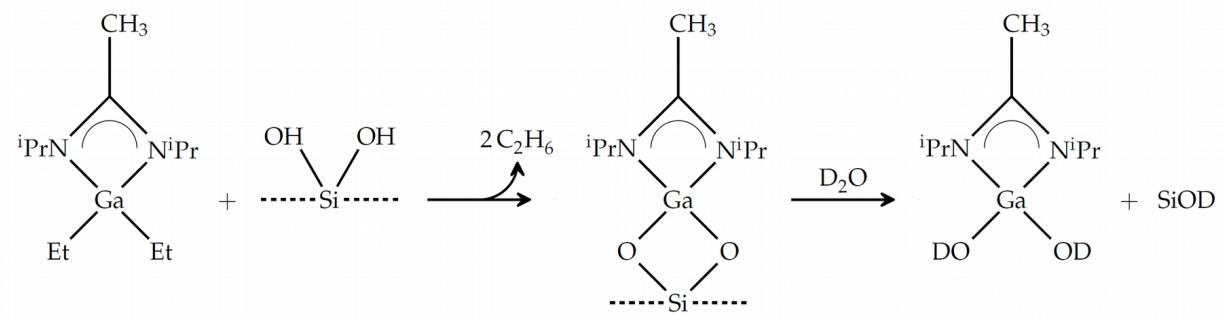

b)



c)
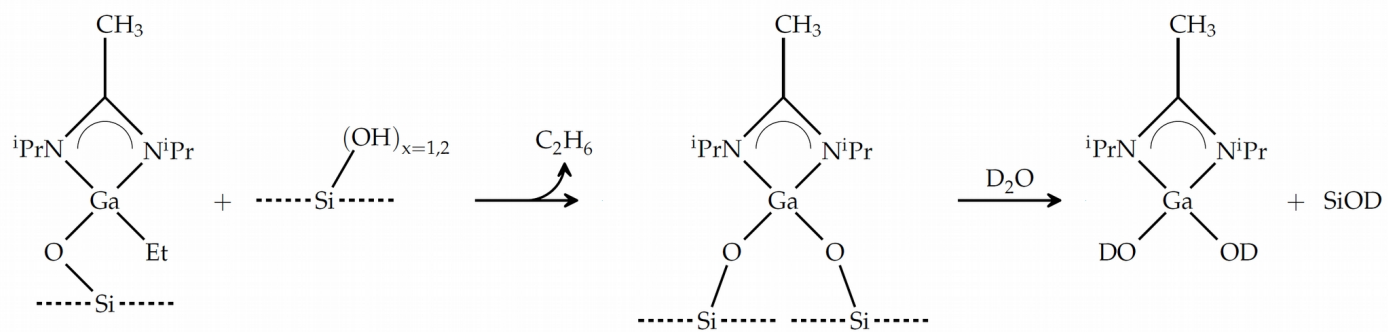

Figure 2.6: Proposed reaction mechanism for compound $\mathbf{2}$ on high surface area silica at $100{ }^{\circ} \mathrm{C}$ and $200{ }^{\circ} \mathrm{C}$ deposition temperature. Proposed route proceeds primarily through the elimination of an ethyl group(s) from the original compound to form a Ga(acetamidinate) species on the surface. The suspected species produced upon etching the substrate with $\mathrm{D}_{2} \mathrm{O}$ is shown as well.

This again shows that $\mathbf{2}$ preferentially chemisorbs at geminal hydroxyl sites, but at higher temperatures, the lone hydroxyls become much more accessible.

To gain insight into the actual nature of the chemisorbed surface species, ${ }^{13} \mathrm{C}$ $\mathrm{CP} / \mathrm{MAS}$ SS-NMR spectra were obtained. Figure 2.7 shows the ${ }^{13} \mathrm{C}$ SS-NMR spectrum of 2 chemisorbed onto silica at $100{ }^{\circ} \mathrm{C}, 200{ }^{\circ} \mathrm{C}$, and $300{ }^{\circ} \mathrm{C}$. Figure 2.7 also contains the ${ }^{13} \mathrm{C}$ HR-NMR (in $d_{6}$-benzene) of $\mathbf{2}$ for comparison.

One can see that the ${ }^{13} \mathrm{C}$ SS-NMR spectra for the exposures at $100{ }^{\circ} \mathrm{C}$ and $200{ }^{\circ} \mathrm{C}$ are very similar. At first glance, there are three obvious aliphatic carbon signals and one aromatic carbon (inset) for the $100{ }^{\circ} \mathrm{C}$ and $200{ }^{\circ} \mathrm{C}$ exposures. In a comparison of the SS-NMR spectra with the ${ }^{13} \mathrm{C}$ HR-NMR spectrum for pure $\mathbf{2}$ it can be seen that the peaks in the ${ }^{13} \mathrm{C}$ SS spectrum match quite well with the peaks in the ${ }^{13} \mathrm{C}$ 
HR spectrum. Since ${ }^{13} \mathrm{C}$ is a spin $1 / 2$ nucleus, with a moderate spinning rate and reasonable ${ }^{1} \mathrm{H}$ decoupling power the isotropic chemical shift of species in the solidstate should be similar to the isotropic chemical shift in the high-resolution NMR spectrum. The peaks at $172,46,23.5$, and $7.5 \mathrm{ppm}$ are similar to the isotropic shifts for the carbons of the amidinate ligand on pure 2. The small differences are likely due to to solvent effects of $d_{6}$-benzene used to obtain the ${ }^{13} \mathrm{C}$ HR-NMR spectrum. This similarity implies that the amidinate environments are likely still bound through gallium at $100{ }^{\circ} \mathrm{C}$ and $200{ }^{\circ} \mathrm{C}$. Although the peaks in the HR-NMR spectrum resulting from the ethyl groups of $\mathbf{2}$ are close to the chemical shift of the exocylic methyl group on the amidinate it is unlikely that the peak at $7.5 \mathrm{ppm}$ corresponds to the ethyl groups of 2 . If this peak at $7.5 \mathrm{ppm}$ was due to the ethyl groups, it would be considerably higher in intensity than what is observed, and there would be an additional peak present around $4.5 \mathrm{ppm}$. As it turns out, there are, in fact, signals present due to ethyl groups on the surface of the exposed silica. There is a relatively broad signal centered around $4 \mathrm{ppm}$ that is barely present in the sample exposed at $200{ }^{\circ} \mathrm{C}$ but is much more intense in the silica exposed at $100{ }^{\circ} \mathrm{C}$, which likely arises from the presence of ethyl groups on the surface. They appear as a very broad signal because they are likely not constrained to a particular geometry on the surface, and this lack of order produces a larger range of chemical shifts in the solid-state. This gives additional proof to the likelihood of $\mathbf{2}$ losing only one ethyl group preferentially (b in Figure 2.6 ) upon exposure to silica at $100{ }^{\circ} \mathrm{C}$ whereas 2 is more likely to lose both ethyl groups either through reaction with a geminal hydroxyl surface site or two lone hydroxyl sites (a and c in Figure 2.6 ) at $200{ }^{\circ} \mathrm{C}$. Another interesting feature of the ${ }^{13} \mathrm{C}$ SS-NMR is the fact that the amidinate peaks appear to have a small shoulder at a slightly higher chemical shift. This is likely due to a possible anisotropy of the amidinate ligand on the surface wherein the ligand is no longer completely symmetrically bonded at the surface. This might be due to the ligand 


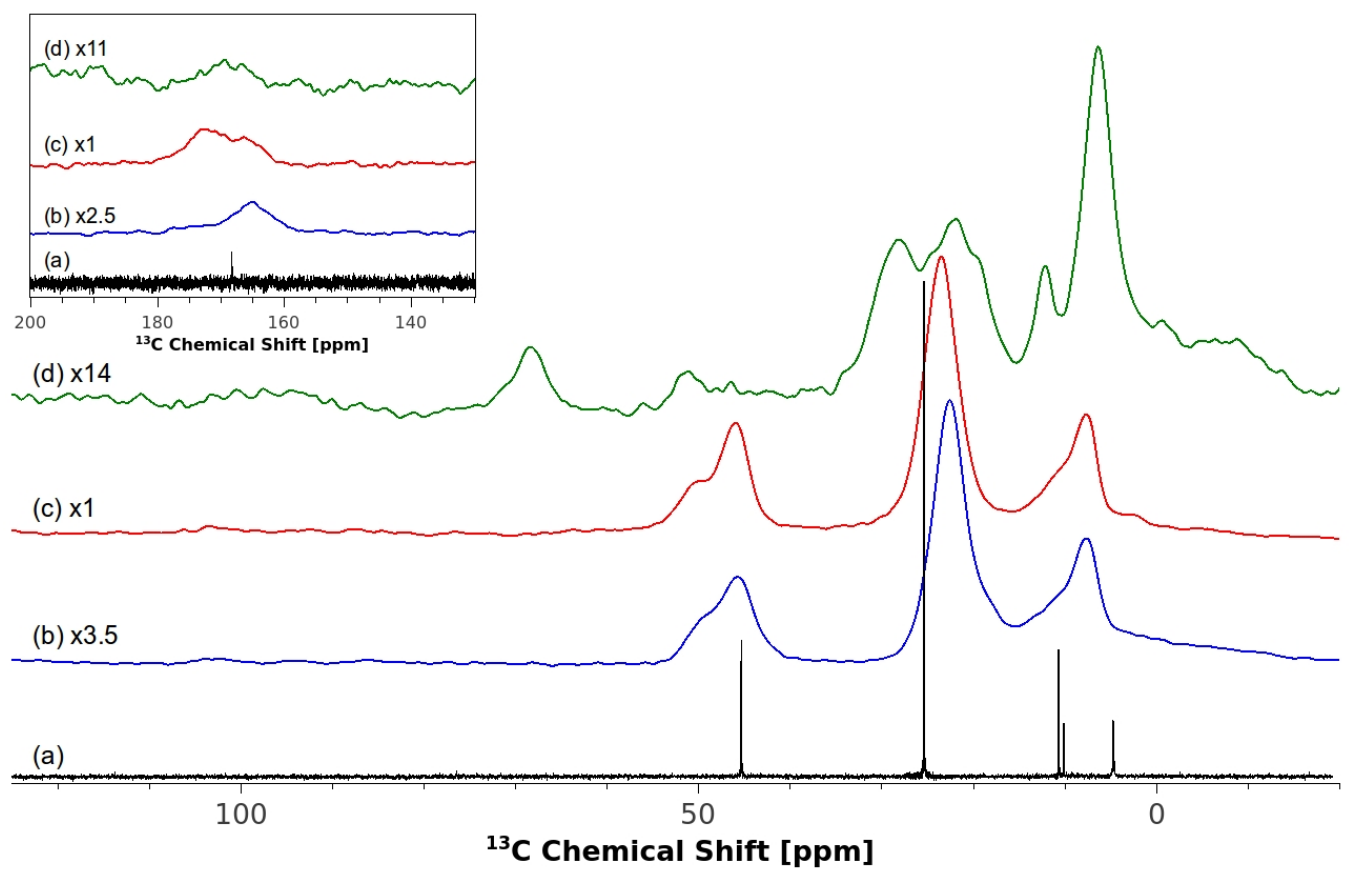

Figure 2.7: ${ }^{13} \mathrm{C}\left\{{ }^{1} \mathrm{H}\right\}$ HR-NMR spectrum of 2 in $d_{6}$-benzene (a). ${ }^{13} \mathrm{C}\left\{{ }^{1} \mathrm{H}\right\} \mathrm{CP} / \mathrm{MAS}$ SS-NMR spectrum of the silica substrate exposed to 2 at $100{ }^{\circ} \mathrm{C}$ (b), $200{ }^{\circ} \mathrm{C}$ (c), and $300{ }^{\circ} \mathrm{C}(\mathrm{d})$. Inset shows a zoom-in of the region where the amidinate quaternary carbon appears. Relative intensity scaling is shown for completeness.

being sterically locked in one position, or possibly due to a nonsymmetrical bonding of the amidinate ligand to the gallium center on the surface.

The ${ }^{13} \mathrm{C}$ SS-NMR spectrum of the sample exposed at $300{ }^{\circ} \mathrm{C}$ is completely different from the $100{ }^{\circ} \mathrm{C}$ and $200{ }^{\circ} \mathrm{C}$ exposures (Figure 2.7 ). While there are peaks that likely represent similar surface species as in the $100{ }^{\circ} \mathrm{C}$ and $200{ }^{\circ} \mathrm{C}$ exposure, there are also several new peaks. It is difficult to assign specific carbon species giving rise to the large number of peaks present in the $300^{\circ} \mathrm{C}$ exposure, but there is likely precursor decomposition occurring at the surface at this temperature. In fact, it has been shown that, in similar ligand systems on single crystal metallic surfaces, above $200{ }^{\circ} \mathrm{C}$ there can be complex decomposition pathways that result in a variety of adsorbed surface species. ${ }^{23,75}$ The presence of more signals in the ${ }^{13} \mathrm{C}$ SS-NMR spectrum also corroborates with a solution-decomposition study performed on $\mathbf{2}$ where it was found to decompose above $200{ }^{\circ} \mathrm{C}$ in benzene. As well, the additional species on the surface would account for the slight increase in coverage of lone hydroxyl groups (Table 
2.1). In fact, decomposition products would appear to increase the overall coverage values if the products interact with the silica surface as to produce dehydroxylated silica. This is, in fact, what is observed in the coverage values. However, the overall intensity of the ${ }^{13} \mathrm{C}$ SS-NMR spectrum obtained for the exposure at $300{ }^{\circ} \mathrm{C}$ is quite low compared to the other exposures (Figure 2.7 ). This likely means that there are some surface species which are very nonordered, have a very large chemical shielding anisotropy, or have significantly different Hartmann-Hahn match for crosspolarization used experimentally. Even though the precursor is undergoing different chemistry at $300{ }^{\circ} \mathrm{C}$ than at $100{ }^{\circ} \mathrm{C}$ and $200{ }^{\circ} \mathrm{C}$, it is remarkable that the surface species formed are persistent and remain stable for days during and after the exposure experiment.

To further probe the nature of the chemisorbed surface species an additional highresolution study was undertaken. After silica was exposed to 2 at $100{ }^{\circ} \mathrm{C}, 200{ }^{\circ} \mathrm{C}$, and $300{ }^{\circ} \mathrm{C}$, a small amount of substrate was washed with $\mathrm{D}_{2} \mathrm{O}$ to etch off the chemisorbed species. This $\mathrm{D}_{2} \mathrm{O}$ was then examined using ${ }^{1} \mathrm{H}$ HR-NMR, shown in Figure 2.8. To understand the signals present in the $\mathrm{D}_{2} \mathrm{O}$ etch, a ${ }^{1} \mathrm{H}$ HR-NMR spectrum of pure 2 in $\mathrm{D}_{2} \mathrm{O}$ was run, shown in Figure 2.8a. As an aside, it is interesting to note that 2 is, in fact, stable in $\mathrm{D}_{2} \mathrm{O}$ for several days. After a few days, however, there is a slow decomposition that occurs. Comparing the ${ }^{1} \mathrm{H}$ HR-NMR of the pure compound to the substrate etch one can see that all the peaks corresponding to the gallium amidinate are present in the $\mathrm{D}_{2} \mathrm{O}$-etched exposed silica for samples exposed at $100{ }^{\circ} \mathrm{C}$ and $200{ }^{\circ} \mathrm{C}$ except the ethyl peaks. This gives additional proof that upon chemisorption the ethyl groups are eliminated to produce a gallium amidinate on the surface of the silica that is coordinated through oxygen on the surface (Figure 2.6 ). However, there is a low intensity ethyl environment present in the $\mathrm{D}_{2} \mathrm{O}$-etched samples at $100{ }^{\circ} \mathrm{C}$ and $200{ }^{\circ} \mathrm{C}$ at $1.04 \mathrm{ppm}(\mathrm{t})$ and $0.28 \mathrm{ppm}(\mathrm{q})$ that does not equate to the ethyl groups in the original compound or to the ${ }^{1} \mathrm{H}$ HR-NMR of $\mathrm{Et}_{3}$ Ga. Given the very shielded nature of this region, it is likely that this ethyl group is bound to gallium as a monoethyl 


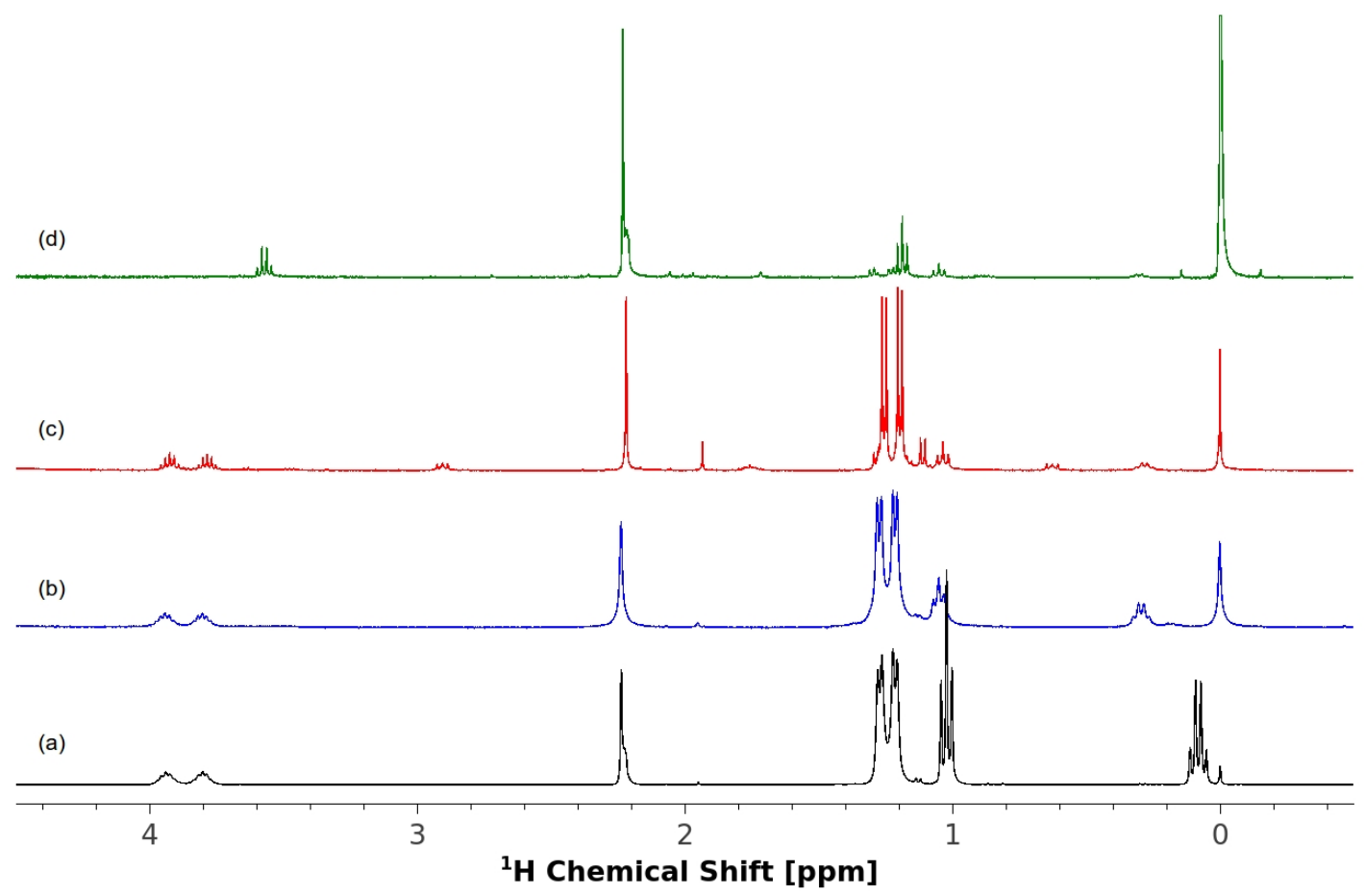

Figure 2.8: ${ }^{1} \mathrm{H}$ HR-NMR of 2 in $\mathrm{D}_{2} \mathrm{O}$ (a). ${ }^{1} \mathrm{H}$ HR-NMR of silica substrate exposed to 2 at $100{ }^{\circ} \mathrm{C}(\mathrm{b}), 200{ }^{\circ} \mathrm{C}(\mathrm{c})$, and $300{ }^{\circ} \mathrm{C}(\mathrm{d})$ etched with $\mathrm{D}_{2} \mathrm{O}$.

gallium species (b in Figure 2.6 ). It is notable that the peaks corresponding to the isopropyl groups from the HR-NMR spectra obtained in the more polar $\mathrm{D}_{2} \mathrm{O}$ solvent in Figure 2.8 are split into doublets. This gives more evidence that in more polar environments the steric bulk of gallium causes the two isopropyl groups on the amidinate ligand to become magnetically inequivalent. This effect is not seen in the less sterically hindered starting material, $\left(\mathrm{MeC}(\mathrm{NiPr})_{2}\right) \mathrm{Li}$, although interestingly, the lithiated amidinate starting material is relatively stable in water and aside from the isopropyl environment shows very similar ${ }^{1} \mathrm{H}$ HR-NMR chemical shifts to that of $\mathbf{2}$. This effect has been documented in similar gallium and aluminum guanidinate compounds and was observed using variable temperature HR-NMR. ${ }^{76}$

The $\mathrm{D}_{2} \mathrm{O}$-etched silica exposed to 2 at $300{ }^{\circ} \mathrm{C}$ shows significantly different signals from the $100{ }^{\circ} \mathrm{C}$ and $200{ }^{\circ} \mathrm{C}$ exposures. Figure $2.8 \mathrm{~d}$ shows the ${ }^{1} \mathrm{H}$ HR-NMR of silica exposed to 2 at $300{ }^{\circ} \mathrm{C}$ and etched with $\mathrm{D}_{2} \mathrm{O}$. While the other exposures show a strong signal for intact gallium amidinate, both monoethylated and without ethyl groups, in the $300{ }^{\circ} \mathrm{C}$ exposure there is only a small signal present for these species that is barely 
above the background noise. The major products are a somewhat broad singlet at 2.24 ppm, a quartet at $3.57 \mathrm{ppm}$, and a triplet at $1.19 \mathrm{ppm}$. Interestingly, the quartet and triplet are due to diethyl ether which indicates that somehow the ethyl groups in $\mathbf{2}$ are able to form diethyl ether either during the high-temperature exposure or when the adsorbed surface species are allowed to react with $\mathrm{D}_{2} \mathrm{O}$. These peaks are not present in the pure $\mathrm{D}_{2} \mathrm{O}$ or when etching just silica so it is difficult to speculate what the mechanism of diethyl ether formation is in this process. The other interesting feature in Figure 2.8d is the singlet at 2.24 ppm that matches with the singlet in all other exposures and in the original gallium compound. The presence of this signal but the lack of the corresponding isopropyl groups leads to the conclusion that the isopropyl groups on the amidinate are eliminated during the $300{ }^{\circ} \mathrm{C}$ exposure and either leave as volatile byproducts or stay adsorbed during the exposure but form a volatile species when exposed to the slightly acidic $\mathrm{D}_{2} \mathrm{O}$. In fact, the species corresponding to the singlet at $2.24 \mathrm{ppm}$ matches exactly with ethanimidamide $\left(\mathrm{CH}_{3} \mathrm{CNH}_{2} \mathrm{NH}\right)$ in $\mathrm{D}_{2} \mathrm{O}$, which is the acetamidine in $\mathbf{2}$ without the isopropyl groups.

\subsection{Conclusions}

A new gallium(III) alkyl amidinate was synthesized using facile salt metathesis routes. Thermogravimetric analysis studies revealed that this compound showed excellent volatility with no decomposition during a ramped TGA experiment. Through a stepped-isotherm TGA experiment coupled to a Langmuir model for volatilization 2 was found to have a 1 Torr vapour pressure at $64{ }^{\circ} \mathrm{C}$. Solution phase HR-NMR also showed that 2 was stable in solution up to $200{ }^{\circ} \mathrm{C}$ for weeks.

A series of gas phase exposures of $\mathbf{2}$ onto high-surface area silica were carried out. At $100{ }^{\circ} \mathrm{C}, 200{ }^{\circ} \mathrm{C}$, and $300{ }^{\circ} \mathrm{C}, 2$ was found to exhibit stable, persistent chemisorbed surface species that could be analyzed by SS-NMR and HR-NMR. With a modification 
of a method developed previously ${ }^{64}$ the surface coverage of the chemisorbed surface species was determined. With ${ }^{29} \mathrm{Si}$ SS-NMR it was determined that the reactivity of $\mathbf{2}$ at geminal and lone hydroxyl surface sites on the high-surface area silica varied slightly which ultimately produced different chemisorbed surface species. A combination of ${ }^{13} \mathrm{C}$ SS-NMR and ${ }^{1} \mathrm{H}$ SS-NMR aided in determining the nature of the adsorbed surface species.

At $100{ }^{\circ} \mathrm{C}$ and $200{ }^{\circ} \mathrm{C}$ the reactivity of $\mathbf{2}$ to geminal and lone hydroxyl surface sites varied slightly, eliminating either one or both ethyl groups to produce an alkylated (or nonalkylated) gallium acetamidinate on the surface of the silica. At $300{ }^{\circ} \mathrm{C}$ there is a larger degree of reactivity producing a minor amount of the same surface species as at $100{ }^{\circ} \mathrm{C}$ and $200^{\circ} \mathrm{C}$ but also giving a mix of chemisorbed products likely arising from the decomposition of the ligand framework. It was found that when etched with $\mathrm{D}_{2} \mathrm{O}$ the exposure at $300{ }^{\circ} \mathrm{C}$ produced mostly diethyl ether and ethanimidamide showing the likelihood of precursor decomposition.

Given the excellent stability and volatility of this new gallium compound, it provides a versatile gaseous gallium complex that has potential in vapour deposition methods. As well, the reactivity to hydroxyl-terminated surfaces shows a stable monolayer at a variety of temperatures that lends itself as a potentially excellent atomic layer deposition precursor for gallium-based film applications.

\subsection{Supporting Information}

\section{Derivation of surface coverage of hydroxyl groups of silica us- ing ${ }^{29} \mathrm{Si} \mathrm{CP} / \mathrm{MAS}$ SS-NMR}

Adapted from Sindorf and Maciel. ${ }^{64}$

Start by examining the surface concentration of geminal-hydroxyl $(G)$, lone-hydroxyl 
$(L)$ which may be in number per unit area (eg. \#/ $\AA^{2}$ ) before and after reaction with a gas-phase precursor:

$$
\begin{aligned}
& G^{r}+G^{u}=G^{i} \\
& L^{r}+L^{u}=L^{i}
\end{aligned}
$$

where superscripts $r, u$, and $i$ refer to reacted, unreacted, and initial surface concentrations respectively. If it is assumed that any compound that allowed to react with the silica will react at the hydroxyl surface sites then the following represents the surface concentration of the chemisorbed precursor, $C$ :

$$
C=L^{r}+G^{r}
$$

Since the cross-polarization efficiencies of lone and geminal hydroxyl sites have been shown to be similar, ${ }^{66}$ a direct comparison between the ${ }^{29} \mathrm{Si}$ SS-NMR signal integrations and the surface concentrations can be made giving an expression for the fraction of silicon sites that are of a particular type. Given that the integration intensity is proportional to the surface concentration, an arbitrary proportionality constant, $K$, can be used to relate surface concentration to integration intensity. These can be expressed as the following:

$$
\begin{aligned}
& I_{c}^{r} \equiv K C \\
& I_{g}^{r} \equiv K G^{u} \\
& I_{l}^{r} \equiv K\left(L^{u}+G^{r}\right) \\
& I_{l}^{i} \equiv K L^{i} \\
& I_{g}^{i} \equiv K G^{i}
\end{aligned}
$$


where $I$ represents the integration intensity of initial (superscript $i$ ) and reacted (superscript $r$ ) geminal (subscript $g$ ) and lone (subscript $l$ ) hydroxyl sites from the ${ }^{29} \mathrm{Si}$ SS-NMR. $I_{c}^{r}$ represents the integrated signal intensity of chemisorbed surface species measured in the silicon SS-NMR. It should be noted that singly reacted geminal hydroxyl sites cannot be distinguished from unreacted lone hydroxyl sites so that integration intensity, (2.19) is represented by the sum of those two concentrations.

From the data presented here, $\mathbf{2}$ does not produce any additional ${ }^{29} \mathrm{Si} \mathrm{CP} / \mathrm{MAS}$ SS-NMR signals upon adsorption onto HSAS. This means that there is no integration intensity for $I_{c}^{r}$ (shown in (2.17)). However, this value can be expressed using the other measurable quantities shown in (2.18) - (2.21). To start, use (2.16) and (2.17) to get:

$$
\begin{aligned}
I_{c}^{r} & =K C \\
& =K\left(L^{r}+G^{r}\right)
\end{aligned}
$$

then using (2.14) and (2.15):

$$
\begin{aligned}
& =K\left(L^{i}-L^{u}+G^{r}\right) \\
& =K\left(L^{i}-L^{u}+G^{i}-G^{u}\right) \\
& =K\left(L^{i}-L^{u}+G^{i}-G^{u}+G^{r}-G^{r}\right) \\
& =K\left(L^{i}-L^{u}+G^{i}-G^{u}+G^{i}-G^{u}-G^{r}\right) \\
& =K\left(L^{i}+2 G^{i}-2 G^{u}-\left(L^{u}+G^{r}\right)\right)
\end{aligned}
$$

then using (2.18) - (2.21):

$$
I_{c}^{r}=I_{l}^{i}+2 I_{g}^{i}-2 I_{g}^{r}-I_{l}^{r}
$$


To develop expressions for the overall surface coverage of hydroxyl sites, first the fraction of each type of hydroxyl group must be examined. For the fraction (or overall population) of initial geminal hydroxyl surface species, $f_{g}^{i}$ :

$$
f_{g}^{i}=\frac{I_{g}^{i}}{I_{g}^{i}+I_{l}^{i}}
$$

This can be related to the surface concentrations via (2.20) and (2.21):

$$
f_{g}^{i}=\frac{I_{g}^{i}}{I_{g}^{i}+I_{l}^{i}}=\frac{K G^{i}}{K G^{i}+K L^{i}}=\frac{G^{i}}{G^{i}+L^{i}}
$$

Once a surface reaction has taken place, the population of geminal hydroxyl surface sites can be expressed as:

$$
f_{g}^{r}=\frac{I_{g}^{r}}{I_{g}^{r}+I_{l}^{r}}=\frac{K G^{u}}{K G^{u}+K\left(L^{u}+G^{r}\right)}=\frac{G^{u}}{G^{i}+L^{u}}
$$

The same treatment can be done for lone hydroxyl sites:

$$
\begin{aligned}
& f_{l}^{i}=\frac{I_{l}^{i}}{I_{g}^{i}+I_{l}^{i}}=\frac{K L^{i}}{K G^{i}+K L^{i}}=\frac{L^{i}}{G^{i}+L^{i}} \\
& f_{l}^{r}=\frac{I_{l}^{r}}{I_{g}^{r}+I_{l}^{r}}=\frac{K\left(L^{u}+G^{r}\right)}{K G^{u}+K\left(L^{u}+G^{r}\right)}=\frac{L^{u}+G^{r}}{G^{u}+L^{u}}
\end{aligned}
$$

As well, since we are interested in the population of chemisorbed surface species, this can be expressed as:

$$
f=\frac{I_{c}^{r}}{I_{g}^{r}+I_{l}^{r}}=\frac{K C}{K G^{u}+K\left(L^{u}+G^{r}\right)}=\frac{C}{G^{i}+L^{u}}
$$

Using $(2.25)$, (2.29) can be expressed in terms of the integration intensities of 
geminal and lone-hydroxyl surface sites:

$$
f=\frac{I_{l}^{i}+2 I_{g}^{i}-2 I_{g}^{r}-I_{l}^{r}}{I_{g}^{r}+I_{l}^{r}}
$$

What is of primary interest is the surface coverage or extent of reaction on these surface hydroxyl species. The formalism adopted herein is one where the surface coverage, $\theta$, us expressed as:

$$
\theta=\frac{G^{r}+L^{r}}{G^{i}+L^{i}}
$$

The coverage specifically on geminal and lone-hydroxyl surface species are:

$$
\theta_{g}=\frac{G^{r}}{G^{i}}
$$

and

$$
\theta_{l}=\frac{L^{r}}{L^{i}}
$$

To determine (2.31) - (2.33) using measurable integrations from ${ }^{29} \mathrm{Si}$ SS-NMR, $(2.14)-(2.21)$ and $(2.26)-(2.29)$ can be combined ${ }^{64}$ to get the following final relationships:

$$
\begin{aligned}
\theta & =\frac{f\left(1+f_{g}^{i}\right)}{\left(1+f+f_{g}^{r}\right)} \\
\theta_{g} & =\frac{\left(1+f-\left(\frac{f_{g}^{r}}{f_{g}^{i}}\right)\right)}{\left(1+f+f_{g}^{r}\right)} \\
\theta_{l} & =\left(\frac{1}{1-f_{g}^{i}}\right) \frac{\left(f+f_{g}^{r}-f_{g}^{i}\right)}{\left(1+f+f_{g}^{r}\right)}
\end{aligned}
$$




\section{Propagation of Uncertainty in Measurements}

To get an understanding of the precision of the results obtained some description is provided for the interest of the reader.

First, the fit parameters (amplitude and width of $\mathrm{G} / \mathrm{L}$ line) of the ${ }^{29} \mathrm{Si} \mathrm{CP} / \mathrm{MAS}$ SS-NMR integrations for each spectra were modified manually to produce a number of normalized integration intensities for the three silicon signals present. The integration intensities were kept when the difference spectrum between the experimental data and the fit were manually judged to represent a good fit. The average integration value was taken as $I_{x}^{y}($ in $(2.17)-(2.21))$ and the standard deviation was taken as the uncertainty on the raw recorded integration data. This is the data shown in Table 2.1 (main paper).

To propagate this uncertainty to the final coverage values, the standard method used for a function $f$ that is a set of non-linear combinations of several variables was employed. Linearizing the function to a first-order Taylor expansion the uncertainty of a given two variable function, $f\left(x_{1}, x_{2}\right)$, in general, can be given as:

$$
\sigma_{f}^{2} \approx\left(\frac{\partial f}{\partial x_{1}}\right)^{2} \sigma_{x_{1}}^{2}+\left(\frac{\partial f}{\partial x_{2}}\right)^{2} \sigma_{x_{2}}^{2}+2 \frac{\partial f}{\partial x_{1}} \frac{\partial f}{\partial x_{2}} \operatorname{cov}\left(x_{1}, x_{2}\right)
$$

where cov is the covariance between $x_{1}$ and $x_{2}$ and $\sigma_{x}$ is the uncertainty or standard deviation on the variable $x$. To show how this was applied in the analysis shown here, the following is how the error was propagated on the population of initial geminal- 
hydroxyl surface sites, $f_{g}^{i}$ :

$$
\begin{aligned}
\sigma_{f_{g}^{i}}^{2} \approx & \left(\frac{\partial f_{g}^{i}}{\partial I_{g}^{i}}\right)^{2} \sigma_{I_{g}^{i}}^{2}+\left(\frac{\partial f_{g}^{i}}{\partial I_{l}^{i}}\right)^{2} \sigma_{I_{l}^{i}}^{2}+2 \frac{\partial f_{g}^{i}}{\partial I_{g}^{i}} \frac{\partial f_{g}^{i}}{\partial I_{l}^{i}} \operatorname{cov}\left(I_{g}^{i}, I_{l}^{i}\right) \\
\sigma_{f_{g}^{i}}^{2} \approx & \left(\frac{I_{g}^{r}}{\left(I_{g}^{i}+I_{l}^{i}\right)}\right)^{2} \sigma_{I_{g}^{i}}^{2}+\left(\frac{-I_{g}^{i}}{\left(I_{l}^{i}+I_{g}^{i}\right)^{2}}\right)^{2} \sigma_{I_{g}^{i}}^{2} \\
& +2\left(\frac{I_{g}^{r}}{\left(I_{g}^{i}+I_{l}^{i}\right)}\right)\left(\frac{-I_{g}^{i}}{\left(I_{l}^{i}+I_{g}^{i}\right)^{2}}\right) \operatorname{cov}\left(I_{g}^{i}, I_{l}^{i}\right)
\end{aligned}
$$

The covariance on all integrations quantities is very close to zero but was included for completeness. Equations similar to (2.39) were generated for all calculated quantities used $\left(f_{g}^{i}, f_{g}^{r}, f, \theta, \theta_{g}\right.$, and $\left.\theta_{l}\right)$ and the final uncertainties on coverages are shown in Table 2.1. 


\section{Chapter 3}

\section{Self-Seeding Gallium Oxide Nanowire Growth by Pulsed Chemical Vapour Deposition}

Modified from the original manuscript published as:

Pallister, P.J., Buttera, S.C., and Barry, S.T., Self-Seeding Gallium Oxide Nanowire Growth by Pulsed Chemical Vapor Deposition, Phys. Status Solidi A, 2015, 212, 1514-1518.

Department of Chemistry, Carleton University, 1125 Colonel By Drive, Ottawa, Ontario, K1S 5B6, Canada 


\section{$3.1 \quad$ Abstract}

A new heteroleptic gallium (III) alkyl amidinate [monoacetamidinatodiethylgallium(III), compound 2 ] was found to undergo self-seeding pulsed chemical vapour deposition (p-CVD) to gallium metal above temperatures of $450{ }^{\circ} \mathrm{C}$. Below this temperature, the mono-layer formed on the surface of silica and alumina is unreactive to itself and $\mathrm{H}_{2} \mathrm{O}$ and $\mathrm{O}_{2}$ co-reactants. With no co-reactant above

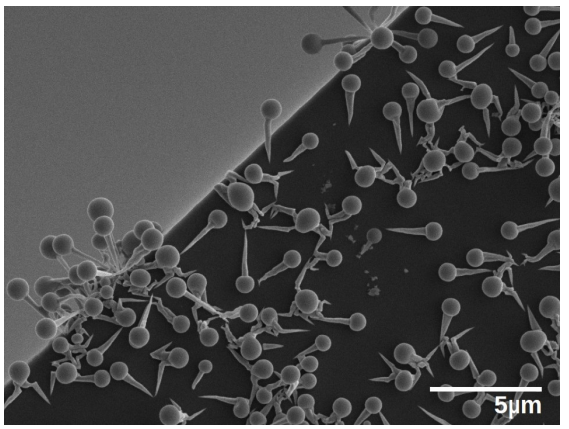

Figure 3.1: Table of Contents graphic used for publication described in Chapter 3 $450{ }^{\circ} \mathrm{C}$ gallium metal spheres $(150-500 \mathrm{~nm})$ formed in a p-CVD experiment. With the addition of short $\mathrm{H}_{2} \mathrm{O}$ pulses interesting morphologies and gallium metal/gallium oxide structures resembling ice cream cones of varying sizes $(<150-500 \mathrm{~nm})$ were produced. The addition of $\mathrm{O}_{2}$ produced micron long nanowires $<250 \mathrm{~nm}$ in width and a mat of nanoparticles on both silicon and alumina.

\subsection{Introduction}

Gallium is an important element for a variety of thin film applications. $\mathrm{Ga}_{2} \mathrm{O}_{3}$ is a wide band gap material ${ }^{41}$ that has a wide range of thin film applications including gas sensing ${ }^{42}$ optoelectronic devices, ${ }^{43}$ and plasmonic applications. ${ }^{77}$

Deposition of gallium or gallium oxide thin films can be achieved through a variety of vapour-phase techniques. Molecular beam epitaxy, ${ }^{78} \mathrm{MO}-\mathrm{CVD},{ }^{47-49}$ and $\mathrm{ALD}^{50-53}$ have been used to deposit thin films of gallium or gallium oxide. There are a variety of known gallium-containing precursors that can be used for vapour phase deposition employing alkyl, ${ }^{54}$ halide, ${ }^{55} \beta$-diketonate, ${ }^{50}$ and alkoxy-based ${ }^{49,56,57}$ ligand systems and there have been a few reviews on the topic as well. ${ }^{79,80}$ 
a)

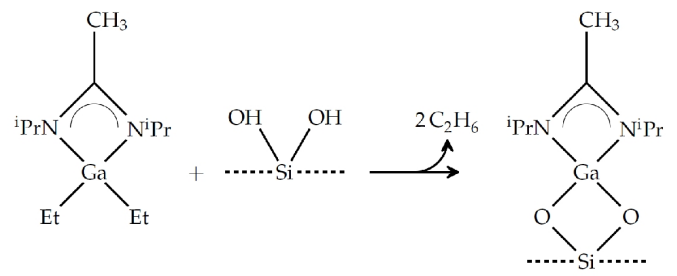

b)

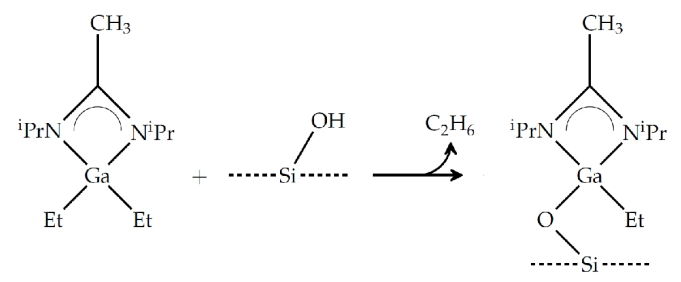

c)

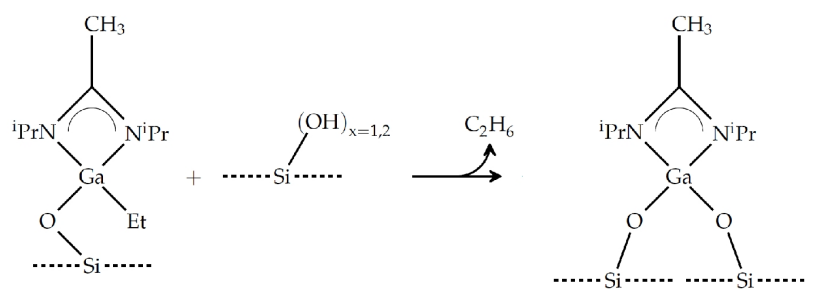

Figure 3.2: Proposed reaction mechanism for monoacetamidinatodiethylgallium(III) on high surface area silica at $100{ }^{\circ} \mathrm{C}$ and $200{ }^{\circ} \mathrm{C}$ deposition temperature. ${ }^{81}$

The surface chemistry of a compound dictates its utility as a vapour phase precursor. Determining the interaction of a vapour phase species with a solid surface is quite challenging due to the constraints of characterizing surface species and so there are limited reports on specific precursor-surface interactions. ${ }^{23,27,59}$ Recently, we reported a novel gallium containing precursor, monoacetamidinatodiethylgallium-(III), 2, along with its subsequent surface chemistry on silica. ${ }^{81}$ Using high surface area substrates and SS-NMR it was determined that this precursor forms a stable monolayer on a silica surface up to $300{ }^{\circ} \mathrm{C}$. The nature of the surface chemistry, up to 200 ${ }^{\circ} \mathrm{C}$, is shown in Figure 3.2. This scheme shows three precursor-substrate interactions which ultimately result in a gallium (acetamidinate) species on the surface. This surface species has impressive thermal stability, which can limit its use as a gallium precursor.

This report discusses the vapour phase deposition of gallium and gallium oxide using this previously reported gallium-containing precursor (2) and resulting structured thin films. It was found that the adsorbed monolayer is so stable that it is 
unreactive to water and oxygen at moderate temperatures. It ultimately undergoes CVD at temperatures above $450{ }^{\circ} \mathrm{C}$ to produce microstructured gallium-containing features on $\mathrm{Si} / \mathrm{SiO}_{2}$ and alumina.

\subsection{Experimental}

\section{Reagents}

The gallium precursor, monoacetamidinatobisethylgallium(III), (MeC(NiPr) $)_{2} \mathrm{GaEt}_{2}$, was synthesized according to a previously reported literature preparation. ${ }^{81}$ Briefly, a solution methyl lithium (1.6 M in diethyl ether) is added to diisopropylcarbodiimide to produce the lithiated acetamidinate. The lithiated acetamidinate is added to gallium (III) chloride (solution in diethyl ether/hexanes) as a Schlenk line transfer at $-78{ }^{\circ} \mathrm{C}$. Two equivalents of ethyl magnesium chloride (2.06 $\mathrm{M}$ in diethyl ether) are added in situ to the monoacetamidinate bischloro gallium (III) at $-30{ }^{\circ} \mathrm{C}$ as a Schlenk line transfer. Lithium chloride precipitate is filtered off and the resultant product is distilled at $35{ }^{\circ} \mathrm{C}$ and 70 mTorr to yield a colourless liquid (77\% yield overall with scale ranging from 0.5 to $8 \mathrm{~g}$ ).

\section{Deposition}

Pulsed chemical vapor deposition experiments were performed in a Picosun SUNALE ${ }^{\mathrm{TM}}$ R150 ALD reactor equipped with a PicoHot ${ }^{\mathrm{TM}}$ heated source for the solid precursor. In a typical deposition experiment, a temperature of $80{ }^{\circ} \mathrm{C}$ was used on the heated source to provide sufficient vapour pressure to volatilize the precursor. $\mathrm{H}_{2} \mathrm{O}$ (MilliQ deionized, 18.2 $\mathrm{M} \Omega \mathrm{cm}$ ) was kept in a separate bubbler cooled to $16{ }^{\circ} \mathrm{C}$ and introduced to the growth zone in separate, dedicated gas lines. $\mathrm{O}_{2}$ gas (Praxair, >99.5\%) was supplied through another dedicated line. Nitrogen $(99.998 \%)$ was used as the carrier 
gas with flows controlled by MFCs: 200 sccm into the reactor as the intermediate space flow, and $150 \mathrm{sccm}$ as precursor line flows. The overall pressure during deposition was $7 \mathrm{hPa}$. A typical pulse sequence for $\mathrm{Ga} / \mathrm{H}_{2} \mathrm{O}$ experiments was: Ga precursor pulse $-\mathrm{N}_{2}$ purge $-\mathrm{H}_{2} \mathrm{O}$ pulse $-\mathrm{N}_{2}$ purge. A typical pulse sequence for $\mathrm{Ga} / \mathrm{H}_{2} \mathrm{O} / \mathrm{O}_{2}$ experiments was: Ga pulse $-\mathrm{N}_{2}$ purge $-\mathrm{O}_{2}$ pulse $-\mathrm{N}_{2}$ purge $-\mathrm{H}_{2} \mathrm{O}$ pulse $-\mathrm{N}_{2}$ purge. $\mathrm{N}_{2}$ purge times were $20 \mathrm{~s}$. The following were used as substrates: glass microscope slides, $\operatorname{Si}(100)$ with a thermally-grown oxide (rinsed in 3:1 piranha solution, followed by distilled water, followed by deionized water (MilliQ, 18.2 M $\Omega \mathrm{cm}$ ), and air-dried), $\mathrm{Si}(100)$ with $772 \AA$ of $\mathrm{ALD}$ grown $\mathrm{Al}_{2} \mathrm{O}_{3}$.

\section{Characterization}

Scanning electron microscopy (SEM) micrographs were taken with a TESCAN Vega II XMU in secondary electron mode. Transmission electron microscopy (TEM) micrographs were taken with a FEI Tecnai G2 F20 Field Emission TEM. Samples were prepared for TEM by mechanical exfoliation of as-deposited films onto TEM grids (Carbon film on copper mesh; CF300Cu; Electron Microscopy Sciences). EDX was carried out on the SEM using an Oxford Instruments INCA XAct and on the TEM using an Oxford Instruments INCA Aztec Xmax.

\subsection{Results and Discussion}

\section{Deposition with only the gallium compound}

A number of p-CVD experiments were carried out with $\mathbf{2}$ and a mixture water and oxygen as co-reactant gases. There was no deposition below $450{ }^{\circ} \mathrm{C}$ on glass and oxidized silicon substrates. This indicates that the mono-layer formed by this compound on silanol-terminated surfaces is unusually stable to common co-reactants, which was 


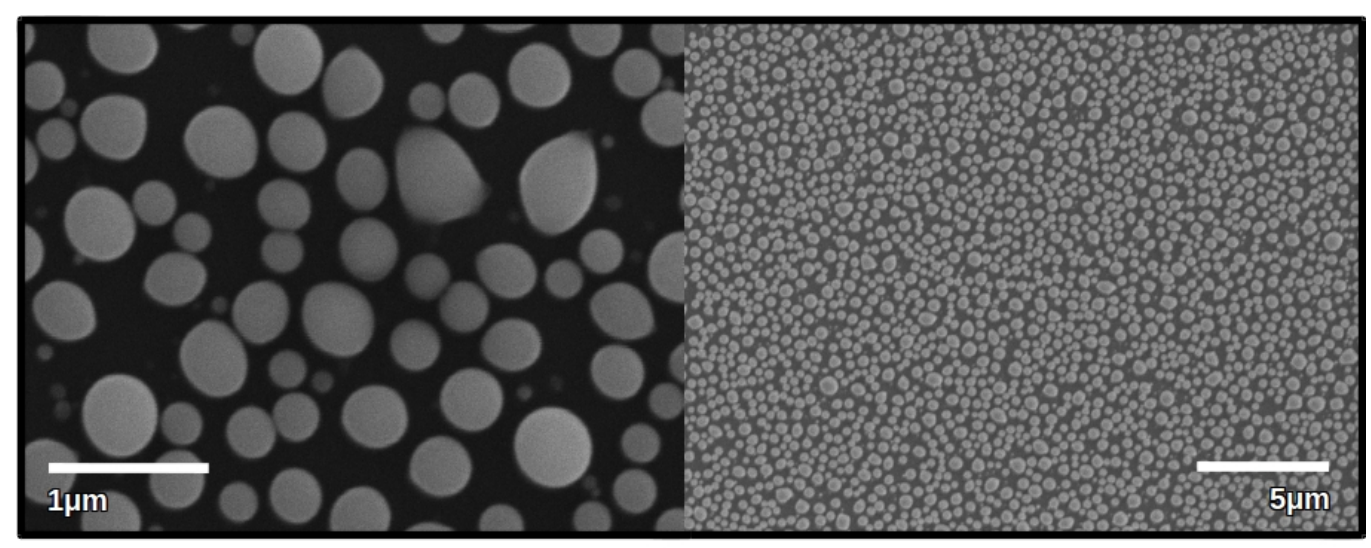

Figure 3.3: SEM micrographs of p-CVD process using only 2 without the addition of $\mathrm{H}_{2} \mathrm{O}$ or $\mathrm{O}_{2}$ in the pulse program at $500{ }^{\circ} \mathrm{C}$.

surprising, given the typical hydrophilicity of group 13 metals. Reactions above 450 ${ }^{\circ} \mathrm{C}$ displayed a range of surface structures. When the precursor was pulsed into the reactor without a co-reactant gas, reduction to gallium metal was seen, and the gallium metal was molten at this process temperature. At all reaction temperatures for which deposition was observed, it is important to note that gallium metal does not exhibit any significant vapour pressure, and thus there is no competing volatile loss of metal. ${ }^{82}$ Deposition on glass showed a non-uniform cloudy white film that could be wiped off with a Kimwipe. Visibly, all films produced with this precursor appeared this way on glass. Figure 3.3 shows SEM images of a pulsed exposure experiment of 2 on silicon (100) with a passivation layer that was previously grown at $500{ }^{\circ} \mathrm{C}$. The image shows smaller spheres of gallium ranging in size from 150 to $300 \mathrm{~nm}$ and larger spheres ranging from 450 to $500 \mathrm{~nm}$. EDX showed that the spheres were pure gallium with very little impurities from carbon and no visible impurity from either nitrogen or oxygen (Figure 3.4).

This reduction is reasonable considering the amidinate ligand: both copper $23,27,59$ and gold ${ }^{83}$ have previously been shown to be deposited as metallic films using amidinate precursors. In the case of copper, the reduction involved loss of the alkyl group by oxidation and fragmentation. ${ }^{84}$ Although it is unclear if this is occurring in the case of $\mathbf{2}$, the previously reported decomposition of the surface species matches that of the copper compound. 


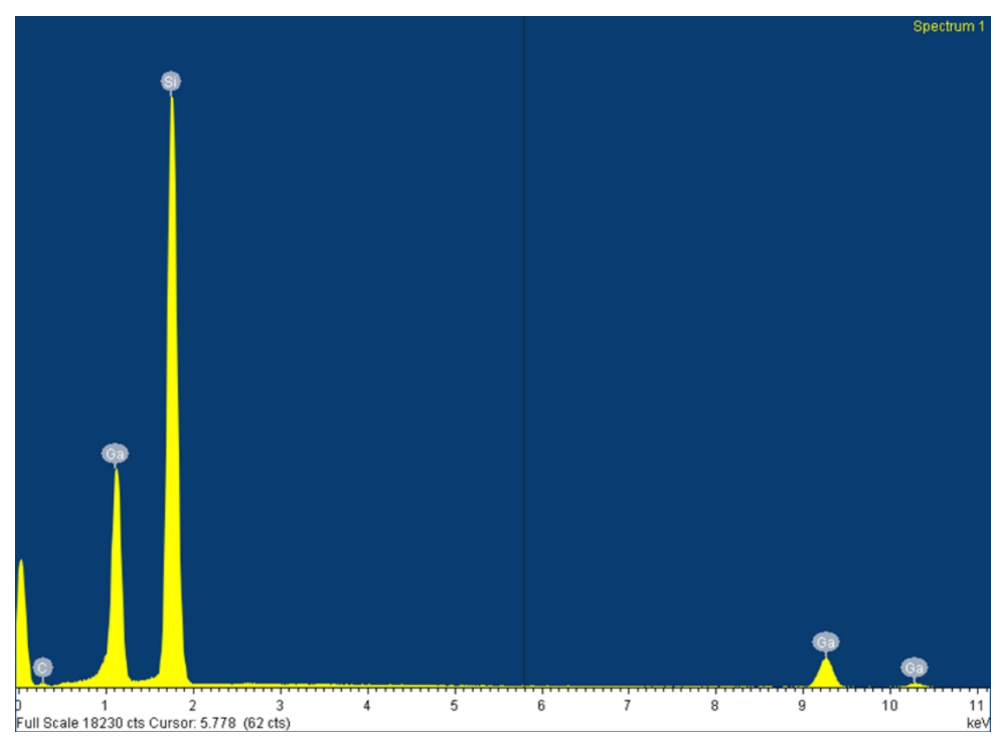

Figure 3.4: EDX spectrum of p-CVD process using only 2 without the addition of $\mathrm{H}_{2} \mathrm{O}$ or $\mathrm{O}_{2}$ in the pulse program at $500{ }^{\circ} \mathrm{C}$. Spectrum taken from particles shown in Figure 3.3. Si signal originates from substrate.

\section{Effect of $\mathrm{H}_{2} \mathrm{O}$ and $\mathrm{O}_{2}$}

To study the effect of a coreactant gas on the deposition, p-CVD with $\mathrm{H}_{2} \mathrm{O}$ and $\mathrm{O}_{2}$ (both in a mixture and independently) at a variety of pulse times and temperatures was performed. Table 1 shows the different experimental conditions examined, including variations of precursor pulse times, precursor pulse ratios, and reactor temperature. All p-CVD experiments showed interesting and varied surface morphologies of gallium metal/gallium oxide structures.

When p-CVD was performed with a long water pulse $(2.0 \mathrm{~s})$ and a moderate Ga pulse $(0.5 \mathrm{~s})$ at $500{ }^{\circ} \mathrm{C}$ (Figure $\left.3.5 \mathrm{a}\right)$, micron long wires that are terminated in a large droplets/particles resulted. Within the ensemble structure, there were examples of wires that ranged from 150 to $500 \mathrm{~nm}$ in width. As determined by EDX, the wires are primarily gallium oxide, whereas the larger droplets terminating the structures showed very little oxygen signal by EDX. This indicates that the precursor is still decomposing to gallium metal and seeding the growth, but the precursor is also reacting with the water to form gallium oxide. This allows the precursor to self-seed the gallium oxide and direct wire growth by forming a gallium metal droplet first. 
Table 3.1: p-CVD deposition parameters used in this study and corresponding SEM image figures.

$\begin{array}{cccccc}\begin{array}{c}\text { Ga pulse } \\ (\mathrm{s})\end{array} & \begin{array}{c}\mathrm{H}_{2} \mathrm{O} \text { pulse } \\ (\mathrm{s})\end{array} & \begin{array}{c}\mathrm{O}_{2} \text { pulse } \\ (\mathrm{s})\end{array} & \begin{array}{c}\text { precursor pulse ratio } \\ \left(\mathrm{Ga}: \mathrm{H}_{2} \mathrm{O}: \mathrm{O}_{2}\right)\end{array} & \begin{array}{c}\text { reactor temperature } \\ \left({ }^{\circ} \mathrm{C}\right)\end{array} & \text { figure } \\ 0.5 & - & - & - & 500 & 3.3 \\ 0.5 & 2.0 & - & 1: 4 & 500 & 3.5 \mathrm{a} \\ 0.2 & 0.1 & - & 1: 0.5 & 500 & 3.5 \mathrm{~b} \\ 0.2 & 0.1 & - & 1: 0.5 & 450 & 3.5 \mathrm{c} \\ 0.5 & 0.5 & - & 1: 1 & 450 & 3.5 \mathrm{~d} \\ 0.5 & 0.5 & 0.5 & 1: 1: 1 & 500 & 3.7\end{array}$

The reaction of $\mathbf{2}$ with water must proceed at a greater rate than the decomposition of 2 since the wires do not increase in diameter as the experiment continues. This growth mechanism is similar to vapor-liquid-solid (VLS) growth, but the gallium must remain in a +3 oxidation state to form an oxide with water.

If the pulse ratio of water vapour to vapour of $\mathbf{2}$ is reduced during p-CVD (by shortening the water pulse time), a different morphology resulted (Figure 3.5b). An ice cream cone morphology is observed, where the droplet portion of the structure was found to be on average $500 \mathrm{~nm}$ in size and consisted entirely of gallium metal with very little oxygen content $(<4$ at.\% O; $>96$ at.\% Ga). The cone portion of the structure was shown to be gallium oxide by EDX measurements (65 at.\% O; 35 at.\% Ga). EDX measurements in this case were taken from TEM images (shown in Figure $3.6)$.

This composition works out to be very close to $\mathrm{Ga}_{2} \mathrm{O}_{3}$ but with a slightly higher oxygen-content. The increased oxygen-content is likely due to background contamination from the TEM grids and instrumental uncertainty on the individual measurements. Figure 3.6b shows a higher magnification TEM image of the cone, showing the degree of crystallinity found in this feature. In fact, the atomic spacing from Figure 3.6b was measured to be $3.07 \pm 0.01 \AA$ (average of 20 measurements) which is close to the GaGa spacing of the (111) plane of $\gamma-\mathrm{Ga}_{2} \mathrm{O}_{3}(2.912 \AA) .{ }^{85}$ This is further evidence to the formation of crystalline gallium oxide extending from a gallium metal droplet. 


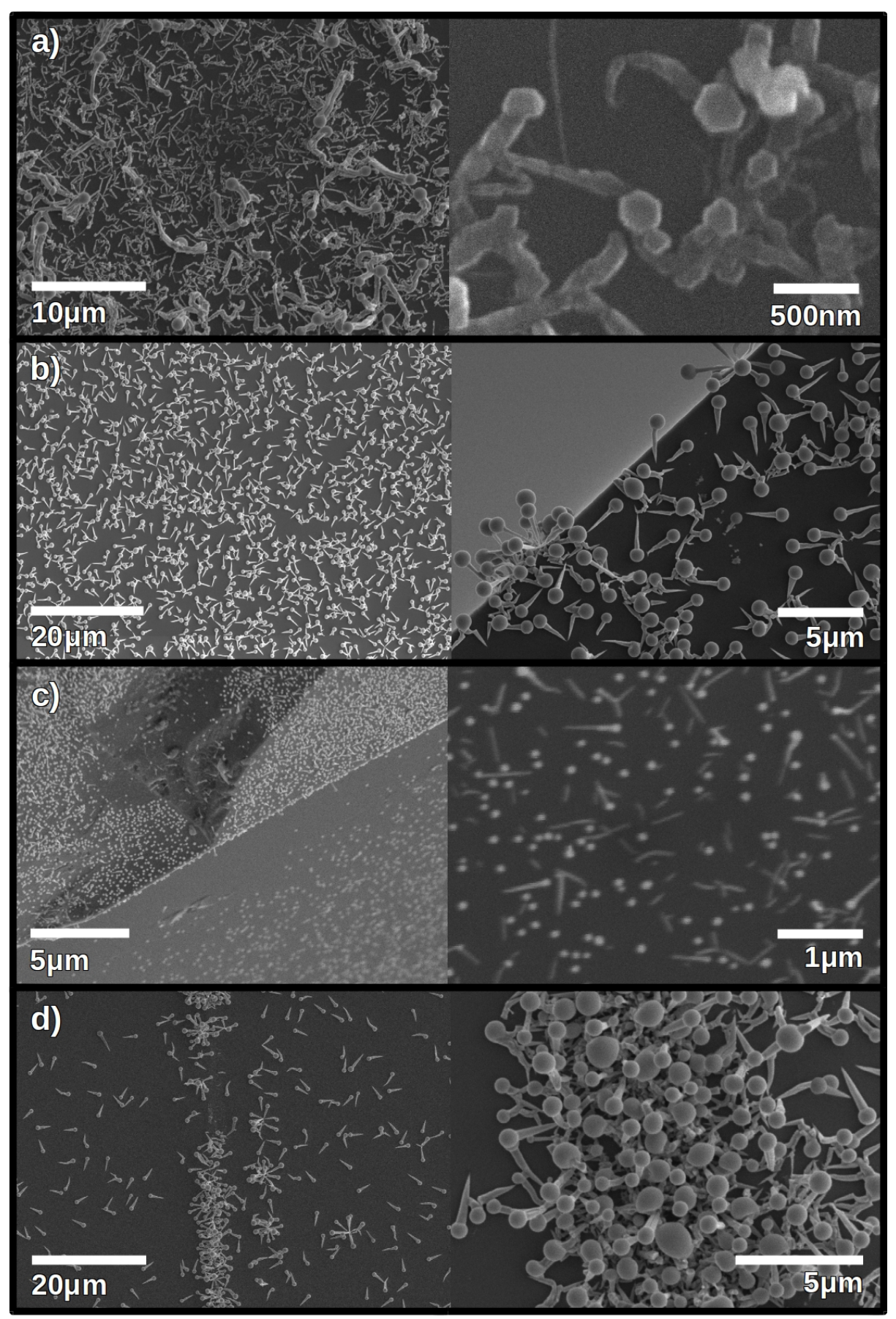

Figure 3.5: SEM micrographs of $2 \mathrm{p}-\mathrm{CVD}$ with $\mathrm{H}_{2} \mathrm{O}$. (a) $0.5 \mathrm{~s}$ gallium pulse; $2.0 \mathrm{~s}$ $\mathrm{H}_{2} \mathrm{O}$ pulse at $500{ }^{\circ} \mathrm{C}$. (b) $0.2 \mathrm{~s}$ gallium pulse; $0.1 \mathrm{~s} \mathrm{H}_{2} \mathrm{O}$ pulse at $500{ }^{\circ} \mathrm{C}$. (c) $0.2 \mathrm{~s}$ gallium pulse; $0.1 \mathrm{~s} \mathrm{H}_{2} \mathrm{O}$ pulse at $450{ }^{\circ} \mathrm{C}$. (d) $0.5 \mathrm{~s}$ gallium pulse; $0.5 \mathrm{~s} \mathrm{H}_{2} \mathrm{O}$ pulse at $450{ }^{\circ} \mathrm{C}$. 
The cone shape demonstrates that the decomposition of $\mathbf{2}$ is now on a similar kinetic time scale as the reaction of $\mathbf{2}$ to form gallium oxide. As the experiment progresses, the gallium droplet increases in diameter, which increases the diameter of the crystal it is templating. This suggests that controlling the partial pressure of water could lead to fine control over the shape of the deposited crystal. This is currently a subject of ongoing research within our group.

When the deposition temperature was lowered but the $\mathrm{Ga}: \mathrm{H}_{2} \mathrm{O}$ pulse ratio was kept constant, smaller features were accessible, showing further shape control by deposition temperature (Figure 3.5c). Deposition at $450{ }^{\circ} \mathrm{C}$ gave a similar but much smaller "ice cream cone" morphology. At $450{ }^{\circ} \mathrm{C}$, the droplet diameters were approximately 100-150 nm and the cones were approximately $50-75 \mathrm{~nm}$ in width. Additionally, when the amount of water during a p-CVD process was increased such that the ratio of the pulses of 2 to $\mathrm{H}_{2} \mathrm{O}$ was 1:1 but the temperature was kept at $450{ }^{\circ} \mathrm{C}$, the features increased in size (Figure 3.5d). The overall size of these structures was very similar to those obtained at $500{ }^{\circ} \mathrm{C}$ with a lower water pulse ratio. It should be noted, however, that at lower temperatures there was much less surface coverage of the substrate by these structures than at higher temperatures. By controlling the ratio of 2 to water along with deposition temperature during a p-CVD process, the level of coverage and overall structure size can be controlled.

A preliminary experiment was performed to investigate the effects of oxygen on 2 during a p-CVD process. In this experiment a $0.5 \mathrm{~s} 2$ pulse was followed by a $0.5 \mathrm{~s} \mathrm{O}_{2}$ pulse, which was followed by a $0.5 \mathrm{~s} \mathrm{H}_{2} \mathrm{O}$ pulse at $500{ }^{\circ} \mathrm{C}$. The resulting structures were markedly different from those produced from just 2 and $\mathrm{H}_{2} \mathrm{O}$ (Figure $3.7)$. With the introduction of $\mathrm{O}_{2}$, long $(>10 \mu \mathrm{m})$ wires with an average thickness of approximately $250 \mathrm{~nm}$ were produced, and EDX analysis showed gallium and oxygen concentrations corresponding to $\mathrm{Ga}_{2} \mathrm{O}_{3}$. Notably, there was no gallium metal droplet at the end of the wire. These wires were shown to grow on both alumina (previously 


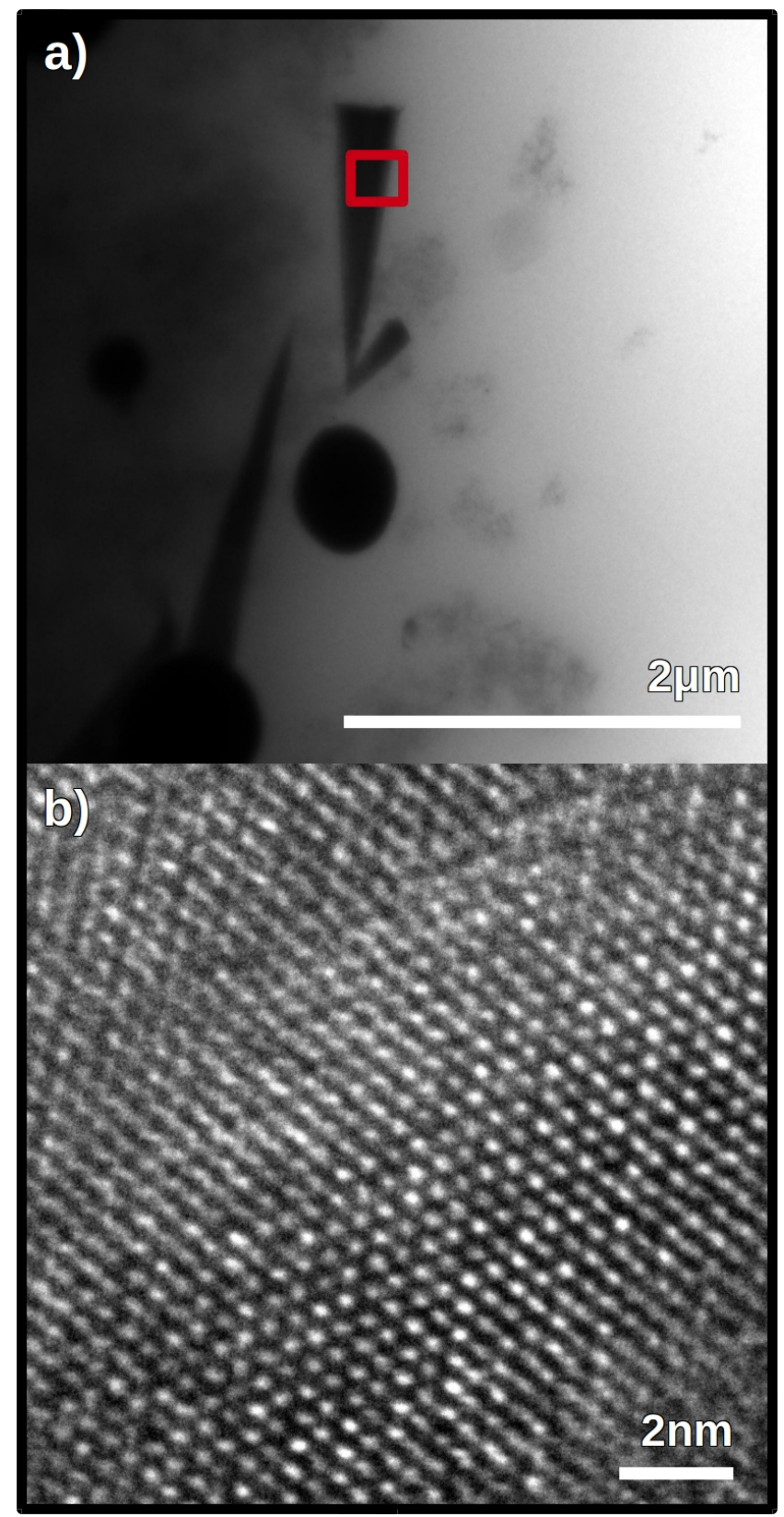

Figure 3.6: TEM micrographs of p-CVD of 2 with $\mathrm{H}_{2} \mathrm{O}$ at $500{ }^{\circ} \mathrm{C}$. Pulse program used: $0.2 \mathrm{~s}$ gallium pulse; $0.1 \mathrm{~s} \mathrm{H}_{2} \mathrm{O}$ pulse. (a) A wide-view of the structures produced under these conditions. (b) Crystallinity of the inset in (a). 


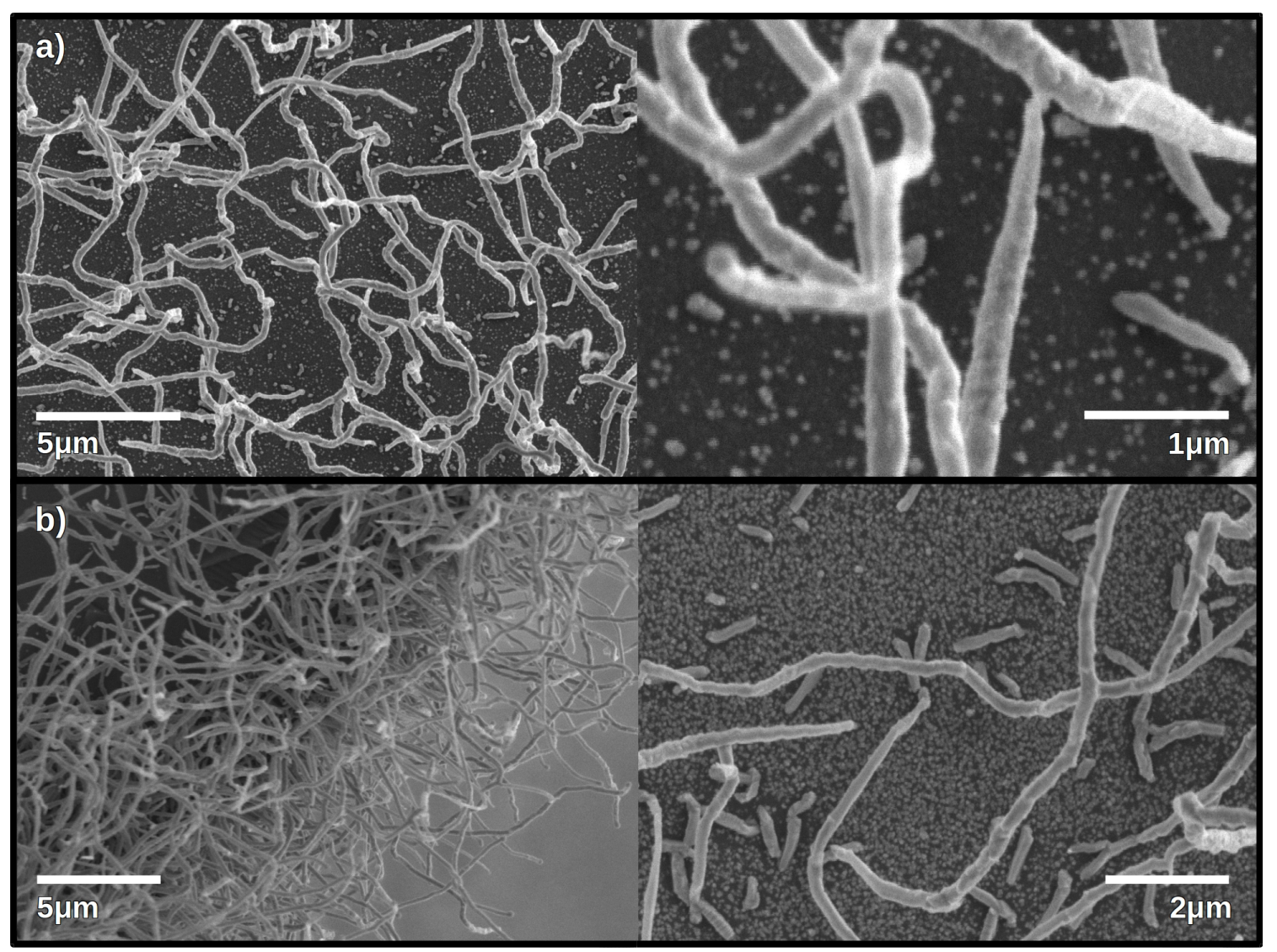

Figure 3.7: SEM micrographs of 2 p-CVD with $\mathrm{H}_{2} \mathrm{O}$ and $\mathrm{O}_{2}$ at $500{ }^{\circ} \mathrm{C}$. Pulse sequence was $0.5 \mathrm{~s}$ gallium pulse; $0.5 \mathrm{~s} \mathrm{O}_{2}$ pulse; $0.5 \mathrm{~s} \mathrm{H}_{2} \mathrm{O}$ pulse. (a) On $772 \AA$ of alumina substrates. (b) $\mathrm{On} \mathrm{Si}(100)$ with thermally-grown surface oxide. 
deposited by ALD, Figure 3.7a and on oxidized silica (Figure 3.7b) with similar wire sizes. Alumina was used as a substrate in addition to oxidized silicon to observe any nucleation differences between substrates with different types and densities of hydroxyl-terminated surfaces. There also appeared to be a relatively uniform mat of nanoparticles ( $<100 \mathrm{~nm}$ particle size) grown on the substrates in addition to the wires. The coverage of nanoparticles is much greater on the $\mathrm{Si} / \mathrm{SiO}_{2}$ substrate than on the alumina substrate. Here $\mathbf{2}$ appears to be forming gallium oxide both by reacting with the water as well as undergoing a redox reaction with the oxygen:

$$
\begin{aligned}
& \left\|-\mathrm{Ga}\left(\mathrm{N}^{i} \mathrm{Pr}\right)_{2} \mathrm{CMe}+\frac{1}{2} \mathrm{H}_{2} \mathrm{O} \longrightarrow\right\|-\mathrm{Ga}-\mathrm{OH}+\mathrm{MeC}\left(\mathrm{N}^{i} \mathrm{Pr}\right)\left(\mathrm{NH}^{i} \mathrm{Pr}\right) \\
& 2\left\|-\mathrm{Ga}^{0}+\frac{3}{2} \mathrm{O}_{2} \longrightarrow\right\|-\mathrm{Ga}_{2} \mathrm{O}_{3}
\end{aligned}
$$

There also appears to be very slow growth at nucleation sites on the substrate relating to the redox reaction, which are not present when only water is used as a co-reactant.

\subsection{Additional Results}

\section{Further depositions without a co-reactant}

Given that 2 undergoes self-seeding CVD to gallium metal at moderate temperatures, an attempt was made to control the size and size distribution of the gallium particles deposited by p-CVD. The ability to finely tune the size of group 13 metal nanoparticles has significant implications in surface-enhanced Raman spectroscopy (SERS) applications, as these nanoparticles are typically plasmonic in the ultravi-

olet region. ${ }^{77,86,87}$ So, further experiments where only 2 was dosed into the reactor chamber were performed and the results can be found in Figure 3.8 and in Table 3.2. Similar results were obtained to published results found in Figure 3.3. However, analysis of particle size shows that the average diameter of the gallium particles can be 


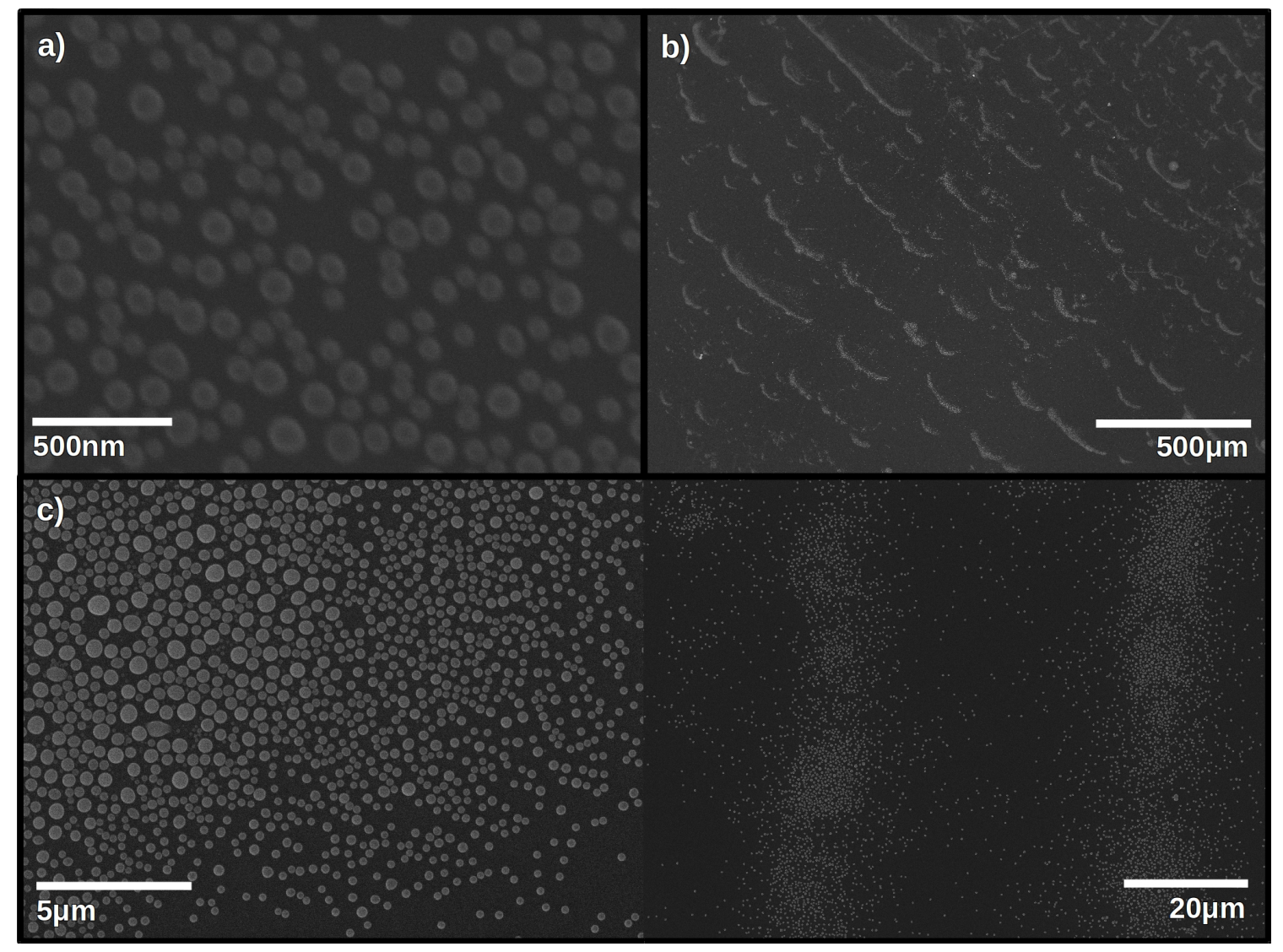

Figure 3.8: SEM micrographs of further p-CVD experiments with $\mathbf{2}$ but without the use of a co-reactant. a) shows 300 cycles of $0.2 \mathrm{~s}$ pulses of 2 at $450{ }^{\circ} \mathrm{C}$. b) shows 300 cycles of $0.1 \mathrm{~s}$ pulses of 2 at $425^{\circ} \mathrm{C}$. c) (bottom-left and bottom-right panels) shows 300 cycles of $0.1 \mathrm{~s}$ pulses of 2 at $500{ }^{\circ} \mathrm{C}$. 
controlled via deposition parameters. By lowering the exposure of $\mathbf{2}$ to the substrate (by lowering the pulse length or the total number of cycles), the average particle size and the overall distribution can be reduced. What seems to make the largest contribution to the average particle size, though, is lowering the deposition temperature. It is intuitive why the particle size increases when exposure of the precursor increases because introducing more material causes the growing particles to become larger. It is not immediately clear why lowering the temperature produces smaller particles. A higher temperature should increase the rate of nucleation on the substrate (and on growing particles) and a denser mat of particles with overall smaller size should result. These larger particles produced at higher temperature must then occur through Ostwald ripening or coalescing of smaller particles on the surface. Looking at Figure 3.8b and 3.8c-right it can be seen that the particles congregate in certain areas of the substrate and almost form "wave-like" structures. The "waves" in Figure 3.8 actually follow the direction of the nitrogen flowing into the reactor. This indicates that the mobility of the growing gallium nanoparticles is very high, and the increased mobility at higher temperatures for extended periods of time (especially after reaction is complete and the reactor cools to room temperature over many hours) is responsible for increased particle size. This is not entirely unsurprising given that gallium metal is molten at reaction conditions. However, even at reduced temperature and reduced exposure, a uniform distribution of plasmonic gallium nanoparticles was not reliably produced by p-CVD of 2 .

\section{Effect of TMA and $\mathrm{H}_{2} \mathrm{O}$ on gallium nanoparticles}

Since the gallium nanoparticles produced from p-CVD of $\mathbf{2}$ could not be reliably controlled (previous section), perhaps if the mobility of the particles could be controlled there would be less Ostwald ripening or coalescence resulting in smaller particles. It was thought that if the particles were coated with a very thin ceramic immedi- 
Table 3.2: Gallium metal particle sizes obtained when undergoing self-seeding p-CVD.

$\begin{array}{cccc}\begin{array}{c}\text { Ga pulse } \\ (\mathrm{s})\end{array} & \begin{array}{c}\text { reactor temperature } \\ \left({ }^{\circ} \mathrm{C}\right)\end{array} & \begin{array}{c}\text { number of cycles } \\ \text { average particle diameter } \\ (\mathrm{nm} \pm \text { S.D. })\end{array} \\ 0.5 & 500 & 500 & 319 \pm 242 \\ 0.1 & 500 & 300 & 298 \pm 88 \\ 0.1 & 500 & 100 & 162 \pm 18 \\ 0.2 & 450 & 300 & 82 \pm 23 \\ 0.2 & 450 & 300 & 94 \pm 30^{a} \\ 0.1 & 450 & 300 & 239 \pm 28^{b}\end{array}$

${ }^{a}$ These particles were further reacted with pulses of TMA and $\mathrm{H}_{2} \mathrm{O}$; see subsequent section for more details. ${ }^{b}$ These particles were further reacted with pulses of $\mathrm{O}_{2}$; see subsequent section for more details.

ately after the particles of desired size were deposited then that would reduce the mobility. To accomplish this, after exposing a substrate to $\mathbf{2}$ without co-reactant, the particles would be exposed to alternating doses of TMA and $\mathrm{H}_{2} \mathrm{O}$, a well-known ALD process for producing aluminum oxide. ${ }^{20}$ The results of this experiment can be found in Figure 3.9 and the resulting average particle size in Table 3.2. In this experiment the substrate was exposed to 300 cycles of 0.1 s pulses of 2 followed by 70 cycles of $\mathrm{TMA}(0.1 \mathrm{~s}$ pulse $) / \mathrm{H}_{2} \mathrm{O}(0.1 \mathrm{~s}$ pulse $)$ at $450{ }^{\circ} \mathrm{C}$. 70 cycles of $\mathrm{TMA} / \mathrm{H}_{2} \mathrm{O}$ was chosen to give roughly $5 \mathrm{~nm}$ of alumina (ALD growth per cycle (GPC) of alumina: $0.7 \AA$ /cycle). ${ }^{19}$ As can be seen in Figure 3.9 a very uniform mat of particles with an average size of $94 \pm 30 \mathrm{~nm}$ (Table 3.2) was deposited and no "waves" of particles were produced as a result of the mobility of the particles at high temperature. The size of the particles is slightly larger than the previously produced particles without the addition of TMA/ $\mathrm{H}_{2} \mathrm{O}$ (Table 3.2) and agrees with a roughly $5 \mathrm{~nm}$ coating. Qualitative EDX results showed presence of both aluminum and gallium in this sample. Even with a uniform size distribution these particles did not exhibit any plasmonic behaviour by UV-visible spectroscopy (UV-vis). At such elevated temperatures, it is known that TMA can undergo CVD behaviour, ${ }^{19}$ so the alumina coating is possibly not deposited in an ALD process. As well, the homogeneity of the particles is unknown and it is possible that there is aluminum within the gallium particles. It is 




Figure 3.9: SEM micrographs of p-CVD with 2 without a co-reactant (300 cycles of $0.1 \mathrm{~s}$ pulses of 2 ) followed by 70 cycles of $\mathrm{TMA} / \mathrm{H}_{2} \mathrm{O}$ at $450{ }^{\circ} \mathrm{C}$.

possible that the particles were not plasmonic for these reasons. Unfortunately, using this method no nanoparticle films produced (by changing temperature or exposure of 2) led to a plasmonic response.

\section{Effect of $\mathrm{O}_{2}$}

It was found that the addition of both $\mathrm{H}_{2} \mathrm{O}$ and $\mathrm{O}_{2}$ as co-reactants during p-CVD of 2 produced wires and nanoparticles. To study the effect of just $\mathrm{O}_{2}$ as a co-reactant, p-CVD experiments were carried out with 2 and $\mathrm{O}_{2}$. Figure 3.10 shows SEM micrographs of two different p-CVD experiments with $\mathrm{O}_{2}$ as a co-reactant. In a typical p-CVD process where the reactants are dosed sequentially, only clusters of wires are produced (Figure 3.10a). These wires have a much smaller diameter than in the $\mathrm{O}_{2}$ and $\mathrm{H}_{2} \mathrm{O}$ p-CVD experiments and have long straight sections with well-defined corners unlike the highly curved wires produced with both $\mathrm{O}_{2}$ and $\mathrm{H}_{2} \mathrm{O}$. This leads to the inference that wires produced with just $\mathrm{O}_{2}$ may be more crystalline (gallium oxide) than when $\mathrm{H}_{2} \mathrm{O}$ is also introduced, although there is no TEM or X-ray diffraction (XRD) data to support this. In Figure 3.10b gallium particles were deposited with 300 doses of 0.1 s 2 followed by 300 doses of 0.1 s $\mathrm{O}_{2}$ at $450{ }^{\circ} \mathrm{C}$. These structures are markedly different from those deposited in Figure 3.10a as particles were produced instead of wires. These particles show a definite lack of spherical symmetry and are covered in cavities. Oxygen introduced after the gallium metal particles are deposited is only able to oxidize the existing particles and does not promote growth away from 
the already existing particles. Particle size analysis shows relatively large particles (Table 3.2) of $239 \pm 28 \mathrm{~nm}$, which are much larger than the particles deposited in a similar p-CVD experiment (Table 3.2; $82 \pm 23 \mathrm{~nm}$ ). Crystalline gallium oxide generally has a much larger unit cell than crystalline gallium metal ${ }^{85,88}$ so it is possible that the oxidation of the gallium particles to gallium oxide causes an expansion of the particles. The cause of the cavities may be due to incomplete oxidation of the entire gallium particle during the oxygen dosing. If there was remaining gallium metal in the centre of the particle, when the reactor was cooled to room temperature and the gallium metal solidified reducing the density, the particles would cavitate slightly producing the observed structures. The possible presence of leftover gallium metal in centre means that kinetically $\mathrm{O}_{2}$ as a co-reactant produces gallium oxide very slowly, however, from the previous experiment $\mathrm{O}_{2}$ also acts as a directing agent for wire growth. This aids in explaining the previous experiments with $\mathrm{H}_{2} \mathrm{O}$ (and $\mathrm{O}_{2}$ ). It seems $\mathrm{H}_{2} \mathrm{O}$ very rapidly produces gallium oxide, but has less ability to direct growth; short "ice cream cones" are produced with just $\mathrm{H}_{2} \mathrm{O}$, but very large, curved wires are produced with both $\mathrm{H}_{2} \mathrm{O}$ and $\mathrm{O}_{2}$. It seems highly possible, then, that by carefully controlling the doses of co-reactants, the morphology of the growing gallium oxide can be controlled. This would be an obvious step for future work for p-CVD with this compound.

\subsection{Conclusions}

It has been shown that a novel gallium-containing precursor forms an unusually stable mono-layer on silica and alumina that undergoes CVD-like behaviour at $450{ }^{\circ} \mathrm{C}$ and above. The precursor itself undergoes self-seeding single-source behaviour to gallium metal without the addition of a co-reactant. With the addition of $\mathrm{H}_{2} \mathrm{O}$ ice cream cone gallium metal/gallium oxide structures are produced at a variety of sizes. The 


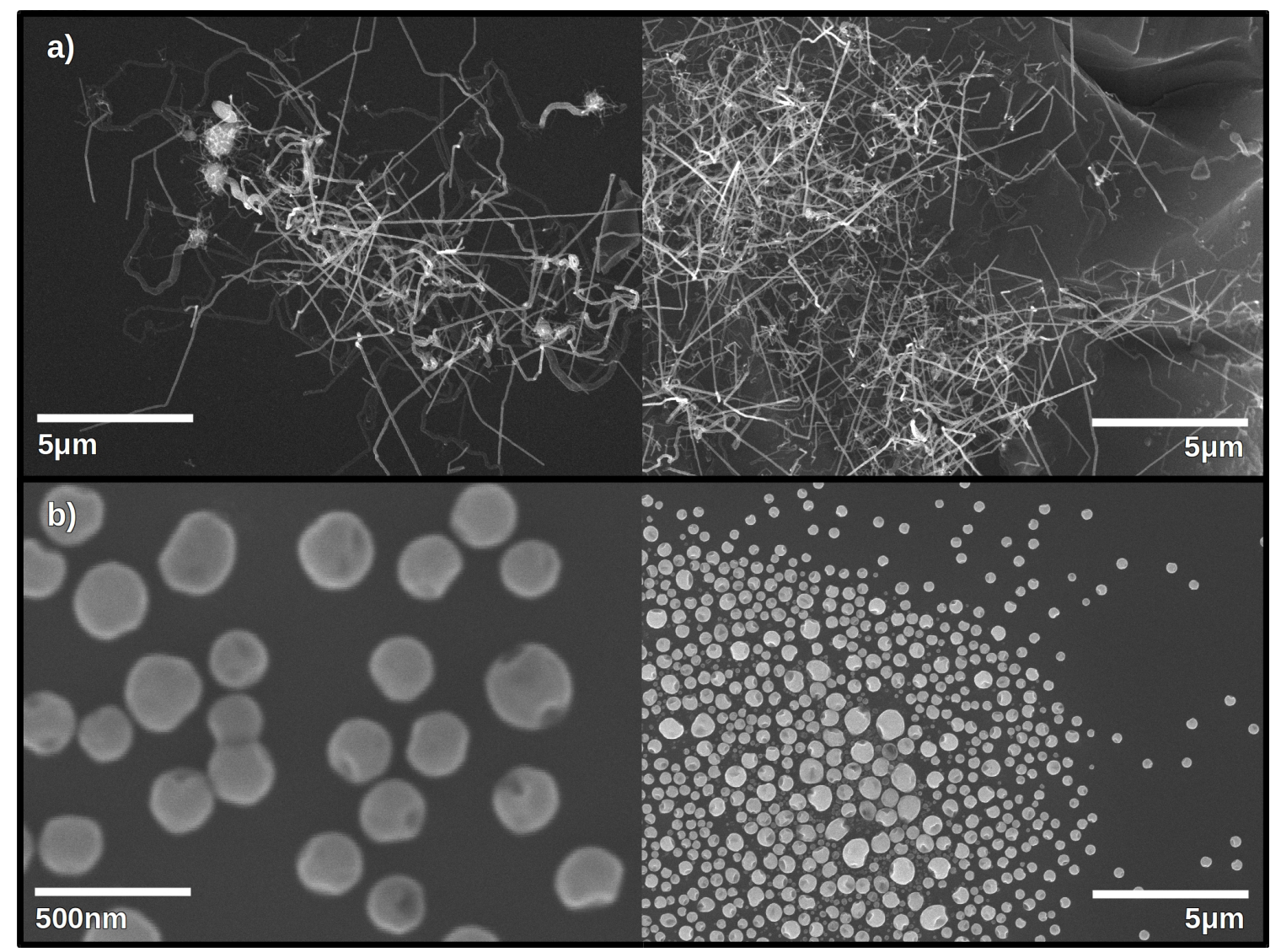

Figure 3.10: SEM micrographs of p-CVD with 2 and $\mathrm{O}_{2}$ co-reactant. a) is 500 cycles of sequential pulses of $2(0.2 \mathrm{~s})$ and $\mathrm{O}_{2}(0.2 \mathrm{~s})$ at $500{ }^{\circ} \mathrm{C}$. b) is $3000.1 \mathrm{~s}$ pulses of 2 followed by $3000.1 \mathrm{~s}$ pulses of $\mathrm{O}_{2}$ at $450{ }^{\circ} \mathrm{C}$. 
size of these features has been found to be a function of the ratio of $\mathrm{H}_{2} \mathrm{O}$ to 2 during the pulse sequence and the temperature of deposition. High $\mathrm{H}_{2} \mathrm{O}$ content and high temperature produce larger features. The introduction of $\mathrm{O}_{2}$ to the system as a coreactant produces gallium oxide nanowires on both silica and alumina. In addition to the wires there is a mat of nanoparticles on the substrate. With only $\mathrm{O}_{2}$ as a co-reactant there is no mat of particles, only very straight nanowires. Additionally, dosing $\mathrm{O}_{2}$ after producing gallium metal particles by p-CVD produces larger particles with cavities showing that without continued addition of $\mathbf{2}$ only oxidizes existing particles. By introducing doses of TMA $/ \mathrm{H}_{2} \mathrm{O}$ after performing p-CVD with just 2 successfully prevents mobility of the gallium metal particles but possibly incorporate alumin(a/um) into the gallium particles. The ability to grow these interesting gallium metal/gallium oxide morphologies lend themselves to a study for a variety of optical and electronic applications. In addition, the p-CVD pulse programs used and resultant structures opens up the possibility for potential shape control of a whole host of interesting gallium metal/gallium oxide substructures. 


\section{Chapter 4}

\section{Synthesis and Thermal Characterization of Novel, Heteroleptic Aluminum Hydrides}

Modified from a manuscript orginally submitted as:

Pallister, P.J., ${ }^{\dagger}$ Pallister, J.R., ${ }^{\dagger}$ Dao, H.A., ${ }^{\ddagger}$ Yap, G.P.A.,${ }^{\ddagger}$ and Barry, S.T. ${ }^{\dagger}{ }^{\text {Synthesis }}$ and Thermal Characterization of Novel, Heteroleptic Amidinato and Guanidinato Aluminum Hydrides, Dalton Trans., submitted but not accepted.

${ }^{\dagger}$ Department of Chemistry, Carleton University, 1125 Colonel By Drive, Ottawa, Ontario, K1S 5B6, Canada

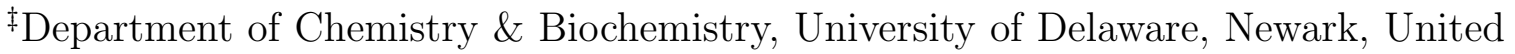
States 


\subsection{Abstract}

Vapour-phase deposition of aluminium thin films continues to require the development of volatile, thermally stable precursors that preferably form a stable, chemisorbed monolayer on a substrate. These precursor requirements are necessary for the development of a valid ther-



Figure 4.1: Table of Contents graphic used for publication described in Chapter 4 mal CVD or ALD process. As yet, there are no aluminium precursors that are able to deposit aluminium metal via a thermal ALD process. Here we report the synthesis of four new aluminium amidinato-and guanidinato-and one hexamethyldisilazide-hydrido compounds $\left(\mathrm{Et}_{2} \mathrm{NC}\left(\mathrm{N}^{i} \mathrm{Pr}\right)_{2}\right)_{2} \mathrm{AlH}(\mathbf{4}),\left({ }^{i} \operatorname{PrHNC}\left(\mathrm{N}^{i} \mathrm{Pr}\right)_{2}\right)_{2} \mathrm{AlH}(5)$, $\left({ }^{i} \mathrm{Pr}_{2} \mathrm{NC}\left(\mathrm{N}^{i} \mathrm{Pr}\right)_{2}\right)_{2} \mathrm{AlH}(\mathbf{6}),\left(\mathrm{MeC}\left(\mathrm{N}^{i} \mathrm{Pr}\right)_{2}\right)_{2} \mathrm{AlH}$ (7) $\left(\mathrm{Me}_{3} \mathrm{Si}\right)_{2} \mathrm{NAlH}_{2} \cdot \mathrm{NMe}_{2} \mathrm{Et}$ (8). 4, 6, and 7 are studied by single-crystal X-ray diffraction. The thermal stability of 4 - 8 and a previously synthesized aluminium hydride $\left(\mathrm{Me}_{2} \mathrm{NC}\left(\mathrm{N}^{i} \mathrm{Pr}\right)_{2}\right)_{2} \mathrm{AlH}(3)$ were examined by TGA and solution-phase decomposition monitored by ${ }^{1} \mathrm{H}$ HR-NMR. 3 - 6 show a variability in thermal behaviour both in solution and in the solid state. In particular, the solution-phase decomposition of $\mathbf{3}$ was found to produce two formamidinate aluminium complexes, suggesting that the compound undergoes carbodiimide deinsertion with rearrangement of the ligand framework followed by rapid reinsertion of carbodiimide. Compound $\mathbf{7}$ and $\mathbf{8}$, however, was found to be very thermally stable and volatile at relatively low temperatures. This demonstrates that the use of guanidinate, amidinate and azide ligands can produce a heteroleptic aluminium hydride complexes that are easily isolable and potentially viable for vapour phase deposition of aluminium metal. 


\subsection{Introduction}

Aluminium metal is an interesting deposition target for chemical deposition methods like CVD and ALD. Due to its high electropositivity and its ability to easily form an oxide passivation layer, the deposition of aluminium metal can be quite difficult to achieve. Currently, there are some processes known for depositing aluminium via CVD. ${ }^{89}$ There are currently only a few reports of aluminium metal deposition by ALD and they all use trimethylaluminium as the aluminium-containing precursor and hydrogen plasma as the reducing agent. ${ }^{90-92}$ PE-ALD can be advantageous to process development due to the lower deposition temperatures used when compared to conventional thermal ALD. However, radical recombination during the plasma pulse can lead to spatial nonuniformity when depositing on very high aspect ratio surfaces and the exposure to plasma can be detrimental to other device components, such as gate oxides or polymers. ${ }^{93}$ Therefore, it would be beneficial to have a thermal ALD process for aluminium metal available to avoid these shortcomings. Currently there is no thermal ALD process for the deposition of aluminium metal. Developing an ALD process for a given material requires that the gaseous precursors exhibit a self-limiting monolayer formation upon chemisorption to a reactive surface.

Aluminium hydrides are compounds commonly investigated as catalysts or reaction intermediates in hydroformylation, olefin metathesis, and hydrogen exchange reactions. ${ }^{94}$ However, alane itself is a highly versatile starting material for producing heteroleptic aluminium hydride compounds that could be suitable for controlled vapour deposition by ALD. In fact, aluminium amidohydrides have shown promise as volatile, relatively stable compounds that may undergo controlled decomposition

to aluminium metal at elevated temperatures. ${ }^{95-97}$ The amidinate and guanidinate classes of ligands are of particular interest in ALD precursor design as they possess many of the desirable characteristics needed for an ALD precursor. The steric bulk 
of this class of ligand has the potential to aid in self-limiting behaviour when allowed to react with a surface. ${ }^{75}$ The peripheral substituents are also highly tunable which gives access to a number of compounds with potentially tunable precursor properties, such as volatility and thermal stability. A review on the coordination chemistry of amidinate and guanidinate ligands by Edelmann ${ }^{98}$ and Bailey et al. ${ }^{99}$ gives an excellent description of the tunability and applicability of these ligands for materials applications.

There are few reports of amidinato-or guanidinato-aluminum hydrides ${ }^{96,100,101}$ and they all employ relatively bulky substituents on the amidinate or guanidinate ligand. This work reports the synthesis and characterization for some novel amidinato-and guanidinato-aluminum hydrides. As well, an investigation into the thermal characteristics of these compounds is discussed and compared to a previously reported

aluminium hydride with a similar ligand system. ${ }^{102}$ The thermal characteristics of $\mathbf{8}$, an aluminum hydride with a similarly bulky ligand, is compared to 3-7. A compound similar to 8 has been previously synthesized ${ }^{97}$ but with a different base adduct and was reported to decompose to elemental aluminum. However there was no quantitative thermal analysis reported for this compound. As such, the suitability of this class of compounds as vapour deposition precursors for aluminium metal will be addressed.

\section{$4.3 \quad$ Experimental}

\section{General Procedures}

All manipulations were performed in an MBraun Unilab nitrogen glove box or using standard air-free Schlenk techniques. Alane $N, N$-dimethylethylamine complex solution (0.5 M in toluene), aluminum chloride (reagent grade, 98\%), trimethyl aluminum (2.0 M in hexanes), butyl lithium (2.5 M in hexanes), methyl lithium (1.6 M in diethyl ether), lithium dimethylamide (95\%), $N, N^{\prime}$-diisopropylcarbodiimide (99\%), 
diethylamine $(\geqslant 99.5 \%)$, isopropylamine $(\geqslant 99.5 \%)$, diisopropylamine $(\geqslant 99.5 \%)$, and hexamethyldisilizane (99.9\%) were purchased from Sigma-Aldrich Co. and used as received. Reagent grade, anhydrous solvents: toluene (99.5\%), diethyl ether (99\%), and hexanes (99\%), were purchased from Caledon Laboratories Ltd. These solvents were stored in an MBraun solvent purification system (MB-SPS) and stored over molecular sieves $(3 \AA)$ in a glove box prior to use. $\left(\mathrm{Me}_{2} \mathrm{NC}\left(\mathrm{N}^{i} \mathrm{Pr}\right)_{2}\right)_{3} \mathrm{Al},{ }^{76}\left(\mathrm{MeC}\left(\mathrm{N}^{i} \mathrm{Pr}\right)_{2}\right)_{3} \mathrm{Al},{ }^{103}$ $\mathrm{Al}_{2}\left(\mathrm{NR}_{2}\right)_{6},{ }^{104}\left(\mathrm{Et}_{2} \mathrm{NC}\left(\mathrm{N}^{i} \mathrm{Pr}\right)_{2}\right) \mathrm{Li},{ }^{99}\left({ }^{i} \operatorname{Pr}_{2} \mathrm{NC}\left(\mathrm{N}^{i} \mathrm{Pr}\right)_{2}\right) \mathrm{Li},{ }^{99}$ and $N, N^{\prime}, N^{\prime \prime}$-triisopropyl guanidine ${ }^{105}$ were prepared following the literature procedures indicated. Thermogravimetric analysis was performed on a TA instruments TGA Q500. ${ }^{1} \mathrm{H}$ and ${ }^{13} \mathrm{C}\left\{{ }^{1} \mathrm{H}\right\}$ HR-NMR spectra were recorded on a Bruker Avance-300 (300 MHz ${ }^{1} \mathrm{H}$ Larmor frequency) spectrometer. Chemical shifts $(\delta)$ are expressed in ppm. All HR-NMR spectra were recorded at $298 \mathrm{~K}$ in deuterated benzene (Sigma-Aldrich, 96.6 atom\% D) using the residual solvent peak as reference $\left(\delta_{H}=7.16 \mathrm{ppm}, \delta_{C}=128.06 \mathrm{ppm}\right)$.

\section{Single-crystal X-ray Diffraction}

X-ray structural analysis for 4, 6, and 7: Crystals were mounted using viscous oil onto plastic mesh and cooled to the data collection temperature. Data were collected on a Bruker-AXS APEX CCD diffractometer with graphite-monochromated Mo-K $\alpha$ radiation $(\lambda=0.71073 \AA)$. Unit cell parameters were obtained from 60 data frames, $0.3^{\circ} \omega$, from three different sections of the Ewald sphere. No symmetry higher than triclinic was observed for $\mathbf{6}$. The systematic absences in the diffraction data are uniquely consistent with $C c$ and $C 2 / c$ for 7 , and, uniquely, with $P 2_{1} 2_{1} 2_{1}$ for 4 . Solution in the centrosymmetric space group options for $\mathbf{4}$ and $\mathbf{6}$ yielded chemically reasonable and computationally stable results of refinement. The data-sets were treated with SADABS absorption corrections based on redundant multiscan data. ${ }^{106}$ The structures were solved using direct methods and refined with full-matrix, least-squares procedures on $F^{2}$. Two chemically identical but symmetry unique molecules of the 
compound were found in the asymmetric unit of $\mathbf{6}$. The compound molecule is located at a two-fold axis in 7 . All non-hydrogen atoms were refined with anisotropic displacement parameters. Hydride ligands were located from the difference map and assigned isotropic parameters equal to $1.2 U_{\text {eq }}$ of the attached aluminum metal. All other hydrogen atoms were treated as idealized contributions. Structure factors are contained in the SHELXTL 6.12 program library. ${ }^{106}$ The CIF has been deposited under CCDC 1025733-1025735.

\section{Solution-phase NMR Thermal Analysis}

Pure, isolated compound (3-8) was placed in a thick-walled $5 \mathrm{~mm}$ HR-NMR tube with dry $d_{6}$-benzene (kept on $4 \AA$ molecular sieves) in a nitrogen-filled drybox. Tube was capped and removed from the dry box and placed under nitrogen via syringe through the cap. The lower half of the tube was placed in liquid nitrogen for several minutes to freeze the solution. The head-space of the tube placed under roughing pump vacuum and flame-sealed with a propane torch. The tube was allowed to sit at room temperature for several hours to allow the solution to melt. The tube was then heated in an isothermal oven. The tube was allowed to cool to room temperature before running a ${ }^{1} \mathrm{H}$ HR-NMR spectrum. The concentration of the species of interest is referenced to the residual solvent signal (benzene) to obtain a relative concentration of each species.

\section{Synthesis and Characterization}

\section{$\left(\mathrm{Me}_{2} \mathrm{NC}\left(\mathrm{N}^{i} \mathrm{Pr}\right)_{2}\right)_{2} \mathrm{AlH}(3)$}

In a $50 \mathrm{~mL}$ pressure vessel, $\left(\mathrm{Me}_{2} \mathrm{NC}\left(\mathrm{N}^{i} \mathrm{Pr}\right)_{2}\right)_{3} \mathrm{Al}(1.050 \mathrm{~g}, 1.950 \mathrm{mmol})$ was dissolved in toluene $(30 \mathrm{~mL})$ with stirring. A solution of alane complexed with $N, N$ dimethylethylamine $(3.0 \mathrm{~mL}, 0.5 \mathrm{M}$ in toluene, $1.5 \mathrm{mmol}$ ) was added dropwise, in 
excess to $\left(\mathrm{Me}_{2} \mathrm{NC}\left(\mathrm{N}^{i} \mathrm{Pr}\right)_{2}\right)_{3} \mathrm{Al}$ and the pressure vessel was heated to $50{ }^{\circ} \mathrm{C}$ for $24 \mathrm{~h}$. The solution was concentrated under reduced pressure and left to crystallize at -30 ${ }^{\circ} \mathrm{C}$. Clear, colourless crystals of $\mathbf{3}$ were collected by filtration (0.916 g, $2.5 \mathrm{mmol}$, 85\%). m.p.: $61-64{ }^{\circ} \mathrm{C} .{ }^{1} \mathrm{H}$ HR-NMR $\delta_{H}\left(300 \mathrm{MHz}, \mathrm{C}_{6} \mathrm{D}_{6}\right): 4.25(1 \mathrm{H}$, br s, $\mathrm{Al}-H)$, $3.54\left(4 \mathrm{H}\right.$, sept, $\left.\mathrm{CH}\left(\mathrm{CH}_{3}\right)_{2}\right), 2.48\left(12 \mathrm{H}, \mathrm{s}, \mathrm{N}\left(\mathrm{CH}_{3}\right)_{2}\right), 1.40\left(24 \mathrm{H}, \mathrm{d}, \mathrm{CH}\left(\mathrm{CH}_{3}\right)_{2}\right) .{ }^{13} \mathrm{C}$ $\left\{{ }^{1} \mathrm{H}\right\} \mathrm{HR}-\mathrm{NMR} \delta_{C}\left(300 \mathrm{MHz}, \mathrm{C}_{6} \mathrm{D}_{6}\right): 169.47\left(\mathrm{NC}\left(\mathrm{N}\left(\mathrm{CH}_{3}\right)_{2}\right) \mathrm{N}\right), 46.14\left(C \mathrm{H}\left(\mathrm{CH}_{3}\right)_{2}\right)$, $39.27\left(\mathrm{~N}\left(\mathrm{CH}_{3}\right)_{2}\right), 25.06\left(\mathrm{CH}\left(\mathrm{C} \mathrm{H}_{3}\right)_{2}\right)$. MS: $m / z 367.3\left([\mathrm{M}-1]^{+}, 2.7 \%\right)$.

\section{$\left(\mathrm{Et}_{2} \mathrm{NC}\left(\mathrm{N}^{i} \mathrm{Pr}\right)_{2}\right)_{2} \mathrm{AlH}(4)$}

Diethylamine (1.90 g, $26.0 \mathrm{mmol})$ was diluted with diethyl ether $(40 \mathrm{~mL})$ and placed in a freezer $\left(-30^{\circ} \mathrm{C}\right)$ to cool. To this solution, butyl lithium $(10 \mathrm{~mL}, 2.5 \mathrm{M}$ in hexanes, $25 \mathrm{mmol}$ ) was added dropwise with stirring. After $1.5 \mathrm{~h}$, a solution of $N, N^{\prime}$-diisopropylcarbodiimide $(3.16 \mathrm{~g}, 25 \mathrm{mmol})$ diluted with diethyl ether $(15 \mathrm{~mL})$ was added dropwise to the reaction flask. The solution was left stirring overnight to form lithiated diethylguanidinate. The guanidinate solution was removed from the nitrogen-filled glove box and hydrolyzed with distilled water $(0.45 \mathrm{~mL}, 25 \mathrm{mmol})$. After 15 minutes, the reaction mixture was filtered by gravity to remove solid LiOH. The resultant solution of diethyl guanidine was concentrated and returned to the nitrogen-filled glove box. The guanidine solution was cooled in the freezer and added to a solution of alane complexed with $N, N$-dimethylethylamine $(19.0 \mathrm{~mL}, 0.5 \mathrm{M}$ in toluene, $9.5 \mathrm{mmol}$ ) in a $250 \mathrm{~mL}$ round bottom flask. The reaction was left to stir at room temperature overnight. The solution was concentrated under vacuum and left to crystallize at $-30^{\circ} \mathrm{C}$. Clear, colourless crystals of 4 were collected by filtration $(4.48 \mathrm{~g}$, $8.2 \mathrm{mmol}, 86 \%)$. m.p.: $117-119{ }^{\circ} \mathrm{C} .{ }^{1} \mathrm{H}$ HR-NMR $\delta_{H}\left(300 \mathrm{MHz}, \mathrm{C}_{6} \mathrm{D}_{6}\right): 4.62(1 \mathrm{H}, \mathrm{br}$ s, $\mathrm{Al}-\mathrm{H}), 3.52\left(4 \mathrm{H}\right.$, sept, $\left.\mathrm{C}\left(\mathrm{NCH}\left(\mathrm{CH}_{3}\right)_{2}\right)_{2}\right), 2.96\left(8 \mathrm{H}, \mathrm{q}, \mathrm{CN}\left(\mathrm{CH}_{2} \mathrm{CH}_{3}\right)_{2}\right), 1.42(24 \mathrm{H}$, d, $\left.\mathrm{NCH}\left(\mathrm{CH}_{3}\right)_{2}\right), 0.89\left(12 \mathrm{H}, \mathrm{t}, \mathrm{CN}\left(\mathrm{CH}_{2} \mathrm{CH}_{3}\right)_{2}\right) .{ }^{13} \mathrm{C}\left\{{ }^{1} \mathrm{H}\right\}$ HR-NMR $\delta_{C}(300 \mathrm{MHz}$, $\left.\mathrm{C}_{6} \mathrm{D}_{6}\right): 170.31\left(\mathrm{NC}\left(\mathrm{N}^{i} \mathrm{Pr}_{2}\right) \mathrm{N}\right), 47.16\left(\mathrm{CN}\left(\mathrm{CH}_{2} \mathrm{CH}_{3}\right)_{2}\right), 43.28\left(\mathrm{CNC}\left(\mathrm{CH}_{3}\right)_{2}\right), 25.98$ 
$\left(\mathrm{CN}\left(\mathrm{CH}_{2} \mathrm{CH}_{3}\right)_{2}\right), 14.32\left(\mathrm{CNC}\left(\mathrm{C} \mathrm{H}_{3}\right)_{2}\right)$. MS: $m / z 423.4\left([\mathrm{M}-1]^{+}, 100 \%\right)$.

\section{$\left({ }^{i} \mathrm{PrHNC}\left(\mathrm{N}^{i} \mathrm{Pr}\right)_{2}\right)_{2} \mathrm{AlH}(5)$}

A solution of alane complexed with $N, N$-dimethylethylamine $(25.0 \mathrm{~mL}, 0.5 \mathrm{M}$ in toluene, $12.5 \mathrm{mmol}$ ) was diluted with toluene $(100 \mathrm{~mL})$ in a $250 \mathrm{~mL}$ round bottom flask and placed in a freezer $\left(-30{ }^{\circ} \mathrm{C}\right)$ to cool for 10 minutes. Triisopropyl guanidine $(4.19 \mathrm{~g}, 22.6 \mathrm{mmol})$ was dissolved in hexanes and transferred to a dropping funnel. The alane solution was removed from the freezer and left to warm up to room temperature as the ligand solution was added at a rate of 15 drops per minute. Once the addition was complete, the reaction mixture was left to stir at room temperature overnight. The solution was concentrated under vacuum and left to crystallize at $-30{ }^{\circ} \mathrm{C}$. Clear, colourless crystals of $\mathbf{5}$ were collected by filtration $(4.18 \mathrm{~g}, 10.5$ mmol, 93\%). m.p.: $110-111{ }^{\circ} \mathrm{C} .{ }^{1} \mathrm{H}$ HR-NMR $\delta_{H}\left(300 \mathrm{MHz}, \mathrm{C}_{6} \mathrm{D}_{6}\right): 4.74(1 \mathrm{H}$, br s, $\mathrm{Al}-H), 3.54\left(2 \mathrm{H}\right.$, sept, $\left.\left.\mathrm{HNCH}\left(\mathrm{CH}_{3}\right)_{2}\right)\right), 3.51\left(4 \mathrm{H}\right.$, sept, $\left.\left.\mathrm{NCH}\left(\mathrm{CH}_{3}\right)_{2}\right)\right), 1.42(24 \mathrm{H}$, d, $\left.\mathrm{NCH}\left(\mathrm{CH}_{3}\right)_{2}\right), 0.89\left(12 \mathrm{H}, \mathrm{d}, \mathrm{HNCH}\left(\mathrm{CH}_{3}\right)_{2}\right) .{ }^{13} \mathrm{C}\left\{{ }^{1} \mathrm{H}\right\}$ HR-NMR $\delta_{C}(300 \mathrm{MHz}$,

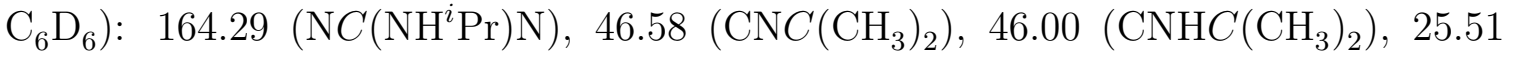
$\left(\mathrm{CNC}\left(\mathrm{CH}_{3}\right)_{2}\right), 24.52\left(\mathrm{CNHC}\left(\mathrm{CH}_{3}\right)_{2}\right)$. MS: $m / z 395\left([\mathrm{M}-1]^{+}, 24 \%\right)$. HRMS (EI) $m / z$ calc'd for $\left(\mathrm{AlN}_{6} \mathrm{C}_{20} \mathrm{H}_{45}-\mathrm{H}\right)^{+}$395.5956, found 395.3396.

\section{$\left({ }^{i} \mathrm{Pr}_{2} \mathrm{NC}\left(\mathrm{N}^{i} \mathrm{Pr}\right)_{2}\right)_{2} \mathrm{AlH}(6)$}

Diisopropylamine $(2.44 \mathrm{~g}, 24.0 \mathrm{mmol})$ was diluted with diethyl ether $(40 \mathrm{~mL})$ and placed in a freezer $\left(-30{ }^{\circ} \mathrm{C}\right)$ to cool. To this solution, methyl lithium $(15 \mathrm{~mL}, 1.6$ $\mathrm{M}$ in ether, $23.3 \mathrm{mmol}$ ) was added dropwise with stirring. After $1.5 \mathrm{~h}$, a solution of $N, N$ '-diisopropylcarbodiimide $(3.17 \mathrm{~g}, 24.0 \mathrm{mmol})$ diluted with diethyl ether $(15 \mathrm{~mL})$ was added dropwise to the reaction flask. The solution was left stirring overnight to form lithiated tetraisopropyl guanidinate. The reaction flask was removed from the nitrogen-filled glove box and opened to atmosphere. 1 equivalent of distilled wa- 
ter $(0.43 \mathrm{~mL}, 24 \mathrm{mmol})$ was added dropwise to this flask with stirring. After 15 minutes, the $\mathrm{LiOH}$ precipitate was filtered off and the resulting guanidine solution was concentrated under vacuum. The flask was returned to the glove box where it was cooled in the freezer $\left(-30{ }^{\circ} \mathrm{C}\right)$. In a $150 \mathrm{~mL}$ round bottom flask, alane complexed with $N, N$-dimethylethylamine $(24.0 \mathrm{~mL}, 0.5 \mathrm{M}$ in toluene, $12 \mathrm{mmol})$ was diluted with toluene $(30 \mathrm{~mL})$ and cooled to $-30{ }^{\circ} \mathrm{C}$. The guanidine ligand solution was added dropwise to the alane solution slowly and left to stir overnight. The volatiles were removed to isolate a yellow powder. The solid was recrystallized from toluene to yield colourless crystals of 6 (4.50 g, $9.4 \mathrm{mmol}, 78 \%)$. m.p.: 112-113 ${ }^{\circ} \mathrm{C} .{ }^{1} \mathrm{H}$ HR-NMR $\delta_{H}\left(300 \mathrm{MHz}, \mathrm{C}_{6} \mathrm{D}_{6}\right): 4.48(1 \mathrm{H}, \mathrm{br}$ s, $\mathrm{Al}-H), 3.74$ (4H, sept, $\left.\mathrm{C}\left(\mathrm{NCH}\left(\mathrm{CH}_{3}\right)_{2}\right)_{2}\right), 3.47\left(4 \mathrm{H}\right.$, sept, $\left.\mathrm{CN}\left(\mathrm{CH}\left(\mathrm{CH}_{3}\right)_{2}\right)_{2}\right), 1.44\left(24 \mathrm{H}, \mathrm{d}, \mathrm{C}\left(\mathrm{NCH}\left(\mathrm{CH}_{3}\right)_{2}\right)_{2}\right)$, $1.14\left(24 \mathrm{H}, \mathrm{d}, \mathrm{CN}\left(\mathrm{CH}\left(\mathrm{CH}_{3}\right)_{2}\right)_{2}\right) \cdot{ }^{13} \mathrm{C}\left\{{ }^{1} \mathrm{H}\right\}$ HR-NMR $\delta_{C}\left(300 \mathrm{MHz}, \mathrm{C}_{6} \mathrm{D}_{6}\right): 170.97$ $\left(\mathrm{NC}\left(\mathrm{N}^{i} \mathrm{Pr}_{2}\right) \mathrm{N}\right), 50.46\left(\mathrm{NC}\left(\mathrm{CH}_{3}\right)_{2}\right), 47.00\left(\mathrm{CN}\left(\mathrm{C}\left(\mathrm{CH}_{3}\right)_{2}\right)_{2}\right), 26.27\left(\mathrm{NC}\left(\mathrm{C} \mathrm{H}_{3}\right)_{2}\right), 24.31$ $\left(\mathrm{CN}\left(\mathrm{C}\left(\mathrm{CH}_{3}\right)_{2}\right)_{2}\right)$. MS: $m / z$ 479([M-1 $\left.]^{+}, 100 \%\right)$.

\section{$\left(\mathrm{MeC}\left(\mathrm{N}^{i} \mathrm{Pr}\right)_{2}\right)_{2} \mathrm{AlH}(7)$}

Ligand Exchange In a $50 \mathrm{~mL}$ flask, $\left(\mathrm{MeC}\left(\mathrm{N}^{i} \mathrm{Pr}\right)_{2}\right)_{3} \mathrm{Al}(1.031 \mathrm{~g}, 3.3 \mathrm{mmol})$ was dissolved in toluene $(20 \mathrm{~mL})$ with stirring. A solution of alane complexed with $\mathrm{N}, \mathrm{N}$ dimethylehylamine $(15.0 \mathrm{~mL}, 0.5 \mathrm{M}$ in toluene, $7.5 \mathrm{mmol}$ ) diluted with toluene (15 $\mathrm{mL})$ was added dropwise, in excess to $\left(\mathrm{MeC}\left(\mathrm{N}^{i} \mathrm{Pr}\right)_{2}\right)_{3} \mathrm{Al}$. The reaction was left to stir at room temperature for $66 \mathrm{~h}$ to reach a point of equilibrium. Volatiles were removed under reduced pressure and the resultant grey-white powder was sublimed at $53{ }^{\circ} \mathrm{C}$ (110 mTorr). Clear, colourless crystals of 7 (0.25 g, $0.56 \mathrm{mmol}, 16 \%)$ were collected from the condenser.

Hydrogen Elimination In a $50 \mathrm{~mL}$ flask inside a glovebox, $N, N^{\prime}$-diisopropylcarbodiimide $1.020 \mathrm{~g}(8.08 \mathrm{mmol})$ was diluted in diethyl ether $(20 \mathrm{~mL})$. To this solution, 
methyl lithium $(5.2 \mathrm{~mL}, 1.6 \mathrm{M}$ in diethyl ether, $8.32 \mathrm{mmol})$ was added dropwise. Allowed solution to stir at room temperature overnight. To this solution, distilled water (180 $\mu$ l, $9.99 \mathrm{mmol})$ was added dropwise. A white precipitate formed almost immediately upon addition. After 20 min solution was filtered through $\mathrm{MgSO}_{4}$. Ether was evacuated under reduced pressure to leave the pure $N, N^{\prime}$-diisopropropylacetamidine, a slightly yellowish oil (0.933 g, $6.56 \mathrm{mmol}, 81.2 \%)$. N, $N^{\prime}$-diisopropropylacetamidine $(0.455 \mathrm{~g}, 3.20 \mathrm{mmol})$ was diluted in toluene $(5 \mathrm{~mL})$ and cooled to $-30{ }^{\circ} \mathrm{C}$. The amidine solution was added dropwise to a solution of alane complexed with $N, N$ dimethylethylamine $(3.2 \mathrm{~mL}, 0.5 \mathrm{M}$ in toluene, $1.6 \mathrm{mmol})$ diluted in $20 \mathrm{~mL}$ of toluene. Concentrated solution under reduced pressure to $5 \mathrm{~mL}$ and filtered through a fine glass frit. Toluene was removed to produce a white solid. Solid was recrystallized from toluene to yield colourless crystals of 7 (0.465 g, $1.498 \mathrm{mmol}, 93.7 \%)$ m.p.: 50-51 ${ }^{\circ} \mathrm{C} .{ }^{1} \mathrm{H}$ HR-NMR $\delta_{H}\left(300 \mathrm{MHz}, \mathrm{C}_{6} \mathrm{D}_{6}\right): 4.88(1 \mathrm{H}$, br s, Al-H), 3.41 (4H, sept, $\left.\mathrm{CH}\left(\mathrm{CH}_{3}\right)_{2}\right), 1.48\left(6 \mathrm{H}, \mathrm{s}, \mathrm{CCH}_{3}\right), 1.27\left(24 \mathrm{H}, \mathrm{d}, \mathrm{CH}\left(\mathrm{CH}_{3}\right)_{2}\right) .{ }^{13} \mathrm{C}\left\{{ }^{1} \mathrm{H}\right\} \mathrm{HR}-\mathrm{NMR}$

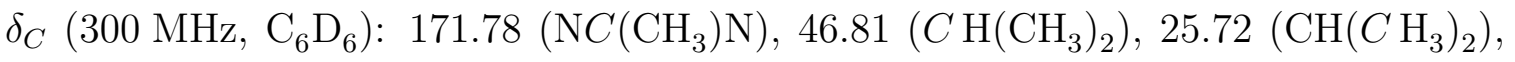
$11.58\left(\mathrm{NC}\left(C \mathrm{H}_{3}\right) \mathrm{N}\right)$. MS: $m / z$ 309.3([M-1 $\left.]^{+}, 5.8 \%\right)$.

\section{$\left(\mathrm{Me}_{3} \mathrm{Si}\right)_{2} \mathrm{NAlH}_{2} \cdot \mathrm{NMe}_{2} \mathrm{Et}(8)$}

In a $250 \mathrm{~mL}$ flask inside a glovebox, alane complexed with $N, N$-dimethylethylamine (7.6 mL, 0.5 M in toluene, $3.8 \mathrm{mmol})$ was diluted in toluene $(100 \mathrm{~mL})$. Hexamethyldisilazane $(0.612 \mathrm{~g}, 3.79 \mathrm{mmol})$ was diluted in $10 \mathrm{~mL}$ of toluene and added dropwise to the alane solution and left to stir overnight. Volatiles were removed under reduced pressure to leave a colourless oil of 8 (0.962 g, 3.66 mmol, 96.7\%). m.p.: -20 $--15{ }^{\circ} \mathrm{C} .{ }^{1} \mathrm{H}$ HR-NMR $\delta_{H}\left(400 \mathrm{MHz}, \mathrm{C}_{6} \mathrm{D}_{6}\right): 4.06\left(2 \mathrm{H}\right.$, br s, Al- $\left.H_{2}\right), 2.31(2 \mathrm{H}, \mathrm{q}$, $\left.\mathrm{NMe}_{2}\left(\mathrm{CH}_{2} \mathrm{CH}_{3}\right)\right), 1.82\left(6 \mathrm{H}, \mathrm{s}, \mathrm{N}\left(\mathrm{CH}_{3}\right)_{2} \mathrm{Et}\right), 0.58\left(3 \mathrm{H}, \mathrm{t}, \mathrm{NMe}_{2}\left(\mathrm{CH}_{2} \mathrm{CH}_{3}\right)\right), 0.42(18 \mathrm{H}$, s, $\left.\mathrm{N}\left(\mathrm{Si}\left(\mathrm{CH}_{3}\right)_{3}\right)_{2}\right) .{ }^{13} \mathrm{C}\left\{{ }^{1} \mathrm{H}\right\}$ HR-NMR $\delta_{C}\left(400 \mathrm{MHz}, \mathrm{C}_{6} \mathrm{D}_{6}\right): 53.05\left(\mathrm{NMe}_{2}\left(\mathrm{CH}_{2} \mathrm{CH}_{3}\right)\right)$, $45.10\left(\mathrm{NMe}_{2}\left(\mathrm{CH}_{2} C \mathrm{H}_{3}\right)\right), 43.74\left(\mathrm{~N}\left(\mathrm{CH}_{3}\right)_{2} \mathrm{Et}\right), 5.95\left(\mathrm{~N}\left(\mathrm{Si}\left(\mathrm{CH}_{3}\right)_{2}\right)_{2}\right)$. 


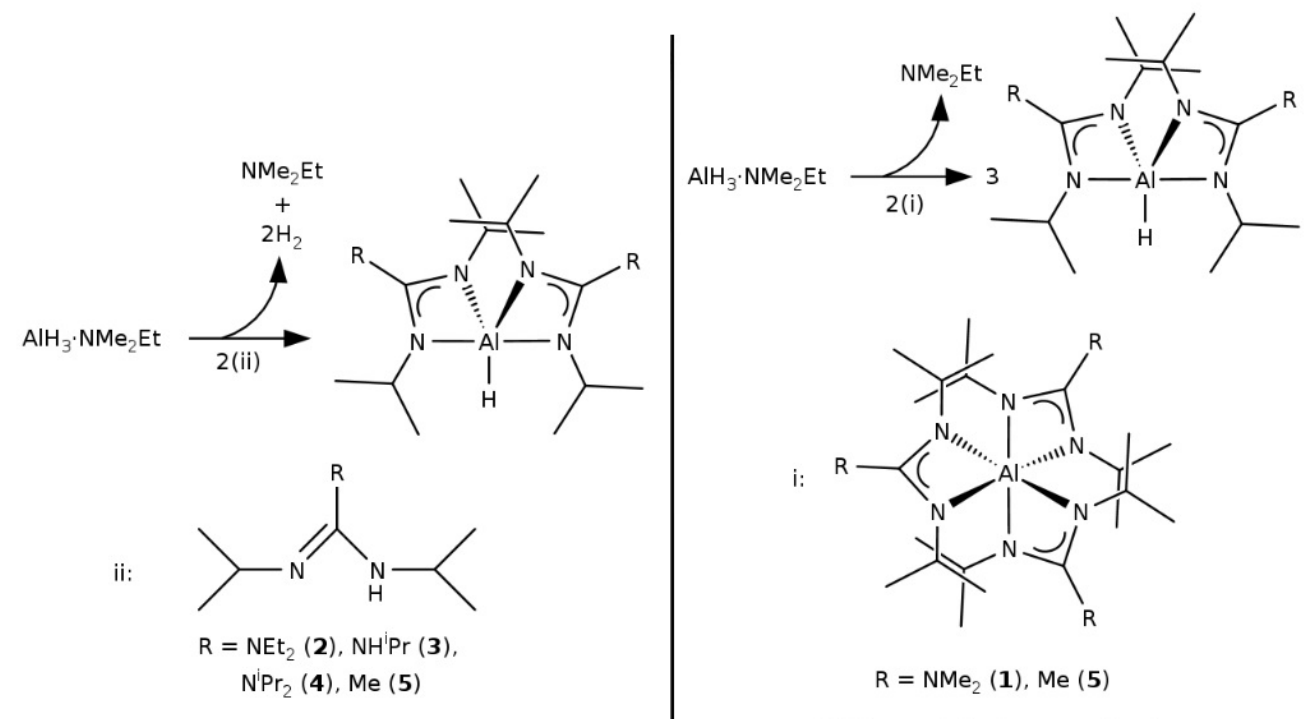

a) Hydrogen Elimination Route

b) Ligand-Exchange Route

Figure 4.2: Synthesis route for producing bisamidinato monohydrido aluminum (III) compounds reported herein. a) shows the route used to synthesize 4-7. Compound $\mathbf{8}$ is synthesized via this route as well, but instead of the guanidine, hexamethyldisilazane is used in 1:1 ratio with alane. b) shows the route used to synthesize $\mathbf{3}$ and 7.

\subsection{Results and Discussion}

\section{Synthesis}

The compounds examined in this work can be found in Figure 4.2, synthesized using either hydrogen elimination or ligand exchange to produce the final hydride products. The synthesis of $\mathbf{3}$ has been reported previously and gave an $86 \%$ yield using ligand exchange. ${ }^{102}$ Compounds $\mathbf{4}, \mathbf{5}, \mathbf{6}$, and $\mathbf{8}$ were synthesized using hydrogen elimination.

Compound 7 was made using both the ligand-exchange and hydrogen elimination routes. Using ligand exchange conditions similar to the synthesis of $\mathbf{3}$, and starting with homoleptic trisacetamidinatoaluminum, the equilibrium for this reaction left a mixture with a molar ratio of 1.15:1.00 starting material to 7. Heating the reaction 
mixture to $75^{\circ} \mathrm{C}$ was found to push the equilibrium to product but it was also found to promote decomposition of the entire mixture, likely to metallic aluminium. Even using excess alane to exert a LeChatelier's pressure on the equilibrium resulted in only a $16 \%$ isolated yield of $\mathbf{7}$. However, when hydrogen elimination was attempted, slow addition of the protonated amidine to a cold solution of alane resulted in near quantitative synthesis of $\mathbf{7}$ (93.7\% isolated yield). This is insightful because it demonstrates that 7 potentially has a thermolysis pathway to metallic aluminum at elevated temperatures.

The synthesis route to a compound very similar to 8 has been reported previously ${ }^{97}$ but with a trimethylamine adduct instead of the dimethylethylamine adduct reported here. However, the synthesis route still uses hydrogen elimination and quantitative yields are obtainable without an extensive work-up. Interestingly, the bishexamethyldisilazide monohydride aluminum can be isolated as a decomposition product of 8 in refluxing toluene but forms oligomers in toluene. ${ }^{97}$ As well, this synthesis method produces other decomposition products including elemental aluminum. It is possible to isolate a hydride-bridged dimer of the bishexamethyldisilazide monohy-

dride aluminum in hexane, ${ }^{107}$ however, the thermal chemistry of this compound is unknown and merits examination.

\section{Crystallography}

Of the five compounds synthesized, crystals of $\mathbf{4 , 6}$, and $\mathbf{7}$ were grown by single-solvent recrystallization in toluene or by sublimation and their structures were determined by single-crystal X-ray diffraction (scXRD). The three compounds all have a distorted trigonal bipyramidal geometry around the aluminium centre where the hydride is in an equatorial position. Interestingly, all compounds reported herein are monomeric in the solid-state. Compounds 4, 6 and $\mathbf{7}$ are shown in Figure 4.3, and selected bond lengths and angles are given in Table 4.1. These compounds show a very similar basic 
structure. The aluminium metal centre is always asymmetric with respect to bond lengths to the chelating nitrogens from one amidinate ligand. The shorter nitrogen aluminium bond ranges from 1.93-1.95 $\AA$ and the longer nitrogen aluminium bond ranges from $2.00-2.06 \AA$.

The nitrogen atoms that participate in the longer bonds to aluminium are in the equatorial positions of the distorted trigonal bipyramid and the nitrogens associated with the shorter bonds are in the axial positions. Comparing these compounds to the previously reported structure of $\mathbf{3},{ }^{102}$ the trend in the chelating ligands bite angle becomes important. For 3, 4 and 6 the chelate bite angle of the guanidinate ligands is similar, with the $\mathrm{N}-\mathrm{Al}-\mathrm{N}$ angles ranging between $67.1^{\circ}-67.8^{\circ}$. The bite angle drops as the steric bulk of the peripheral substituents increases, as expected. For the amidinate in $\mathbf{7}$, the smallest bite angle $\left(66.7^{\circ}\right)$ was found. This does not follow the steric bulk trend and one would expect the lack of steric congestion in the exocyclic position to allow the $\mathrm{N}-\mathrm{C}-\mathrm{N}$ ligand backbone to relax resulting in a wider bite angle. This is thus likely due to a change in the electronic characteristics of the amidinate ligand versus the guanidinate. By changing the exocyclic position from an amine to a methyl, the exocyclic moiety is less electron-donating and does not participate in the ligand resonance with the metal, allowing for a smaller ligand bite angle. As will be discussed, this trend in bite angle matches the thermal stability of these compounds. It is possible that this added strain around the aluminium centre increases the reactivity of the compound. 

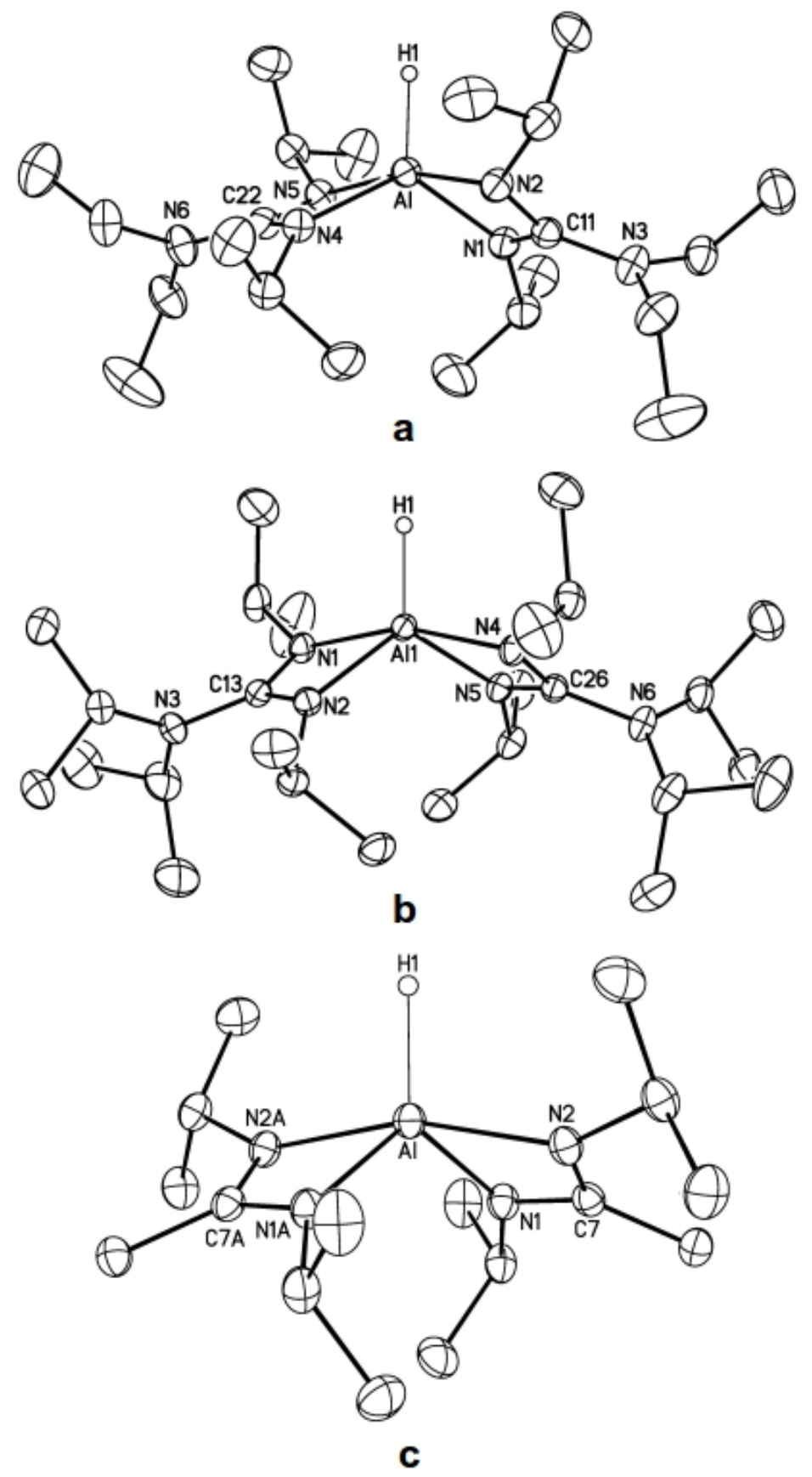

Figure 4.3: Molecular crystal structure diagram for a) $\left(\mathrm{Et}_{2} \mathrm{NC}\left(\mathrm{N}^{i} \mathrm{Pr}\right)_{2}\right)_{2} \mathrm{AlH}$ (4), b) $\left({ }^{i} \mathrm{Pr}_{2} \mathrm{NC}\left(\mathrm{N}^{i} \mathrm{Pr}\right)_{2}\right)_{2} \mathrm{AlH}$ (6), c) $\left(\mathrm{MeC}\left(\mathrm{N}^{i} \mathrm{Pr}\right)_{2}\right)_{2} \mathrm{AlH}$ (7). The thermal ellipsoids are shown at the $50 \%$ level of probability, and all hydrogen atoms, except for the aluminum-bonded hydride, are not shown for simplicity. 
Table 4.1: Selected bond lengths $(\AA)$ and angles $\left(^{\circ}\right)$ for compounds $\mathbf{3}, \mathbf{4}, \mathbf{6}$ and $\mathbf{7}$. Compound $\mathbf{6}$ includes the pertinent metrics for both molecules in the repeating unit.

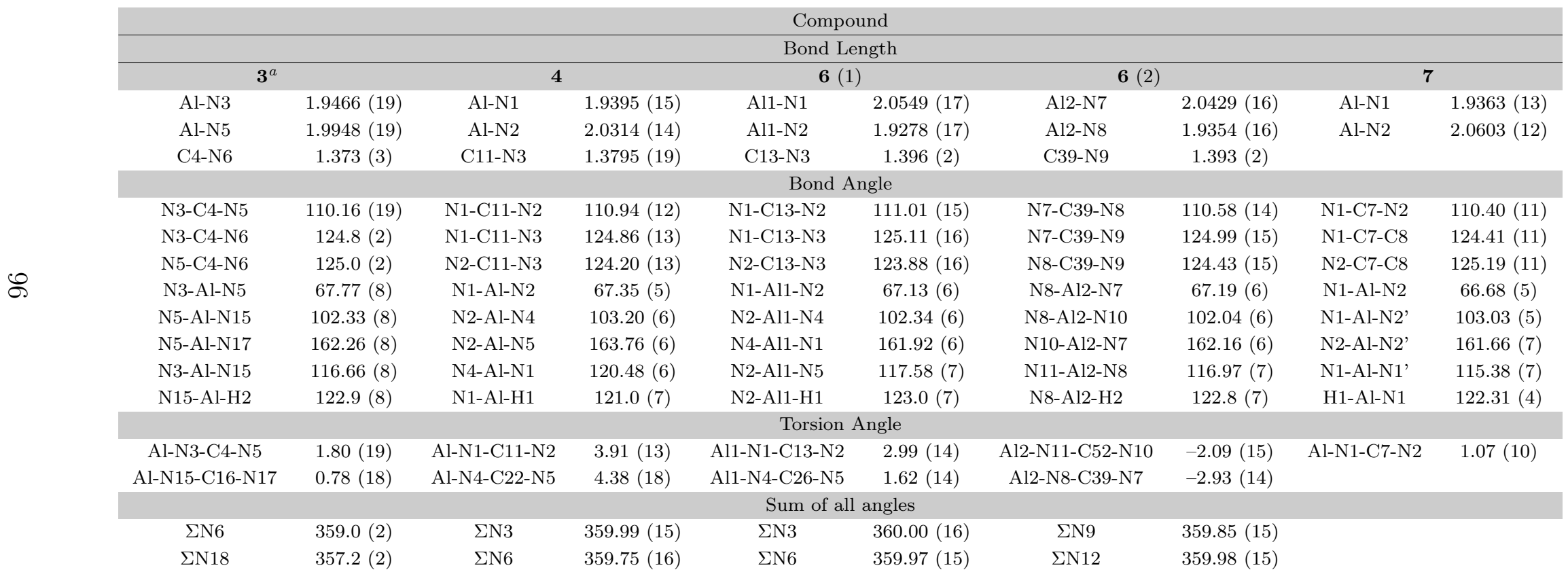

${ }^{a}$ Previously reported. ${ }^{102}$ 


\section{Thermolysis Studies}

The design strategy for these compounds was straightforward. The main requirement for an aluminium hydride precursor is to deposit aluminium metal, and the presence of the hydride maintains a strongly reducing ligand environment at the metal centre. However, the previously reported $\mathbf{3}$ showed poor thermal stability and a complex thermal decomposition. This compound has a melting point of $61{ }^{\circ} \mathrm{C}-64{ }^{\circ} \mathrm{C}$, but decomposed in solution in a sealed HR-NMR tube at $56{ }^{\circ} \mathrm{C}$ with a half-life of 1.8 days (Figure 4.4, Table 4.2). This thermal decomposition is exceedingly slow but still problematic, considering its use in CVD or ALD would require it to be kept at an elevated temperature for several hours at a time above its melting point. Interestingly, the decomposition products of $\mathbf{3}$ were easily identifiable in ${ }^{1} \mathrm{H}$ HR-NMR studies (Figure 4.6, raw data in Section 4.6: Figure 4.9).

Compound 3 exhibited ligand exchange to produce the homoleptic trisamidinate species, and also underwent exchange of the amidinate "exocyclic" position (vide infra). The relatively low decomposition temperature of $\mathbf{3}$ is supported by TGA data, which showed a complex derivative curve (Figure 4.5), indicative of several thermal processes occurring on the same time and temperature scales. The exocyclic moiety of the amidinate was altered to see if that would significantly change the melting point, onset of volatility or thermal decomposition process. Although we expected the melting point to be lowered by a longer alkyl chain, ${ }^{108}$ an opposite trend was observed. As well, the onset of volatility remained similar, if not somewhat lower (Table 4.3).

Compound 4 (differing only from 3 by having ethyl groups on the exocyclic amide) showed a similarly low decomposition temperature, also decomposing at $56{ }^{\circ} \mathrm{C}$ with a half-life of 7.5 days. Here, the decomposition products were harder to identify in

${ }^{1} \mathrm{H}$ HR-NMR due to the proliferation of the triplets and quartets from multiple ethyl 

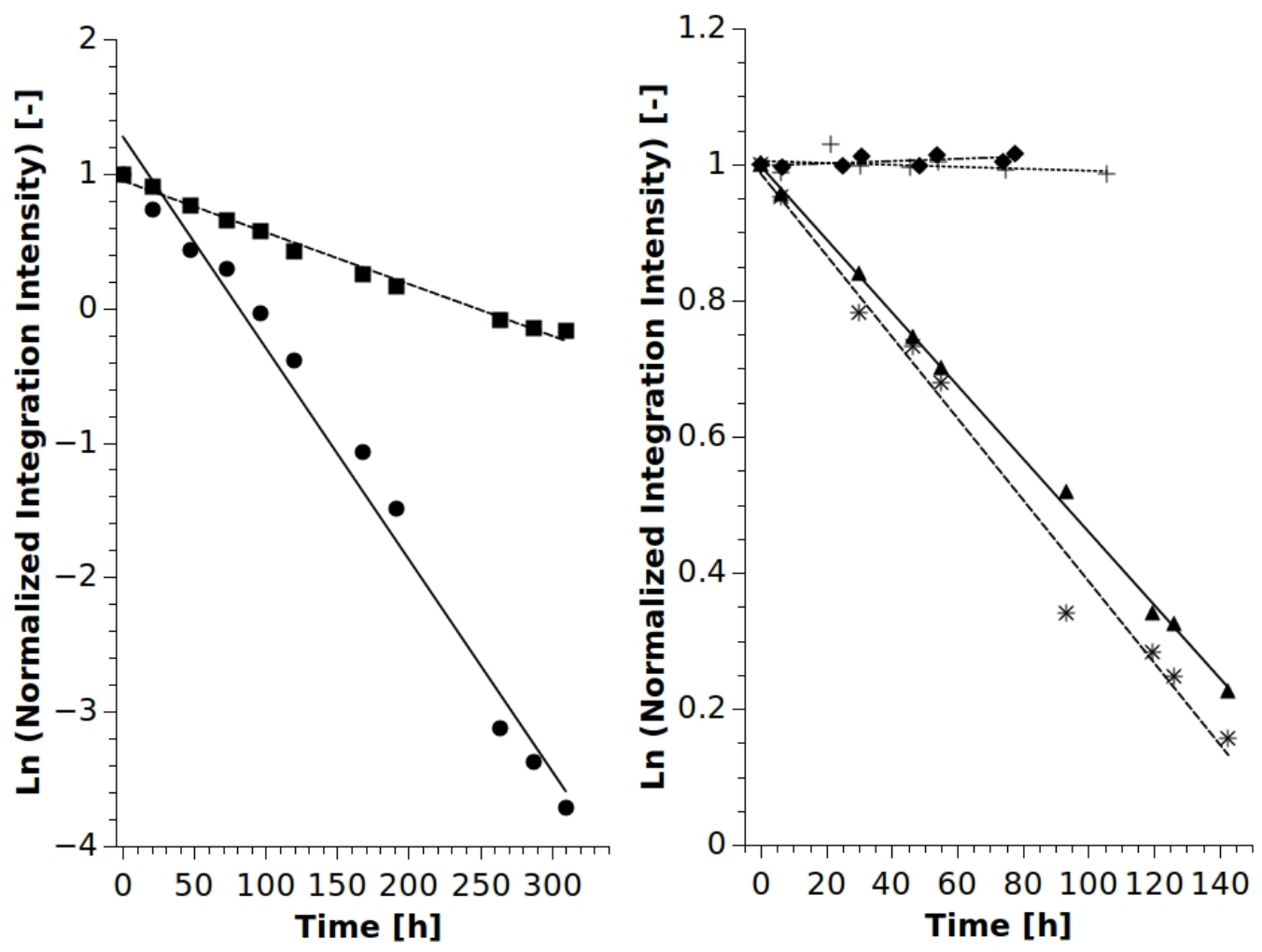

Figure 4.4: Solution-phase decomposition of compounds 3-8. Concentration monitored by ${ }^{1} \mathrm{H}$ HR-NMR in $d_{6}$-benzene. Decomposition for each compound, except 7 and 8, showed first-order decomposition kinetics. $3(\bullet)$ and $4(\square)$ were held at 56 ${ }^{\circ} \mathrm{C}$ and $\mathbf{5}(\mathbf{\Delta}), \mathbf{6}(*), \mathbf{7}(+)$, and $\mathbf{8}(\bullet)$ were held at $65{ }^{\circ} \mathrm{C}$. Pertinent decomposition metrics from these plots can be found in Table 4.2.

Table 4.2: Solution-phase kinetic thermal decomposition of 3-8. $\mathrm{R}$ refers to the exocyclic moiety on the amidinate ligand of each compound.

$\begin{array}{cccccc}\text { Compound } & \mathrm{R} & \begin{array}{c}\text { Temperature } \\ \left({ }^{\circ} \mathrm{C}\right)\end{array} & \begin{array}{c}\text { Rate Constant } \\ \left(\mathrm{s}^{-1}\right)\end{array} & \begin{array}{c}\text { Half-life } \\ t_{1 / 2}(\text { days })\end{array} & \begin{array}{c}\text { Correlation Coefficient } \\ R^{2}\end{array} \\ \mathbf{3} & \mathrm{NMe}_{2} & 56 & 4.40 \pm 0.2 \cdot 10^{-6} & 1.8 & 0.984 \\ \mathbf{4} & \mathrm{NEt}_{2} & 56 & 1.07 \pm 0.04 \cdot 10^{-6} & 7.5 & 0.987 \\ \mathbf{5} & \mathrm{NH}^{i} \mathrm{Pr} & 65 & 1.49 \pm 0.02 \cdot 10^{-6} & 5.4 & 0.998 \\ \mathbf{6} & \mathrm{N}^{i} \mathrm{Pr} & 65 & 1.66 \pm 0.07 \cdot 10^{-6} & 4.8 & 0.983 \\ \mathbf{7} & \mathrm{Me} & 65 & \mathrm{~N} / \mathrm{A} & \mathrm{N} / \mathrm{A} & \mathrm{N} / \mathrm{A} \\ \mathbf{8} & \mathrm{N}\left(\mathrm{SiMe}_{3}\right)_{2} & 65 & \mathrm{~N} / \mathrm{A} & \mathrm{N} / \mathrm{A} & \mathrm{N} / \mathrm{A}\end{array}$



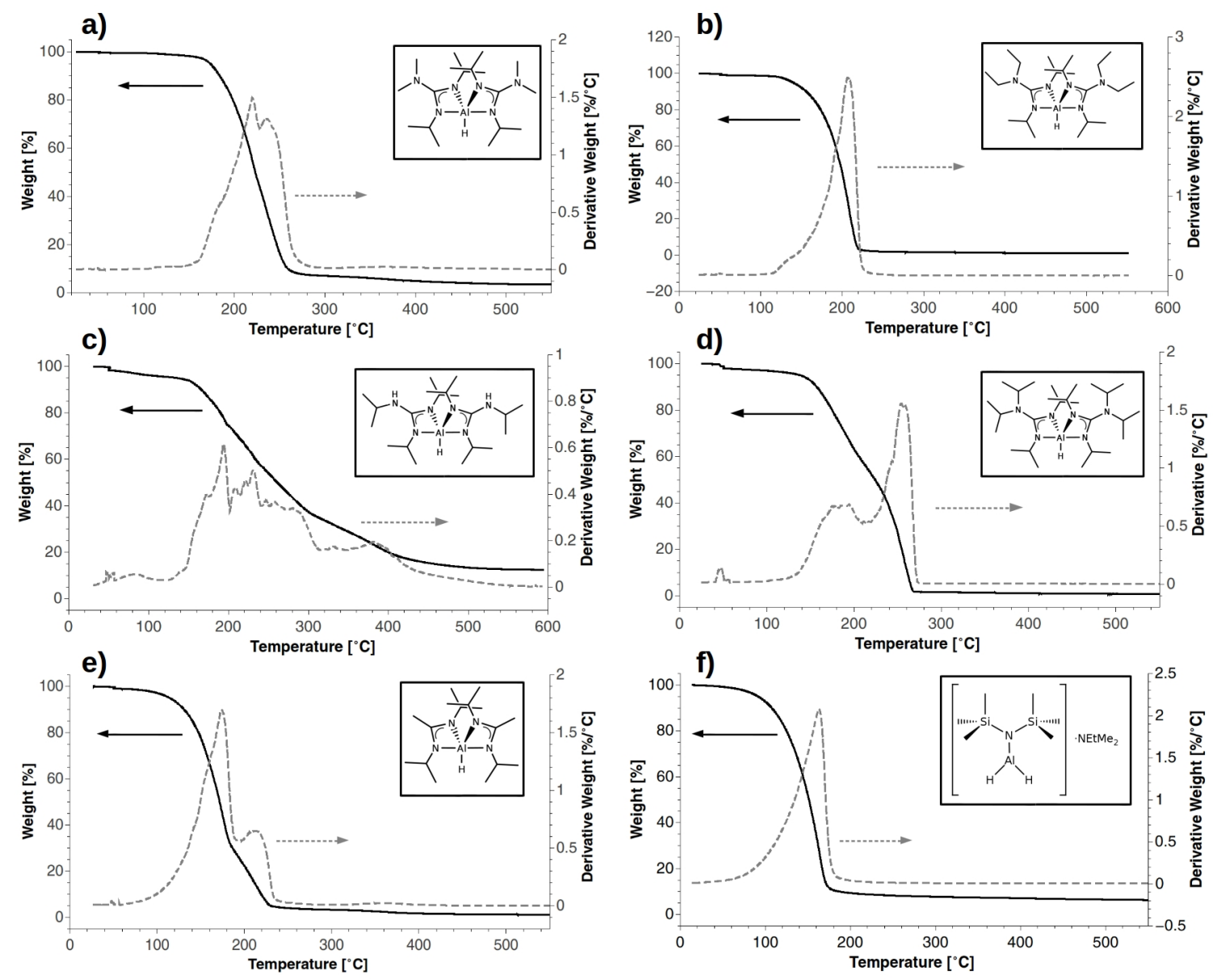

Figure 4.5: Thermogravimetric analysis (ramp of $5{ }^{\circ} \mathrm{C} / \mathrm{min}$ ) of $\mathbf{3}$ (a), 4 (b), 5 (c), 6 (d), 7 (e) and 8 (f). Percentage mass loss and derivative weight loss with respect to temperature are shown.

signals. The TGA data was similar, but with a lower onset of volatilization and a less complicated derivative curve. It was tempting to initially suggest that this compound was volatilizing cleanly compared to $\mathbf{3}$, but solution decomposition data and TGA residual mass $(3.36 \%$ for $\mathbf{3}, 0.97 \%$ for $\mathbf{4}$ ) supports the idea that both compounds decompose easily to a family of volatile side products. This is not favourable for vapour deposition processes due to the complicated nature of the ensuing vapour and the variety of different surface chemistries that could occur with such a mixture.

Compounds 5 and $\mathbf{6}$ have somewhat better thermal onset, but share similar behaviour with 3 and 4 . Both compounds were stable at $56{ }^{\circ} \mathrm{C}$, and showed thermal decomposition in solution at $65^{\circ} \mathrm{C}(\mathbf{5}$ had a half-life of 5.4 days and $\mathbf{6}$ had a half-life of 4.8 days). ${ }^{1} \mathrm{H}$ HR-NMR analysis showed that the thermal side products was similar 
Table 4.3: Thermal characteristics of compounds $\mathbf{3}-\mathbf{8}$. Onset of volatility and residual mass was determined from TGA while sublimation and melting temperatures were determined from benchtop techniques. TGA traces can be found in Figure 4.5 and in Supporting Information.

\begin{tabular}{|c|c|c|c|c|}
\hline Compound & $\begin{array}{l}\text { Melting Point } \\
\qquad\left({ }^{\circ} \mathrm{C}\right)\end{array}$ & $\begin{array}{l}\text { Sublimation } \\
\text { Temperature } \\
\left({ }^{\circ} \mathrm{C} / \mathrm{mTorr}\right)\end{array}$ & $\begin{array}{l}\text { Onset of } \\
\text { Volatility }(5 \% \\
\text { mass loss) } \\
\qquad\left({ }^{\circ} \mathrm{C}\right)\end{array}$ & $\begin{array}{l}\text { Residual Mass (Al in } \\
\text { compound) } \\
\qquad(\%)\end{array}$ \\
\hline 3 & $61-64$ & $51 / 80$ & 174.4 & $3.36(7.32)$ \\
\hline 4 & $117-119$ & $75 / 60$ & 143.3 & $0.97(6.35)$ \\
\hline 5 & $110-111$ & $95 / 105$ & 153.5 & $12.6(6.80)$ \\
\hline 6 & $112-113$ & $84 / 70$ & 148.9 & $0.76(5.61)$ \\
\hline 7 & $50-51$ & $53 / 110$ & 118.8 & $1.01(8.04)$ \\
\hline 8 & $-20--15$ & $\mathrm{~N} / \mathrm{A}^{a}$ & 91.4 & $6.22(10.28)$ \\
\hline
\end{tabular}

to 4 in that the presence of multiple isopropyl signals confounded any reliable identification. However, the complex thermolysis was supported by TGA, which showed complicated derivative curves, suggesting a variety of thermally activated chemistry. Particularly with 5, the residual mass (12.6\%) and broad and "feature-filled" weight loss suggests that the exocyclic proton might be the reason for such behaviour. Indeed, the similar nature of the derivative curves of $\mathbf{3}, \mathbf{5}$, and $\mathbf{6}$ indicate that these complicated thermolyses might be related to thermally accessible side products identified in $\mathbf{3}$. It should be noted that $\mathbf{4}$ appeared by TGA to be a very good precursor, with low residual mass and a derivative curve indicative of volatilization. However, we suspect in this case that the temperature profile of thermal decomposition and volatility are coincident in this compound, and its solution decomposition offers a window into this complexity.

Given that $\mathbf{3}$ showed an identifiable thermal decomposition product with a proton in the exocyclic position, we propose that carbodiimide elimination followed by a subsequent reinsertion is likely the thermal pathway leading to the poor thermal behaviour of these compounds (Figure 4.7). This coupled with ligand exchange, predicts all of the decomposition products in Figure 4.6. To prevent this reaction, an 




Figure 4.6: Reaction by-product monitoring from the solution-phase decomposition study at $56{ }^{\circ} \mathrm{C}$ for 3 . All species were monitored via ${ }^{1} \mathrm{H}$ HR-NMR. Concentration data for species $\mathrm{D}$ is not shown on the plot since the relative molar concentration was below $1 \%$.

amidinate was employed.

Our previous work on amidinates showed that carbodiimide deinsertion was an accessible decomposition route, ${ }^{76}$ but occurred at higher temperature than guanidinates. ${ }^{103,109}$ This was true in the case of $\mathbf{7}$, where the low thermal events were a significant change in melting point $\left(50{ }^{\circ} \mathrm{C}-51{ }^{\circ} \mathrm{C}\right)$ and onset of volatility $\left(119{ }^{\circ} \mathrm{C}\right)$. As well, 7 showed no decomposition at $56{ }^{\circ} \mathrm{C}$ nor $65{ }^{\circ} \mathrm{C}$. These parameters make 7 a much better candidate as a precursor since the melting point is well below the thermal decomposition point, and the onset of volatility suggests that this compound can be entrained into a deposition reactor without decomposition. It should be noted that the onset of volatility here was measured at approximately one atmosphere, and (as a rule of thumb) the onset will drop by $50{ }^{\circ} \mathrm{C}$ to $60{ }^{\circ} \mathrm{C}$ under vacuum.

The most promising candidate for vapour deposition of aluminum metal, however, is $\mathbf{8}$, given its thermal characteristics determined by TGA and ${ }^{1} \mathrm{H}$ HR-NMR thermolysis studies. The decision to examine an aluminum hydride with a HMDS ligand is two-fold. First, the HMDS ligand has proven to be an excellent handle for examining the surface chemistry of metal-HMDS complexes on silica substrates (see Chapter 5) 




Figure 4.7: Proposed solution-phase decomposition mechanism for bisamidinato monohydride aluminum (III) compounds by sequential deinsertion / reinsertion of a carbodiimide moiety.

and so analysis of future surface work would prove fruitful in this case. Secondly, initial synthetic reports of $\mathbf{8}^{97}$ have shown that when refluxed in toluene, 8 decomposes to the bis-substituted HMDS complex $\left((\mathrm{HMDS})_{2} \mathrm{AlH}\right)$ and alane which further decomposes to aluminum metal. If it is possible to volatilize $\mathbf{8}$ before thermally decomposing then it might provide a route to a vapour-phase deposition process for aluminum metal. Looking at the simple ramp TGA experiment (Figure 4.5f) there appears to be only one feature in the weight loss curve and derivative weight loss curve. Initially this appears that only volatilization is occurring without any signs of decomposition. There is, however, a residual mass of $6.22 \%$ which indicates that decomposition is certainly happening in this compound. The lack of complex features in the derivative weight loss curve suggests that the small amount of decomposition occurring is happening at higher temperatures but also coincides with volatilization so a simple ramp TGA experiment cannot differentiate between both processes. Unlike in the case of $\mathbf{4}$ or $\mathbf{7}$, though, there is not an obvious feature in the derivative curve either before or after volatilization occurs to suggest decomposition. To attempt to separate volatilization from decomposition in this compound, a stepped-isotherm TGA experiment was performed. In this experiment the sample mass is monitored 

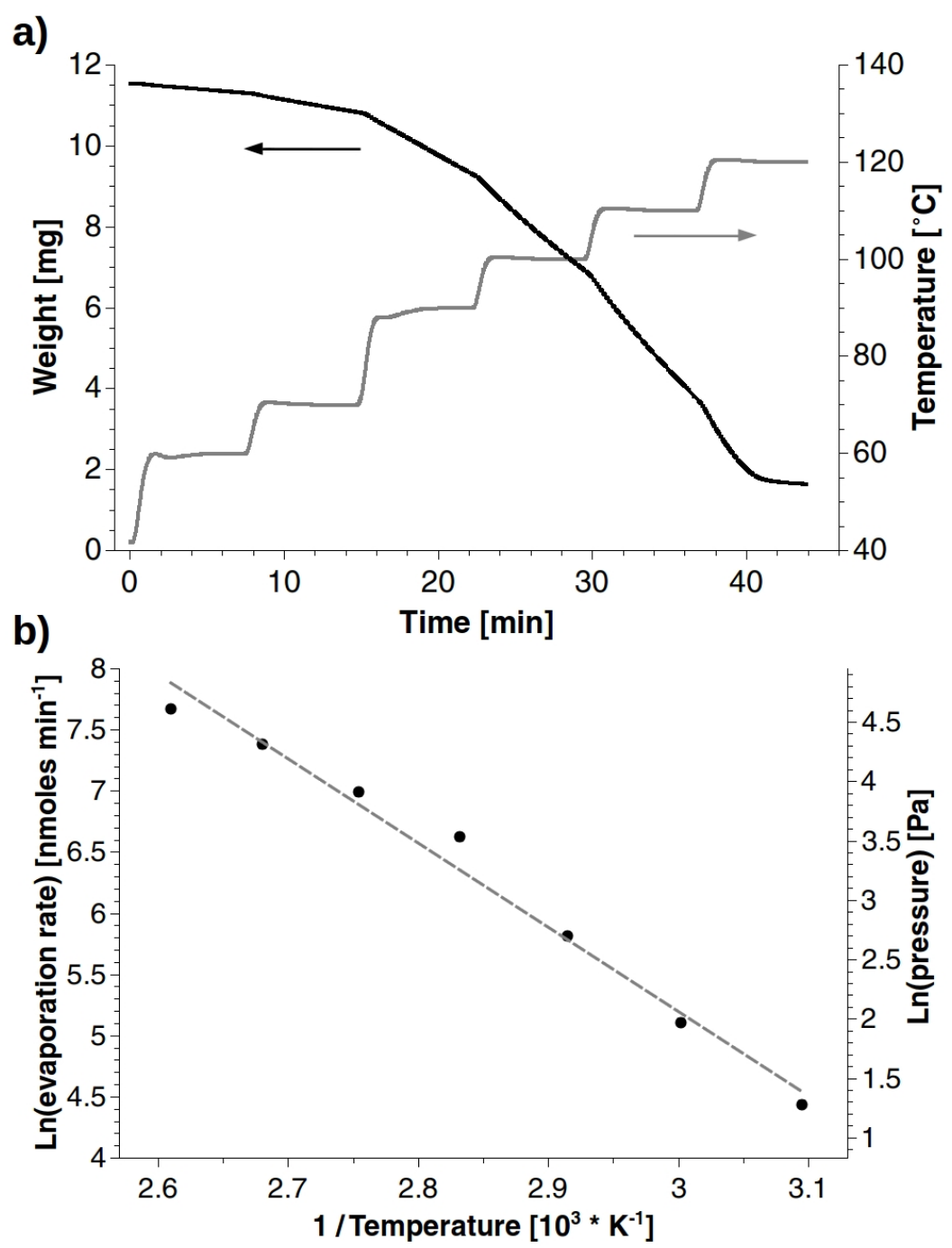

Figure 4.8: Stepped-isotherm TGA for 8. a) shows the mass loss over time as temperature is increased. b) shows the Clausius-Clapeyron evaporation kinetics with respect to temperature, the details of the analysis are described in the references herein. ${ }^{71,72}$ The line of best fit is shown with respect to evaporation rate: evaporation rate $=\left[1.686 \cdot 10^{11}( \pm 3.149)\right] e^{\frac{-6885( \pm 403)}{T}}$ and $R^{2}=0.975$. Note that evaporation rate is in a natural logarithm-based scale. 
over time while the temperature is raised in $10^{\circ} \mathrm{C}$ increments (starting at $60{ }^{\circ} \mathrm{C}$ ) and then held isothermally for $7 \mathrm{~min}$. It is expected the mass loss over time would be linear if only volatilization was occurring, and that the surface area of the sample would not change significantly during the course of the experiment. ${ }^{70}$ If there is decomposition occurring, then the mass loss curve would not be linear. Figure 4.8 shows the stepped-isotherm and Langmuir model of evaporation for 8. From Figure 4.8a it can be seen that the mass loss is reasonably linear at each isotherm right up until $120{ }^{\circ} \mathrm{C}$. It is very clear that the $120{ }^{\circ} \mathrm{C}$ isotherm is non-linear after only a few minutes and a non-zero residual mass is left. This shows that below $120{ }^{\circ} \mathrm{C}$ at

room pressure 8 is quite volatile. A Langmuir model for evaporation rate ${ }^{71,110}$ can be used and gives the data shown in Figure 4.8b. The slight non-linearity that exists in Figure $4.8 \mathrm{~b}$ can be attributed to the fact that the enthalpy of vaporization has a temperature dependence not accounted for in the model or that the surface area of evaporating compound does not remain constant. However, given the approximations of the model, the 1 Torr vapour pressure for 8 was estimated to be $105^{\circ} \mathrm{C}$. This shows that 8 has excellent volatility and below $120^{\circ} \mathrm{C}$ has potential as a thin film precursor. Similar to the other hydrides studied, 8 was also examined by ${ }^{1} \mathrm{H}$ HR-NMR solution thermolysis. The results are shown in Figure 4.4 and Table 4.2. The behaviour of 8 was very similar to that of 7 in that at $65{ }^{\circ} \mathrm{C} 8$ showed no signs of decomposition in $\mathrm{C}_{6} \mathrm{D}_{6}$ over several days. However, at $75^{\circ} \mathrm{C} \mathbf{8}$ did begin to show signs of decomposition (see Figure 4.14). This shows that 8 likely has the greatest promise as a precursor for aluminum deposition.

\subsection{Conclusions}

This work describes the synthesis of four novel aluminum hydride complexes using two synthetic routes. While the ligand-exchange method was successful for synthesizing 
the previously reported 3 and gave poor yields of $\mathbf{7}$, it was not effective method for synthesizing a new aluminum hydrides with amidinate and guanidinate ligands. The hydrogen elimination route was, however, very effective in synthesizing $\mathbf{4 - \mathbf { 8 }}$ in excellent yields and with uncomplicated purification steps.

scXRD analysis of these compounds has shown that all these aluminum complexes are monomeric molecules in the solid-state. The aluminum bisguanidinate hydrides $(\mathbf{3}, \mathbf{4}$, and 6) exhibit much more steric crowding from the ligands causing a large distortion from ideal trigonal bipyramidal geometry around the aluminum centre. The acetamidinate complex $(\mathbf{7})$, however, shows a geometry that nears ideal trigonal bipyramidal around the metal centre. It is suspected that this lack of steric strain around the metal centre for 7 helps give it some thermal stability.

The thermogravimetric analysis of these compounds revealed that changing the substitution of the guanidinate ligand marginally change the solid-state thermal behaviour of the resulting complex, while substituting an amidinate for the guanidinate had a more drastic effect. The biggest change, however, occurred when a HMDS ligand was used. It was found that $\mathbf{8}$ exhibited the earliest onset of volatility with a small amount of decomposition likely occurring only at higher temperatures. Compound 7 also showed excellent volatility with a slightly more pronounced decomposition feature at higher temperatures. Compounds 3, 5, and $\mathbf{6}$ showed a high temperature for onset of volatility and a myriad of thermal events including volatilization and decomposition, as evidenced by the derivative weight loss curve. Compound 4 showed a moderate onset of volatility but an excellent residual mass and a derivative curve suggestive of simple volatilization.

As a contrast to TGA studies, the ${ }^{1} \mathrm{H}$ HR-NMR thermal analysis showed that 7 and 8 were indeed the most thermally stable compounds in solution. The other compounds studied showed signs of decomposition above $56{ }^{\circ} \mathrm{C}$ with varying rates of decomposition. In terms of solution-phase thermal stability the compounds ranked as 
$\mathbf{3}<\mathbf{4}<\mathbf{6}<\mathbf{5}<\mathbf{7}<\mathbf{8}$. By tracking the decomposition products of $\mathbf{3}$, it was found that aluminum formamidinate compounds were some of the primary byproducts. For this to occur it is suspected that there must be carbodiimide (CDI) deinsertion and reinsertion with the hydride playing a role during the decomposition.

The facile synthesis and interesting thermal characteristics of these novel aluminum hydride complexes are encouraging as potential precursors for vapour deposition techniques. The less thermally stable compounds may be more suitable for CVD processes while $\mathbf{7}$ and $\mathbf{8}$ shows great promise as a potential ALD precursor for aluminum metal thin films. 


\subsection{Supporting Information}
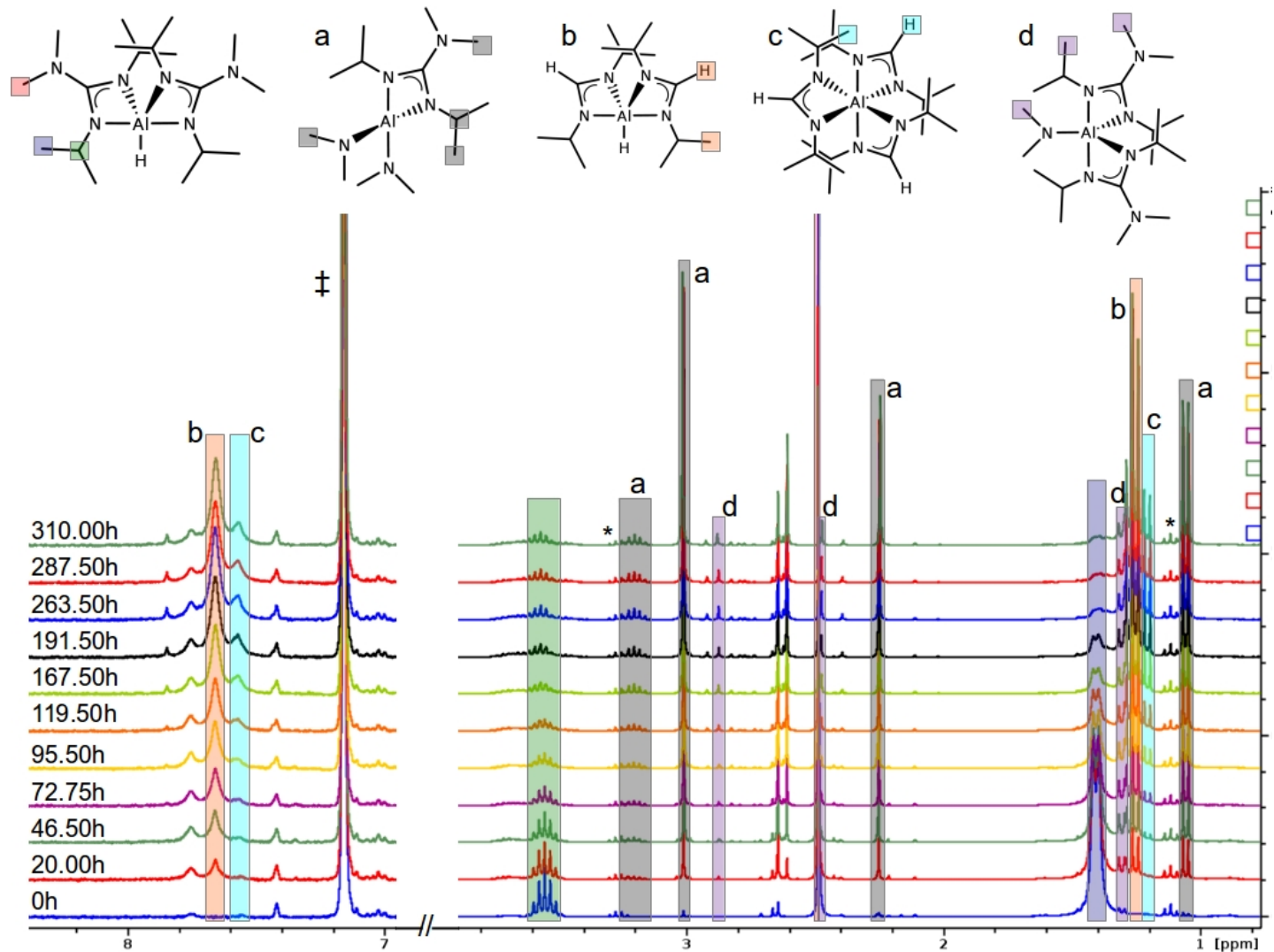

Figure 4.9: ${ }^{1} \mathrm{H}$ HR-NMR spectra for the thermolysis of $\mathbf{3}$. The time shown (in hours) indicates the time held at $56{ }^{\circ} \mathrm{C}$. * and $\ddagger$ is residual diethyl ether and benzene respectively. The $\mathrm{y}$-axis (intensity) scale for the 7-8 ppm region has been enlarged to show decomposition products. 


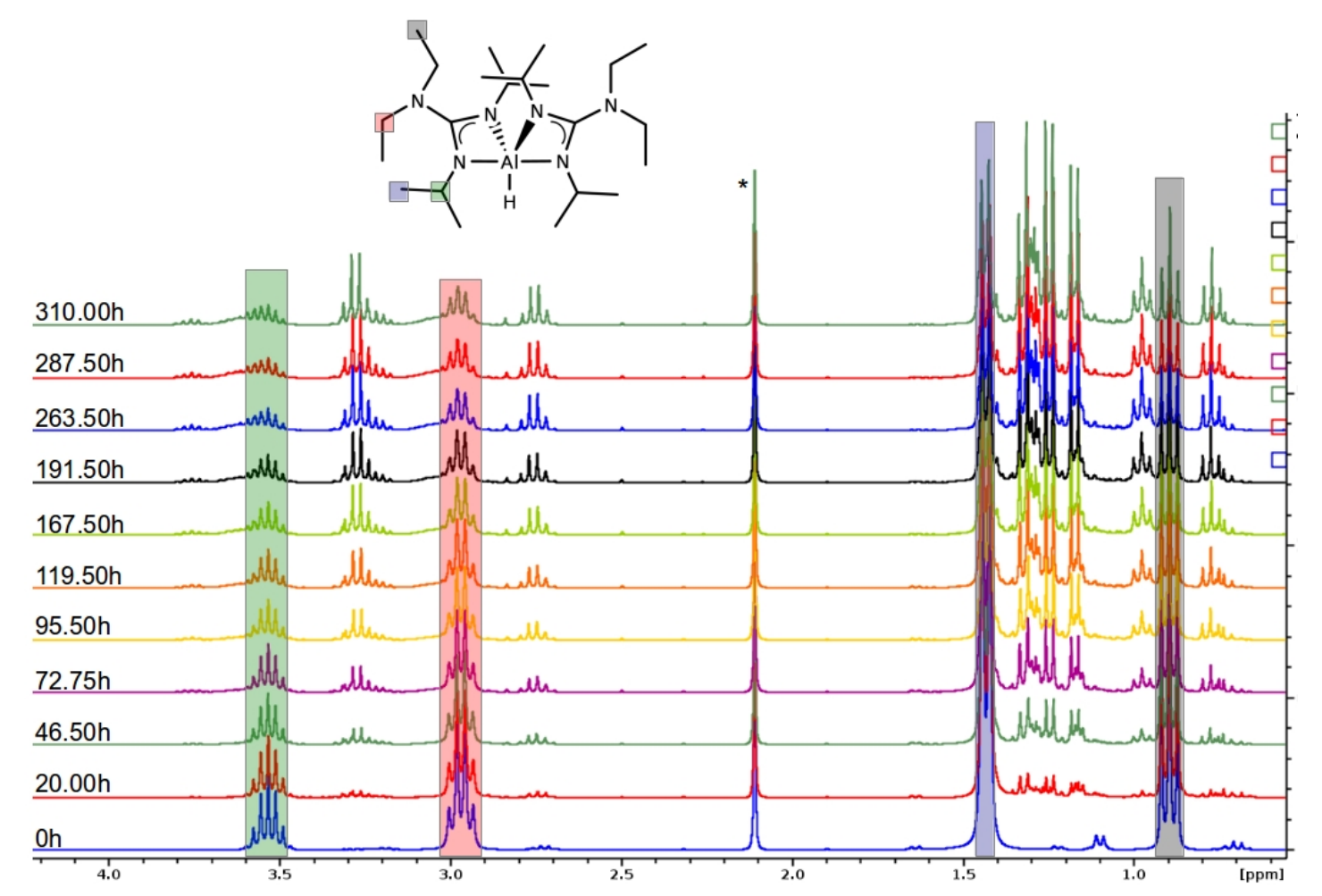

Figure 4.10: ${ }^{1} \mathrm{H}$ HR-NMR spectra for the thermolysis of 4 . The time shown (in hours) indicates the time held at $56{ }^{\circ} \mathrm{C}$. * is residual toluene.
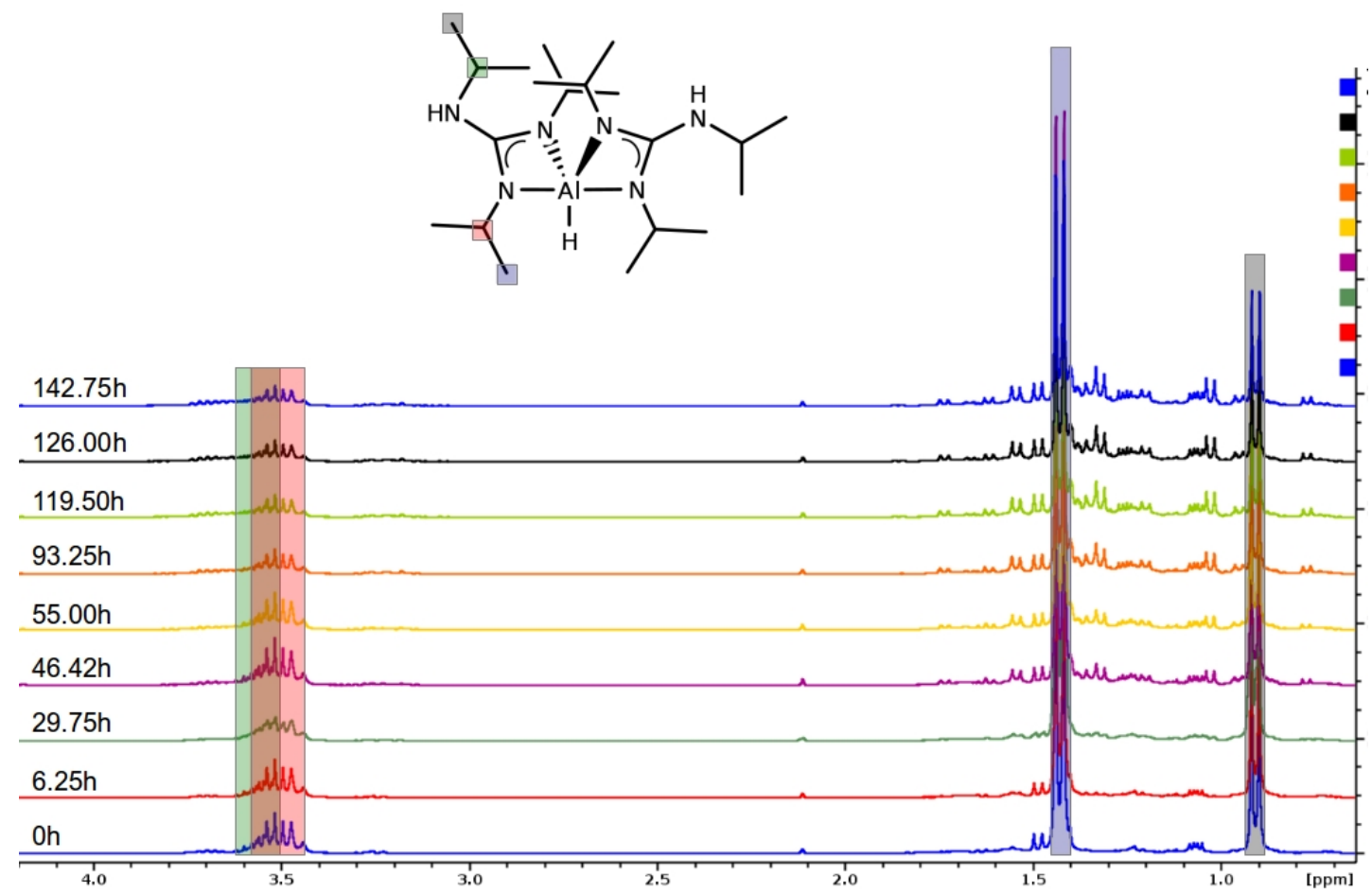

Figure 4.11: ${ }^{1} \mathrm{H}$ HR-NMR spectra for the thermolysis of 5 . The time shown (in hours) indicates the time held at $65^{\circ} \mathrm{C}$. 


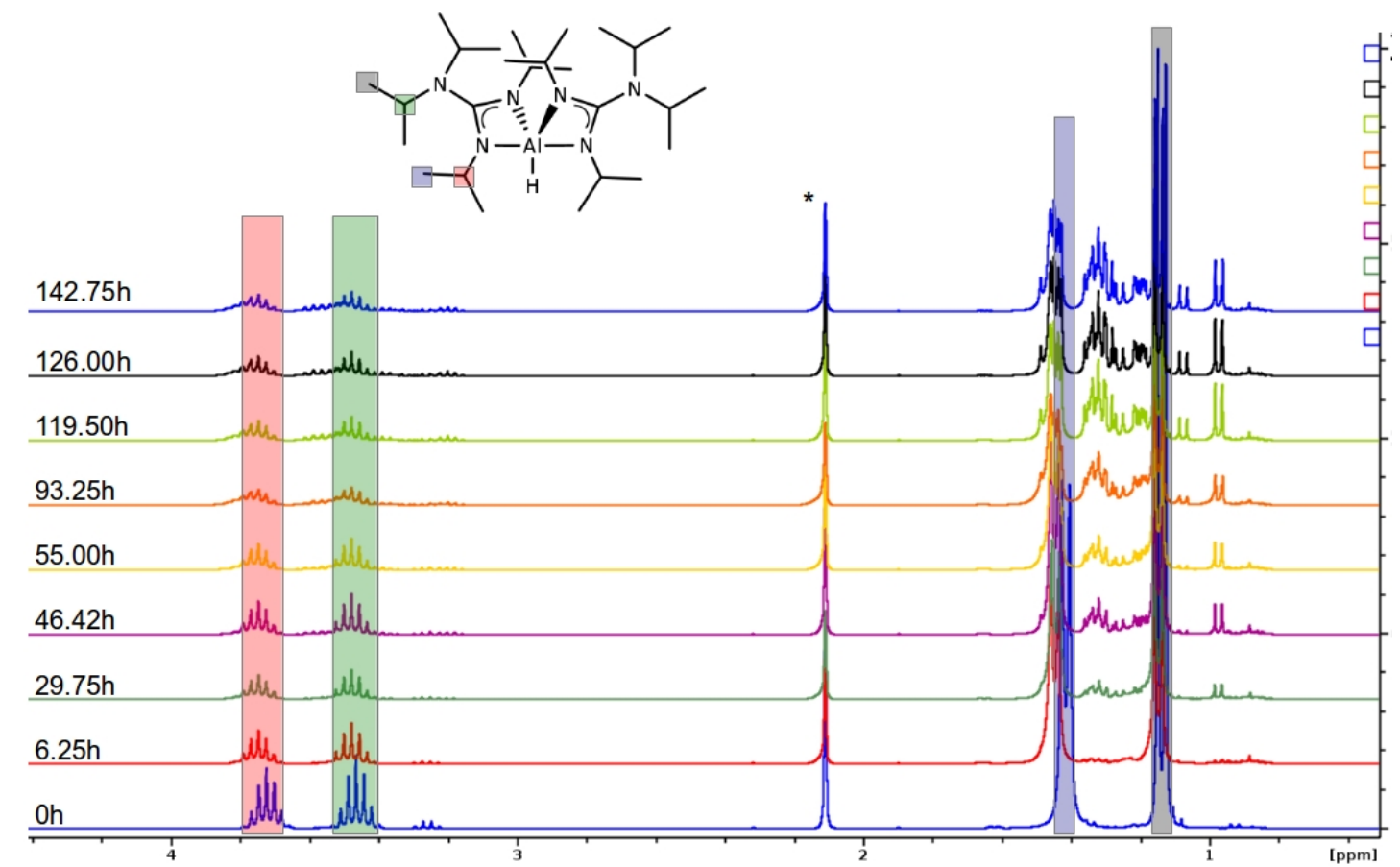

Figure 4.12: ${ }^{1} \mathrm{H}$ HR-NMR spectra for the thermolysis of $\mathbf{6}$. The time shown (in hours) indicates the time held at $65^{\circ} \mathrm{C}$. * is residual toluene.
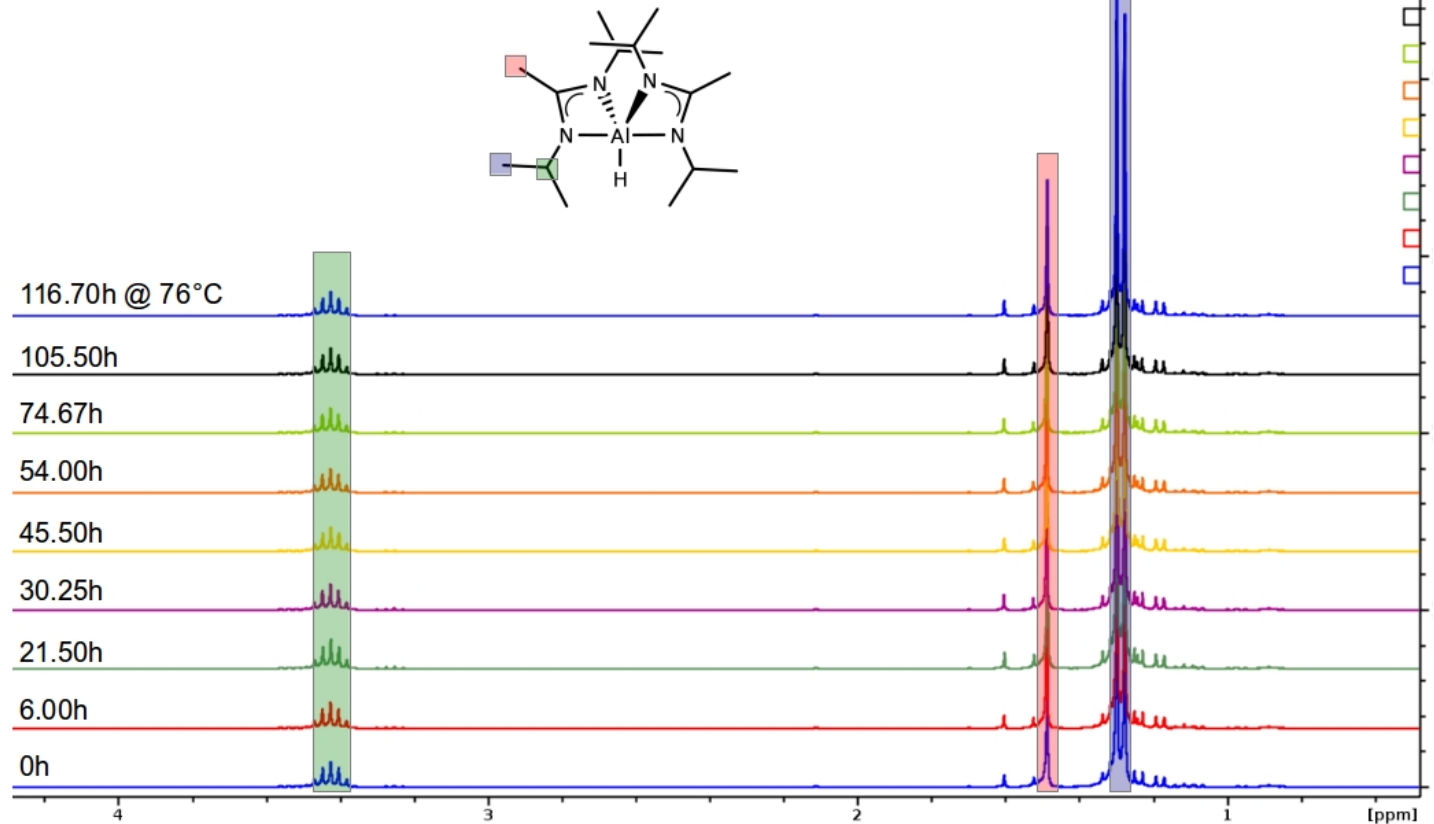

Figure 4.13: ${ }^{1} \mathrm{H}$ HR-NMR spectra for the thermolysis of 7 . The time shown (in hours) indicates the time held at $65{ }^{\circ} \mathrm{C}$. The top trace shows 7 held at $76{ }^{\circ} \mathrm{C}$ for $116.70 \mathrm{~h}$ after being held at $65^{\circ} \mathrm{C}$ for $105.50 \mathrm{~h}$. 


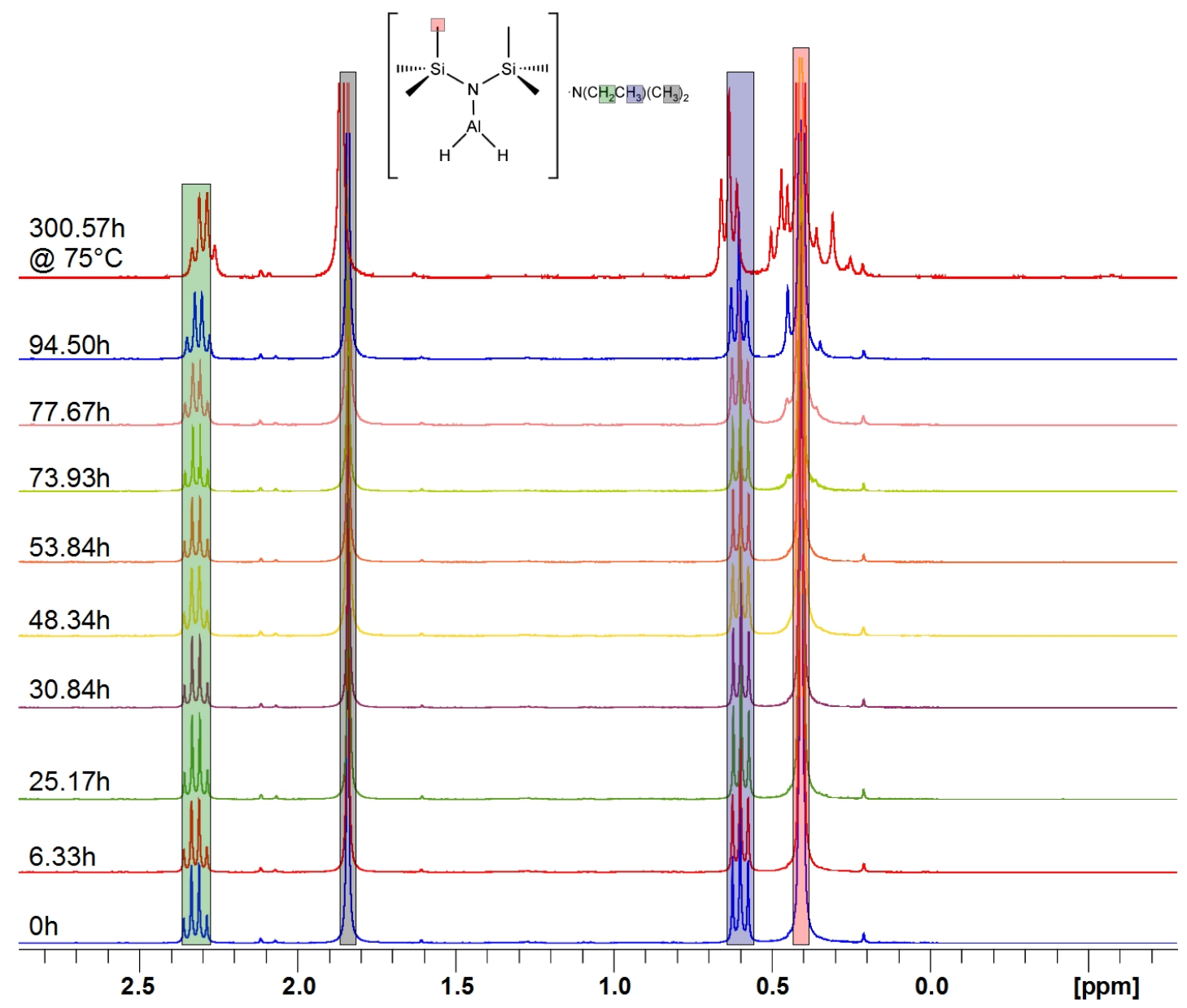

Figure 4.14: ${ }^{1} \mathrm{H}$ HR-NMR spectra for the thermolysis of 8 . The time shown (in hours) indicates the time held at $65{ }^{\circ} \mathrm{C}$. The top trace shows 8 held at $75{ }^{\circ} \mathrm{C}$ for $300.57 \mathrm{~h}$ after being held at $65{ }^{\circ} \mathrm{C}$ for $94.50 \mathrm{~h}$. 


\section{Part II}

\section{Group 11}




\section{Chapter 5}

\section{Copper Iminopyrrolidinates: A Study of Thermal and Surface Chemistry}

Modified from the original manuscripts published as:


S.T. ${ }^{\dagger}$ Preventing Thermolysis: Precursor Design for Volatile Copper Compounds, Chem. Commun., 2012, 48, 10440-10442.

Coyle, J.P., ${ }^{\dagger}$ Pallister, P.J., ${ }^{\dagger}$ Kurek, A., ${ }^{\dagger}$ Sirianni, E.R. ${ }^{\ddagger}{ }^{\text {Yap, G.P.A. }},{ }^{\ddagger}$ and Barry, S.T. ${ }^{\dagger}$ Copper Iminopyrrolidinates: A Study of Thermal and Surface Chemistry, Inorg. Chem., 2013, 52, 910-917.

${ }^{\dagger}$ Department of Chemistry, Carleton University, 1125 Colonel By Drive, Ottawa, Ontario, K1S 5B6, Canada

${ }_{\ddagger}^{\ddagger}$ Department of Chemistry \& Biochemistry, University of Delaware, Newark, United States 


\subsection{Abstract}

Several copper(I) iminopyrrolidinates have been evaluated by TGA and solution based ${ }^{1} \mathrm{H}$ HR-NMR studies to determine their thermal stability and decom-

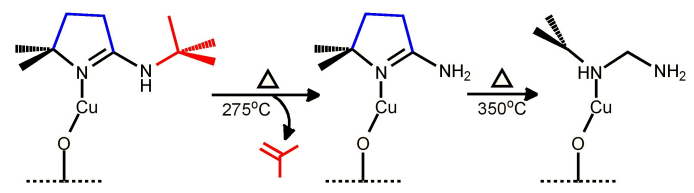

Figure 5.1: Table of Contents graphic used for publication described in Chapter 5 position mechanisms. Iminopyrrolidinates were used as a ligand for copper(I) to block previously identified decomposition routes of carbodiimide deinsertion and $\beta$-hydrogen abstraction. The compounds copper(I) isopropyl-iminopyrrolidinate (9) and copper(I) tert-butyl-iminopyrrolidinate (10) were synthesized for this study, and compared to the previously reported copper(I) tert-butyl-imino-2,2-dimethylpyrrolidinate (11) and the copper(I) guanidinate $\left(\mathrm{Me}_{2} \mathrm{NC}(\mathrm{iPrN})_{2} \mathrm{Cu}\right)_{2}$ (12). Compounds 9 and $\mathbf{1 0}$ were found to be volatile yet susceptible to decomposition during TGA. At $165{ }^{\circ} \mathrm{C}$ in $\mathrm{C}_{6} \mathrm{D}_{6}$, they had half-lives of $181.7 \mathrm{~h}$ and $23.7 \mathrm{~h}$, respectively. The main thermolysis product of $\mathbf{9}$ and $\mathbf{1 0}$ was their respective protonated iminopyrrolidine ligand. $\beta$-Hydrogen abstraction was proposed for the mechanism of thermal decomposition. Since compound $\mathbf{1 1}$ showed no thermolysis at $165{ }^{\circ} \mathrm{C}$, it was further studied by chemisorption on high surface area silica. It was found to eliminate an isobutene upon chemisoption at $275^{\circ} \mathrm{C}$. Annealing the sample at $350{ }^{\circ} \mathrm{C}$ showed further evidence of the decomposition of the surface species, likely eliminating ethene, and producing a surface bound methylene diamine.

\subsection{Introduction}

Copper metal remains an interesting topic for CVD and ALD because of its use in microelectronics, primarily as an interconnect. ${ }^{111}$ One class of particularly well-studied precursors are the amidinates, which originated from the Gordon group in the early 


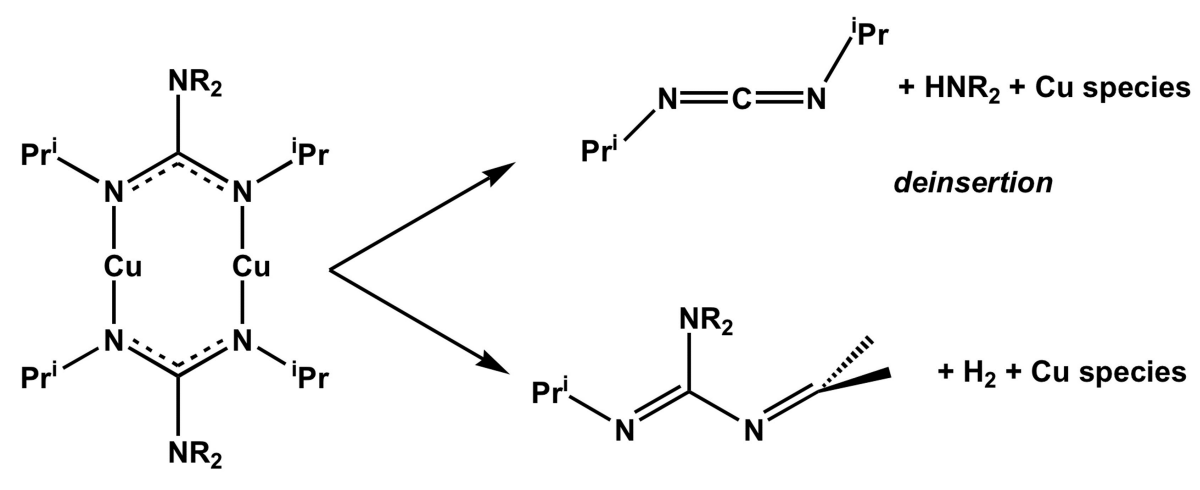

$\beta$-hydrogen elimination

Figure 5.2: Two thermal decomposition pathways for a copper(I) guanidinate species. 2000s. ${ }^{84,108}$ Copper amidinates have utility in $\mathrm{ALD}^{84}$ and $\mathrm{CVD}^{112}$ processes between temperatures of $150-240{ }^{\circ} \mathrm{C}$ when using hydrogen as a reducing agent. Copper(I)$N, N$-diisopropylacetamidinate has been shown to undergo CVD deposition as low as $140{ }^{\circ} \mathrm{C},{ }^{75,113}$ and produces free amidine, acetonitrile, propene, and iminopropane when allowed to thermally decompose in the absence of a reducing agent. ${ }^{114}$ These findings have been corroborated in the surface study work of copper(I) acetamidinates on nickel where, above $130{ }^{\circ} \mathrm{C}$, the self-limiting nature of the monolayer is compromised and continuous uptake of the copper precursor is observed. Similar ligand fragments were identified in the surface work as in the gas phase work.

We have previously investigated the thermal decomposition of copper(I) guanidinates, which are similar to amidinates except that the exocyclic group is an amide, rather than an alkyl. ${ }^{115,116}$ Using a guanidinate with isopropyl groups on the chelating nitrogens, we found two distinct thermal decomposition mechanisms (Figure 5.2). In solution at lower temperatures, the guanidinate deinserted CDI and produced the parent amine of the exocyclic amide group. ${ }^{115} \mathrm{In}$ the gas phase at greater than $150{ }^{\circ} \mathrm{C}$, the methylene carbon of the isopropyl group on the chelating nitrogen loses a hydrogen and produces an oxidized guanidine. Hydrogen gas is also found as a thermolysis side product. ${ }^{116}$

Both of these thermal decomposition mechanisms are troubling from the point of view of developing a copper precursor for ALD. In the first case, the elimination 
of the oxidized guanidinate by $\beta$-hydrogen abstraction produces a copper hydride, which readily eliminates dihydrogen or parent guanidine to produce copper metal. This circumscribes an ALD process in favour of a CVD process. CDI deinsertion also greatly limits the use of this precursor in thermal processes. The formation of a (transient) copper-amide bond creates a species that will readily decompose ${ }^{117}$ thus also preventing ALD in favour of a CVD process.

A redesign of the basic amidinate framework is necessary to remove the known thermal decomposition pathways of this ligand family. Our group has developed and extensively characterized a novel iminopyrrolidinate ligand family that has evidenced good thermal stability. Recently, we have reported a family of volatile, stable aluminum compounds. ${ }^{118}$ This ligand has a five-membered ring linking one chelate nitrogen to the bridgehead (i.e., quaternary) carbon of the amidinate, thus preventing CDI deinsertion. Likewise, the ligand has been synthesized to allow control over the number of $\beta$-hydrogens, resulting in a series of four related copper(I) iminopyrrolidinates (Figure 5.3). Herein we introduce three novel copper iminopyrrolidinates (copper(I) isopropyl-iminopyrrolidinate- $\mathbf{9}$, copper(I) tert-butyl-iminopyrrolidinate-10, and copper(I) tert-butyl-imino-2,2-dimethylpyrrolidinate-11) to complement our previously reported copper(I) $N, N$-diisopropyl- $N, N$-dimethyl guanidinate (12). ${ }^{115} \mathrm{~A}$ thorough exploration of the thermal chemistry of these four compounds was made to demonstrate how the redesign of this ligand has influenced thermal behavior. We have investigated the thermal stability of this series in the solid phase using a variety of TGA methods, as well as in solution phase using ${ }^{1} \mathrm{H}$ HR-NMR of sealed tubes that have been treated at elevated temperatures to study decomposition kinetics. Finally, because of the superior thermal stability of 11, we have undertaken an extensive study of the nature of the chemisorbed species produced on silica by $\mathbf{1 1}$ as deposited at $275^{\circ} \mathrm{C}$ and when annealed at $350{ }^{\circ} \mathrm{C}$. 

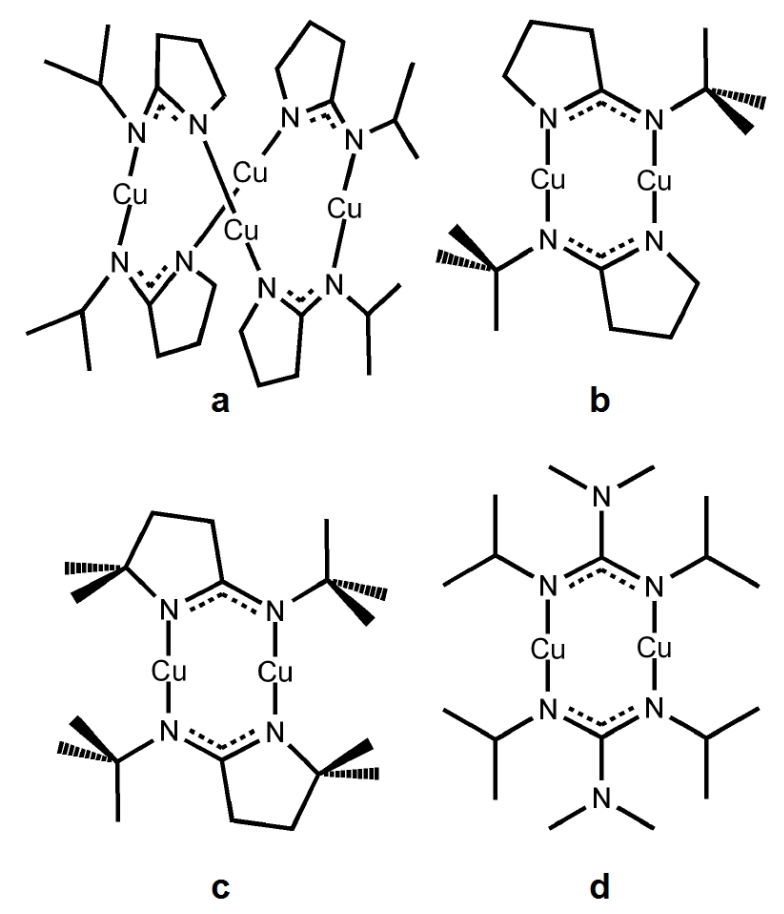

Figure 5.3: Series of amidinate-type ligands with differing numbers of $\beta$-hydrogens, shown as their corresponding copper(I) compounds 9 (a), 10 (b), 11 (c), and 12 (d).

\subsection{Experimental}

\section{General Considerations}

All manipulations involving the synthesis and handling of copper(I) compounds were performed in a nitrogen filled drybox. The chemicals $\mathrm{CuCl}$ and $2.5 \mathrm{M} \mathrm{BuLi}$ in hexanes were purchased from Aldrich Chemical Co. and used as received. All solvents used in manipulation of copper(I) compounds were ACS grade and purified from an Mbraun Solvent Purifier System. All other solvents were ACS grade and used as received. High-resolution nuclear magnetic resonance was done on $300 \mathrm{MHz}$ Avance 3 and $400 \mathrm{MHz}$ Bruker AMX. Canadian Microanalytical Service Ltd. performed combustion analyses. Thermogravimetric analysis was performed on a TA Instruments Q50 apparatus located in an MBraun Labmaster 130 Drybox under a nitrogen atmosphere. Isopropyl-iminopyrrolidine and tert-butyl iminopyrrolidine were prepared by literature procedures. ${ }^{118}$ 


\section{Copper(I) Isopropyl-iminopyrrolidinate (9)}

Isopropyl-iminopyrrolidine $(5.11 \mathrm{~g}, 40.49 \mathrm{mmol})$ was partially dissolved in $60 \mathrm{ml}$ of $\mathrm{Et}_{2} \mathrm{O}$ and cooled to $0{ }^{\circ} \mathrm{C}$ in an ice bath. A $16.2 \mathrm{ml}$ portion of butyl lithium was added dropwise, and a suspension formed after stirring for $2 \mathrm{~h}$. In a separate flask, $\mathrm{CuCl}$ (4.2 g, $42.42 \mathrm{mmol}$ ) was suspended in $60 \mathrm{ml}$ of tetrahydrofuran (THF) and cooled to $0{ }^{\circ} \mathrm{C}$ in an ice bath. The suspension of lithium isopropyl-iminopyrrolidine was added via cannula to the cooled suspension of $\mathrm{CuCl}$ and was then allowed to warm to room temperature and stirred overnight. The volatiles were removed from the reaction flask by reduced pressure, and the remaining solid was stirred in $100 \mathrm{ml}$ of toluene for $10 \mathrm{~min}$. The cloudy solution was filtered, and the clear filtrate was concentrated under vacuum and kept at $-35{ }^{\circ} \mathrm{C}$ for 2 days. A mass of small, needle crystals was collected by filtration, washed with pentane, and then dried under vacuum to afford $5.03 \mathrm{~g}, 65.8 \%$. Mp $138{ }^{\circ} \mathrm{C} .{ }^{1} \mathrm{H}$ HR-NMR $\left(400 \mathrm{MHz}, \mathrm{C}_{6} \mathrm{D}_{6}\right): \delta 3.49, \delta 3.24(\mathrm{~m}, 1 \mathrm{H}$, $\left.\mathrm{NCH}\left(\mathrm{CH}_{3}\right)_{2}\right) ; \delta 3.34, \delta 3.26\left(\mathrm{t}, 2 \mathrm{H}, \mathrm{NCH}_{2} \mathrm{CH}_{2} \mathrm{CH}_{2} \mathrm{C}\right) ; 2.04\left(\mathrm{t}, 2 \mathrm{H}, \mathrm{NCH}_{2} \mathrm{CH}_{2} \mathrm{CH}{ }_{2} \mathrm{C}\right) ;$ $\delta 1.58$ (quintet, $2 \mathrm{H}, \mathrm{NCH}_{2} \mathrm{CH}_{2} \mathrm{CH}_{2} \mathrm{C}$ ) $; \delta 1.487, \delta 1.304, \delta 1.208, \delta 1.158(\mathrm{~d}, 6 \mathrm{H}$, $\left.\mathrm{NCH}\left(\mathrm{CH}_{3}\right)_{2}\right) .{ }^{13} \mathrm{C}$ HR-NMR $\left(300 \mathrm{MHz}, \mathrm{C}_{6} \mathrm{D}_{6}\right) \delta 179.84, \delta 175.38, \delta 54.19, \delta 53.30$, $\delta 53.15, \delta 51.19, \delta 50.48, \delta 50.00, \delta 29.02, \delta 28.69, \delta 28.65, \delta 27.70, \delta 27.55, \delta$ $27.39, \delta 27.36, \delta 24.99, \delta 24.72, \delta 24.64$. Combustion analysis, found (calculated): C, 44.63(44.55); H, 7.11(6.94); N, 14.84(14.84).

\section{Copper(I) tert-Butyl-iminopyrrolidinate (10)}

tert-Butyl iminopyrrolidine $(1.72 \mathrm{~g}, 12.26 \mathrm{mmol})$ was dissolved in $60 \mathrm{ml}$ of THF. A $4.9 \mathrm{ml}$ portion of $2.5 \mathrm{M}$ butyl lithium was added, and the solution was stirred for $2 \mathrm{~h} . \mathrm{CuCl}(1.25 \mathrm{~g}, 12.62 \mathrm{mmol})$ was added in one portion, and the suspension was stirred overnight. Volatiles were removed under reduced pressure, and the remaining solid was taken up in THF and filtered. The filtrate was concen- 
trated and then kept at $-35{ }^{\circ} \mathrm{C}$ for 1 day. Colourless, block crystals were collected by decanting the solution, washing with pentane, and then drying under vacuum; obtained $1.59 \mathrm{~g}, 63.9 \%$. Mp $148{ }^{\circ} \mathrm{C} .{ }^{1} \mathrm{H}$ HR-NMR $\left(300 \mathrm{MHz}, \mathrm{C}_{6} \mathrm{D}_{6}\right): \delta$ $3.25\left(\mathrm{t}, 2 \mathrm{H}, \mathrm{NCH}_{2} \mathrm{CH}_{2} \mathrm{CH}_{2} \mathrm{C}\right), \delta 2.19\left(\mathrm{t}, 2 \mathrm{H}, \mathrm{NCH}_{2} \mathrm{CH}_{2} \mathrm{CH}_{2} \mathrm{C}\right.$ ), $\delta 1.63$ (quintet, $2 \mathrm{H}$, $\left.\mathrm{NCH}_{2} \mathrm{CH}_{2} \mathrm{CH}_{2} \mathrm{C}\right), \delta 1.32\left(\mathrm{~s}, 9 \mathrm{H}, \mathrm{NC}\left(\mathrm{CH}_{3}\right)_{3}\right) .{ }^{13} \mathrm{C}$ HR-NMR $\left(300 \mathrm{MHz}, \mathrm{C}_{6} \mathrm{D}_{6}\right): \delta$ $180.01\left(\mathrm{NCH}_{2} \mathrm{CH}_{2} \mathrm{CH}_{2} \mathrm{C}\right), \delta 52.45\left(\mathrm{NCH}_{2} \mathrm{CH}_{2} \mathrm{CH}_{2} \mathrm{C}\right), \delta 33.72\left(\mathrm{NC}\left(\mathrm{CH}_{3}\right)_{3}\right), \delta 33.26$ $\left(\mathrm{NC}\left(\mathrm{CH}_{3}\right)_{3}\right), \delta 31.64\left(\mathrm{NCH}_{2} \mathrm{CH}_{2} \mathrm{CH}_{2} \mathrm{C}\right), \delta 26.33\left(\mathrm{NCH}_{2} \mathrm{CH}_{2} \mathrm{CH}_{2} \mathrm{C}\right)$. Combustion analysis, found (calculated): C, 47.08(47.39); H, 7.49(7.46); N, 13.69(13.82).

\section{Copper(I) tert-Butyl-imino-2,2-dimethylpyrrolidinate (11)}

Tert-butyl-imino-2,2-dimethylpyrrolidine (5.103 g, $13.07 \mathrm{mmol}$ ) was dissolved in $170 \mathrm{ml}$ of toluene and the solution was cooled on an ice bath. $12.13 \mathrm{ml}$ of $2.5 \mathrm{M} \mathrm{BuLi}$ was added dropwise. The solution warmed to r.t as it stirred overnight. $\mathrm{CuCl}$ (3.26 g, $32.9 \mathrm{mmol})$ was added and stirring continued for $18 \mathrm{~h}$. The cloudy, light brown solution was filtered and the filter cake was extracted with 4 x 20 of THF. Volatiles were stripped from the combined toluene and THF solutions to afford an off-white solid. The solid was sublimed at $130{ }^{\circ} \mathrm{C}$ at 40 mTorr and $5.795 \mathrm{~g}$, $82.7 \%$, of a white solid was obtained. $\mathrm{Mp}>270{ }^{\circ} \mathrm{C} . \quad{ }^{1} \mathrm{H}$ HR-NMR $(300 \mathrm{MHz}$, $\left.\mathrm{C}_{6} \mathrm{D}_{6}\right): \delta 2.428\left(\mathrm{t}, 2 \mathrm{H}, \mathrm{NC}\left(\mathrm{CH}_{3}\right)_{2} \mathrm{CH}_{2} \mathrm{CH}_{2} \mathrm{C}\right), \delta 1.581\left(\mathrm{t}, 2 \mathrm{H}, \mathrm{NC}\left(\mathrm{CH}_{3}\right)_{2} \mathrm{CH}_{2} \mathrm{CH}_{2} \mathrm{C}\right)$, $\delta 1.328\left(\mathrm{~s}, 9 \mathrm{H}, \mathrm{NC}\left(\mathrm{CH}_{3}\right)_{3}\right), \delta 1.196\left(\mathrm{~s}, 6 \mathrm{H}, \mathrm{NC}\left(\mathrm{CH}_{3}\right)_{2} \mathrm{CH}_{2} \mathrm{CH}_{2} \mathrm{C}\right) \cdot{ }^{13} \mathrm{C}$ HR-NMR $\left(300 \mathrm{MHz}, \mathrm{C}_{6} \mathrm{D}_{6}\right): \delta 177.617\left(\mathrm{NC}\left(\mathrm{CH}_{3}\right)_{2} \mathrm{CH}_{2} \mathrm{CH}_{2} C\right), \delta 61.176\left(\mathrm{NC}\left(\mathrm{CH}_{3}\right)_{3}\right), \delta 53.332$ $\left(\mathrm{NC}\left(\mathrm{CH}_{3}\right)_{2} \mathrm{CH}_{2} \mathrm{CH}_{2} \mathrm{C}\right), \delta 38.095\left(\mathrm{NC}\left(\mathrm{CH}_{3}\right)_{2} \mathrm{CH}_{2} \mathrm{CH}_{2} \mathrm{C}\right), \delta 33.215\left(\mathrm{NC}\left(\mathrm{CH}_{3}\right)_{3}\right), \delta$ $31.931\left(\mathrm{NC}\left(\mathrm{CH}_{3}\right)_{2} \mathrm{CH}_{2} \mathrm{CH}_{2} \mathrm{C}\right), \delta 30.940\left(\mathrm{NC}\left(\mathrm{CH}_{3}\right)_{2} \mathrm{CH}_{2} \mathrm{CH}_{2} \mathrm{C}\right)$. Combustion analysis, found (calculated): C, 52.44(52.04); H, 8.36(8.30); N, 12.27(12.14). 


\section{Crystallography}

X-ray structural analysis for 9-11: Crystals were selected and mounted on plastic mesh using viscous oil flash-cooled to the data collection temperature. Data were collected on a Bruker-AXS APEX CCD diffractometer with graphite-monochromated MoK $\alpha$ radiation $(\lambda=0.71073 \AA)$. Unit cell parameters were obtained from 60 data frames, $0.3^{\circ} \omega$, from three different sections of the Ewald sphere. The systematic absences in the data and the unit cell parameters were uniquely consistent to $C c c a$ for 9 to $P 21 / c$ for 10 and 11. The data sets were treated with SADABS absorption corrections based on redundant multiscan data. ${ }^{106}$ The structures were solved using direct methods and refined with full-matrix, least-squares procedures on $F^{2}$. The compound molecules were each located on an inversion point in 10 and 11. Two symmetry unique but chemically identical molecules of the compound in $\mathbf{9}$ are each located on a 2-fold rotation axis: in one case the 2-fold axis is parallel to the $\mathrm{NCuN}$ axis and in the other case the 2-fold axis is perpendicular to the $\mathrm{NCuN}$ axis bisecting the $\mathrm{Cu}$ atoms on the opposite distal positions of the tetracopper rhombus. One THF solvent molecule of crystallization per two tetrameric complexes in $\mathbf{9}$ was located

severely disordered and treated as diffused contribution. ${ }^{119}$ One isopropyl group in 9 was located disordered with a 23/77 refined occupancy ratio. Chemically equivalent bond distances and angles in the disordered group were restrained to average values with equal atomic displacement atomic parameter constraints on equivalent atoms. All non-hydrogen atoms were refined with anisotropic displacement parameters. All hydrogen atoms were treated as idealized contributions. Atomic scattering factors are contained in the SHELXTL 6.12 program library. ${ }^{106}$ 


\section{Surface Exposure Experiments}

The exposure experiments were performed in a home-built reactor. The reaction chamber consisted of a stainless steel ring support covered in 200 stainless steel mesh with a plug of glass wool to prevent loss of silica powder. The system had one inlet from a heated bubbler and one inlet for He (purity of 99.999\%). All fittings used in this system were either CF or VCR to ensure a high-vacuum seal. The system was leak checked using a gas thermal conductivity/leak detector (Gow-Mac Instrument Co.) and an overpressure of He. For the exposure experiments, typically about $1 \mathrm{~g}$ of high surface area $\mathrm{SiO}_{2}$ powder (EP10X; PQ Corporation; $300 \mathrm{~m}^{2} / \mathrm{g}$ S.A.; $1.8 \mathrm{c}^{3} \mathrm{~m} / \mathrm{g}$ P.V.; $24 \mathrm{~nm}$ P.S.; $100 \mu \mathrm{m}$ P.D.) was used. The powder was pretreated in the reactor at 350 ${ }^{\circ} \mathrm{C}$ for $16 \mathrm{~h}$ under vacuum before exposure to the precursor. The reactor and lines were heated to temperature and allowed to equilibrate for $1-2 \mathrm{~h}$ before introduction of the precursor. The precursor (typically $0.6-0.8 \mathrm{~g}$ ) was then vapourized and transported to the substrate with the system under $10^{3}$ Torr vacuum. The substrate was exposed to volatilized precursor for $17 \mathrm{~h}$ before the system was cooled to room temperature for handling. Both precursor and substrate were handled in inert atmosphere.

Annealing experiments were performed in a tube furnace while under vacuum. Samples were loaded into the furnace under a blanket of nitrogen gas. Samples were annealed for $2 \mathrm{~h}$.

\section{Characterization of Surface Species}

SS-NMR experiments were performed at $4.7 \mathrm{~T}$ on a Bruker Avance III console. All spectra were obtained using a Bruker $7 \mathrm{~mm}{ }^{1} \mathrm{H} / \mathrm{X} / \mathrm{Y}$ probe. ${ }^{13} \mathrm{C}\left(\nu_{0}=50.3 \mathrm{MHz}\right)$ $\mathrm{CP} / \mathrm{MAS}$ experiments were collected at a spinning rate of $4.5 \mathrm{kHz}$ using a $3.4 \mu \mathrm{s}$ $90^{\circ}$ proton pulse with a contact time of $2 \mathrm{~ms}$ where the contact pulse was ramped on the ${ }^{1} \mathrm{H}$ channel. A relaxation delay of $2 \mathrm{~s}$ was sufficient to prevent saturation 
and typically total acquisition times were 16-30 h. Glycine was used as an external secondary reference for the ${ }^{13} \mathrm{C}$ chemical shift scale. Spectra were treated with $40 \mathrm{~Hz}$ line broadening during processing. ${ }^{29} \mathrm{Si}\left(\nu_{0}=39.7 \mathrm{MHz}\right) \mathrm{CP} / \mathrm{MAS}$ experiments were collected at a spinning rate of $4.5 \mathrm{kHz}$ using a $3.85 \mu \mathrm{s} 90^{\circ}$ proton pulse with a contact time of $10 \mathrm{~ms}$ where the ${ }^{1} \mathrm{H}$ channel contact pulse was ramped. The relaxation delay was $2 \mathrm{~s}$ and typically required $2-8 \mathrm{~h}$ acquisition times. TMSS was used as an external reference for the ${ }^{29} \mathrm{Si}$ chemical shift scale. Spectra were treated with $30 \mathrm{~Hz}$ line broadening during processing. All spectra were obtained with high power proton decoupling during acquisition.

Samples were prepared for HR-NMR by adding a small amount, typically 40-50 $\mathrm{mg}$, of modified silica powder to $2 \mathrm{~mL}$ of $\mathrm{D}_{2} \mathrm{O}$ (Sigma), agitating, and allowed to sit for 15 min. The $\mathrm{D}_{2} \mathrm{O}$ solution was then decanted and studied via HR-NMR. $d_{4}$-TSP was used as an internal reference.

EDX was performed on the modified silica samples as qualitative proof for the presence of copper. Samples were mounted on an aluminum support using carbon tape and loaded into a Tescan Vega II SEM equipped with an Oxford Inca 200 EDX for analysis.

\subsection{Results and Discussion}

\section{Synthesis}

The copper compounds $\mathbf{9}$ and $\mathbf{1 0}$ were simply made by salt methathesis of copper(I) chloride with the in situ generated lithium iminopyrrolidinates. These compounds were isolated as white crystalline materials in moderate to high yields. Similarly, a recent paper describes trimeric, heteroleptic copper(I) guanidinates isolated from the attempted synthesis of $\left(\mathrm{Me}_{2} \mathrm{NC}(\mathrm{NtBu})_{2} \mathrm{Cu}\right)_{2} \cdot{ }^{120}$ We believe the ring of the iminopyrrolidinates reported herein was necessary to slightly reduce the steric bulk 



Figure 5.4: The synthetic procedure for producing the tert-butyl-imino-2,2dimethylpyrrolidine ligand.

and permit the isolation of $\mathbf{1 0}$ as a dimeric species (Figure 5.5). The synthesis of $\mathbf{1 1}$ was not as straightforward. The iminopyrrolidines without substitutions on the ring could easily be synthesized by starting with the 2-pyrrolidone. The 5,5-dimethyl-2pyrrolidone was not commercially available and so a novel synthetic route for producing substituted iminopyrrolidines was developed, particularly for tert-butyl-imino-2,2dimethylpyrrolidinate (Figure 5.4). The lithium salt of this compound could then be prepared using BuLi followed by salt metathesis with copper(I) chloride to produce 11.

The ${ }^{1} \mathrm{H}$ HR-NMR of $\mathbf{1 0}$ was simple, suggesting a symmetrical oligomeric solution structure, similar to known copper guanidinate dimers. ${ }^{115}$ However, 9 showed a more complex ${ }^{1} \mathrm{H}$ HR-NMR. The doublets for the methyls of the isopropyl moiety in $\mathbf{9}$ suggested several environments. It is unclear if these multiple environments were due to an equilibrium of oligomers or from asymmetry in the molecule, but the relative integrations of these doublets were dependent on the concentration of $\mathbf{9}$. Neither serial dilution of an NMR sample or heating of the sample to $60{ }^{\circ} \mathrm{C}$ yielded a trivial set of peaks similar to the spectra of $\mathbf{1 0}$. The data from the ${ }^{1} \mathrm{H}$ HR-NMR suggests that the species might be in an oligomeric equilibrium where the exterior proton environments are disordered in the structure, while the interior ring protons are more disordered. Fortunately, 9 could be isolated as X-ray quality crystals. 

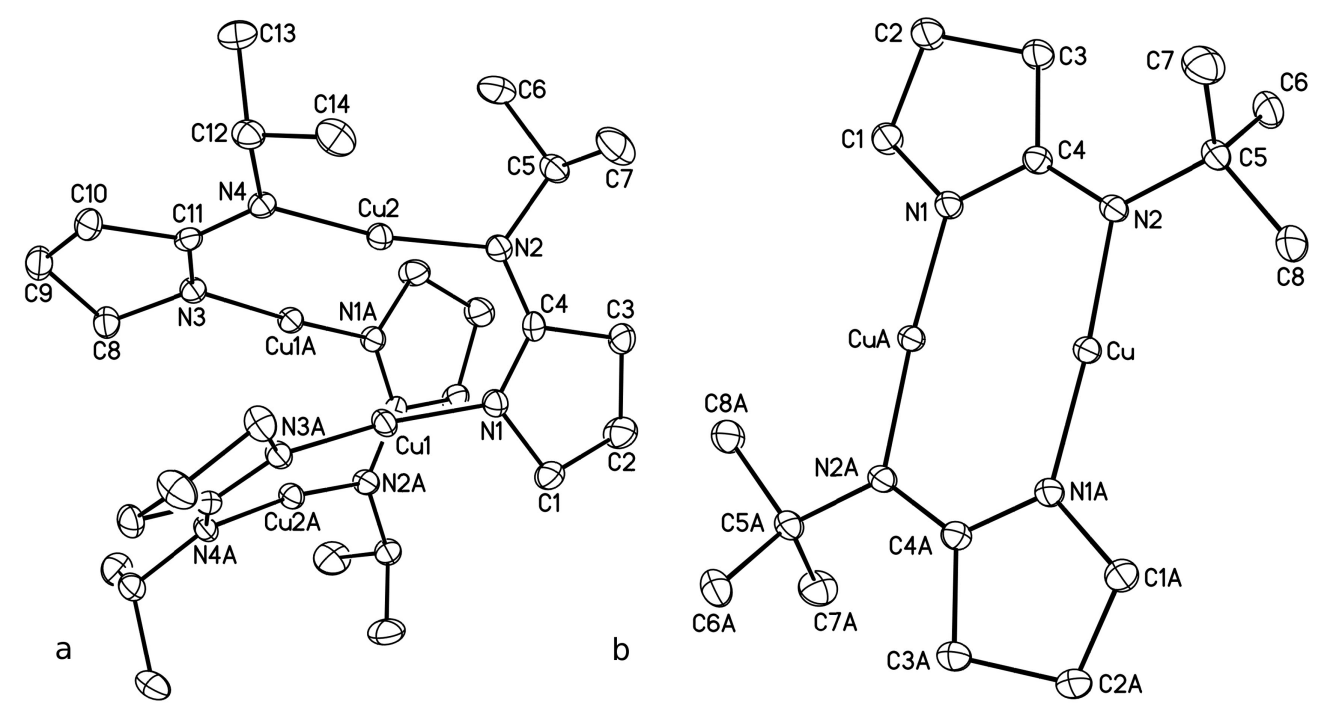

Figure 5.5: X-ray structures of (a) 9 and (b) 10, shown with the hydrogens removed for clarity. The thermal ellipsoids are at $30 \%$.

\section{Crystallography}

The structure of $\mathbf{9}$ shows a tetrameric arrangement in the solid state with an orthorhombic Ccca space group (Figure 5.5, Table 5.1). There are 16 tetramers in the unit cell, but only two that are crystallographically distinct. These molecules each have a core of four copper atoms that lay in a rhombohedral plane, with the rhombus of one molecule centered perpendicular to a C2 axis (with a minor torsion angle of $1.31^{\circ}$ ), and the other parallel to a different $\mathrm{C} 2$ axis (with a torsion angle of $0^{\circ}$ ). The closest $\mathrm{Cu}-\mathrm{Cu}$ contact in the unit cell is $2.76 \AA$, which suggests there is no significant $\mathrm{Cu}-\mathrm{Cu}$ interactions. ${ }^{121}$ This is supported by the fact that the $\mathrm{N}-\mathrm{Cu}-\mathrm{N}$ bonds only deviate from linearity by about $10^{\circ}$, which is likely caused by steric hindrance in the ligands (see below). Since the connectivity of the molecules in the unit cell is very similar, only one molecule will be discussed in depth.

Interestingly, the two ligands bonded to any specific copper are bonded through the same type of nitrogen. For example Cu1 is bonded to the ring nitrogens N1 and N3, where one might expect the ligands to alternate. Additionally, the isopropyl groups of the ligand are all oriented toward the copper plane. These observations suggest that there is a fine balance of steric interference across the copper plane 


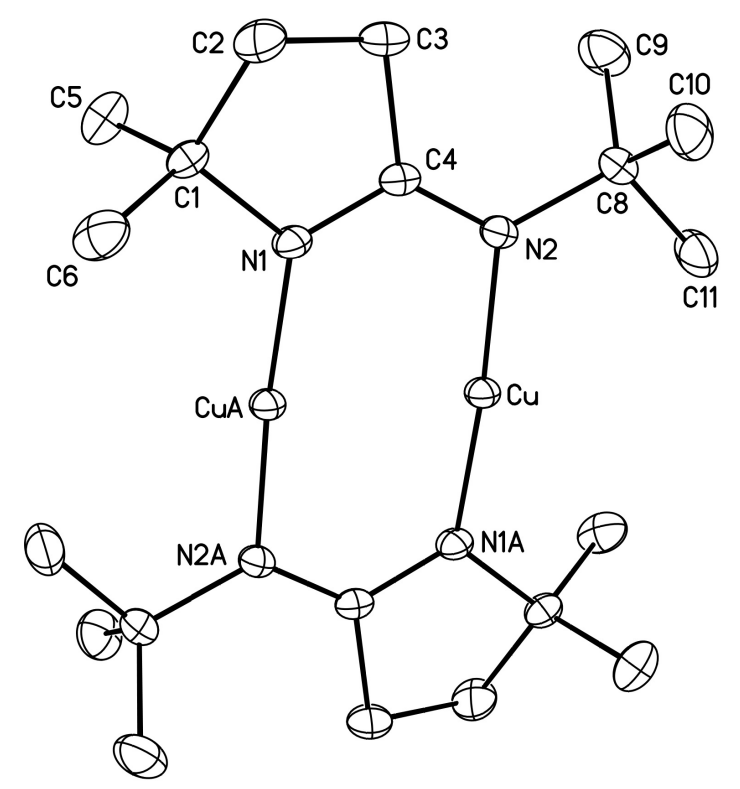

Figure 5.6: X-ray structure of $\mathbf{1 1}$, shown with the hydrogens removed for clarity. The thermal ellipsoids are at $30 \%$.

allowing a tetramer to form. This structure type has been seen previously for group 11. ${ }^{122-124}$ The $\mathrm{Cu}-\mathrm{N}$ bonds in this molecule have an average length of $1.88 \AA$, which is the same as in $\mathbf{1 1}$.

Considering the ligands oriented parallel to each other and on the same side of the copper plane, it is obvious that more crowding exists here. The ligands bend out slightly from one another, on average $26.5^{\circ}$ from parallel. As well, there is a slight twist of about $6^{\circ}$ across each ligand with respect to the line defined by the coppers which bind them.

The metallocycle C-N bonds are all about equivalent in this molecule $(1.31 \AA-1.34 \AA)$, suggesting complete delocalization of the double bond, similar to 11. The ligands bridging N-C-N angle is about $123^{\circ}$, which is slightly larger than 11 (Figure 5.6) and 12. ${ }^{115}$ This is quite understandable in the case of the tetramer, however, since the ligand is bridging a significantly large $\mathrm{Cu}-\mathrm{Cu}$ distance.

The structure of $\mathbf{1 0}$ is more typical of the expected dimeric structures, considering 11 and 12 (Figure 5.5 and 5.6, Table 5.1). It crystallized in the monoclinic $P 2_{1} / c$ space group with two molecules in the unit cell centered on inversion centers, where 
Table 5.1: Selected Bond Lengths and Angles for $\mathbf{9 - 1 1}$

\begin{tabular}{|c|c|c|c|c|c|}
\hline \multicolumn{2}{|c|}{ compound $\mathbf{9}$} & \multicolumn{2}{|c|}{ compound 10} & \multicolumn{2}{|c|}{ compound 11} \\
\hline selected bond & length $(\AA)$ & selected bond & length $(\AA)$ & selected bond & length $(\AA)$ \\
\hline $\mathrm{Cu} 1-\mathrm{Cu} 2$ & $2.756(1)$ & $\mathrm{Cu}-\mathrm{Cu}$ & $2.481(2)$ & $\mathrm{Cu}-\mathrm{Cu}$ & $2.4726(5)$ \\
\hline Cu1-Cu1a & $2.995(1)$ & $\mathrm{Cu}-\mathrm{N} 1$ & $1.862(2)$ & $\mathrm{Cu}-\mathrm{N} 1$ & $1.867(1)$ \\
\hline $\mathrm{Cu} 1-\mathrm{N} 1$ & $1.871(5)$ & $\mathrm{Cu}-\mathrm{N} 2$ & $1.887(2)$ & $\mathrm{Cu}-\mathrm{N} 2$ & $1.887(1)$ \\
\hline Cu1-N3 & $1.861(5)$ & N1-C4 & $1.336(2)$ & N1-C4 & $1.330(2)$ \\
\hline $\mathrm{Cu} 2-\mathrm{N} 2$ & $1.885(5)$ & $\mathrm{N} 2-\mathrm{C} 4$ & $1.328(2)$ & $\mathrm{N} 2-\mathrm{C} 4$ & $1.328(2)$ \\
\hline $\mathrm{Cu} 2-\mathrm{N} 4$ & $1.894(5)$ & & & & \\
\hline N1-C4 & $1.311(8)$ & & & & \\
\hline $\mathrm{N} 2-\mathrm{C} 4$ & $1.337(8)$ & & & & \\
\hline N3-C11 & $1.311(8)$ & & & & \\
\hline N4-C11 & $1.331(8)$ & & & & \\
\hline N1-C1 & $1.443(9)$ & & & & \\
\hline $\mathrm{N} 2-\mathrm{C} 5$ & $1.458(9)$ & & & & \\
\hline $\mathrm{N} 3-\mathrm{C} 8$ & $1.462(8)$ & & & & \\
\hline N4-C12 & $1.487(9)$ & & & & \\
\hline \multicolumn{2}{|c|}{ compound $\mathbf{9}$} & \multicolumn{2}{|c|}{ compound $\mathbf{1 0}$} & \multicolumn{2}{|c|}{ compound 11} \\
\hline selected angle & angle $\left(^{\circ}\right)$ & selected angle & angle $\left(^{\circ}\right)$ & selected angle & angle $\left(^{\circ}\right)$ \\
\hline $\mathrm{Cu} 2-\mathrm{Cu} 1-\mathrm{Cu} 2$ & $114.13(2)$ & $\mathrm{N} 1-\mathrm{Cu}-\mathrm{N} 2$ & $175.29(6)$ & $\mathrm{N} 1-\mathrm{Cu}-\mathrm{N} 2$ & $175.59(6)$ \\
\hline $\mathrm{Cu} 1-\mathrm{Cu} 2-\mathrm{Cu} 1$ & $65.86(1)$ & N1-C4-N2 & $122.05(1)$ & N1-C4-N2 & $122.5(1)$ \\
\hline N3-Cu1-N1 & $170.5(1)$ & & & & \\
\hline $\mathrm{N} 2-\mathrm{Cu} 2-\mathrm{N} 4$ & $170.5(1)$ & & & & \\
\hline N1-C4-N2 & $123.6(3)$ & & & & \\
\hline N3-C11-N4 & $123.1(3)$ & & & & \\
\hline
\end{tabular}


both molecules in the unit cell are identical. The $\mathrm{Cu}-\mathrm{Cu}$ distance is $\approx 2.5 \AA$, which is significantly closer than in $\mathbf{9}$. The copper geometry is very close to linear, contorting by $4.7^{\circ}$ to lengthen the $\mathrm{Cu}-\mathrm{Cu}$ bond. The metallocycle core is planar with the core N-C bonds all essentially equivalent $(1.33 \AA-1.34 \AA)$, suggesting that the inherent double bond character is delocalized between these two bonds.

\section{Thermolysis}

\section{Thermogravimetric Analysis}

The thermolyses of $\mathbf{9}$ and $\mathbf{1 0}$ are quite encouraging. Compound $\mathbf{9}$ showed low residual mass using TGA, and a single feature in weight loss, suggesting that the species volatilized easily. This low residual mass was surprising. Not only does this compound possess $\beta$-hydrogen atoms for abstraction, but the tetrameric structure was expected to yield a lower vapor pressure from increased molecular mass. It is possible that there exists an oligomeric equilibrium that allows $\mathbf{9}$ to volatilize as a lower order oligomer (mass spectral analysis shows a dimer), thus providing a larger vapour pressure at lower temperature. This also explains why $\mathbf{9}$ has a similar onset of volatilization to the dimeric compounds $\mathbf{1 1}$ and $\mathbf{1 2}$.

Compound 10 showed more complex behavior. The residual mass was $28.1 \%$, which was close to the percent mass of copper $(31.3 \%)$ in this compound. The residual mass was confirmed to be metallic copper by powder X-ray diffraction, suggesting that $\mathbf{1 0}$ undergoes a low temperature reduction to produce $\mathrm{Cu}^{0}$. This has previously been observed in the case of both 12 and the copper amidinates. ${ }^{75,113}$ Because of the presence of the exocyclic pyrrolidine ring, the more favorable path for this thermal decomposition is $\beta$-hydrogen elimination rather than CDI deinsertion. This can be rationalized considering the crystal structure of $\mathbf{1 0}$. The distortion of the dimer core and lack of steric protection exposes the copper and enables it to interact with the 



Figure 5.7: Thermal stress test of compounds (a) $\mathbf{1 1}$ showing no change in residual mass with increasing sample mass, and (b) $\mathbf{9}$, showing increasing residual mass with increasing initial sample mass.

$\beta$-hydrogen atoms of neighboring molecules.

These compounds were also investigated by a thermal stress test using TGA. Essentially, a compound is measured using the same temperature ramp rate $\left(10{ }^{\circ} \mathrm{C} / \mathrm{min}\right)$ but using different sample masses. Thus, more sample would see higher temperatures because of the kinetics of thermolysis or volatilization. This valuable test can be used to gauge the behavior of the compound with respect to thermal handling during a deposition process, whether in the source bubbler or during the volatilization and entrainment to the deposition zone. A good example of this is the thermal stress test of 9 (Figure 5.7b). Compound 9 was shown to have a higher residual mass as the initial pan loading of the TG was increased. This indicated that it underwent decomposition as more compound was exposed to higher temperature. Compound 11 (Figure 5.7a) was seen to undergo no decomposition as pan loading was increased, demonstrating a superior thermal stability.

The residual mass trends for $\mathbf{9 - 1 2}$ can be seen in Figure 5.8. It should be noted that the top sample mass that could be accommodated was about $65 \mathrm{mg}$; this filled the sample pan in all cases. With the exception of $\mathbf{9}$, the stress trends are quite linear with an $R^{2}$ of 0.99 (fit lines not shown). Compound 9 showed a very slight deviation from linearity with an $R^{2}$ of 0.97 . This might be due to a higher preponderance of a dimeric rather than tetrameric species at higher temperature, caused by a shift 


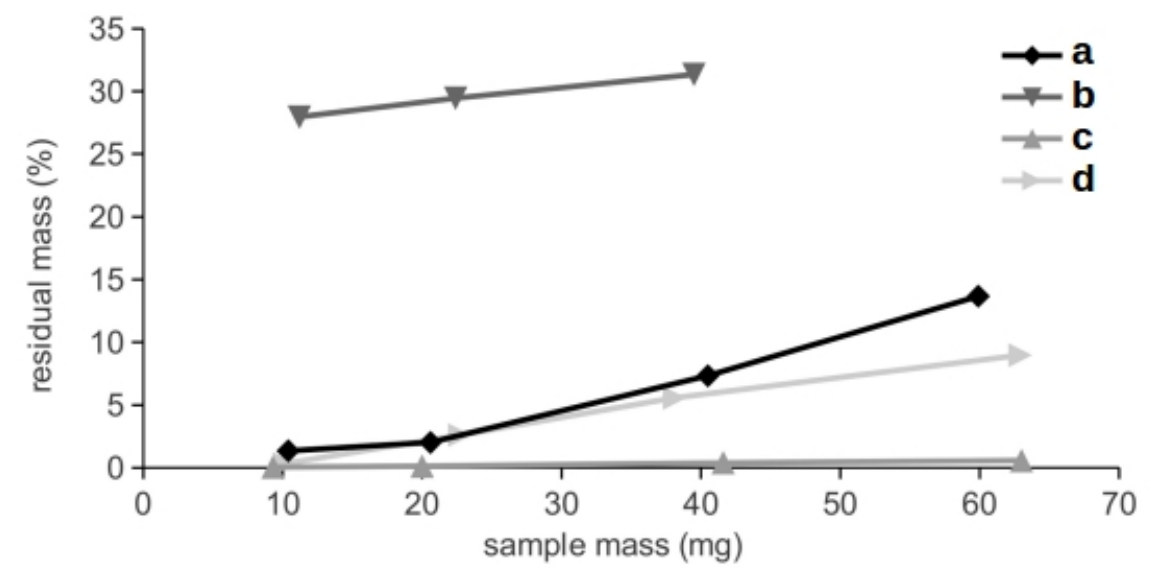

Figure 5.8: Thermal stress test trends for compounds 9 (a), 10 (b), 11 (c), and 12 (d).

in oligomer equilibrium. This shift may then alter the volatilization/decomposition properties of the overall sample.

Compounds 9 and 12 show the most stress, deviating from a negligible residual mass at low loadings to quite high residual masses (13.7\% for $\mathbf{9}$ and $9.0 \%$ for $\mathbf{1 2}$ ) at high loadings. It is not surprising that these two compounds show similar thermal stress, since they both bear an isopropyl group for $\beta$-hydrogen elimination although CDI deinsertion cannot be ruled out in the case of $\mathbf{1 2}$.

Compound 10 again showed poor thermal behavior with very high residual masses. Indeed, the highest loading was not attempted for $\mathbf{1 0}$ since the $39.5 \mathrm{mg}$ of sample gave $31.35 \%$, which is the mass percent of copper in that compound $(31.32 \%)$. This was not surprising, given the high residual mass seen previously. This reactivity stands out because $\mathbf{1 0}$ can be considered of intermediate reactivity with respect to number of $\beta$-hydrogens within this family. However, it has a dimeric structure (unlike $\mathbf{9}$, which exists in the solid as a tetramer) and so is less sterically protected at the copper centers. This would lend it worse thermal stability.

Compound 11 showed very good thermal stress resistance, rising only to $0.56 \%$ residual mass at $63.0 \mathrm{mg}$ sample mass. This supports our hypothesis that $\mathbf{1 1}$ will be the most thermally stable of this series of compounds because of its lack of reactive hydrogens and the robust nature of the core of this ligand with respect to CDI 




Figure 5.9: Evaporation kinetics of 9 (a), 10 (b), 11 (c), and 12 (d) by TGA. deinsertion.

Using TGA, the evaporation kinetics were evaluated for 9-12 (Figure 5.9). Compound 12 showed the highest evaporation at the lowest temperatures. Compounds 9 and 10 showed similar evaporation kinetics within the temperatures studied. This is unsurprising since $\mathbf{9}$ and $\mathbf{1 0}$ are expected to both volatilize as dimers and have similar molecular masses (a mass difference of only two methyl groups). Surprisingly, 11 showed the slowest evaporation kinetics even though it has a mass close to that of 12. It is possible that the measured evaporation kinetics of the copper(I) iminopyrrolidinates are slower than $\mathbf{1 2}$ because of the more rigid framework of the iminopyrrolidinate ligand. The rigidity of the ligand would cause a compact, planar structure and allow for stronger intermolecular attraction within the solid. Additionally, the copper(I) iminopyrrolidinates would be expected to have less entropy gain during volatilization than 12: the rigid ligand has fewer bonds that are free to rotate in the gas phase than in the solid state, compared to the relatively less constrained guanidinate of 12. From the isothermal TGA and using the Langmuir equation, ${ }^{71}$ the temperatures at which 1 Torr of vapour pressure was obtained was estimated to be $158^{\circ} \mathrm{C}, 161^{\circ} \mathrm{C}, 187^{\circ} \mathrm{C}$, and $125^{\circ} \mathrm{Cfor} \mathbf{9 - 1 2}$, respectively. 


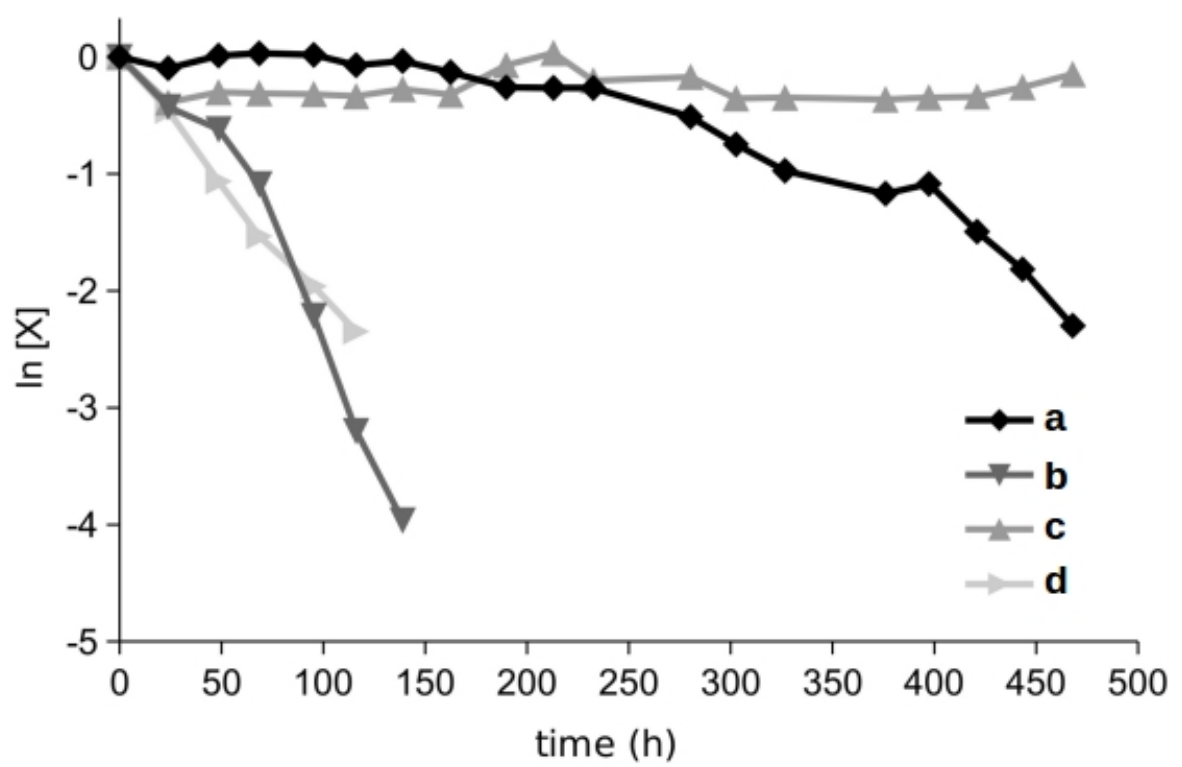

Figure 5.10: Thermal decomposition of 9 (a), $\mathbf{1 0}$ (b), $\mathbf{1 1}$ (c), and $\mathbf{1 2}$ (d) at $165{ }^{\circ} \mathrm{C}$ over 21 days in solution.

\section{Solution-Phase Analysis}

To further illuminate the thermal chemistry of these compounds, they were each sealed in heavy walled HR-NMR tubes and heated in an oven at $165^{\circ} \mathrm{C}$ over a period of days. A ${ }^{1} \mathrm{H}$ HR-NMR spectrum was collected each day to observe their thermal decomposition (Figure 5.10, Table 5.2). Compound 12 revealed decomposition to produce diisopropylcarbodiimide, as previously seen. ${ }^{115}$ The decomposition of $\mathbf{1 2}$ that followed first order decomposition kinetics and had a calculated half-life of $33.8 \mathrm{~h}$. The parent guanidine was also observed as a product of thermolysis, and its origin of production is discussed below.

Compound 9 showed much better thermal behavior than 12, as was expected from the TGA data. The compound decomposed following first order kinetics with a half-life of $181.1 \mathrm{~h}$, and there was very obvious plating of copper on the HR-NMR tube walls. The main byproduct from the thermolysis was the parent ligand, isopropyliminopyrrolidine. There was no evidence of CDI nor any evidence of oxidized ligand. There was an obvious flocculant in the HR-NMR tube after the thermolysis; this might be the oxidized ligand wherein a proton was lost. Compound 10 showed 
similar decomposition to $\mathbf{9}$, but much more quickly $\left(t_{1 / 2}=23.7 \mathrm{~h}\right)$. The HR-NMR tube was again obscured with plated $\mathrm{Cu}$ metal and had a flocculant precipitate, and the ${ }^{1} \mathrm{H}$ HR-NMR showed free, protonated ligand. It is possible that since $\mathbf{9}$ forms a tetramer, this imparts thermal stability to the compound, perhaps because the tetramer has to dissociate to a smaller oligomer to thermalize. This would also account for the relatively poor linear fit to first order kinetics: if the tetramer forms at higher concentration, then there would be a slightly higher rate of decomposition as the overall concentration of $\mathbf{9}$ dropped and the dimer-tetramer equilibrium began to favor the dimer.

The full mechanism that produces the protonated ligand remains unclear. We propose $\beta$-hydrogens as the most likely source for protons for the origin of free ligand. Surface work by Gordon and Zaera ${ }^{75,113}$ found that butene elimination occurs from copper(I)- $N, N$-di-sec-butylacetamidinate leaving an $\mathrm{N}-\mathrm{H}$ moiety, which might be another source for protons. However, no ${ }^{1} \mathrm{H}$ signals were observed in the HRNMR tube thermolysis experiment that suggest a similar mechanism occurring here. Evidence for disproportionation of $\mathrm{Cu}(\mathrm{I})$ acetamidinates has also been demonstrated in surface studies on $\mathrm{SiO}_{2}$ substrates. ${ }^{125}$ Since disproportionation of $\mathrm{Cu}$ (I) to $\mathrm{Cu}$ (II) and $\mathrm{Cu}(0)$ is a common thermolysis route for $\mathrm{Cu}(\mathrm{I})$ compounds, we offer the following insight. We observed a blue color imparted to $\mathbf{1 0}$ during the ${ }^{1} \mathrm{H}$ HR-NMR thermolysis study (Figure 5.10), suggesting the formation of a $\mathrm{Cu}(\mathrm{II})$ species. Attempts to isolate a $\mathrm{Cu}(\mathrm{II})$ compound by crystallization failed and resulted only in the isolation of crystals of $\mathbf{1 0}$ with a blue impurity. Interestingly, we previously had prepared oxidized guanidine (i.e., the product of $\beta$-hydrogen elimination) from the reaction between guanidine and a $\mathrm{Cu}(\mathrm{II})$ compound. ${ }^{116}$ Therefore, a $\mathrm{Cu}(\mathrm{II})$ intermediate might be involved in $\beta$-hydride abstraction thermolysis for this class of compound. We are continuing to study the thermolysis mechanisms of these compounds to gain a fuller understanding of this complicated thermal behavior. 
Table 5.2: Kinetic Data for the Thermal Decomposition of $\mathbf{9 - 1 1}$ at $165^{\circ} \mathrm{C}{ }^{a}$

$\begin{array}{cccc}\text { compound } & \text { rate constant }\left(s^{-1}\right) & \text { calculated half-life }(\mathrm{h}) & \text { correlation coefficient } \\ \mathbf{9} & 1.06 \cdot 10^{-6} & 181.1 & 0.902 \\ \mathbf{1 0} & 8.14 \cdot 10^{-6} & 23.7 & 0.944 \\ \mathbf{1 1} & & \text { no measurable decomposition } \\ \mathbf{1 2} & 5.69 \cdot 10^{-6} & 33.8 & 0.995 \\ & & \end{array}$

Compound 11 showed no decomposition at $165{ }^{\circ} \mathrm{C}$ over 21 days. It was expected that its ligand (with no $\beta$-hydrogens and without the CDI deinsertion pathway) would impart the best thermal stability; however, this marked difference was surprising. To further explore this, 11 was subjected to a rigorous surface study. This study used a combination of SS-NMR, elemental analysis, and HR-NMR to determine the initial monolayer and surface chemistry of 11 on HSAS. SS-NMR has been shown to be a useful tool in analysis of initial adsorption complexes on high-surface area substrates. ${ }^{29,31}$

\section{Surface Chemistry}

Approximately $1 \mathrm{~g}$ of high surface area silica was loaded into a reactor and annealed under vacuum at $350{ }^{\circ} \mathrm{C}$ for about $16 \mathrm{~h}$ prior to exposure to precursor. This ensured a consistent hydroxyl density at the surface between each experiment. Under these conditions, silica is expected to have a hydroxyl density of $2-3.5 \mathrm{OH} / \mathrm{nm}^{2} .{ }^{30}$ According to the TGA data a bubbler temperature of $165^{\circ} \mathrm{C}$ produces a sufficient vapour pressure for $\mathbf{1 1}$ so this temperature was used for all experiments. A deposition temperature of $200{ }^{\circ} \mathrm{C}$ was attempted but it was determined that the precursor did not react with the silica. When the silica that was exposed to vapourous $\mathbf{1 1}$ was washed with $\mathrm{D}_{2} \mathrm{O}$, only unreacted, dimeric precursor was found at this temperature, suggesting that 11 was simply physisorbed at this temperature. This was quite interesting, since it demonstrated the stability of 11: it was stable in aqueous solution 
for several hours, which was not an anticipated characteristic of this precursor. As well, it existed in a physisorbed state on the silica surface for up to $17 \mathrm{~h}$ without decomposing or significantly desorbing.

It was found that a temperature of $275^{\circ} \mathrm{C}$ was needed to chemisorb 11 . There are three main experiments that will be discussed: sample $\mathbf{A}$ is unmodified silica, sample B has undergone chemisorption of $\mathbf{1 1}$, and sample $\mathbf{C}$ has undergone chemisorption of 11 with a subsequent anneal at $350{ }^{\circ} \mathrm{C}$ for $4 \mathrm{~h}$. EDX showed the presence of copper on samples $\mathbf{B}$ and $\mathbf{C}$. No copper was detected on sample $\mathbf{A}$, as expected. Interestingly, when $\mathbf{B}$ was allowed to sit in air, it changed color to turquoise-green within $15 \mathrm{~min}$. This is likely a conversion of the as-deposited surface species to a hydrated copper oxide.

${ }^{1} \mathrm{H} / \mathrm{X} \mathrm{CP} / \mathrm{MAS}$ SS-NMR was used as the primary method of characterization for the samples $\mathbf{A}-\mathbf{C}$. The benefit of this technique is that the observed signals originate only from nuclei that are in close proximity to protons; in these samples, this means surface species only. The ${ }^{29} \mathrm{Si}$ CP/MAS SS-NMR spectra of samples $\mathbf{A}-\mathbf{C}$ showed typically silica signals (Figure 5.11) ${ }^{66}$ In $\mathbf{A}$, there are signals at around $-101.6 \mathrm{ppm}$, $-110.5 \mathrm{ppm}$ and a shoulder at $-92 \mathrm{ppm}$. The signal at $-101.6 \mathrm{ppm}$ is attributed to silanol groups $(||-\mathrm{Si}-\mathrm{OH})$ at the surface while the signal at $-110.5 \mathrm{ppm}$ is attributed to fully dehydroxylated silicon near the surface of the bulk sample $(||-\mathrm{Si})$. The shoulder at $-92 \mathrm{ppm}$ arises from silandiol species at the surface $\left(\|-\mathrm{Si}(\mathrm{OH})_{2}\right)$.

The middle trace in Figure 5.11 shows the ${ }^{29} \mathrm{Si}$ CP/MAS SS-NMR spectrum for B. It is apparent that the only signals present are similar to those of the unmodified silica. Indeed, the lack of other signals demonstrated that chemisorbed precursor interacts with the silica through an oxygen atom, rather than forming direct precursor-silicon bonds. That is, the precursor likely chemisorbs through a $\|-\mathrm{Si}-\mathrm{O}-\mathrm{Cu}$ interaction, rather than a $\|-\mathrm{Si}-\mathrm{Cu}$ or $\|-\mathrm{Si}-\mathrm{N}$. As well, the relative intensities of the various $\mathrm{Si}$ species present at the surface differ from that of $\mathbf{A}$. The silidiol shoulder vanished in 


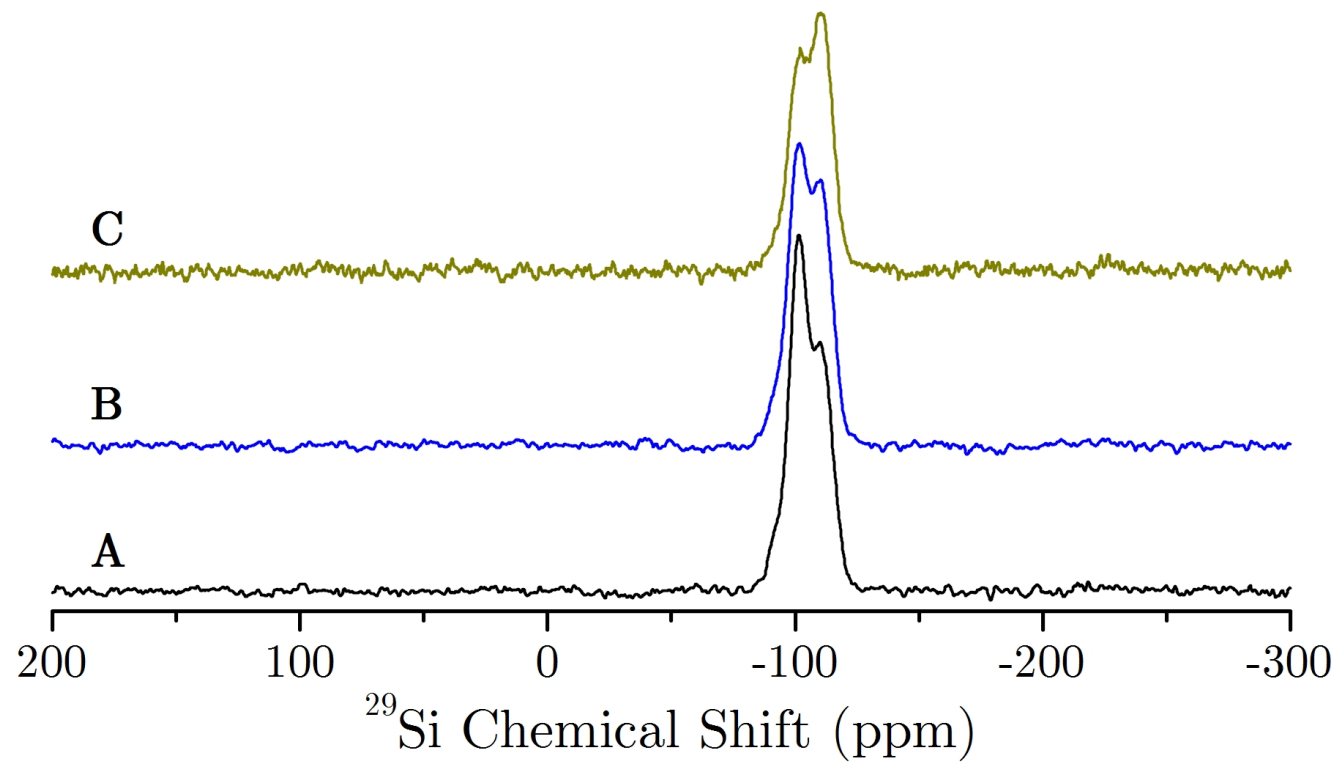

Figure 5.11: ${ }^{29} \mathrm{Si}\left\{{ }^{1} \mathrm{H}\right\} \mathrm{CP} / \mathrm{MAS}$ SS-NMR of samples $\mathbf{A}-\mathbf{C}$

$\mathbf{B}$, and the relative intensity of the silanol peak decreased in $\mathbf{B}$ compared to $\mathbf{A}$. Thus, the active surface hydroxyl groups are being consumed as precursor is taken up by the silica surface. However, the continued presence of a hydroxyl signal showed that saturation has not been reached under these experimental conditions.

The ${ }^{13} \mathrm{C} \mathrm{CP} /$ MAS SS-NMR spectra of samples $\mathbf{A}-\mathbf{C}$ were diagnostic of the nature of the surface species (Figure 5.12). As expected, A did not show any carbon signals, and highlights the lack of carbon impurities at the silica surface before exposing the system to precursor (data not shown as it is simply a noisy baseline spectrum). The trace for $\mathbf{B}$ gave four clear signals centered at 28.5, 35.8, 65.9, and $176.5 \mathrm{ppm}$. The signal at $176.5 \mathrm{ppm}$ was attributed to the quaternary carbon between the two chelating nitrogens on the iminopyrrolidinate ligand. The broadening of this peak was likely due to the rigidity of the ligand in the chemisorbed surface species. This caused an incomplete averaging of the dipolar and scalar coupling at the $4.5 \mathrm{kHz}$ MAS speed used. The signal at $65.9 \mathrm{ppm}$ came from the quaternary carbon in the iminopyrrolidinate ring. The quaternary carbon from the tert-butyl substituent likely contributed to this peak as well. This peak has a similar broadening to the previous peak. The sharp signals $28.5 \mathrm{ppm}$ and $35.8 \mathrm{ppm}$ were due to the methyl substituents attached to the ring and the methylene carbons that are part of the ring in the iminopyrrolidinate 




Figure 5.12: ${ }^{13} \mathrm{C}\left\{{ }^{1} \mathrm{H}\right\}$ HR-NMR of $\mathbf{1 1}$ (a) and ${ }^{13} \mathrm{C}\left\{{ }^{1} \mathrm{H}\right\}$ CP/MAS SS-NMR of high surface area silica samples $\mathbf{B}(\mathrm{b})$ and $\mathbf{C}(\mathrm{c})$.

ligand respectively. The methyl groups on the tert-butyl substituent would appear in the same range as these peaks and so were likely buried therein. The assignment of these peaks agreed very well with the ${ }^{13} \mathrm{C}$ HR-NMR for pure $\mathbf{1 1}$ (shown in Figure $5.12 a)$.

Elemental analysis for carbon, hydrogen, and nitrogen was also performed on samples A-C (Table 5.3). Given the assumed hydroxyl density at the surface of 2-3.5 hydroxyls $/ \mathrm{nm}^{2}$, the elemental analysis showed about $60 \%$ saturation of the surface, corroborating evidence from the ${ }^{29} \mathrm{Si}$ SS-NMR. To give more insight into the nature of the surface species present, a molar ratio of each element was determined relative to nitrogen, which was fixed at 2 to represent the stoichiometry of nitrogen in the ligand. Given the molar ratios, the majority of the ligand appeared to be intact on the surface. However, the carbon ratio is lower than expected for a completely intact ligand, which can be explained by the loss of a fragment as large as $\mathrm{C}_{4}$ from the ligand upon surface adsorption. 
Table 5.3: Elemental Analysis Samples $\mathbf{A}-\mathbf{C}^{a}$

\begin{tabular}{ccccc} 
& & sample A & sample B & sample $\mathbf{C}$ \\
C & wt \% & $<0.3$ & 2.71 & 4.16 \\
& mole ratio & & 7 & 7 \\
$\mathrm{H}$ & wt \% & $<0.3$ & 0.59 & 0.79 \\
& mole ratio & & 17 & 16 \\
$\mathrm{~N}$ & wt \% & $<0.3$ & 0.95 & 1.40 \\
& mole ratio & 2 & 2 \\
\multirow{2}{*}{ The data for sample A were below the limit of detection. }
\end{tabular}

To further elucidate the adsorption mechanism a small amount of sample $\mathbf{B}$ was washed with $\mathrm{D}_{2} \mathrm{O}$ to etch off the chemisorbed surface species for study using HRNMR (Figure 5.13b). This relatively clean spectrum shows that all the peaks from the surface species match what is known for the iminopyrrolidinate ligand, with an absence of the signal for the methyl groups from the tert-butyl substituent. Figure 5.13a shows the ${ }^{1} \mathrm{H}$ HR-NMR of 11 in $\mathrm{D}_{2} \mathrm{O}$ and not only does this show a surprisingly stability of the iminopyrrolidinate ligand system of this compound, it also shows the excellent match with the surface etched species. Although the signals from the tertbutyl substituent and the methyl groups on the pyrrolidinate ring have a similar chemical shift, the integrations of the ${ }^{1} \mathrm{H}$ HR-NMR show an absence of the tert-butyl substient for the surface-etched species (Figure 5.13b). This concretely demonstrate that the tert-butyl substituent was eliminated upon initial surface adsorption at 275 ${ }^{\circ} \mathrm{C}$. The somewhat higher hydrogen ratio likely had a contribution from the silica hydroxyl groups, which dehydrated during the combustion analysis.

The thermal stability of the initial chemisorbed species was examined by annealing B at $350{ }^{\circ} \mathrm{C}$ for $4 \mathrm{~h}$ under vacuum, producing sample $\mathbf{C}$. The ${ }^{13} \mathrm{C} \mathrm{CP} / \mathrm{MAS}$ SS-NMR for $\mathbf{C}$ gave a spectrum that was somewhat similar to that of $\mathbf{B}$ (Figure 5.12). However, the quaternary carbon signal originally at 176.5 ppm was not present, and a new quaternary carbon signal appeared at $160 \mathrm{ppm}$. The other quaternary carbon signal present in $\mathbf{B}$ also appeared for $\mathbf{C}$ with a considerably weakened intensity from 




Figure 5.13: ${ }^{1} \mathrm{H}$ HR-NMR of pure $\mathbf{1 1}$ in $\mathrm{D}_{2} \mathrm{O}$ (a) and $\mathrm{D}_{2} \mathrm{O}$ after it was washed over sample $\mathbf{B}(\mathrm{b})$ and $\mathbf{C}(\mathrm{c})$.

the annealing process. Two new carbon signals have appeared at 10 and $45 \mathrm{ppm}$, confirming that a new surface species forms. The ${ }^{29} \mathrm{Si} \mathrm{CP} / \mathrm{MAS}$ SS-NMR spectrum for C was very similar to unmodified silica (Figure 5.11). Even at temperatures as high as $350{ }^{\circ} \mathrm{C}$, no alkylation of the silicon occurred at the surface, and any thermolyzed chemisorbed species were still bonded through a $\|-\mathrm{SiO}-\mathrm{R}$ type interaction. Again, there was a change in the intensity of the peaks originating from each silica environment. Similar to the signal from $\mathbf{B}$, the intensity of the silanol species at the surface decreased with respect to the signal for completely dehydroxylated silicon. This is likely due to the participation of silanol protons in the decomposition mechanism of the chemisorbed species from $\mathbf{B}$.

Similar to the study done for $\mathbf{B}$, a small of amount of $\mathbf{C}$ was washed with $\mathrm{D}_{2} \mathrm{O}$ and examined via ${ }^{1} \mathrm{H}$ HR-NMR (Figure 5.13, top trace). Similar to the ${ }^{1} \mathrm{H}$ HR-NMR of $\mathbf{B}$, the spectrum for $\mathbf{C}$ was very clean and exhibited only one species. There were 

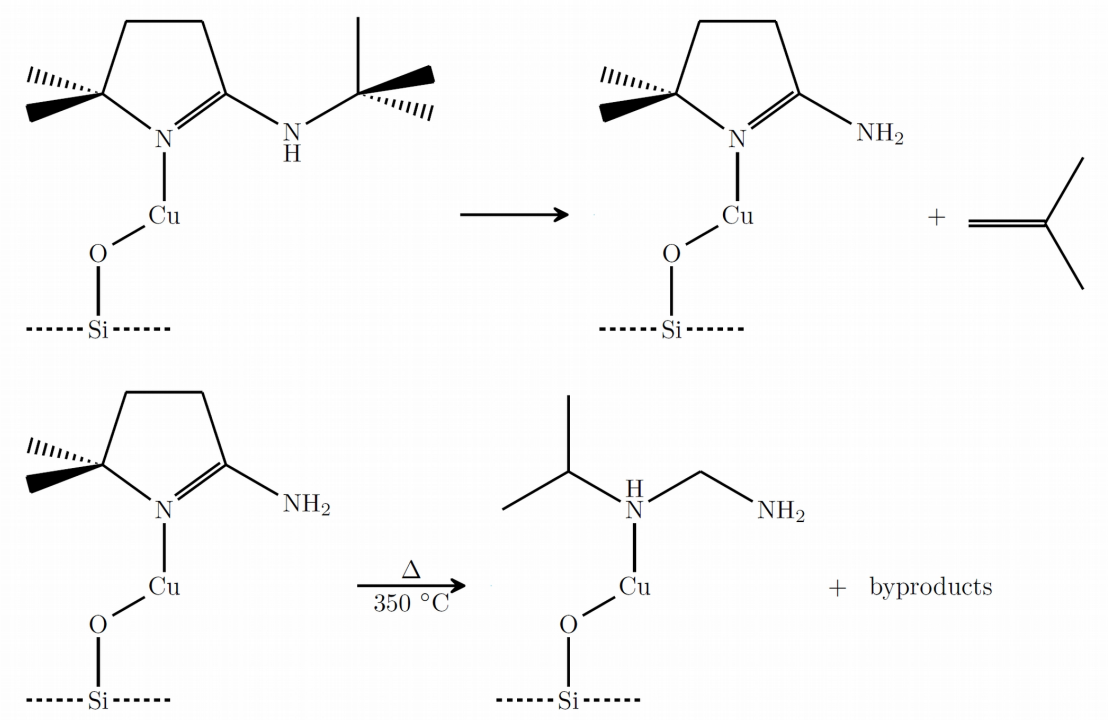

Figure 5.14: Possible thermolysis of the surface species formed by 11 on HSAS. two doublets and two septets, representing isopropyl groups. There was an isolated singlet which integrated to two protons relative to the isopropyl group. This singlet is too shielded to be an imine group (like ${ }^{i} \mathrm{PrN}=\mathrm{CH}_{2}$ ), and thus it could be that both nitrogen atoms remain in the surface species to form a methylene diimine. A mass spectral analysis of a (nondeuterated) aqueous solution found a peak at $89 \mathrm{amu}$, which is the mass of this surface species with an additional proton. Using a hybrid quadrupole time-of-flight mass spectrometer, the fragmentation of this parent ion supported the formulation ${ }^{i} \operatorname{PrN}(\mathrm{H}) \mathrm{CH}_{2} \mathrm{NH}_{2}$ (Figure 5.14). Thus, the ring methyls become the methyls of an isopropyl group, and the quatenary carbon is protonated to produce a methylene. Interestingly, Chabal et al. also suggest a diamine as a stable surface species during $\mathrm{ALD}$ of $\mathrm{Cu}$ metal on $\mathrm{SiO}_{2}$ substrates. ${ }^{125}$ Combustion analysis of $\mathbf{C}$ did not clarify the formulation, giving very similar carbon, hydrogen, and nitrogen molar ratios to that of $\mathbf{B}$ (Table 5.3). A more rigorous surface study is planned to clarify the $350{ }^{\circ} \mathrm{C}$ thermolysis mechanism. 


\subsection{Additional Results}

In addition to studying the surface chemistry of a stable copper(I) iminopyrrolidinate (11), the surface chemistry of two other copper(I) compounds was examined using the techniques described in this Chapter. Other than the iminopyrrolidinates, another class of copper(I) compounds that showed promise as vapour-phase deposition precursors are N-heterocyclic carbene (NHC)-containing copper(I) amides. Indeed, work from our group has shown that 1,3-diisopropyl-imidazolin-2-ylidene copper hexamethyldisilazide (13) successfully deposits copper metal by PE-ALD using $\mathrm{H}_{2}$ plasma. ${ }^{126}$ So, the initial surface chemistry of this compound, an analogue with equally promising thermal characteristics ${ }^{127}$ (1,3-diethyl-imidazolin-2-ylidene copper hexamethyldisilazide, 14), and hexamethyldisilazane (HMDS) on HSAS was studied by SS-NMR.

The small experimental differences between the NHC-copper(I) compounds and the iminopyrrolidinate should be briefly mentioned. First, the thermal characteristics and synthesis of $\mathbf{1 3}$ and $\mathbf{1 4}$ are reported elsewhere and are beyond the scope of this discussion. ${ }^{126,127}$ Second, from this previous work on these compounds it was found that $100{ }^{\circ} \mathrm{C}$ was the temperature required to produce sufficient vapour pressure of 13 and 14. So, this was used as the bubbler temperature for exposure of 13 and 14 to HSAS. HMDS is a high-vapour pressure liquid so heating was not required to expose this compound to HSAS. Otherwise, all other experimental considerations are the same as described in Section 5.3.

Figure 5.15 shows the ${ }^{29} \mathrm{Si}$ SS-NMR of HMDS, $\mathbf{1 3}$, and $\mathbf{1 4}$ exposed to pre-treated HSAS at both $250{ }^{\circ} \mathrm{C}$ and $150{ }^{\circ} \mathrm{C}$. The first thing to note is that all spectra look very similar to each other, save small differences in the silica region $(-94--110 \mathrm{ppm})$. In

all cases there is a new signal at $\approx 15 \mathrm{ppm}$. At least in the case of the exposure of HMDS to HSAS (Figure 5.15a), this is unsurprising. It is well known that exposing 


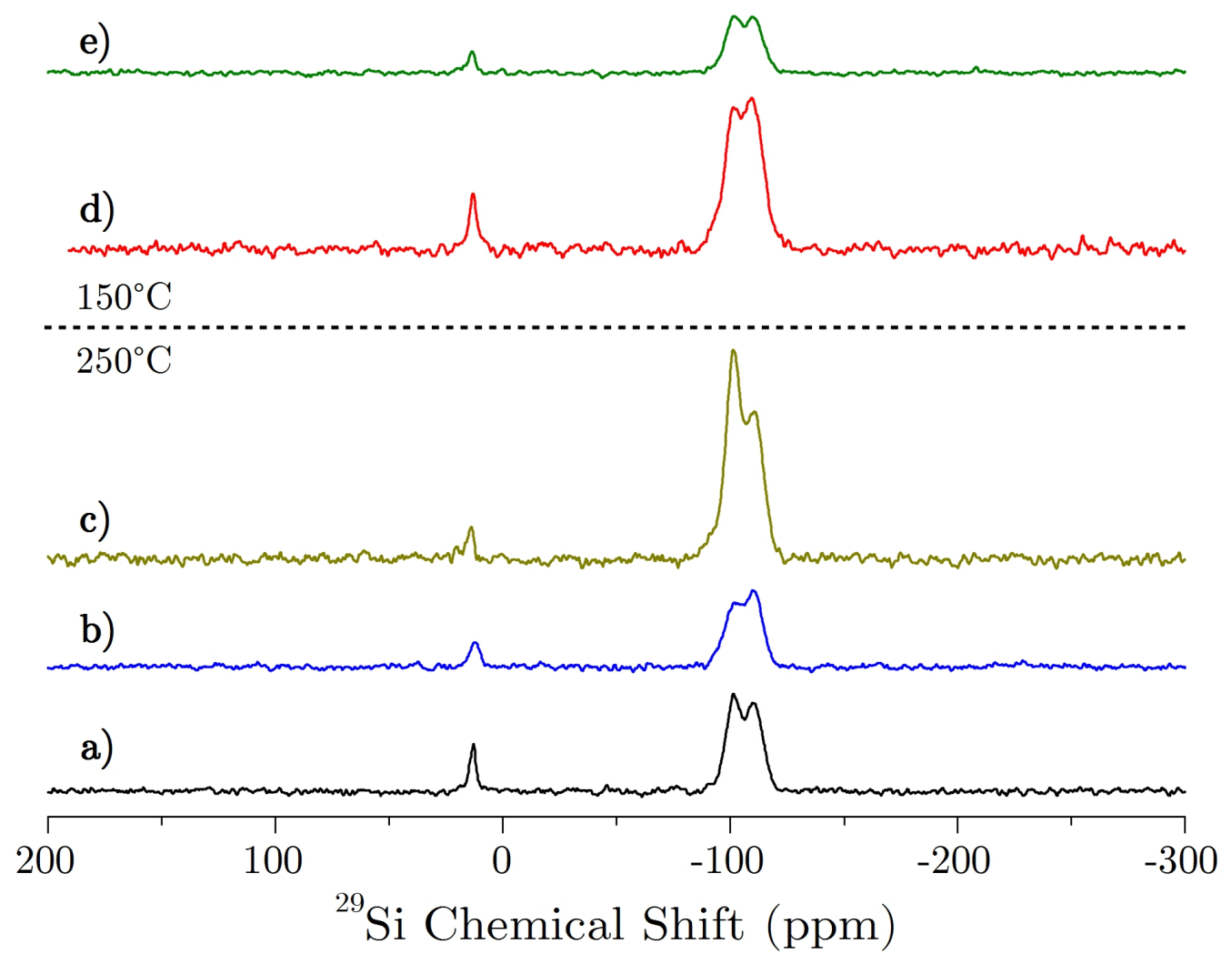

Figure 5.15: ${ }^{29} \mathrm{Si}\left\{{ }^{1} \mathrm{H}\right\} \mathrm{CP} / \mathrm{MAS}$ SS-NMR of HMDS (a), 13 (b), and 14 (c) exposed to HSAS at $250{ }^{\circ} \mathrm{C}$. Also, 13 (d), and 14 (e) exposed to HSAS at $150{ }^{\circ} \mathrm{C}$.

vapour-phase HMDS to HSAS produces methylated silicon on the surface $\left(\|-\mathrm{SiMe}_{3}\right)$ and ammonia from reaction of the surface hydroxyl groups with the HMDS. ${ }^{64}$ It is this methylated silicon $\left(\|-\mathrm{SiMe}_{3}\right)$ on the surface that produces the signal at $15 \mathrm{ppm}$ in Figure 5.15. Interestingly, there is only one signal for fully methylated silicon $\left(\|-\mathrm{SiMe}_{3}\right)$ and there is no evidence of mixed hydroxyl/methyl-terminated silicon species on the surface $\left(\|-\mathrm{Si}(\mathrm{OH})_{\mathrm{x}}(\mathrm{Me})_{\mathrm{y}}\right)$ which shows the high reactivity of HMDS to surface hydroxl groups. Consequently, there is also a relative reduction in the silanol signals on the surface of the HSAS after exposure to HMDS (when compared to pretreated silica, Figure 5.11a). There is an obvious reduction in both silanol (\|-Si(OH), $-101 \mathrm{ppm})$ and silandiol $\left(\|-\mathrm{Si}(\mathrm{OH})_{2},-110 \mathrm{ppm}\right)$ peaks showing reactivity at both surface sites.

Looking at the ${ }^{29} \mathrm{Si}$ SS-NMR spectra for the exposure of $\mathbf{1 3}$ to HSAS (Figure 5.15b and d), the results are very similar to the HMDS exposure. There is only one additional peak at 15 ppm corresponding to methylated silicon on the surface as well 
as the signals in the silica region. This indicates that the anionic HMDS ligand on 13 reacts strongly with the surface of the silicon in a manner similar to protonated HMDS, and the NHC ligand does not introduce any additional bonding environments for the silicon on the surface. In terms of changing intensity of the silica region, it is similar to the HMDS exposure, although it seems that there is a greater reduction in the silanol peak $(\|-\mathrm{Si}(\mathrm{OH}))$ than in the HMDS exposure indicating perhaps a greater reactivity or coverage of $\mathbf{1 3}$ on HSAS than HMDS. From the ${ }^{29} \mathrm{Si}$ SS-NMR signals there does not appear to be a large difference between $\mathbf{1 3}$ exposed to HSAS at $250{ }^{\circ} \mathrm{C}$ (Figure $5.15 \mathrm{~b}$ ) and $150{ }^{\circ} \mathrm{C}$ (Figure $5.15 \mathrm{~d}$ ).

The ${ }^{29} \mathrm{Si}$ SS-NMR spectra for $\mathbf{1 4}$ exposed to HSAS (Figure 5.15c and e), again, show results similar to $\mathbf{1 3}$ and HMDS exposures, although there are a few key differences. Firstly, the signal for methylated silica at $15 \mathrm{ppm}$ seems to be somewhat reduced compared to the signals in the silica region indicating that by changing the $\mathrm{R}$ groups on the NHC ligand on the overall complex reduces the reactivity of the HMDS ligand with surface hydroxyl groups. Additionally, in the $250{ }^{\circ} \mathrm{C}$ exposure of $\mathbf{1 4}$, there is very little reduction in the silanol and silandiol signals in the silica region. This is markedly different from the exposure at $150{ }^{\circ} \mathrm{C}$ where the loss in hydroxyl-terminated silicon signals is similar to that of the HMDS or 13 exposures (although not completely to the same extent). This shows that at $250{ }^{\circ} \mathrm{C}$ there is not only reduced reactivity of the HMDS ligand with surface hydroxyl groups but there is an overall reduced coverage or extent of reaction with the hydroxyl groups overall compared to 13 and HMDS. However, reducing the temperature to $150{ }^{\circ} \mathrm{C}$ appears to increase the reactivity or coverage of $\mathbf{1 4}$ on HSAS.

This interesting behaviour may be due to a significant change in the surface reaction kinetics of 13, 14 and HMDS on HSAS. It is possible the by changing the R groups on the NHC ligand to ethyl reduces the reaction rate and, because at elevated temperatures the sticking coefficient is reduced due to competitive desorption of the 


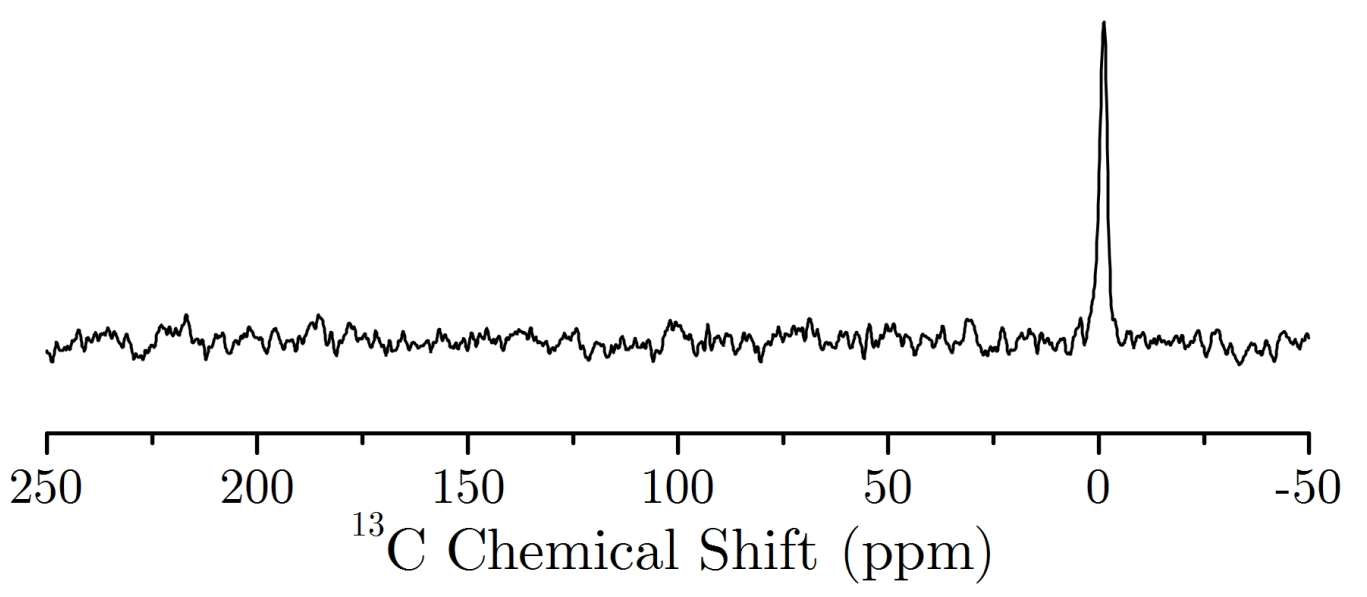

Figure 5.16: ${ }^{13} \mathrm{C}\left\{{ }^{1} \mathrm{H}\right\} \mathrm{CP} / \mathrm{MAS}$ SS-NMR of HMDS exposed to HSAS at $250{ }^{\circ} \mathrm{C}$.

precursor, the precursor is not given enough time to react at the surface and desorbs instead. Or, another possibility is that at elevated temperatures the NHC-Cu species on the surface (vide infra) undergoes decomposition to regenerate surface hydroxyl groups. In either case, it is remarkable that such a small change in the neutral ligand in a copper(I) complex can have such significant effects on the reactivity/coverage on HSAS.

The ${ }^{13} \mathrm{C}$ CP/MAS SS-NMR of HMDS, 13, and 14 exposed HSAS offers some elucidation into the nature of the adsorbed surface species. Figure 5.16 shows the ${ }^{13} \mathrm{C}$ SS-NMR spectrum of HMDS exposed HSAS at $250{ }^{\circ} \mathrm{C}$. As expected, there is only one peak at $-1 \mathrm{ppm}$ which must correspond to the carbon nucleus of fully methylated $\left(\|-\mathrm{Si}\left(\mathrm{CH}_{3}\right)_{3}\right)$ silicon on the surface.

Somewhat more interesting is the ${ }^{13} \mathrm{C}$ SS-NMR spectra for $\mathbf{1 3}$ (Figure 5.17) and 14 (Figure 5.18) exposed HSAS. The exposure of 13 at $250{ }^{\circ} \mathrm{C}$ (Figure 5.17b) shows the same peak at $-1 \mathrm{ppm}$ as in the HMDS exposure. This, again, corresponds to fully methylated silicon surface species which corroborates the ${ }^{29} \mathrm{Si}$ SS-NMR results. However, there are 3 additional signals in the ${ }^{13} \mathrm{C}$ SS-NMR. If the ${ }^{13} \mathrm{C}$ SS-NMR is compared to the HR-NMR of pure $\mathbf{1 3}$ (similar to what was done for 11) the identity of the peaks in the SS-NMR spectrum becomes more clear. The 3 additional peaks are identical to the ${ }^{13} \mathrm{C}$ signals for the $\mathrm{NHC}$ ligand of the complex (at $51 \mathrm{ppm}$ $\left(\mathrm{NCH}\left(\mathrm{CH}_{3}\right)_{2}\right)$, $42 \mathrm{ppm}\left(\mathrm{N}\left(\mathrm{CH}_{2}\right)_{2} \mathrm{~N}\right)$, and $\left.20 \mathrm{ppm}\left(\mathrm{NCH}\left(\mathrm{CH}_{3}\right)_{2}\right)\right)$. Unfortunately, 


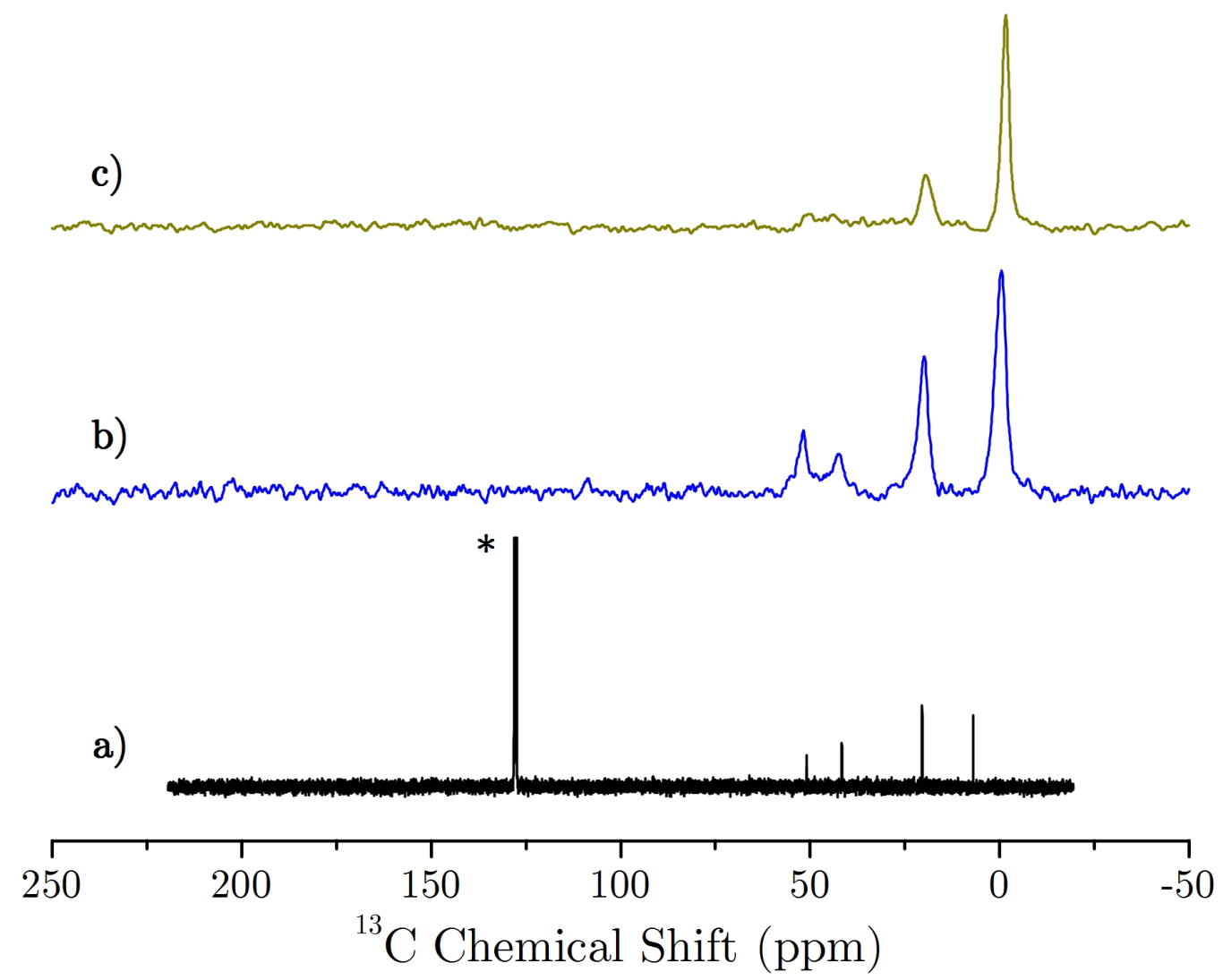

Figure 5.17: ${ }^{13} \mathrm{C}\left\{{ }^{1} \mathrm{H}\right\}$ HR-NMR of $\mathbf{1 3}$ (a) and CP/MAS SS-NMR of $\mathbf{1 3}$ exposed to HSAS at $250{ }^{\circ} \mathrm{C}(\mathrm{b})$ and $150{ }^{\circ} \mathrm{C}(\mathrm{c})$. * is residual solvent $\left(\mathrm{C}_{6} \mathrm{H}_{6}\right)$.

given the relatively long spin-lattice relaxation times $\left(T_{1}\right)$ and the possibility of a poor Hartman-Hahn match in the SS-NMR acquisition, the carbenic carbon was not observed in any of the spectra obtained. However, the presence and exact match for the chemical shift of the other carbon environments in the NHC ligand on the silica shows that not only is the NHC ligand also attached to the surface of the silica but it is still in the same relative environment as the pure precursor, 13. This means that the NHC is bound to the surface through copper and not oxygen or silicon. Additionally, there is no evidence of HMDS bound to copper on the surface as in the pure compound (7 ppm, Figure 5.17a). This means that when $\mathbf{1 3}$ adsorbs to the surface of HSAS it reacts with hydroxyl groups to produce a $\mathrm{Cu}-\mathrm{NHC}$ species bound through oxygen while the HMDS ligand reacts with neighbouring hydroxyl groups fully methylating them (see Figure 5.19a). Interestingly, when the reaction temperature is lowered to $150{ }^{\circ} \mathrm{C}$ (Figure $5.17 \mathrm{c}$ ) there is a change in the relative concentrations of surface 
species. The NHC signals are still present but at a much lower intensity compared to the signal from $\|-\mathrm{Si}\left(\mathrm{CH}_{3}\right)_{3}$ groups. It is possible that at lower temperatures, the rate of reaction of $\mathbf{1 3}$ with surface hydroxyl groups is reduced, while the rate of reaction of HMDS with surface hydroxyl groups still remains quite high. So, when $\mathbf{1 3}$ is exposed to the surface the compound does not form a $\|-\mathrm{O}-\mathrm{Cu}-\mathrm{NHC}$ species and protonated HMDS but instead weakly physisorbs while the HMDS ligand is free to react with a hydroxyl group to produce one $\mathrm{SiCH}_{3}$ group on the surface while the remaining $\mathrm{NHC}-\mathrm{Cu}-\mathrm{NHSi}\left(\mathrm{CH}_{3}\right)_{3}$ species desorbs from the surface. Another possibility is that with the reduced reaction to produce a $\|-\mathrm{O}-\mathrm{Cu}-\mathrm{NHC}$ surface species, any physisorbed $\mathbf{1 3}$ may be more mobile on the surface. It is possible that two physisorbed molecules of $\mathbf{1 3}$ could then react on the surface to produce an NHCdimer which would desorb and volatilize into the vacuum leaving some form of copper adatom, and HMDS, which would react with surface hydroxyls to produce methylated silicon species on the surface (Figure 5.19b). Whichever may be the case, there is obviously a reduced NHC presence on the surface of HSAS compared to $\|-\mathrm{Si}\left(\mathrm{CH}_{3}\right)_{3}$ groups for low temperature $\mathbf{1 3}$ exposures.

The ${ }^{13} \mathrm{C}$ CP/MAS SS-NMR results for the exposure of $\mathbf{1 4}$ is shown in Figure 5.18. The first thing to note is again the strong signal for $\|-\mathrm{Si}\left(\mathrm{CH}_{3}\right)_{3}$ groups on the surface at $-1 \mathrm{ppm}$ for both $250^{\circ} \mathrm{C}$ and $150{ }^{\circ} \mathrm{C}$ exposures of $\mathbf{1 4}$, similar to the case for 13. However, unlike in the case for $\mathbf{1 3}$ exposures, there are no other strong signals in the ${ }^{13} \mathrm{C}$ SS-NMR spectra. Figure 5.18a shows the HR-NMR for pure 14 and the signals for the NHC ligand appear at $47.5 \mathrm{ppm}\left(\mathrm{NCH}_{2} \mathrm{CH}_{3}\right), 45 \mathrm{ppm}\left(\mathrm{N}\left(\mathrm{C} \mathrm{H}_{2}\right)_{2} \mathrm{~N}\right)$, and $14 \mathrm{ppm}\left(\mathrm{NCH}_{2} \mathrm{CH}_{3}\right)$. Again, similar to reasons described previously for $\mathbf{1 3}$ the carbenic carbon environment is not visible. In the $250{ }^{\circ} \mathrm{C}$ exposure of $\mathbf{1 4}$ there is no evidence of NHC signals in the ${ }^{13} \mathrm{C}$ SS-NMR spectrum (Figure 5.18b). Similar to the 13 exposures the signals from the $\mathrm{CH}_{3}$ groups on HMDS shift from $7.5 \mathrm{ppm}$ in the pure compound to -1 ppm upon adsorption. This shows the HMDS ligand 


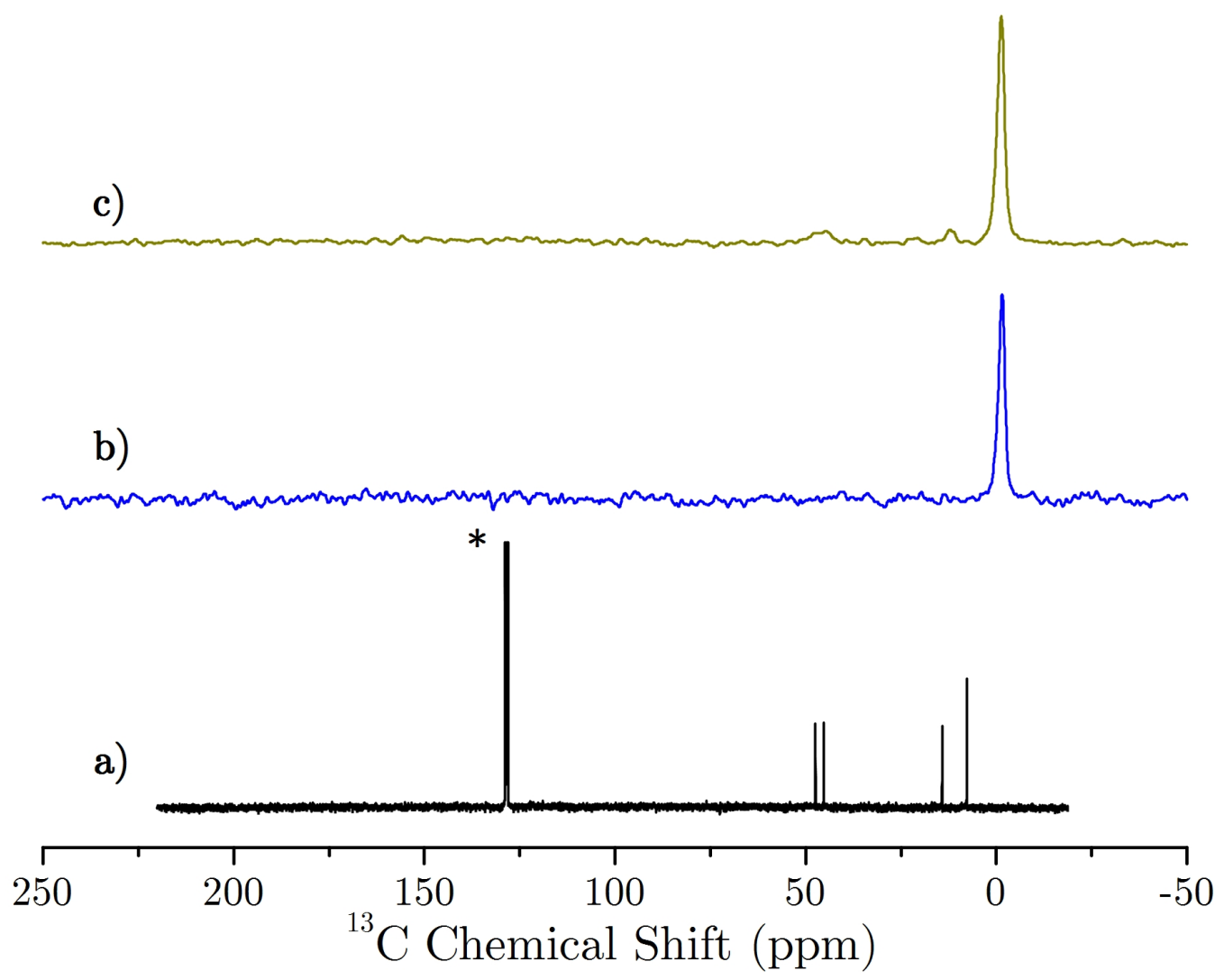

Figure 5.18: ${ }^{13} \mathrm{C}\left\{{ }^{1} \mathrm{H}\right\}$ HR-NMR of $\mathbf{1 4}$ (a) and CP/MAS SS-NMR of $\mathbf{1 4}$ exposed to HSAS at $250{ }^{\circ} \mathrm{C}(\mathrm{b})$ and $150{ }^{\circ} \mathrm{C}(\mathrm{c})$. * is residual solvent $\left(\mathrm{C}_{6} \mathrm{H}_{6}\right)$.

in $\mathbf{1 4}$ methylates hydroxyl groups on the surface of HSAS. The reason that $\mathbf{1 4}$ does not react with HSAS to leave NHC groups on the surface at $250^{\circ} \mathrm{C}$ may be explained through similar reasoning to the $150{ }^{\circ} \mathrm{C}$ exposure of $\mathbf{1 3}$ (see above), although it is surprising that there is no evidence of NHC groups on the surface. This is not the case, however, for the $150{ }^{\circ} \mathrm{C}$ exposure of $\mathbf{1 4}$ (Figure 5.18c). Although very weak, there are signals that match the NHC signals of the ${ }^{13} \mathrm{C}$ HR-NMR spectrum for pure 14. This shows that there is some reaction of $\mathbf{1 4}$ to produce a $\|-\mathrm{O}-\mathrm{Cu}-\mathrm{NHC}$ species on the surface at $150{ }^{\circ} \mathrm{C}$. This is interesting as it seems to be the opposite trend as observed for 13 exposures. It is possible that at higher temperatures there is simply increased desorption of molecular 14 and although there is a signal for methylated silicon on the surface it is relatively low compared to exposures $\mathbf{1 3}$, which would agree with the ${ }^{29} \mathrm{Si}$ SS-NMR data. It is also possible that NHC-dimer formation on the surface is much more likely in the case for $\mathbf{1 4}$ than with $\mathbf{1 3}$ which would explain the relative lack of 
a)

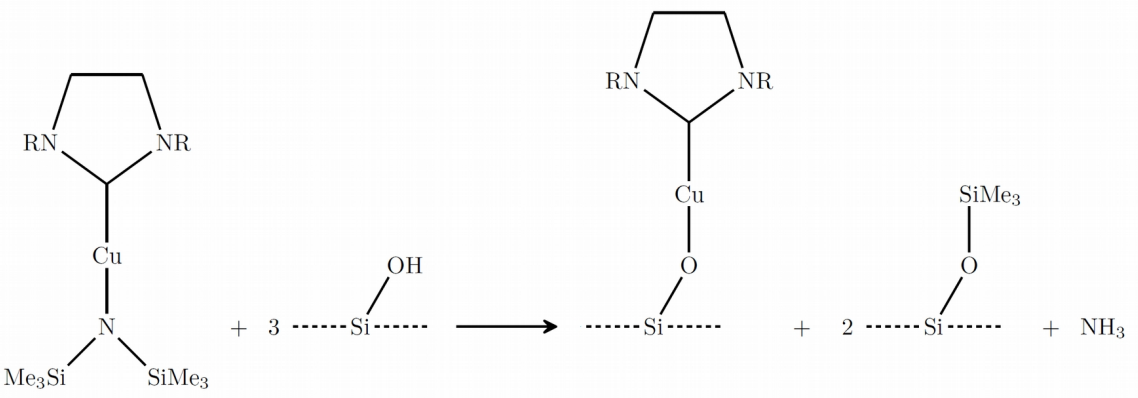

b)

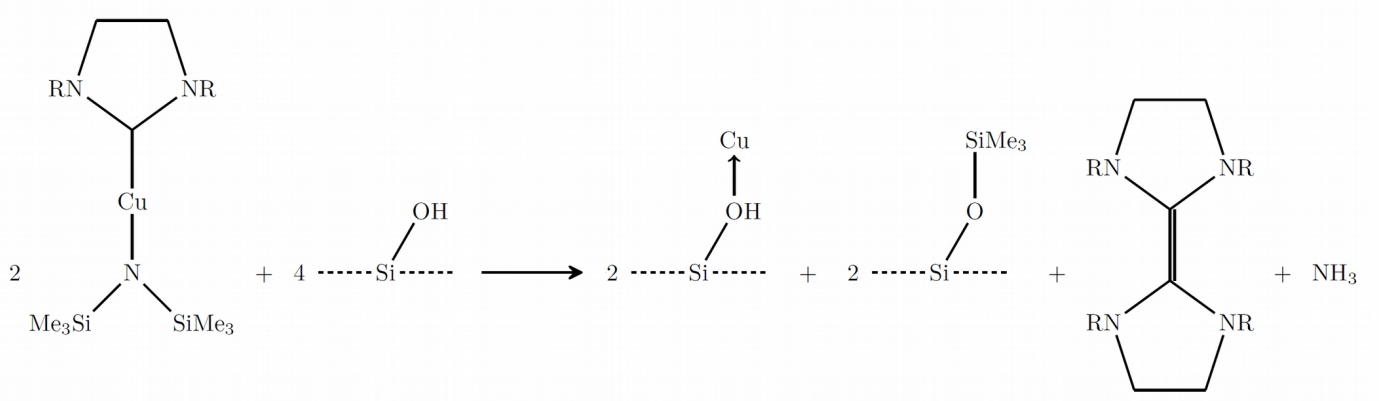

Figure 5.19: Proposed surface adsorption mechanism for $\mathbf{1 3}$ and $\mathbf{1 4}$ on HSAS. Both show methylation of the surface via the HMDS ligand while a) shows adsorption in which the NHC remains on the surface and b) shows adsorption where the NHC ligand from the compound dimerizes and results in a reduced coverage of carbene chemisorbed to the surface.

$\mathrm{NHC}$ signals in the ${ }^{13} \mathrm{C}$ SS-NMR results. It is quite interesting that by making simple alkyl substitutions on the NHC ligand of these copper complexes drastically changes that nature of chemisorption on HSAS. This has large implications for nucleation and growth on oxide surfaces when designing a potential ALD process using this class of compounds.

\subsection{Conclusions}

A series of copper(I) iminopyrrolidinates were synthesized and evaluated by TGA and in $\mathrm{C}_{6} \mathrm{D}_{6}$ solutions by ${ }^{1} \mathrm{H}$ HR-NMR to determine their thermal stability and suitability as precursors in CVD processes. The employed asymmetric, cyclic amidinate ligand proved to impart excellent thermal stability when no $\beta$-hydrogens were present. A direct comparison of the number of $\beta$-hydrogens to thermal stability was complicated by the tetrameric structure of $\mathbf{9}$, which was thought to influence thermal stability. 
A valuable thermal stress test by TGA was devised and provided complementary thermal stability trends to solution based thermolysis studies. Advantages of the thermal stress test by TGA were faster data collection and use of conditions more pertinent to CVD processes. The solution based thermolysis studies identified the parent amidine and copper metal as thermolysis products of $\mathbf{9}$ and $\mathbf{1 0}$. The amidines were produced through an intramolecular hydrogen abstraction, and a $\beta$-hydride abstraction mechanism was proposed. Compound $\mathbf{1 1}$ showed negligible decomposition in both the TGA and the solution experiments, and is an excellent candidate for copper deposition experiments.

An extensive surface reactivity study of $\mathbf{1 1}$ was undertaken, revealing some interesting thermal behavior. Compound $\mathbf{1 1}$ lost an alkyl group on chemisorption at 275 ${ }^{\circ} \mathrm{C}$, but was stable to thermolysis up to $350{ }^{\circ} \mathrm{C}$, demonstrating that the design of the ligand system did indeed protect the monolayer from thermolysis. At $350{ }^{\circ} \mathrm{C}$, the surface species underwent further thermolysis by an unknown mechanism to produce a surface species suspected to be the methylenediamine ${ }^{i} \operatorname{PrN}(\mathrm{H})-\mathrm{CH}_{2} \mathrm{NH}_{2}$.

Additional work was done on the surface reactivity of HMDS, 13, and 14 on HSAS. All three compounds were found to produce $\|-\mathrm{SiCH}_{3}$ groups on the surface from reaction of the HMDS ligand with surface hydroxyl groups. The chemisorption coverage/reaction of $\mathbf{1 4}$ was found to be relatively lower than 13 at both $150{ }^{\circ} \mathrm{C}$ and $250{ }^{\circ} \mathrm{C}$. Compound 13 chemisorbed to produce a $\|-\mathrm{O}-\mathrm{Cu}-\mathrm{NHC}$ species and methylated silicon although the concentration of surface NHC groups was lower at lower temperature. Compound $\mathbf{1 4}$ was only found to leave NHC groups on the surface at $150{ }^{\circ} \mathrm{C}$ and only methylated silicon was found at $250{ }^{\circ} \mathrm{C}$. 


\section{Chapter 6}

\section{Atomic Layer Deposition of Gold Metal}

Modified from a manuscript orginally published as:

Griffiths, M.B.E., Pallister, P.J., Mandia, D.J., and Barry, S.T., Atomic Layer Deposi-

tion of Gold Metal, Chem. Mater., 2016, asap (DOI: 10.1021/acs.chemmater.5b04562).

Department of Chemistry, Carleton University, 1125 Colonel By Drive, Ottawa, Ontario, K1S 5B6, Canada 


\subsection{Abstract}

A method for depositing gold metal by PEALD has been developed. Using the precursor trimethylphosphinetrimethylgold(III) (15), gold metal was found to deposit using oxygen plasma followed by a brief water pulse. In the absence of water, a film with a significant phosphorus impurity (suspected to be a mixture of gold(III) oxide and phosphorous(V) oxide). The metal deposi-

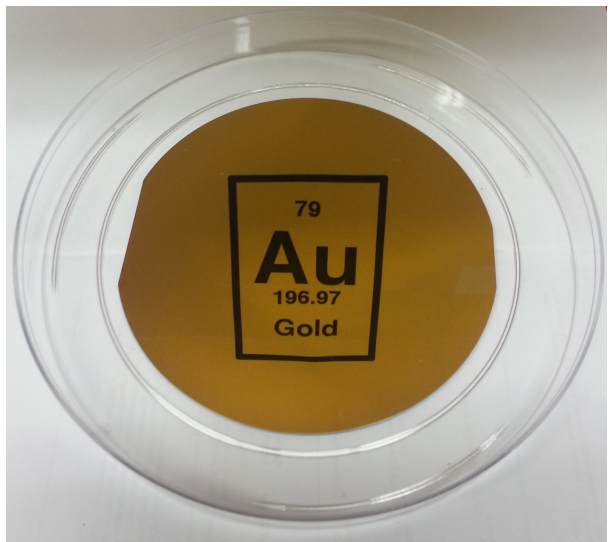

Figure 6.1: Table of Contents graphic used for publication described in Chapter 6

tion process has a growth rate of $0.5 \AA /$ cycle

and shows some carbon impurity. The gold metal appears to nucleate in crystalline nanoparticles showing the closest-packing face, with an average diameter of less than $1 \mathrm{~nm}$ for a five-cycle run.

\subsection{Introduction}

Nanoparticulate gold is an innovative material being used in applications like gassensing, ${ }^{128}$ heterogeneous catalysis, ${ }^{129}$ and by virtue of its surface plasmon resonance, photonics. ${ }^{130}$ Currently, solution phase reduction of gold salts in the presence of facetspecific surfactants and capping agents is the method of choice for producing gold nanoparticles. Solution-phase synthesis can be a drawback if the nanoparticles are needed for an application where the surfactant might interfere. One straight-forward method of controlling the nucleation and growth of metallic nanoparticles is by the use of ALD. ALD is a layer-by-layer, gas-phase deposition technique that has been used to deposit a wide array of metallic, semiconducting, and insulating films and 
features. ${ }^{131}$ Gold nanoparticles have been deposited by several vapor-based methods including physical vapor deposition (PVD) and chemical vapor deposition (CVD). ${ }^{132}$

Materials that are deposited by ALD are grown from a gas phase precursor chemical that, by virtue of surface chemical reactions, react on a surface to form the target material. It is surface chemistry, not surfactants, which control the size and shape of deposited nanofeatures. The versatility of this technique is reflected in the number of available processes that exist to deposit a variety of different materials. ${ }^{20} \mathrm{~A}$ significant amount of research has been undertaken to study the deposition of metal films (including copper), ${ }^{133}$ but the other group 11 metals have proved more challenging. ${ }^{134-136}$ Reported here for the first time is gold metal deposition by ALD.

\subsection{Experimental}

\section{Synthesis}

Starting from auric acid, $\mathrm{HAuCl}_{4} \cdot \mathrm{H}_{2} \mathrm{O}$ (49.9 wt.\% Au, Strem Chemicals), tetrahydrothiophenegold(I) chloride, THTAuCl, is synthesized via a redox reaction in ethanol between THT and auric acid in the presence of water. Excess THT then acts as the coordinating ligand to produce $\mathrm{THTAuCl}$ in quantitative yields. Trimethylphosphinegold(I) chloride, $\mathrm{Me}_{3} \mathrm{PAuCl}$, is then synthesized from $\mathrm{THTAuCl}$ via ligand exchange with a solution of $\mathrm{PMe}_{3}$ in toluene and $\mathrm{THTAuCl}$ in dichloromethane in an inert atmosphere drybox. $\mathrm{Me}_{3} \mathrm{PAuCl}$ is purified by recrystallization in dichloromethane in air.

\section{$\mathrm{Me}_{3} \mathrm{PAuMe}_{3}(15)$}

$5.9059 \mathrm{~g}$ (19.144 mmol) of $\mathrm{Me}_{3} \mathrm{PAuCl}$ was placed in a $500 \mathrm{~mL}$ Schlenk flask along with a stir bar and was then dried under high vacuum for 2 hours. Meanwhile, a $100 \mathrm{~mL}$ dropping funnel was flame dried under high vacuum, then cooled to room temperature 
under vacuum. Both Schlenk flask and dropping funnel were then back-filled with $\mathrm{N}_{2}$. The $\mathrm{Me}_{3} \mathrm{PAuCl}$ was suspended in $300 \mathrm{~mL}$ of dry $\mathrm{Et}_{2} \mathrm{O}$, and the dropping funnel was then attached under a stream of $\mathrm{N}_{2}$ from both flask and funnel. The top of the dropping funnel was then fitted with a dry rubber septum, flowing nitrogen from the Schlenk arm of the $500 \mathrm{~mL}$ flask. With the apparatus assembled, the suspension was cooled to $-78{ }^{\circ} \mathrm{C}$ in a dry ice / isopropanol bath. One bottle of MeLi $(25 \mathrm{~mL}, 40$ mmol, 1.6 $\mathrm{M}$ in $\mathrm{Et}_{2} \mathrm{O}$ ) was transferred to the dropping funnel via cannula using a slight vacuum assist from the Schlenk arm. The Schlenk arm was only slighty opened to vacuum, and then closed again. This was repeated until all the MeLi had been transferred. Care was taken not to keep the system under active vacuum since this was found to cause MeLi to precipitate in the dropping funnel. A backflow prevention bubbler was used on the nitrogen line to ensure that no air could enter the system during the vacuum-assist. Once transferred, the cannula was removed, and the MeLi solution was added dropwise (rate of 1 drop every 6-8 s). A very slow addition is important because the intermediate formed before the next addition is thermally unstable. A total addition time of 50-60 min is ideal. Once all the MeLi was added, the funnel was rinsed with $20 \mathrm{~mL}$ of $\operatorname{dry} \mathrm{Et}_{2} \mathrm{O}$, which was then added dropwise to the stirring solution. By this point, the suspension often appears yellow to green in colour. This suspension is stirred for 2 hours after completion of MeLi addition at $-78^{\circ} \mathrm{C}$.

Neat MeI $(1.91 \mathrm{~mL}, 30.6 \mathrm{mmol})$ was then added dropwise over $10 \mathrm{~min}$, and the reaction was stirred for a further 2 hours at $-78^{\circ} \mathrm{C}$. The suspension usually returns to white at this point, but yellow or grey was also observed. The reaction was allowed to warm to ice bath temperature. $40 \mathrm{~mL}$ of distilled water was added to the funnel, and was then added dropwise to the stirring suspension to quench leftover MeLi. This step is very exothermic and so a controlled addition is required to prevent decomposition of product to gold metal. The ethereal layer was extracted and dried over $\mathrm{MgSO}_{4}$. Crude 
product was isolated by removal of ether on a rotary evaporator. Vacuum distillation $\left(80{ }^{\circ} \mathrm{C}, 100\right.$ mTorr) yields pure $\mathbf{1 5}(5.1979 \mathrm{~g}, 16.338 \mathrm{mmol}, 85.37 \%)$. m.p.: $22{ }^{\circ} \mathrm{C} .{ }^{1} \mathrm{H}$ HR-NMR $\delta_{H}\left(300 \mathrm{MHz}, \mathrm{CDCl}_{3}\right): 1.49\left(9 \mathrm{H}, \mathrm{d}, \mathrm{P}\left(\mathrm{CH}_{3}\right)_{3},{ }^{2} J_{H P}=9.6 \mathrm{~Hz}\right), 0.81(3 \mathrm{H}$, d, $\mathrm{Au}\left(\mathrm{CH}_{3}\right)_{2}\left(\mathrm{CH}_{3}\right),{ }^{3} J_{H P}($ trans $\left.)=9.6 \mathrm{~Hz}\right), 0.09\left(6 \mathrm{H}, \mathrm{d}, \mathrm{Au}\left(\mathrm{CH}_{3}\right)_{2}\left(\mathrm{CH}_{3}\right),{ }^{3} J_{H P}(\right.$ cis $)$ $=7.6 \mathrm{~Hz}) \cdot{ }^{13} \mathrm{C}\left\{{ }^{1} \mathrm{H}\right\}$ HR-NMR $\delta_{C}\left(75 \mathrm{MHz}, \mathrm{CDCl}_{3}\right): 12.02\left(\mathrm{P}\left(\mathrm{CH}_{3}\right)_{3},{ }^{2} J_{C P}=\right.$ $28.9 \mathrm{~Hz}), 10.87\left(\mathrm{Au}\left(\mathrm{CH}_{3}\right)_{2}\left(C \mathrm{H}_{3}\right),{ }^{3} J_{C P}(\right.$ trans $\left.)=133.0 \mathrm{~Hz}\right), 6.46\left(\mathrm{Au}\left(\mathrm{CH}_{3}\right)_{2}\left(\mathrm{CH}_{3}\right)\right.$, $\left.{ }^{3} J_{C P}(c i s)=6.1 \mathrm{~Hz}\right) . \delta_{C}\left(300 \mathrm{MHz}, \mathrm{CDCl}_{3}\right): 12.02\left(\mathrm{P}\left(C \mathrm{H}_{3}\right)_{3},{ }^{2} J_{C P}=28.9 \mathrm{~Hz}\right), 10.87$ $\left(\mathrm{Au}\left(\mathrm{CH}_{3}\right)_{2}\left(\mathrm{CH}_{3}\right),{ }^{3} J_{C P}(\right.$ trans $\left.)=133.0 \mathrm{~Hz}\right), 6.46\left(\mathrm{Au}\left(\mathrm{CH}_{3}\right)_{2}\left(\mathrm{CH}_{3}\right),{ }^{3} J_{C P}(\right.$ cis $)=6.1$ $\mathrm{Hz}) .{ }^{31} \mathrm{P}\left\{{ }^{1} \mathrm{H}\right\}$ HR-NMR $\delta_{P}\left(121 \mathrm{MHz}, \mathrm{CDCl}_{3}\right):-9.75\left(P\left(\mathrm{CH}_{3}\right)_{3}\right)$.

\section{Thermogravimetric Analysis}

In a typical experiment, $\approx 20 \mathrm{mg}$ of $\mathbf{1 5}$ was loaded in a platinum pan which was hung on the microbalance arm of a TA Instruments Q500 TGA, which is housed in an inert atmosphere MBraun glovebox. All experiments were purged by nitrogen gas. In the ramp experiment (Supplemental Figure 6.9), a ramp rate of $10{ }^{\circ} \mathrm{C} / \mathrm{min}$ was employed from room temperature to $500{ }^{\circ} \mathrm{C}$. For the isothermal experiment (Supplemental Figure 6.9), the temperature was ramped automatically to a set-point of $65{ }^{\circ} \mathrm{C}$ and held at this temperature for 175 minutes.

\section{Vapor Pressure Determination}

To calculate a Langmuir vapor pressure curve for $15, \approx 20 \mathrm{mg}$ of $\mathbf{1 5}$ was loaded in a platinum pan which was hung on the microbalance arm of a TA Instruments Q500 TGA, which is housed in an inert atmosphere MBraun glovebox. A temperature program was run such that the temperature was ramped by $10{ }^{\circ} \mathrm{C}$ and then held isothermally for 10 minutes. This was repeated from room temperature to $400{ }^{\circ} \mathrm{C}$. The slope of the linear weight loss per unit time at each isothermal step was calculated and expressed with respect to the area of the pan. This was graphed on a 
logarithmic scale against 1 /temperature to extract a relationship for evaporation rate (Supplemental Figure 6.10). A known method was used to calculate the Langmuir expression for vapor pressure. ${ }^{71}$

\section{Deposition}

All thin films were deposited using a Picosun R200 ALD reactor with a Picoplasma remote plasma source system (plasma RF power of $2800 \mathrm{~W}$ ). Oxygen gas $(99.999 \%$ ) was mixed with Argon gas (99.999\%) at flow rates of 110 sccm and 185 sccm, respectively, during plasma ignition. A conductive screen between the plasma source and the substrate blocked charged species from participating in surface chemistry. The reactor pressure and temperature were $5 \mathrm{hPa}$ and $120^{\circ} \mathrm{C}$, respectively. Silicon (100) with native oxide and soda lime microscope slides were used as substrates, and were pre-treated with 10 plasma pulses $\left(14 \mathrm{~s}_{2}\right.$ plasma $\left.\mid 10 \mathrm{~s}_{2}\right)$ before beginning ALD experiments. Milli-Q de-ionized water $(18.2 \mathrm{M} \Omega \mathrm{cm})$ was used in the water bubbler, and was cooled to $19^{\circ} \mathrm{C}$ using a Pelletier cooler.

A fresh sample of $\mathbf{1 5}$ was loaded into a cleaned glass vial and then inserted into the Picosolid booster crucible before each experiment. The head-space of the bubbler was purged of air and replaced with nitrogen before heating to $85^{\circ} \mathrm{C}$. In a typical experiment, 1000 cycles with a pulse duration of $4 \mathrm{~s}$ volatilized approximately $550 \mathrm{mg}$ of $\mathbf{1 5}$, and 1250 cycles of $10 \mathrm{~s}$ pulses used between $1 \mathrm{~g}$ and $1.2 \mathrm{~g}$ of $\mathbf{1 5}$. The typical pulse sequence was $4 \mathrm{~s} \mathrm{Au} \mid 14 \mathrm{~s} \mathrm{O}_{2}$ plasma $\mid 0.1 \mathrm{~s}$ water each separated by a $10 \mathrm{~s}$ nitrogen gas (99.999\%) purge. The purge times were chosen to be reliable, rather than optimal. The flow rates of $\mathrm{N}_{2}$ carrier gas for the gold precursor and water were $120 \mathrm{sccm}$ and 100 sccm, respectively. Leftover precursor from each experiment was stored in a separate vial, and the booster vial wiped clean with ethanol. Accumulated spent precursor was re-purified by vacuum distillation as described in the synthetic procedure (included as Supplementary Material; Section 6.7) and used without noticeable loss of film quality. 


\section{Thin Film Characterization}

Typically, the gold films were deposited using 1000 cycles using 4 s pulses of $\mathbf{1 5}$, $14 \mathrm{~s}$ pulses of $\mathrm{O}_{2}$ plasma, and $0.1 \mathrm{~s}$ pulses of water with $10 \mathrm{~s}$ nitrogen gas purges between each step. These films were imaged using a Tescan Vega-II XMU Variable

Pressure scanning electron microscope with $20 \mathrm{keV}$ potential (Supplemental Figure 6.11). The films appeared well connected and uniform. Attempts at characterizing the resistivity were unsuccessful due to poor adhesion of the gold metal film on glass and silicon $/ \mathrm{SiO}_{2}$ substrates. XPS spectra were collected in the analysis chamber of a Specs/RHK multi-technique ultrahigh vacuum system using a Phoibos 100 SCD power supply, hemispherical analyzer, and detector. Whenever possible, the sample being analyzed was electrically grounded. An XR-50 X-ray source containing an $\mathrm{Al}$ anode $(400 \mathrm{~W})$ was used in this study (14.26 keV Al K $\alpha$ source), and analyses were performed within a base pressure range of $7 \cdot 10^{-10}-1 \cdot 10^{-9}$ Torr. Survey (Supplemental Figure 6.12) and high-resolution scans of the as-deposited gold films were collected using SpecsLab2 software, and post-processed and deconvoluted using CasaXPS. High-resolution spectra were fitted to a Shirley background and fitted using the appropriate Scofield-based factors for photoelectron cross-section.

\section{Surface Exposure Experiments}

The exposure experiments were performed in a home-built reactor. A stainless steel tube reactor was fitted with a stainless steel ring support covered in 200 stainless steel mesh with a plug of glass wool to hold the substrate powder. The system had one inlet for a heated stainless steel bubbler and one inlet for He (purity of 99.999 \%). Pressure was monitored using a VCR-531 thermocouple (Vacuum Research Corp.). All fittings used in this system were either CF or VCR to ensure an air-free highvacuum seal. The system was leak checked using a gas thermal conductivity/leak 
detector (Gow-Mac Instrument Co.) and an overpressure of He. For exposure experiments, typically about $1 \mathrm{~g}$ of high surface area $\mathrm{SiO}_{2}$ powder (EP10X; PQ Corp.; $300 \mathrm{~m}^{2} /$ g S.A.; $1.8 \mathrm{~cm}^{3} / \mathrm{g}$ P.V.; 24 nm P.S.; $100 \mu \mathrm{m}$ P.D.) was used as the substrate. The substrate was pre-treated in the reactor at $350{ }^{\circ} \mathrm{C}$ overnight under vacuum before exposure to the precursor. The base pressure after pre-treatment was typically around 20 mTorr. The reactor and lines were heated to temperature and allowed to equilibrate for $1-2 \mathrm{~h}$ before introduction of the precursor. The precursor (typically $0.4-0.8 \mathrm{~g}$ was then vapourized and transported to the substrate with the system under $10^{-3}$ Torr vacuum. The substrate was exposed to volatilized precursor for $20 \mathrm{~h}$ before the system was cooled to room temperature for handling. After exposure was complete, the system (precursor bubbler and reaction chamber) was filled with an overpressure of He (99.999\%), closed, disassembled, and brought into a nitrogen drybox for handling.

\section{Characterization of Surface Species}

Solid-state NMR experiments were performed at 4.7 T on a Bruker Avance III console. All spectra were obtained using a Bruker $7 \mathrm{~mm}{ }^{1} \mathrm{H} / \mathrm{X} / \mathrm{Y}$ probe. ${ }^{13} \mathrm{C}\left(\nu_{0}=50.3 \mathrm{MHz}\right)$ cross-polarization magic angle spinning (CP/MAS) experiments were collected at a spinning rate of $4.5 \mathrm{kHz}$ using a $3.40 \mu \mathrm{s} 90^{\circ}$ proton pulse with a contact time of $2 \mathrm{~ms}$ where the contact pulse was ramped on the ${ }^{1} \mathrm{H}$ channel. A relaxation delay of $2 \mathrm{~s}$ was sufficient to prevent saturation, and typically, total acquisition times were 18-20 h. Glycine was used as an external secondary reference for the ${ }^{13} \mathrm{C}$ chemical shift scale. Spectra were treated with $40 \mathrm{~Hz}$ line broadening during processing. ${ }^{29} \mathrm{Si}$ $\left(\nu_{0}=39.8 \mathrm{MHz}\right) \mathrm{CP} / \mathrm{MAS}$ experiments were collected at a spinning rate of $4.5 \mathrm{kHz}$ using a $3.70 \mu \mathrm{s} 90^{\circ}$ proton pulse with a contact time of $7.5 \mathrm{~ms}$ where the ${ }^{1} \mathrm{H}$ channel contact pulse was ramped. The relaxation delay was $2 \mathrm{~s}$ and typically required 15-20 h acquisition times. TMSS was used as an external reference for the ${ }^{29} \mathrm{Si}$ chemical shift 
scale. Spectra were treated with $30 \mathrm{~Hz}$ line broadening during processing. Peak deconvolution was accomplished using the dmfit software package (v. 20110512)36 and the Solids Lineshape Analysis tool included in the Bruker Topspin software package (version 3.2). The sites were fit using a mixed Gaussian/Lorentz fit with a $0.8 \mathrm{G} / \mathrm{L}$ ratio. ${ }^{31} \mathrm{P}\left(\nu_{0}=81.0 \mathrm{MHz}\right) \mathrm{CP} / \mathrm{MAS}$ experiments were collected at a spinning rate of $4.5 \mathrm{kHz}$ using a $3.30 \mu \mathrm{s} 90^{\circ}$ proton pulse with a contact time of $2 \mathrm{~ms}$ where the ${ }^{1} \mathrm{H}$ channel contact pulse was ramped. The relaxation delay was $5 \mathrm{~s}$ and typically required $2-3 \mathrm{~h}$ acquisition times. ADP was used as an external reference for the ${ }^{31} \mathrm{P}$ chemical shift scale. Spectra were treated with $5 \mathrm{~Hz}$ line broadening during processing. ${ }^{13} \mathrm{C},{ }^{29} \mathrm{Si}$, and ${ }^{31} \mathrm{P}$ spectra were obtained with high power proton decoupling during acquisition.

\subsection{Results and Discussion}

We used trimethylphosphinotrimethylgold(III) (15) as the chemical precursor, a compound that has previously been employed in CVD. ${ }^{137,138}$ This compound is air and water stable, is a liquid at room temperature, and has a vapour pressure that follows this Langmuir equation: ${ }^{71}$

$$
\ln (p)=0.059 T-1.65
$$

where: $p$ is pressure in Pascals and $T$ is temperature in Celsius.

Heating 15 to $85{ }^{\circ} \mathrm{C}$ was sufficient to deliver the precursor into the ALD reactor. To reduce this compound at the surface to metallic gold, we found that hydrogen gas was not effective: at temperatures lower that $130{ }^{\circ} \mathrm{C}$, no deposition was observed, and at temperatures over $130{ }^{\circ} \mathrm{C}, \mathbf{1 5}$ begins to decompose to gold metal without a reducing co-reagent (i.e., by a CVD mechanism).

Noble metal deposition by ALD can employ molecular oxygen as a co-reagent: the 

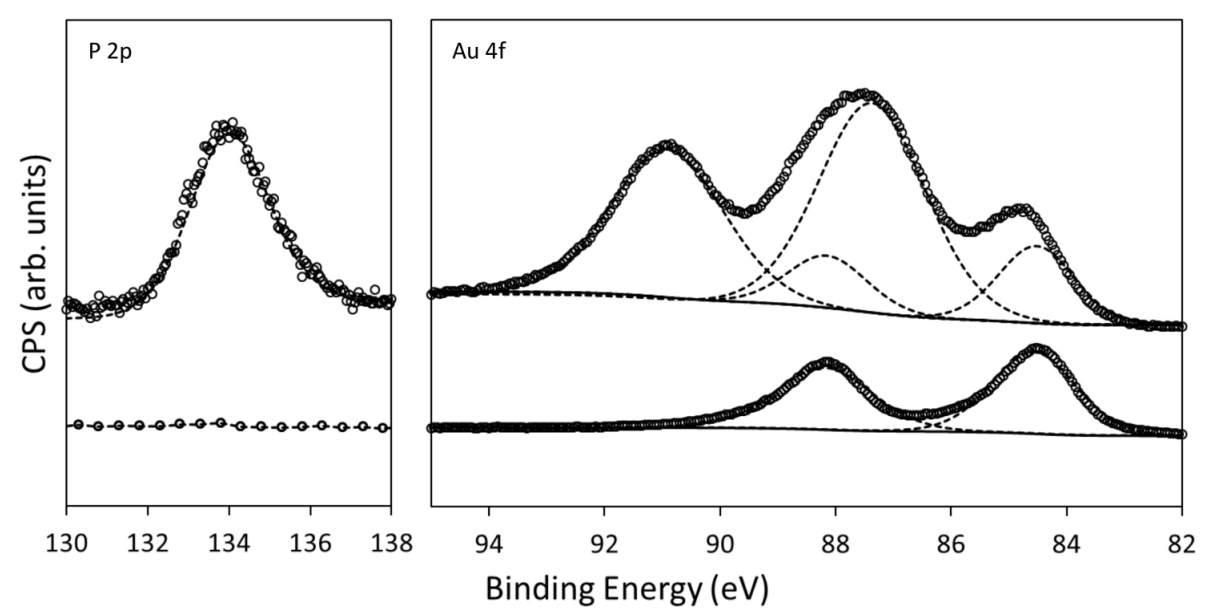

Figure 6.2: XPS spectra of the phosphorous $2 \mathrm{p}$ and gold $4 \mathrm{f}$ regions for the film deposited without a water pulse (top), and with a water pulse (bottom).

strategy is to oxidize the organic ligand system, leaving the noble metal behind. ${ }^{139}$ We found that using molecular oxygen did not react with 15 under $130{ }^{\circ} \mathrm{C}$. Other oxygen-containing co-reactants (i.e., $\mathrm{H}_{2} \mathrm{O}$ and $\mathrm{O}_{3}$ ) were similarly unreactive with 15 under thermal conditions. However, using a plasma-enhanced process with $\mathbf{1 5}$ showed that oxygen plasma did produced a film of gold metal by ALD at $120^{\circ} \mathrm{C}$.

Using just oxygen plasma, the films were discoloured and non-metallic in appearance; typically they were brown or dark purple. These films discoloured and delaminated over time in ambient conditions, and developed a foul odour. EDX and XPS (Figure 6.2, Table 6.1) showed that gold was certainly present, but so too were oxygen and phosphorous.

In the XPS spectrum (Figure 6.2 (top-left)), a peak was observed centred at 134.1 $\mathrm{eV}$, which is in the range of the $\mathrm{P}(\mathrm{V})$ oxidation state. There was also evidence of $\mathrm{Au}(0)$ (Figure 6.2 (right)), with peaks at $84.5 \mathrm{eV}$ and $88.2 \mathrm{eV}$, and $\mathrm{Au}(\mathrm{III})$ at $87.5 \mathrm{eV}$ and $90.9 \mathrm{eV}$. This suggests that the phosphine ligand from the precursor remained with the gold adatom at the surface, and was converted into a gold-phosphine containing film when reacted with oxygen plasma.

Although the nature of this film isn't presently understood, further characterization has shed some insight. Trimethylphosphine is known to react with oxygen to produce $\mathrm{P}_{2} \mathrm{O}_{5}$ and other phosphorus $(V)$ oxides. Since treatment of $\mathrm{P}_{2} \mathrm{O}_{5}$ with water 
Table 6.1: Compositional analysis (at.\%) by XPS of the film formed without water and the film formed with water. ${ }^{a}$

$\begin{array}{ccc}\text { Species } & \text { Without Water Co-reactant } & \text { With Water Co-reactant } \\ \mathrm{Au} & 76.16 & 91.52 \\ \mathrm{C} & 5.61 & 6.65 \\ \mathrm{~N} & 1.43 & 0^{b} \\ \mathrm{P} & 6.26 & 0^{b} \\ \mathrm{O} & 10.54 & 1.83\end{array}$

${ }^{a}$ These data represent the surface measured "as is", and likely contains carbon and oxygen from atmospheric sources. ${ }^{b}$ These species were below the detection limit of XPS.

yields phosphoric acid, the impure film was sonicated in $\mathrm{D}_{2} \mathrm{O}$, and $\mathrm{D}_{3} \mathrm{PO}_{4}(1.12 \mathrm{ppm}$ rel. to $\mathrm{H}_{3} \mathrm{PO}_{4}$ ) was observed as a major product by ${ }^{31} \mathrm{P}\left\{{ }^{1} \mathrm{H}\right\}$ HR-NMR spectroscopy, suggesting the presence of phosphorus(V) oxides in the film. Interestingly, rinsing these films with water was enough to seemingly dissolve them, even though they were well-adhered to the silicon substrate.

The simplest chemistry that rationalizes these facts is that the oxygen plasma combusts the precursor, forming oxides of both gold and phosphine in the process:

$$
\mathrm{Me}_{3} \mathrm{P}-\mathrm{AuMe}_{3}+\left(\mathrm{O}^{*}\right) \longrightarrow \mathrm{Au}_{2} \mathrm{O}_{3}+\mathrm{P}_{2} \mathrm{O}_{5}+6 \mathrm{CO}_{2}+9 \mathrm{H}_{2} \mathrm{O}
$$

Gold metal is then slowly formed from the gold oxide, which agrees with the presence of both oxidation states in the XPS. This conversion occurs in the bulk at $160{ }^{\circ} \mathrm{C},{ }^{140}$ but the higher chemical potential of a deposited monolayer could allow this conversion to happen at lower temperature:

$$
\mathrm{Au}_{2} \mathrm{O}_{3} \longrightarrow 2 \mathrm{Au}^{0}+\frac{3}{2} \mathrm{O}_{2}
$$

In an attempt to eliminate the phosphorus impurity in the film, water was chosen as a ternary reactant with the purpose of hydrolizing the impurity to phosphoric acid, which would then be volatilized away. Using, an ABC-type pulse sequence of $4 \mathrm{~s}$ of $\mathbf{1 5}$, $14 \mathrm{~s}$ oxygen plasma, and $0.1 \mathrm{~s}$ water produced very pure gold metal films at $120{ }^{\circ} \mathrm{C}$. XPS analysis of these film showed very clearly that there was only metallic gold $(0)$ 

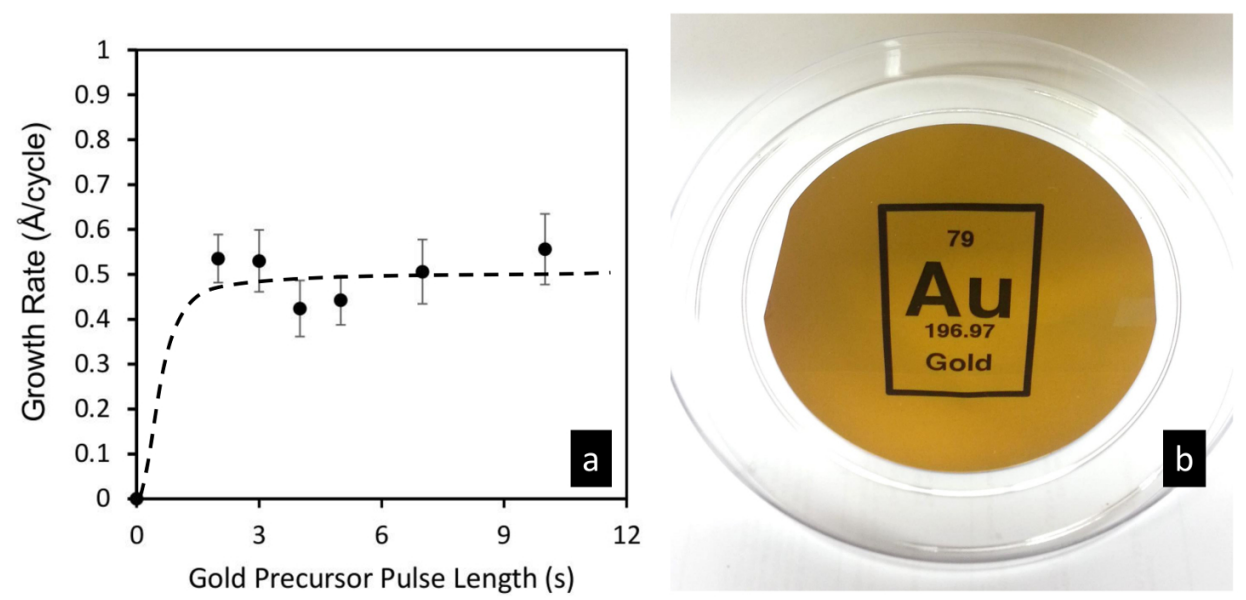

Figure 6.3: Saturation curve of $\mathbf{1 5}$ showing ALD behaviour. a) shows the $\mathbf{1 5}$ saturation curve where oxygen plasma and water pulse is kept at $14 \mathrm{~s}$ and $0.1 \mathrm{~s}$, respectively. b) shows the as-deposited film.

(84.5 eV and $88.2 \mathrm{eV}$ ), with no phosphorus signals observed (Figure 6.2, Table 6.1). EDX also confirmed the absence of phosphorous in the film. Since gold oxide converts to gold metal faster in the presence of water, ${ }^{140}$ this explains the formation of the metallic film. Likewise, the phosphorous oxide is converted into volatile hydrogen phosphate, and is removed during the purge step:

$$
\mathrm{P}_{2} \mathrm{O}_{5}+3 \mathrm{H}_{2} \mathrm{O} \longrightarrow 2 \mathrm{H}_{3} \mathrm{PO}_{4}
$$

Using this process, gold thin films were deposited using a range of process parameters with high fidelity on both silicon and borosilicate substrates. Thickness measurements were calculated from the k-ratios measured by EDX using a program called GMRFilm, ${ }^{141}$ and the resulting growth rates demonstrated ALD-characteristic self-saturating growth after $2 \mathrm{~s}$ pulse lengths of $\mathbf{1 5}$ (Figure 6.3a). A growth rate of $0.5 \AA$ /cycle was observed, and is typical for metal films. ${ }^{20}$ The films themselves were highly reflective metallic gold mirrors (Figure 6.3b).

Since our desire is to exploit this technique to form metallic nanoparticles, we were very interested in studying the effect of a small number of cycles of the process. Deposition of gold metal on polymer-coated copper TEM grids was done with 2 and 5 cycles. With two ALD cycles, EDX showed the presence of gold, but features were 


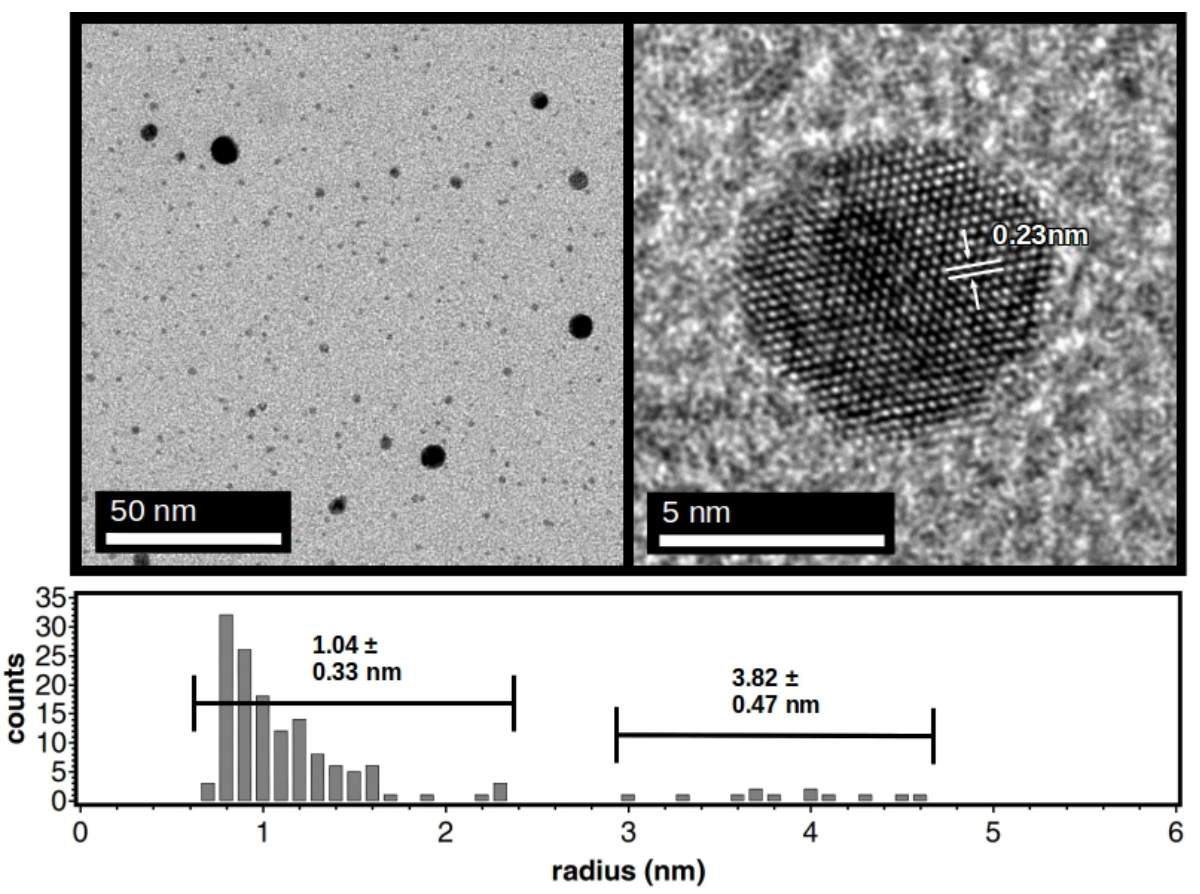

Figure 6.4: TEM of gold metal nanoparticles deposited on a TEM grid after 5 ALD cycles using 15 with oxygen plasma and water co-reactants. The histogram shows the distribution of particle sizes.

difficult to differentiate from the background carbon of the polymer film. With 5 ALD cycles, obvious gold nanoparticles were observed by TEM and EDX (Figure 6.4). The lattice spacing of atoms in the TEM was $0.23 \mathrm{~nm}$, which is indicative of the $\mathrm{Au}(111)$ crystal face. ${ }^{88}$

The deposited gold metal particles showed some polydispersity, which we attribute to mobility of the reduced gold adatoms formed during the plasma step. At 5 cycles the particles had a bimodal dispersity, clustered in small and large particles. The large particles were few in number and had an average radius of $3.8( \pm 0.5) \mathrm{nm}$ while the smaller particles were much more numerous and had an average diameter of 1.0 $( \pm 0.3) \mathrm{nm}$ with the most common radius being $0.8 \mathrm{~nm}$.

This shows that ALD deposited gold can produce nanoparticles on a substrate without the need for solution-phase chemistry and capping agents (other than the inherent ligand system). The overall growth during ALD cycles as well the movement of adatoms on the surface to various nucleation points suggests a Volmer-Weber type growth. This is expected due to the energetics of the plasma step and the propensity 
for precursor nucleation onto metallic gold rather than the carbon mesh of the TEM grid.

\subsection{Additional Results}

To study the initial chemisorption mechanism of $\mathbf{1 5}$ on oxide surfaces like silica, an exposure experiment was carried out and studied ex situ using SS-NMR. To accomplish this exposure, $0.6 \mathrm{~g}$ of $\mathbf{1 5}$ was placed in a bubbler, heated to $85^{\circ} \mathrm{C}$, and entrained over a sample of HSAS at $100{ }^{\circ} \mathrm{C}$ under active vacuum. The HSAS sample was previously pre-treated to $350{ }^{\circ} \mathrm{C}$ under vacuum before exposing it to $\mathbf{1 5}$. After exposure, the HSAS was handled in inert atmosphere and characterized by ${ }^{13} \mathrm{C},{ }^{29} \mathrm{Si}$, and ${ }^{31} \mathrm{P}$ SS-NMR. The details of this type of exposure experiment and analysis have been previously reported. ${ }^{72,73,81}$ The analysis discussed herein uses the same methodology described in those publications.

Figure 6.5 shows the ${ }^{29} \mathrm{Si} \mathrm{CP} / \mathrm{MAS}$ SS-NMR spectrum (experimental and deconvoluted) of silica exposed to 15 at $100{ }^{\circ} \mathrm{C}$. The most prominent features in this spectrum come from hydroxylated and dehydroxylated silicon on the surface of the silica. The peaks at $-94,-101$, and $-110 \mathrm{ppm}$ come from $\|-(\mathrm{Si}-\mathrm{O})_{2}-\mathrm{Si}^{*}-(\mathrm{OH})_{2}$ (geminal-hydroxyl), $\|-(\mathrm{Si}-\mathrm{O})_{3}-\mathrm{Si}^{*}-\mathrm{OH}$ (lone-hydroxyl), and $\|-(\mathrm{Si}-\mathrm{O})_{4}-\mathrm{Si}^{*}$ (dehydroxylated) surface silicon sites, respectively. ${ }^{64,81}$ The most interesting thing to note after exposing 15 to HSAS is the lack of signals other than those originating from silica in the ${ }^{29} \mathrm{Si}$ SS-NMR. This indicates that upon adsorption, 15 interacts with the surface through the oxygen atoms on the surface and does not form any direct silicon bonds. This means that there are no $\|-\mathrm{Si}-\mathrm{X}$ interactions where $\mathrm{X}$ could be $\mathrm{Au}, \mathrm{C}, \mathrm{P}$, or $\mathrm{H}$. This behaviour of metal-organic vapour phase deposition precursors interacting only through the oxygen on the surface of HSAS has been observed for Ga and $\mathrm{Cu}$ compounds. ${ }^{72,81}$ 
Table 6.2: Normalized Integration and Surface Coverage of Compound 15 from ${ }^{29} \mathrm{Si}$ CP/MAS SS-NMR Signal of Pure and Modified Silica ${ }^{a}$

\begin{tabular}{|c|c|c|c|c|c|}
\hline \multirow[b]{2}{*}{ sample } & \multicolumn{2}{|c|}{$\begin{array}{l}\text { normalized integration of }{ }^{29} \mathrm{Si} \\
\mathrm{SS}^{-N M R}{ }^{b}\end{array}$} & \multicolumn{3}{|c|}{ surface coverage $^{c}$} \\
\hline & $\|-\mathrm{Si}-\mathrm{OH}$ & $\|-\mathrm{Si}-(\mathrm{OH})_{2}$ & $\theta$ & $\theta_{g}$ & $\theta_{l}$ \\
\hline pretreated silica & $0.547 \pm 0.011$ & $0.040 \pm 0.001$ & & & \\
\hline $\begin{array}{l}\text { silica exposed to } \\
\mathbf{1 5} \text { at } 100^{\circ} \mathrm{C}\end{array}$ & $0.491 \pm 0.009$ & $0.038 \pm 0.003$ & $0.102 \pm 0.021$ & $0.049 \pm 0.053$ & $0.113 \pm 0.021$ \\
\hline
\end{tabular}

Using a method previously developed, ${ }^{81}$ the coverage, or extent of reaction at the surface hydroxyl sites, can be determined for this precursor when comparing the integrated intensities of the ${ }^{29} \mathrm{Si}$ SS-NMR signals in the silica region for the exposed sample versus a blank sample similarly pre-treated at $350{ }^{\circ} \mathrm{C}$. The calculated coverage values determined for 15 on $\mathrm{HSAS}$ at $100{ }^{\circ} \mathrm{C}$ adsorption are shown in Table 6.2. The surface coverage values determined herein show about a $10 \%$ reaction of $\mathbf{1 5}$ with the surface of HSAS at $100{ }^{\circ} \mathrm{C}$. These values are reasonable considering the steric bulk of the compound and the average density of hydroxyl groups on $\mathrm{HSAS}$ at $350{ }^{\circ} \mathrm{C}(\approx 5$ $\left.\mathrm{OH} / \mathrm{nm}^{2}\right)$. Given that the van der Waals radii for $\mathrm{Au}, \mathrm{P}$, and $\mathrm{C}$ are in the range of 1.5-2.0 $\AA,{ }^{142}$ this means that it is highly unlikely that even a fragment of $\mathbf{1 5}$ will be able to react with more than $40 \%$ of the surface hydroxyls. So, the determined coverages show that there is likely a large fragment of $\mathbf{1 5}$ left on the surface, possibly trimethylgold or trimethylphosphine. The coverage between lone-hydroxyl groups and geminal-hydroxyl groups was found to differ quite substantially for $\mathbf{1 5}$ adsorbed on HSAS at $100{ }^{\circ} \mathrm{C}$. The coverage of lone-hydroxyl groups was $0.113( \pm 0.021)$ while the coverage of geminal-hydroxyl groups was $0.049( \pm 0.053)$. Given the relatively large uncertainty on the coverage of geminal-hydroxyl groups, the actual coverage at these sites is possibly quite small, if not negligible. However, there is an obvious propensity for $\mathbf{1 5}$ to adsorb at lone-hydroxyl sites rather than geminal-hydroxyl sites. 


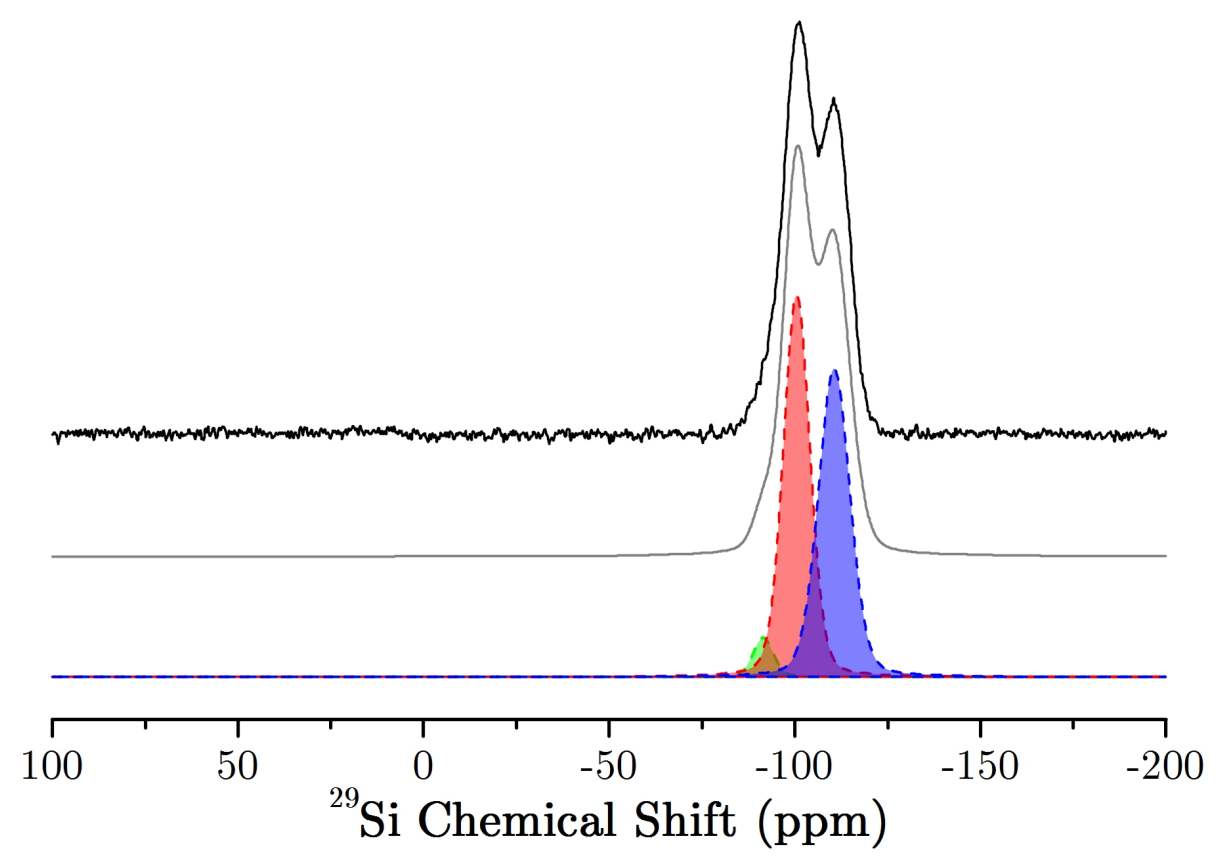

Figure 6.5: ${ }^{29} \mathrm{Si} \mathrm{CP} / \mathrm{MAS}$ SS-NMR spectrum of HSAS exposed to 15 at $100{ }^{\circ} \mathrm{C}$. Deconvolution spectra (middle line) show only contributions from three separate silica surface species (bottom lines). The peaks at $-94,-101$, and $-110 \mathrm{ppm}$ represent geminal-hydroxyl, lone-hydroxyl, and dehydroxylated silicon signals, respectively.

The nature of 15's preference for lone-hydroxyl sites on silica is currently unknown but merits further investigation.

To determine the nature of the adsorbed species, both ${ }^{13} \mathrm{C}$ and ${ }^{31} \mathrm{P} \mathrm{CP} / \mathrm{MAS}$ SSNMR were done on the HSAS exposed to 15 at $100{ }^{\circ} \mathrm{C}$. The ${ }^{31} \mathrm{P}$ SS-NMR is shown in Figure 6.6a. There are four distinct ${ }^{31} \mathrm{P}$ signals present on the surface of the HSAS after exposure to $\mathbf{1 5}$. The most prominent signal occurs at $4.5 \mathrm{ppm}$ while the three other very low intensity signals occur at $-7.3 \mathrm{ppm},-12.3 \mathrm{ppm}$, and $-17.2 \mathrm{ppm}$. To assist in determining what surface species is responsible for these signals, the ${ }^{31} \mathrm{P} \mathrm{HR}$ NMR of pure $\mathbf{1 5}$ is shown as well (Figure 6.6b). Unsurprisingly, the ${ }^{31} \mathrm{P}$ HR-NMR for 15 shows one ${ }^{31} \mathrm{P}$ signal at $-9.75 \mathrm{ppm}$ corresponding to the phosphorus in the trimethyl phosphine ligand. Interestingly, the major signal in the SS-NMR does not correspond to the HR-NMR data for 15. This signal is in the correct range for a $\mathrm{PO}_{4}{ }^{3-}$ species (typically between 0 to $10 \mathrm{ppm}) .{ }^{143} \mathrm{So}$, the signal at $4.5 \mathrm{ppm}$ is likely a surfacebound phosphorus(V) species that is completely surrounded by oxygen. This shows that the phosphine ligand on $\mathbf{1 5}$ readily reacts with the surface hydroxyl groups on 


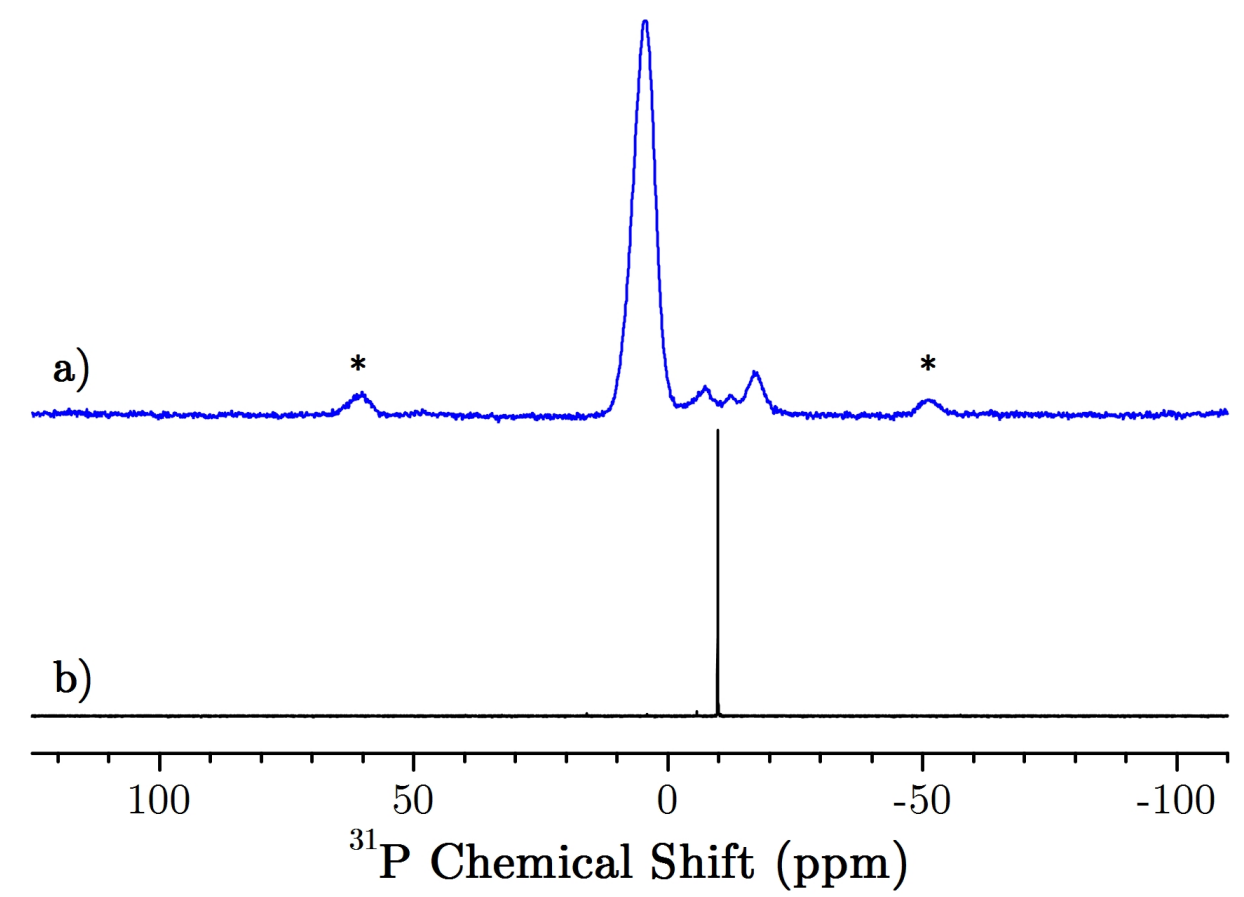

Figure 6.6: a) ${ }^{31} \mathrm{P} \mathrm{CP} / \mathrm{MAS}$ SS-NMR spectrum of HSAS exposed to $\mathbf{1 5}$ at $100{ }^{\circ} \mathrm{C}$. b) ${ }^{31} \mathrm{P}\left\{{ }^{1} \mathrm{H}\right\}$ HR-NMR of $\mathbf{1 5}$. ${ }^{*}$ spinning sidebands.

HSAS to produce an oxidized phosphorus species and likely methane as a byproduct (Figure 6.8). This helps to explain the other signals in the ${ }^{31} \mathrm{P}$ SS-NMR spectrum as well. In general, alkyl phosphines have a relatively large chemical shift range (from $-75-75 \mathrm{ppm}$ ), however, alkylated phosphoxides are typically below 0 ppm. Given that the trimethylphosphine readily reacts with surface hydroxyl groups, it seems likely that the other peaks are substituted methylphosphoxide surface species (Figure 6.8). Another possibility for these peaks (particularly the peak at $-17.2 \mathrm{ppm}$ ) is the existence of a $\|-\mathrm{Au}-\mathrm{PMe}_{3}$ surface species (evidence in the ${ }^{13} \mathrm{C}$ data, see below). Given the likelihood of forming a completely oxidized phosphorus $\left(\mathrm{PO}_{4}{ }^{3-}\right)$ species on the surface, the only reason a methylated phosphoxide appears would be due to the reduced hydroxyl density at $350{ }^{\circ} \mathrm{C}$ pre-treatment temperature and that once bound to the surface there is no access to other surrounding hydroxyl groups or there is enough steric crowding from other adsorbates such that it does not have the opportunity to react further.

${ }^{13} \mathrm{C}$ SS-NMR can also be used get a better understanding of the surface-bound species. Figure 6.7 shows the ${ }^{13} \mathrm{C}$ SS-NMR of HSAS exposed to $\mathbf{1 5}$ (a) as well 


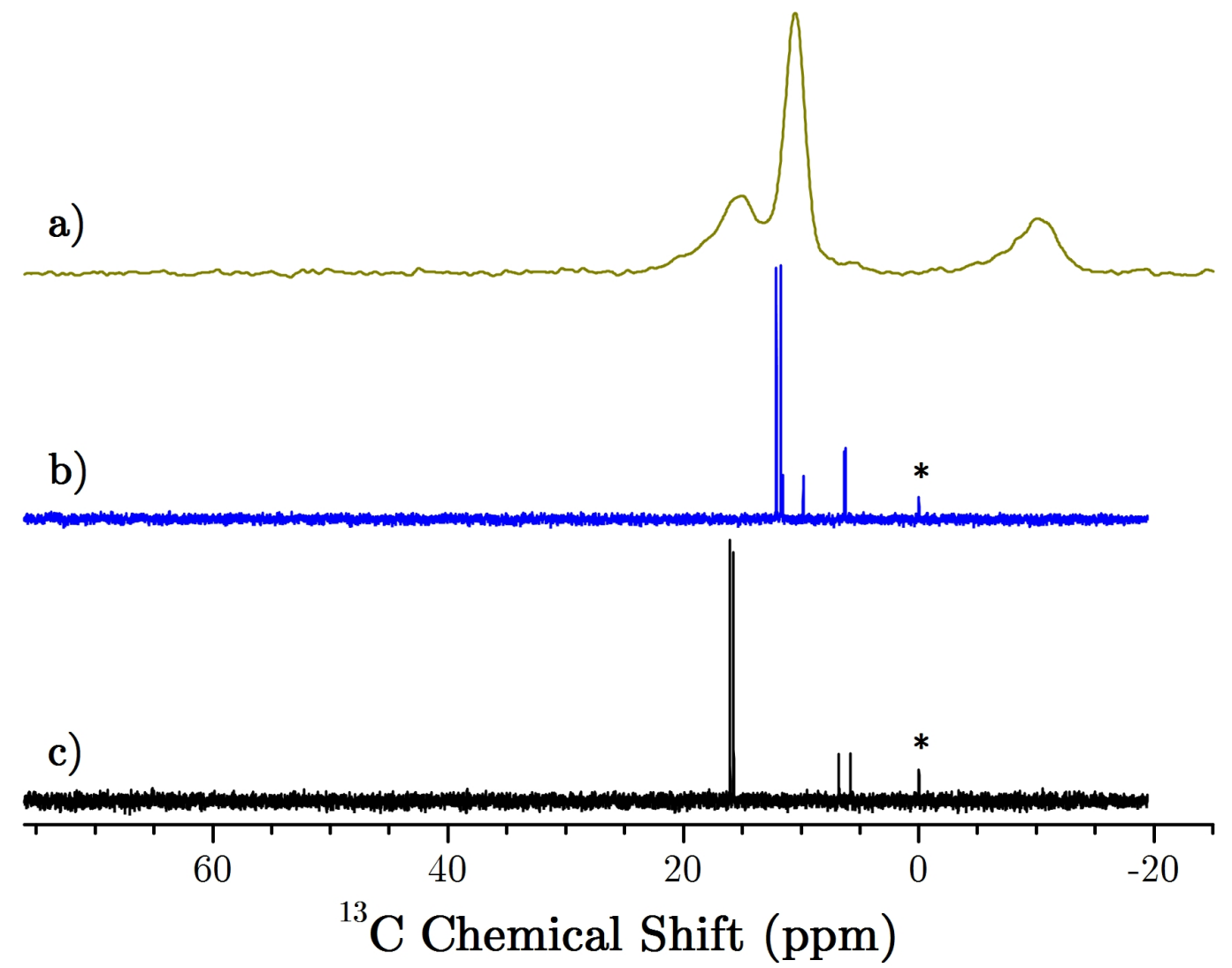

Figure 6.7: a) ${ }^{13} \mathrm{C} \mathrm{CP} / \mathrm{MAS}$ SS-NMR spectrum of HSAS exposed to $\mathbf{1 5}$ at $100{ }^{\circ} \mathrm{C}$. b) ${ }^{13} \mathrm{C}\left\{{ }^{1} \mathrm{H}\right\}$ HR-NMR of 15. c) ${ }^{13} \mathrm{C}\left\{{ }^{1} \mathrm{H}\right\}$ HR-NMR of $\mathrm{MeAu}\left(\mathrm{PMe}_{3}\right)$. * internal TMS reference. 
as the ${ }^{13} \mathrm{C}$ HR-NMR for pure 15 (b) and trimethylphosphinemonomethylgold(I) $\left(\mathrm{MeAu}\left(\mathrm{PMe}_{3}\right)\right)(\mathrm{c})$. In the ${ }^{13} \mathrm{C}$ SS-NMR spectrum there are three obvious signals at $15.3 \mathrm{ppm}, 10.5 \mathrm{ppm}$, and $-10 \mathrm{ppm}$. Again, to aid in the assignment of these signals, the ${ }^{13} \mathrm{C}$ HR-NMR spectrum for pure $\mathbf{1 5}$ is included (b). The most intense signal in Figure $6.7 \mathrm{~b}$ is at $12 \mathrm{ppm}$ and corresponds to the carbon on the trimethylphosphine ligand of $\mathbf{1 5}$ (a doublet due to $J^{2}{ }^{31} \mathrm{P}$ coupling). The chemical shift of this peak very closely matches that of the most intense peak in the ${ }^{13} \mathrm{C}$ SS-NMR spectrum. It seems likely, then, that this peak arises from a surface-bound gold(III)trimethylphosphine species. This species is likely responsible for the peak at $-17.2 \mathrm{ppm}$ in the ${ }^{31} \mathrm{P}$ SS-NMR spectrum in Figure 6.6a. Both the ${ }^{13} \mathrm{C}$ and ${ }^{31} \mathrm{P}$ signal for these surface species are more shielded (lower chemical shift) in the solid-state due to the gold now interacting through oxygen atoms on the surface rather than methyl groups as in the pure compound. The peak at $15.3 \mathrm{ppm}$ in the ${ }^{13} \mathrm{C}$ SS-NMR is somewhat difficult to discern. Figure $6.7 \mathrm{c}$ shows the ${ }^{13} \mathrm{C}$ HR-NMR for the analogous gold(I) compound $\left(\mathrm{MeAu}\left(\mathrm{PMe}_{3}\right)\right)$ and the major peak at $15.9 \mathrm{ppm}$ comes from the carbon on the trimethylphosphine ligand. This spectrum shows that the carbon signal in trimethylphosphine gold becomes more deshielded (higher chemical shift) the more reduced the gold centre becomes. So, it is likely that the signal in the ${ }^{13} \mathrm{C}$ SS-NMR at $15.3 \mathrm{ppm}$ arises from a slightly reduced gold trimethylphosphine species (gold(I) or gold $(0)$ ) on the surface (see Figure 6.8). The mechanism for this type of adsorption is unknown but it is possible that the surface aids in an ethene (or other alkyl species) elimination of the methyl groups on gold to reduce the metal centre from +3 to +1 (or 0 ). Finally, there is a very shielded peak in the ${ }^{13} \mathrm{C}$ SS-NMR spectrum at $-10 \mathrm{ppm}$. The nature of this peak is very difficult to determine, however, given it's highly shielded, it does not arise from functional groups typically observed in organic compounds. In fact, this peak most likely comes from some form of elemental or graphitic carbon (chemical shift can be as low as -300 ppm for graphitic carbon ${ }^{144,145}$ ) 


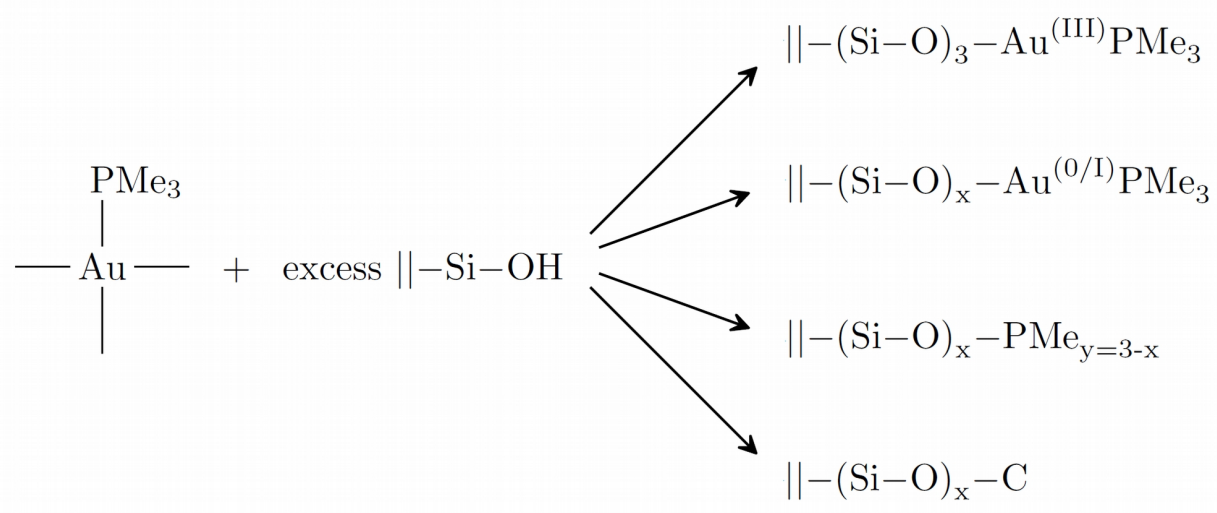

Figure 6.8: Proposed surface adsorption species for $\mathbf{1 5}$ on HSAS at $100{ }^{\circ} \mathrm{C}$.

on the surface. This signal indicates a source for possible carbon contamination in the resultant gold ALD film. The exact nature and mechanism for how this carbon is produced is yet unknown and requires further investigation.

From the surface adsorption mechanisms determined in this work, the role of the co-reactants in the ALD process are further elucidated. The oxygen plasma is responsible for completely oxidizing any phosphine ligands (including those attached to a gold centre) that have not completely converted to the phosphorus oxide species. The combustion of these phosphorus species would likely also produce the electrons necessary to reduce any oxidized gold left to metallic gold. The water pulse, then, is responsible for producing hydrogen phosphate (as shown previously) from phosphorus oxide which leaves as a volatile by-product while also reproducing some hydroxyl density on the growing gold surface. The hydroxyl density after the water pulse need not be as high as in the silica substrate since from the coverage calculations it is clear that the precursor does not make use of most of the hydroxyl surface sites anyway. This initial surface adsorption mechanism provides some insight into the overall ALD process for $\mathbf{1 5}$ and shows which aspects of the process are important for growth and film purity. 


\subsection{Conclusions}

The compound trimethylphosphinetrimethylgold(III) has excellent precursor characteristics: it is a liquid at room temperature, and has great volatility. It is tolerant of ambient water and oxygen under standard conditions, which makes it easier to handle in laboratory conditions. The process is robust and repeatable, and allows Ångström-level control over the deposition of gold metal nanostructures. This newly discovered gold process is a vast improvement over typical chemical vapour deposition processes.

Initial surface adsorption experiments on $\mathrm{HSAS}$ at $100{ }^{\circ} \mathrm{C}$ indicate several aspects of the mechanism of adsorption for the first half-cycle on a silica surface. First, from the ${ }^{29} \mathrm{Si}$ analysis, the adsorption of $\mathbf{1 5}$ does not produce any silicon environments other than those present in HSAS to begin with. This means no $\mathrm{Si}-\mathrm{X}$ interactions where $\mathrm{X}=\mathrm{C}, \mathrm{Au}, \mathrm{P}$, or $\mathrm{H}$. As well, 15 reacts with $\approx 10 \%$ of surface hydroxyl groups and primarily reacts with lone-hydroxyl groups rather than geminal-hydroxyl groups. From the ${ }^{31} \mathrm{P}$ analysis it was found that the trimethylphosphine ligand on $\mathbf{1 5}$ primarily reacts with surface hydroxyl groups to produce a surface $\mathrm{PO}_{4}$ group although some methylated phosphine/phosphoxide does exist on the surface as well. This is exemplified in the ${ }^{13} \mathrm{C}$ data where $\|-\mathrm{Au}-\mathrm{PMe}_{3}$ species are found on the surface where the gold is in the +3 oxidation state as well as in a reduced form, likely +1 but metallic gold is also possible. Additionally, a graphitic carbon signal is present on the surface which may be a source for carbon contamination in the ALD deposited films. 


\subsection{Supplementary Material}
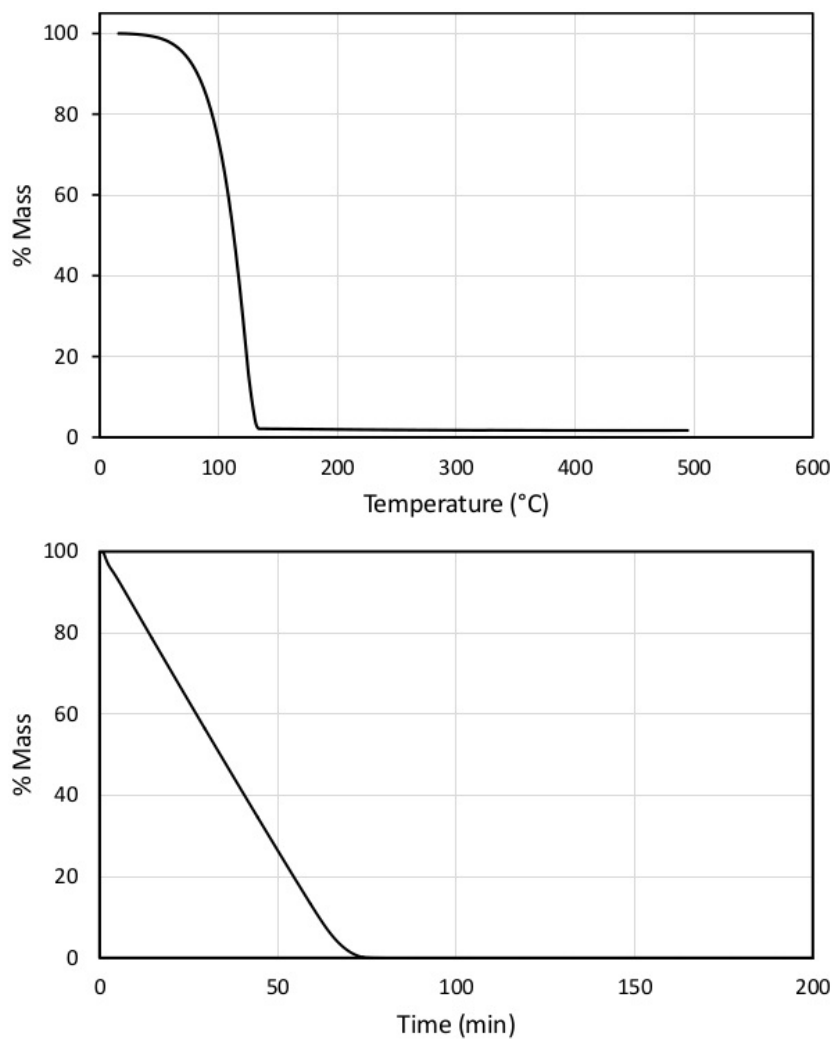

Figure 6.9: TGA traces for 15. a) shows a standard ramp experiment with a rate of $10{ }^{\circ} \mathrm{C} / \mathrm{min}$. b) shows an isothermal experiment of $\mathbf{1 5}$ at $65{ }^{\circ} \mathrm{C}$.

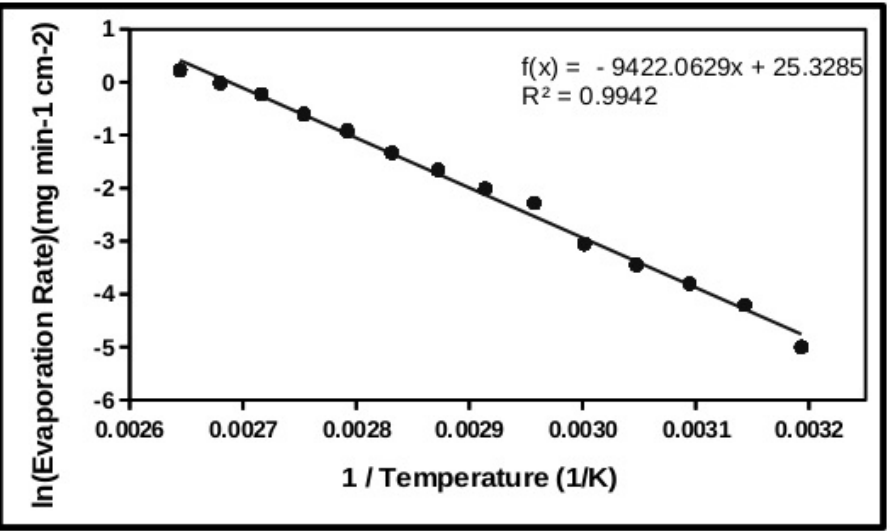

Figure 6.10: The evaporation rate for $\mathbf{1 5}$ determined from TGA. The inset is the fitted linear regression and coefficient of determination for the fit. 
Figure 6.11: SEM micrographs of gold metal films deposited by 15. Each of these independent depositions were comprised of 1000 ALD cycles using 4 s pulses of 15, 14 s pulses of $\mathrm{O}_{2}$ plasma, and $0.1 \mathrm{~s}$ pulses of $\mathrm{H}_{2} \mathrm{O}$ with $10 \mathrm{~s}$ nitrogen gas purges between each step.

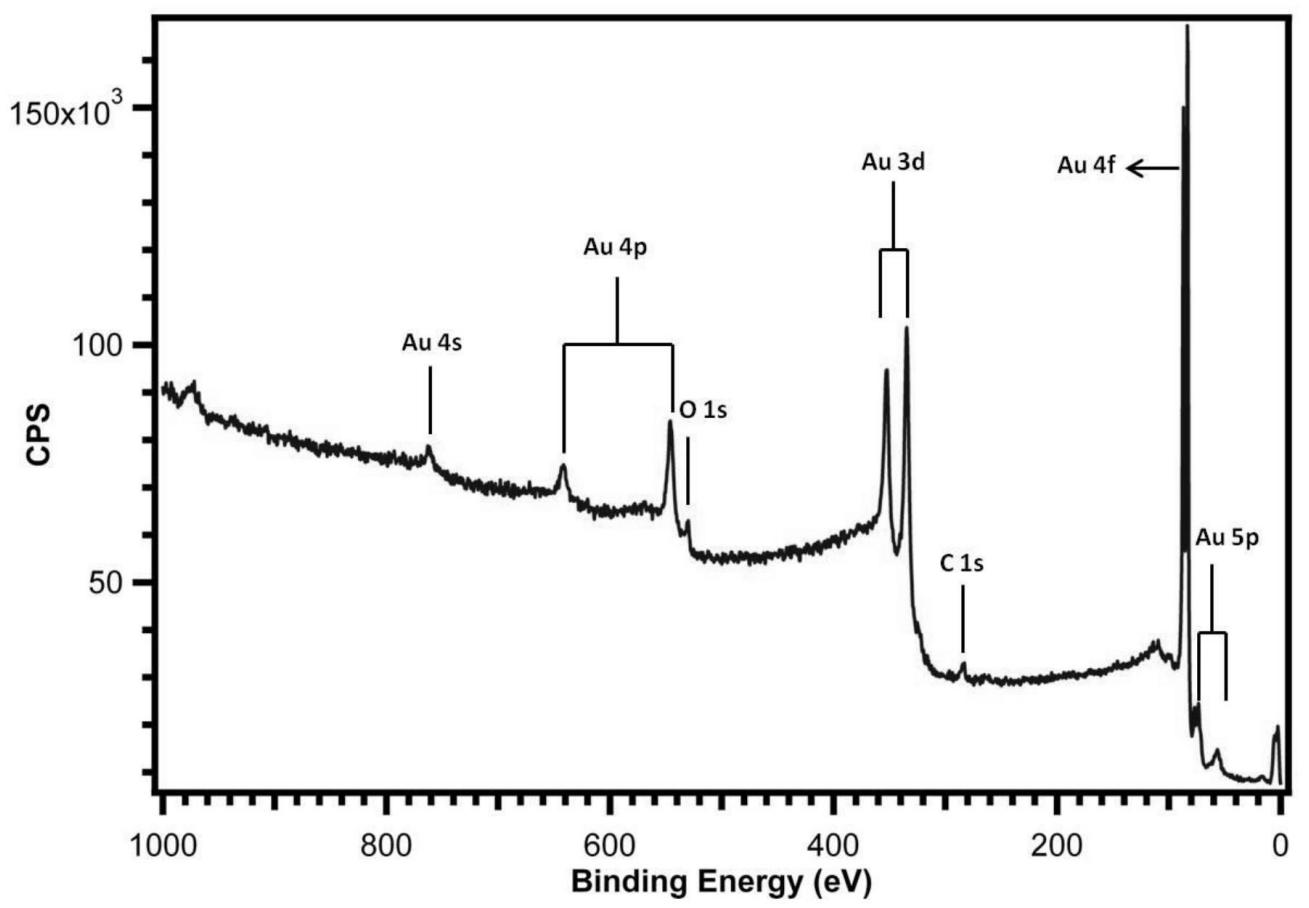

Figure 6.12: XPS survey spectrum of a gold film deposited on $\mathrm{Si}(100)$ with native oxide from 1000 cycles of $4 \mathrm{~s}$ pulses of 15, $14 \mathrm{~s}$ pulses of $\mathrm{O}_{2}$ plasma, and $0.1 \mathrm{~s}$ pulses of $\mathrm{H}_{2} \mathrm{O}$ with $10 \mathrm{~s}$ nitrogen gas purges between each step. 


\section{Chapter 7}

\section{Conclusions}

This thesis presents work from a considerable variety of projects. However, there is a central theme of developing novel vapour deposition precursors and examining their thermal characteristics and how they interact with surfaces. This was accomplished using a variety of techniques on a variety of systems. One methodology for examining the surface chemistry that featured prominently in this work was using SS-NMR to determine initial adsorption chemistry of ALD and CVD precursors on HSAS. The methodology developed in this work proved to be an excellent way to study the bulk properties / chemistry of chemisorption ex situ. The use of SS-NMR allowed for the examination of the various nuclei on the surface of HSAS to get information on bonding and chemical environments. Specifically, the CP technique made obtaining SS-NMR data feasible and allowed for only examination of surface-bound species. From this data surface bonding environments and coverage can be determined for a given precursor. The nucleation and growth of ALD and CVD processes using these precursors was also studied and interesting results were determined for $\mathrm{Ga} / \mathrm{Ga}_{2} \mathrm{O}_{3}$ and $\mathrm{Au}$ metal deposition. Although $\mathrm{Al}$ metal deposition and the subsequent study of precursor surface chemistry was not accomplished in this work, the thermal characteristics of some novel aluminum hydrides were examined, resulting in several very promising candidates. 
From the work discussed in Chapters 2 and 3, several important results were obtained. First, a novel gallium(III) alkyl amidinate, 2, was synthesized and thermally characterized. Compound $\mathbf{2}$ showed excellent promise as a vapour-phase thin film deposition precursor given its high volatility (1 Torr vapour pressure at $64{ }^{\circ} \mathrm{C}$ ) and high thermal stability. In solution, it was found that this compound was stable for weeks at $200{ }^{\circ} \mathrm{C}$ and showed no signs of decomposition in TGA experiments.

This precursor was used to develop the methodology for studying surface chemistry used in subsequent chapters. The methodology developed was used to examine the surface coverage or extent of reaction with surface hydroxyl species on the surface of the HSAS. By quantitatively assessing the ${ }^{29} \mathrm{Si}$ SS-NMR it was determined that the reactivity of $\mathbf{2}$ at geminal and lone hydroxyl sites varied slightly and each produced slightly different chemisorbed surface species. At $100{ }^{\circ} \mathrm{C}$ and $200{ }^{\circ} \mathrm{C} \mathbf{2}$ eliminated either one or both ethyl groups to produce an alkylated (or non-alkylated) gallium acetamidinate on the surface of the HSAS. At $300{ }^{\circ} \mathrm{C}$ there was a higher degree of reactivity (larger coverage) which produced surface species similar to the $100{ }^{\circ} \mathrm{C}$ and $200{ }^{\circ} \mathrm{C}$ exposures but also producing a mix of chemisorbed products arising from the decomposition of the ligand framework. From the $300{ }^{\circ} \mathrm{C}$ exposure the proposed decomposition products were diethyl ether and ethanimidamide. The results and methodology developed in this work have great implications for the surface chemistry of ALD processes. The persistence of the amidinate framework on the surface shows that bulky ligands have the potential to act as a protecting group for the metal atom and ultimately aids in producing a self-terminating surface species. Additionally, these results show the utility of alkyl groups in designing an ALD precursor given their high reactivity to relatively acidic surface species. However, one of the major contributions from this work is the use of quantitative NMR measurements for studying surface coverage and the nature of chemisorption. SS-NMR can not only be used to identify surface species, but it also can be used to investigate the relative reactivity 
of different surface sites and the extent of reaction on these sites, even for amorphous, not well-defined surfaces like HSAS.

There is currently a need for low temperature, thin film vapour deposition processes of gallium compounds (particularly III-V binary compounds) so the ability of 2 to behave as a vapour-phase thin film deposition precursor was then examined. It was found that the monolayer formed that was examined in Chapter 2 was so stable that it was unreactive to $\mathrm{H}_{2} \mathrm{O}$ or $\mathrm{O}_{2}$ in an ALD-type deposition experiment below 450 ${ }^{\circ} \mathrm{C}$. Above $450{ }^{\circ} \mathrm{C}$, however, 2 undergoes self-seeding single-source CVD to gallium metal without the addition of a co-reactant. Given the high mobility of gallium metal nanoparticles at high temperatures, an attempt to prevent aggregation of the particles was accomplished with the use of $\mathrm{TMA} / \mathrm{H}_{2} \mathrm{O}$. While the particles were successfully immobilized preventing further aggregation, the introduction of aluminum and oxygen at high temperatures was detrimental to the gallium metal particle. This initial work shows promise for the controlled deposition of gallium metal nanoparticles, but a more effective method still needs to be developed. The addition of a co-reactant to the deposition process, such as $\mathrm{H}_{2} \mathrm{O}$ or $\mathrm{O}_{2}$, was found to produce a wide variety of $\mathrm{Ga} / \mathrm{Ga}_{2} \mathrm{O}_{3}$ structures. The size and distribution of these features was found to be dependent on temperature and relative precursor concentrations. Although the structures produced in this study were limited to $\mathrm{Ga}$ metal or $\mathrm{Ga}_{2} \mathrm{O}_{3}$, this work shows that it is possible to rationally fabricate complex structures if the correct co-reactant is chosen and introduced under the correct conditions. This may have implications for potentially controlling the growth of complex structures of GaN and other III-V semiconductor materials of gallium.

In an attempt to develop a thermal ALD process for aluminum metal and provide another interesting system for studying surface mechanisms, several novel aluminum(III) amidinate/guanidinate hydrides were investigated and discussed in Chapter 4. Compounds 3-8 were synthesized in excellent yields and thermally characterized 
using primarily TGA and solution-phase thermolysis techniques. From the solutionphase studies, it was found that the guanidinate compounds decompose with varying rates at moderate temperatures. The amidinate aluminum hydride (7) and the HMDS aluminum hydride (8) compounds were found to be stable for many hours at elevated temperatures in solution. This not only shows the usefulness of this technique for evaluating potential vapour deposition precursors, but in this particular case, it also shows that guanidinate compounds are not thermally stable. It is possible that they undergo CDI deinsertion and reinsertion to produce unstable intermediates as was shown for the $\mathrm{NMe}_{2}$-guanidinate aluminum hydride $(\mathbf{3})$. This work also showed the usefulness of TGA for evaluating a compound's potential as a vapour deposition precursor. Not only is TGA able to determine the temperature of volatility, but it is also able to distinguish between volatilization and decomposition events occurring at different temperatures. It was found that, again, the guanidinate aluminum hydride compounds tended to decompose while simultaneously volatilizing while the HMDS aluminum hydride compound showed excellent thermal characteristics. However, in all cases there was a non-zero residual mass in the TGA experiments. This indicates that while it is possible to develop volatile aluminum hydride compounds, in general, hydrides of aluminum are quite reactive and tend to decompose when given enough energy. Overall, this work demonstrates a process for developing novel aluminum hydride compounds and represents a stepping-stone to the development of a thermal ALD process for aluminum metal.

The importance of copper metal thin films for the future microelectronics cannot be understated. Chapter 5 highlights the development and characterization of several novel copper(I) compounds ultimately for thin film vapour deposition of copper metal. A rational design strategy was implemented to eliminate known gas-phase and solution-phase decomposition routes to produce a volatile, thermally stable precursor. This was accomplished with a copper(I) tert-butyl-imino-2,2-dimethylpyrrolidinate 
compound (11) as well as two copper(I) $N$-heterocyclic carbene hexamethyldisilazide compounds $(\mathbf{1 3}, \mathbf{1 4})$. However, to develop a vapour deposition process for copper metal that produces impurity-free, continuous films, the surface chemistry of the precursor must be understood. The surface chemistry of 11, 13, and 14 on HSAS was examined using the methodology described in Chapter 2. Chemisorption of 11 on HSAS at $275{ }^{\circ} \mathrm{C}$ showed a symmetric dissociation of the compound followed by elimination of the tert-butyl alkyl group from the ligand system. Further annealing showed additional decomposition of the ligand framework. In the case of $\mathbf{1 3}$ and $\mathbf{1 4}$, the ligand system was found to react with and passivate the hydroxyl-terminated surface upon chemisorption. As well, the temperature of adsorption was found to dictate whether the protecting ligand (NHC) would remain on the surface. These results again demonstrate that SS-NMR is an excellent tool for examining the nature of the chemisorption process of complex compounds on non-ordered substrates. However, in this particular case, it shows that on initial chemisorption, it is possible that the ligand system can rearrange to produce an unexpected surface species that will either aid or hinder further film growth. In the former case, it is possible that the ligand rearrangement produces a surface species that provides the perfect steric interaction to form a self-terminating monolayer. However, the latter case will either impede deposition (as in the case of $\mathbf{1 3}$ and $\mathbf{1 4}$ with surface passivation) or introduce potential impurities into the growing film. In either case, this work indicates the importance of understanding the surface chemistry for developing usable and efficient CVD and ALD processes.

Another desirable metal for thin film applications is gold. Chapter 6 discusses the discovery and characterization of a novel gold metal ALD process using trimethylphosphinetrimethylgold(III) (15), oxygen plasma, and water. This work represents the first ever reported ALD process for gold metal. Interestingly, initial work showed that without the addition of water as a ternary co-reactant in the ALD process, films were 
plagued with a phosphorus impurity. It is speculated that the water is necessary to aid in the volatilization of the phosphorus by-products created during the oxygen plasma dose. Initial nucleation studies of early cycle growth (2 and 5 ALD cycles) showed that with this process, it is possible to deposit nanoparticulate gold without the use of a surfactant in a very controlled way. To gain insight into the complex chemistry occurring in this 3-step ALD process, the surface chemistry of $\mathbf{1 5}$ on HSAS was investigated using the same methodology described in the previous chapters. In this case it was possible to also examine the ${ }^{31} \mathrm{P}$ nuclei on the surface given its presence in the precursor. In this case it was determined that oxidation of the ligand system likely occurs during chemisorption, which may be responsible for the phosphorus impurity in the films deposited without water co-reactant. As well, there was an elemental or graphitic carbon impurity observed upon initial chemisorption of $\mathbf{1 5}$ on HSAS. The results obtained in this chapter demonstrates that the methodology developed not only shows which portion of the ligand system remains and ultimately acts as the self-terminating monolayer, but is also able to show the source for potential film impurties, such as carbon.

The work presented herein describes many aspects of a broad range of thin film vapour deposition processes. In all the metal and metal oxide systems studied, novel vapour-phase deposition precursors were investigated and their efficacy for CVD and ALD was discussed. In this work a new CVD process for gallium/gallium oxide and the first ALD process for gold metal was discovered. How these, and novel copper(I) vapour-phase deposition precursors fundamentally interact with substrates, however, was the major focus of this work. Using a wide range of analytical techniques, the nucleation and growth of these precursors was investigated. The impact of this work speaks to many aspects of thin film vapour deposition processes. Understanding the nature of film growth is imperative to producing thin, conformal and uniform films of desired purity. The initial nucleation events, like those examined for gold and 
gallium, show that nanoparticle formation during initial growth is greatly affected by the precursor-substrate interaction during the first few deposition cycles. Being able to control the size and distribution of these seed particles is necessary to control film uniformity and is completely dictated by surface chemistry. By examining the initial adsorption of these precursors on high surface area substrates by NMR provides insight into what aspects of the precursor are responsible for film growth. From understanding the nature of self-limiting behaviour for ALD processes to determining the origin of potential film impurities, the methodology described in this work is useful for assessing potential vapour-phase deposition precursor and investigating fundamental adsorbate-substrate interactions for materials science applications. 


\section{References}

[1] Gates, B. D.; Xu, Q.; Stewart, M.; Ryan, D.; Willson, C. G.; Whitesides, G. M. Chemical Reviews 2005, 105, 1171-96.

[2] Cho, A. Y. Journal of Vacuum Science and Technology 1979, 16, 275.

[3] Kern, W.; Jensen, K. F. In Thin Film Processes II; Vossen, J. L., Kern, W., Eds.; Academic Press Inc.: San Diego, 1991; pp 283-312.

[4] Crowell, J. E. Journal of Vacuum Science \& Technology A: Vacuum, Surfaces, and Films 2003, 21, S88.

[5] Shibata, N.; Zembutsu, S. Japanese Journal of Applied Physics 1987, 26, 14161421.

[6] Ylilammi, M. Journal of The Electrochemical Society 1995, 142, 2474.

[7] Gordon, R.; Hausmann, D.; Kim, E.; Shepard, J. Chemical Vapor Deposition 2003, 9, 73-78.

[8] Yanguas-Gil, A.; Elam, J. W. Journal of Vacuum Science $\&$ Technology A: Vacuum, Surfaces, and Films 2012, 30, 01A159.

[9] Dendooven, J.; Deduytsche, D.; Musschoot, J.; Vanmeirhaeghe, R. L.; Detavernier, C. Journal of The Electrochemical Society 2009, 156, P63 - P67.

[10] Travis, C. D.; Adomaitis, R. A. Chemical Vapor Deposition 2013, 19, 4-14. 
[11] Adomaitis, R. A. Physica Status Solidi C 2015, 12, 934-943.

[12] Koponen, S. E.; Gordon, P. G.; Barry, S. T. Polyhedron 2015,

[13] Suntola, T.; Anston, J. Method for Producing Compound Thin Films. US Patent 4,058,430. 1977.

[14] Shevjakov, A. M.; Kuznetsova, G. N.; Aleskovskii, V. B. Chemistry of HighTemperature Materials. Proceedings of the Second USSR Conference on HighTemperature Chemistry of Oxides. Leningrad, 1967; pp 149-155.

[15] Suntola, T.; Hyvarinen, J. Annual Review of Materials Science 1985, 15, 177195.

[16] Leskelä, M.; Ritala, M. Le Journal de Physique IV 1995, 05, C5-937-C5-951.

[17] Higashi, G. S.; Fleming, C. G. Applied Physics Letters 1989, 55, 1963.

[18] Ott, A.; Klaus, J.; Johnson, J.; George, S. Thin Solid Films 1997, 292, 135-144.

[19] Puurunen, R. L. Journal of Applied Physics 2005, 97, 121301.

[20] Miikkulainen, V.; Leskela, M.; Ritala, M.; Puurunen, R. L. Journal of Applied Physics 2013, 113, 021301.

[21] Kessels, W.; Profijt, H. B.; Potts, S.; van de Sanden, M. C. M. In Atomic Layer Deposition of Nanostructured Materials; Pinna, N., Knez, M., Eds.; Wiley-VCH Verlag GmbH, 2012; Chapter Chapter 7, pp 131-157.

[22] Profijt, H. B.; Potts, S. E.; van de Sanden, M. C. M.; Kessels, W. M. M. Journal of Vacuum Science 85 Technology A: Vacuum, Surfaces, and Films 2011, 29, 050801.

[23] Zaera, F. Coordination Chemistry Reviews 2013, 257, 3177-3191. 
[24] Jezewski, C.; Lanford, W. A.; Wiegand, C. J.; Singh, J. P.; Wang, P.-I.; Senkevich, J. J.; Lu, T.-M. Journal of The Electrochemical Society 2005, 152, C60C64.

[25] Knoops, H. C. M.; Mackus, A. J. M.; Donders, M. E.; van de Sanden, M. C. M.; Notten, P. H. L.; Kessels, W. M. M. Electrochemical and Solid-State Letters 2009, 12, G34-G36.

[26] Zaera, F. The Journal of Physical Chemistry Letters 2012, 3, 1301-1309.

[27] Knapas, K.; Ritala, M. Critical Reviews in Solid State and Materials Sciences 2013, 38, 167-202.

[28] Kim, T.; Yao, Y.; Coyle, J. P.; Barry, S. T.; Zaera, F. Chemistry of Materials 2013, 25, 3630-3639.

[29] Wasslen, Y. A.; Tois, E.; Haukka, S.; Kreisel, K. A.; Yap, G. P. A.; Halls, M. D.; Barry, S. T. Inorganic Chemistry 2010, 49, 1976-1982.

[30] Zhuravlev L. T.,; Payne Charles C.,; Bergna Horacio E.,; Firment Lawrence E.,; Swartzfager Dennis G.,; Furlong D. Neil,; Birchall J. D.,; Patterson Robert E.,; Falcone James S., In The Colloid Chemistry of Silica; Bergna, H. E., Ed.; Advances in Chemistry; American Chemical Society: Washington DC, 1994; Vol. 234; p 724 .

[31] Haukka, S.; Lakomaa, E. L.; Root, A. The Journal of Physical Chemistry 1993, 97, 5085-5094.

[32] Soto, C.; Tysoe, W. T. Journal of Vacuum Science 83 Technology A: Vacuum, Surfaces, and Films 1991, 9, 2686.

[33] Kiselev, A. V.; Lygin, V. I. Infrared Spectra of Surface Compounds; Wiley \& Sons: New York, 1975. 
[34] Levitt, M. H. Spin Dynamics: Basics of Nuclear Magnetic Resonance, 2nd ed.; John Wiley \& Sons Ltd.: West Sussex, England, 2008.

[35] Duer, M. J., Ed. Solid-State NMR Spectroscopy: Principles and Applications; Blackwell Science Ltd.: Oxford, 2002.

[36] Ramsey, N. F. Physical Review 1950, 78, 699-703.

[37] Pople, J. A. Proceedings of the Royal Society A: Mathematical, Physical and Engineering Sciences 1957, 239, 541-549.

[38] Laws, D. D.; Bitter, H.-M. L.; Jerschow, A. Angewandte Chemie (International ed. in English) 2002, 41, 3096-129.

[39] Jameson, C. J.; Jameson, A. K.; Burrell, P. M. The Journal of Chemical Physics 1980, 73, 6013.

[40] Van Vleck, J. H. Physical Review 1948, 74, 1168-1183.

[41] Tippins, H. Physical Review 1965, 140, A316-A319.

[42] Fleischer, M.; Meixner, H. Sensors and Actuators B: Chemical 1991, 4, 437441.

[43] Harwig, T.; Kellendonk, F. Journal of Solid State Chemistry 1978, 24, 255-263.

[44] Maruska, H. P. Applied Physics Letters 1969, 15, 327-330.

[45] Bhargava, R. N. Electron Devices, IEEE Transactions on 1975, 22, 691-701.

[46] Bedair, S. M.; Tischler, M. A.; Katsuyama, T.; El-Masry, N. A. Applied Physics Letters 1985, 47, 51-53.

[47] Hellwig, M.; Xu, K.; Barreca, D.; Gasparotto, A.; Niermann, B.; Winter, J.; Becker, H.-W.; Rogalla, D.; Fischer, R.; Devi, A. MOCVD Of Gallium Oxide 
Thin Films Using Homoleptic Gallium Complexes: Precursor Evaluation and Thin Film Characterisation. ECS Transactions. 2009; pp 617-624.

[48] Hoffman, D. M. Journal of Vacuum Science 83 Technology A: Vacuum, Surfaces, and Films 1996, 14, 306-312.

[49] Lee, H.; Kim, K.; Woo, J.-J.; Jun, D.-J.; Park, Y.; Kim, Y.; Lee, H. W.; Cho, Y. J.; Cho, H. M. Chemical Vapor Deposition 2011, 17, 191-197.

[50] Nieminen, M.; Niinisto, L.; Rauhala, E. Journal of Materials Chemistry 1996, $6,27-31$.

[51] Nishizawa, J.-i. Journal of The Electrochemical Society 1985, 132, 1197-1200.

[52] Gong, J. R.; Nakamura, S.; Leonard, M.; Bedair, S. M.; El-Masry, N. A. Journal of Electronic Materials 1992, 21, 965-970.

[53] Sumakeris, J.; Sitar, Z.; Ailey-Trent, K.; More, K.; Davis, R. Thin Solid Films 1993, 225, 244-249.

[54] Wang, H.; Huang, S.; Yan, T.; Gong, J.; Lin, T.; Chen, Y. Materials Science and Engineering: B 1999, 57, 218-223.

[55] Kobayashi, R.; Ishikawa, K.; Narahara, S.; Hasegawa, F. Japanese Journal of Applied Physics 1992, 31, L1730-L1732.

[56] Valet, M.; Hoffman, D. M. Chemistry of Materials 2001, 13, 2135-2143.

[57] Choi, D.-w.; Chung, K.-B.; Park, J.-S. Thin Solid Films 2013, 546, 31-34.

[58] Elers, K.-E.; Saanila, V.; Soininen, P.; Li, W.-M.; Kostamo, J.; Haukka, S.; Juhanoja, J.; Besling, W. Chemical Vapor Deposition 2002, 8, 149-153.

[59] Bernal Ramos, K.; Saly, M. J.; Chabal, Y. J. Coordination Chemistry Reviews 2013, 257, 3271-3281. 
[60] Langereis, E.; Heil, S. B. S.; Knoops, H. C. M.; Keuning, W.; van de Sanden, M. C. M.; Kessels, W. M. M. Journal of Physics D: Applied Physics 2009, 42, 073001.

[61] Elliott, S. D. Semiconductor Science and Technology 2012, 27, 074008.

[62] Mochizuki, Y.; Takada, T.; Usui, A. Applied Surface Science 1994, 82-83, 200207.

[63] Murray, C.; Elliott, S. D. ACS Applied Materials \& Interfaces 2013, 5, 37043715 .

[64] Sindorf, D. W.; Maciel, G. E. The Journal of Physical Chemistry 1982, 86, 5208-5219.

[65] Sindorf, D. W.; Maciel, G. E. The Journal of Physical Chemistry 1983, 87, $5516-5521$.

[66] Maciel, G. E.; Sindorf, D. W. Journal of the American Chemical Society 1980, 102, 7606-7607.

[67] Sindorf, D. W.; Maciel, G. E. Journal of the American Chemical Society 1983, 105, 1487-1493.

[68] Haukka, S.; Root, A. The Journal of Physical Chemistry 1994, 98, 1695-1703.

[69] Coles, M. P.; Swenson, D. C.; Jordan, R. F.; Young, V. G. Organometallics 1997, 16, 5183-5194.

[70] Penner, S. S. The Journal of Physical Chemistry 1952, 56, 475-479.

[71] Kunte, G. V.; Shivashankar, S. A.; Umarji, A. M. Measurement Science and Technology 2008, 19, 025704-025711. 
[72] Coyle, J. P.; Pallister, P. J.; Kurek, A.; Sirianni, E. R.; Yap, G. P. A.; Barry, S. T. Inorganic Chemistry 2013, 52, 910-917.

[73] Coyle, J. P.; Kurek, A.; Pallister, P. J.; Sirianni, E. R.; Yap, G. P. A.; Barry, S. T. Chemical Communications 2012, 48, 10440-10442.

[74] Gong, B.; Peng, Q.; Jur, J. S.; Devine, C. K.; Lee, K.; Parsons, G. N. Chemistry of Materials 2011, 23, 3476-3485.

[75] Ma, Q.; Guo, H.; Gordon, R. G.; Zaera, F. Chemistry of Materials 2011, 23, 3325-3334.

[76] Kenney, A. P.; Yap, G. P. A.; Richeson, D. S.; Barry, S. T. Inorganic Chemistry 2005, 44, 2926-2933.

[77] Wu, P. C.; Khoury, C. G.; Kim, T.-H.; Yang, Y.; Losurdo, M.; Bianco, G. V.; Vo-Dinh, T.; Brown, A. S.; Everitt, H. O. Journal of the American Chemical Society 2009, 131, 12032-3.

[78] Wu, P. C.; Kim, T.-H.; Brown, A. S.; Losurdo, M.; Bruno, G.; Everitt, H. O. Applied Physics Letters 2007, 90, 103119.

[79] Marchand, P.; Carmalt, C. J. Coordination Chemistry Reviews 2013, 25\%, $3202-3221$.

[80] Bloor, L. G.; Carmalt, C. J.; Pugh, D. Coordination Chemistry Reviews 2011, 255, 1293-1318.

[81] Pallister, P. J.; Buttera, S. C.; Barry, S. T. The Journal of Physical Chemistry C 2014, 118, 1618-1627.

[82] Stull, D. In American Institute of Physics Handbook, 3rd ed.; E., G. D., Ed.; McGraw Hill: New York, 1972. 
[83] Whitehorne, T. J. J.; Coyle, J. P.; Mahmood, A.; Monillas, W. H.; Yap, G. P. A.; Barry, S. T. European Journal of Inorganic Chemistry 2011, 3240-3247.

[84] Li, Z.; Rahtu, A.; Gordon, R. G. Journal of The Electrochemical Society 2006, 153, C787.

[85] Playford, H. Y.; Hannon, A. C.; Barney, E. R.; Walton, R. I. Chemistry - A European Journal 2013, 19, 2803-2813.

[86] Yang, Y.; Callahan, J. M.; Kim, T.-H.; Brown, A. S.; Everitt, H. O. Nano Letters 2013, 13, 2837-41.

[87] Jha, S. K.; Ahmed, Z.; Agio, M.; Ekinci, Y.; Löffler, J. F. Journal of the American Chemical Society 2012, 134, 1966-9.

[88] Wyckoff, R. W. G. Crystal Structures; Interscience Publishers: New York, 1963.

[89] Simmonds, M. G.; Gladfelter, W. L. In Chemical Vapor Deposition of Aluminum; Kodas, T. T., Hampden-Smith, M. J., Eds.; Wiley-VCH Verlag GmbH: Weinheim, 2007.

[90] Xiong, Y.-Q.; Li, X.-C.; Chen, Q.; Lei, W.-W.; Zhao, Q.; Sang, L.-J.; Liu, Z.-W.; Wang, Z.-D.; Yang, L.-Z. Chinese Physics B 2012, 21, 078105.

[91] Lee, Y. J.; Kang, S.-W. Journal of Vacuum Science \& Technology A: Vacuum, Surfaces, and Films 2002, 20, 1983-1988.

[92] Lee, Y. J.; Kang, S.-W. Electrochemical and Solid-State Letters 2002, 5, C91C93.

[93] Kim, H. Journal of Vacuum Science \& Technology B: Microelectronics and Nanometer Structures 2003, 21, 2231-2261.

[94] Kaesz, H. D.; Saillant, R. B. Chemical Reviews 1972, 72, 231-281. 
[95] Himmel, H.-J. Inorganic Chemistry 2007, 46, 6585-93.

[96] Cole, M. L.; Jones, C.; Junk, P. C.; Kloth, M.; Stasch, A. Chemistry: A European Journal 2005, 11, 4482-4491.

[97] Janik, J. F.; Duesler, E. N.; Paine, R. T. Journal of Organometallic Chemistry 1997, 539, 19-25.

[98] Edelmann, F. T. In Advances in Organometallic Chemistry, volume 57 ed.; Perez, P. J., Ed.; Elsevier Inc., 2008; Chapter 3, pp 183-352.

[99] Bailey, P. J.; Pace, S. Coordination Chemistry Reviews 2001, 214, 91-141.

[100] Duchateau, R.; Meetsma, A.; Teuben, J. H. Chemical Communications 1996, 223.

[101] Bonyhady, S. J.; Collis, D.; Frenking, G.; Holzmann, N.; Jones, C.; Stasch, A. Nature Chemistry 2010, 2, 865-869.

[102] Brazeau, A. L.; Wang, Z.; Rowley, C. N.; Barry, S. T. Inorganic Chemistry 2006, 45, 2276-81.

[103] Rowley, C. N.; DiLabio, G. A.; Barry, S. T. Inorganic Chemistry 2005, 44, $1983-91$.

[104] Waggoner, K.; Olmstead, M.; Power, P. Polyhedron 1990, 9, 257-263.

[105] Foley, S. R.; Yap, G. P. A.; Richeson, D. S. Chemical Communications 2000, $1515-1516$.

[106] Sheldrick, G. M. Acta Crystallographica A, 2008, 64, 112-122.

[107] Janik, J. F.; Wells, R. L.; Rheingold, A. L.; Guzei, I. A. Polyhedron 1998, 17, 4101-4108. 
[108] Li, Z.; Barry, S. T.; Gordon, R. G. Inorganic Chemistry 2005, 44, 1728-35.

[109] Rowley, C. N. Theoretical and Synthetic Studies of Carbodiimide Insertions into Aluminum Non-Metal Bonds. B. Sc. Thesis, B.Sc. Thesis, Carleton University, 2004 .

[110] Langmuir, I. Physical Review 1913, 2, 329-342.

[111] 2013 Edition of the International Technology Roadmap for Semiconductors. 2013; http://www.itrs .net/ITRS1999-2014MtgsPresentationsLinks/ 2013ITRS/Summary2013.htm.

[112] Krisyuk, V.; Aloui, L.; Prudhomme, N.; Sysoev, S.; Senocq, F.; Samelor, D.; Vahlas, C. Electrochemical and Solid-State Letters 2011, 14, D26.

[113] Ma, Q.; Guo, H.; Gordon, R. G.; Zaera, F. Chemistry of Materials 2010, 22, $352-359$.

[114] Turgambaeva, A.; Prud'homme, N.; Krisyuk, V.; Vahlas, C. Journal of Nanoscience and Nanotechnology 2011, 11, 8198-8201.

[115] Coyle, J. P.; Monillas, W. H.; Yap, G. P. A.; Barry, S. T. Inorganic Chemistry 2008, 47, 683-9.

[116] Coyle, J. P.; Johnson, P. A.; DiLabio, G. A.; Barry, S. T.; Müller, J. Inorganic Chemistry 2010, 49, 2844-50.

[117] Tsuda, T.; Watanabe, K.; Miyata, K.; Yamamoto, H.; Saegusa, T. Inorganic Chemistry 1981, 20, 2728-2730.

[118] Wasslen, Y. A.; Kurek, A.; Johnson, P. A.; Pigeon, T. C.; Monillas, W. H.; Yap, G. P. A.; Barry, S. T. Dalton Transactions 2010, 39, 9046-54.

[119] Spek, A. L. Journal of Applied Crystallography 2003, 36, 7-13. 
[120] Willcocks, A. M.; Robinson, T. P.; Roche, C.; Pugh, T.; Richards, S. P.; Kingsley, A. J.; Lowe, J. P.; Johnson, A. L. Inorganic Chemistry 2012, 51, 246-57.

[121] Cotton, F.; Daniels, L. M.; Feng, X.; Maloney, D. J.; Matonic, J. H.; Murilio, C. A. Inorganica Chimica Acta 1997, 256, 291-301.

[122] Abdou, H. E.; Mohamed, A. A.; Fackler, J. P. Journal of Cluster Science 2007, $18,630-641$.

[123] Jiang, X.; Bollinger, J. C.; Baik, M.-H.; Lee, D. Chemical Communications 2005, 1043-5.

[124] Beck, J.; Strahle, J. Angewandte Chemie (International ed. in English) 1986 , 25, 95-96.

[125] Dai, M.; Kwon, J.; Halls, M. D.; Gordon, R. G.; Chabal, Y. J. Langmuir 2010, 26, 3911-7.

[126] Coyle, J. P.; Dey, G.; Sirianni, E. R.; Kemell, M. L.; Yap, G. P. A.; Ritala, M.; Leskelä, M.; Elliott, S. D.; Barry, S. T. Chemistry of Materials 2013, 25, 11321138.

[127] Coyle, J. P. Group 11 Precursors for Atomic Layer Deposition: Design and Synthesis of Advanced Precursors Enabled by Investigations in Thermolysis. Ph.D., Carleton University, 2014.

[128] Saha, K.; Agasti, S. S.; Kim, C.; Li, X.; Rotello, V. M. Chemical Reviews 2012, 112, 2739-79.

[129] Stratakis, M.; Garcia, H. Chemical Reviews 2012, 112, 4469-506.

[130] Eustis, S.; El-Sayed, M. A. Chemical Society Reviews 2006, 35, 209-17.

[131] George, S. M. Chemical Reviews 2010, 110, 111-31. 
[132] Louis, C.; Pluchery, O. Gold Nanoparticles for Physics, Chemistry and Biology; Imperial College Press: London, 2012.

[133] Gordon, P. G.; Kurek, A.; Barry, S. T. ECS Journal of Solid State Science and Technology 2015, 4, N3188-N3197.

[134] Niskanen, A.; Hatanpää, T.; Arstila, K.; Leskelä, M.; Ritala, M. Chemical Vapor Deposition 2007, 13, 408-413.

[135] Chalker, P. R.; Romani, S.; Marshall, P. A.; Rosseinsky, M. J.; Rushworth, S.; Williams, P. A. Nanotechnology 2010, 21, 405602.

[136] Kariniemi, M.; Niinisto, J.; Hatanpaa, T.; Kemell, M.; Sajavaara, T.; Ritala, M.; Leskela, M. Chemistry of Materials 2011, 23, 2901-2907.

[137] Messelhäuser, J.; Flint, E. B.; Suhr, H. Applied Physics A: Solids and Surfaces 1992, 55, 196-202.

[138] Messelhäuser, J.; Flint, E. B.; Suhr, H. Applied Surface Science 1992, 54, 6468.

[139] Hämäläinen, J.; Ritala, M.; Leskelä, M. Chemistry of Materials 2014, 26, 786801.

[140] Krozer, A. Journal of Vacuum Science $\mathcal{E}$ Technology A: Vacuum, Surfaces, and Films 1997, 15, 1704.

[141] Waldo, R. A. In Microbeam Analysis; Newbury, D. E., Ed.; San Francisco Press: San Francisco, 1988; pp 310-314.

[142] Bondi, A. The Journal of Physical Chemistry 1964, 68, 441-451.

[143] Bruker, Bruker Almanac 2011: Analytical Tables and Product Overview. 2011.

[144] Hiroyama, Y.; Kume, K. Solid State Communications 1988, 65, 617-619. 
[145] Maniwa, Y.; Sato, M.; Kume, K.; Kozlov, M.; Tokumoto, M. Carbon 1996, 34 , $1287-1291$. 